Prepared in Cooperation with the U.S. Environmental Protection Agency

\title{
Hydrogeochemical Investigation of the Standard Mine Vicinity, Upper Elk Creek Basin, Colorado
}

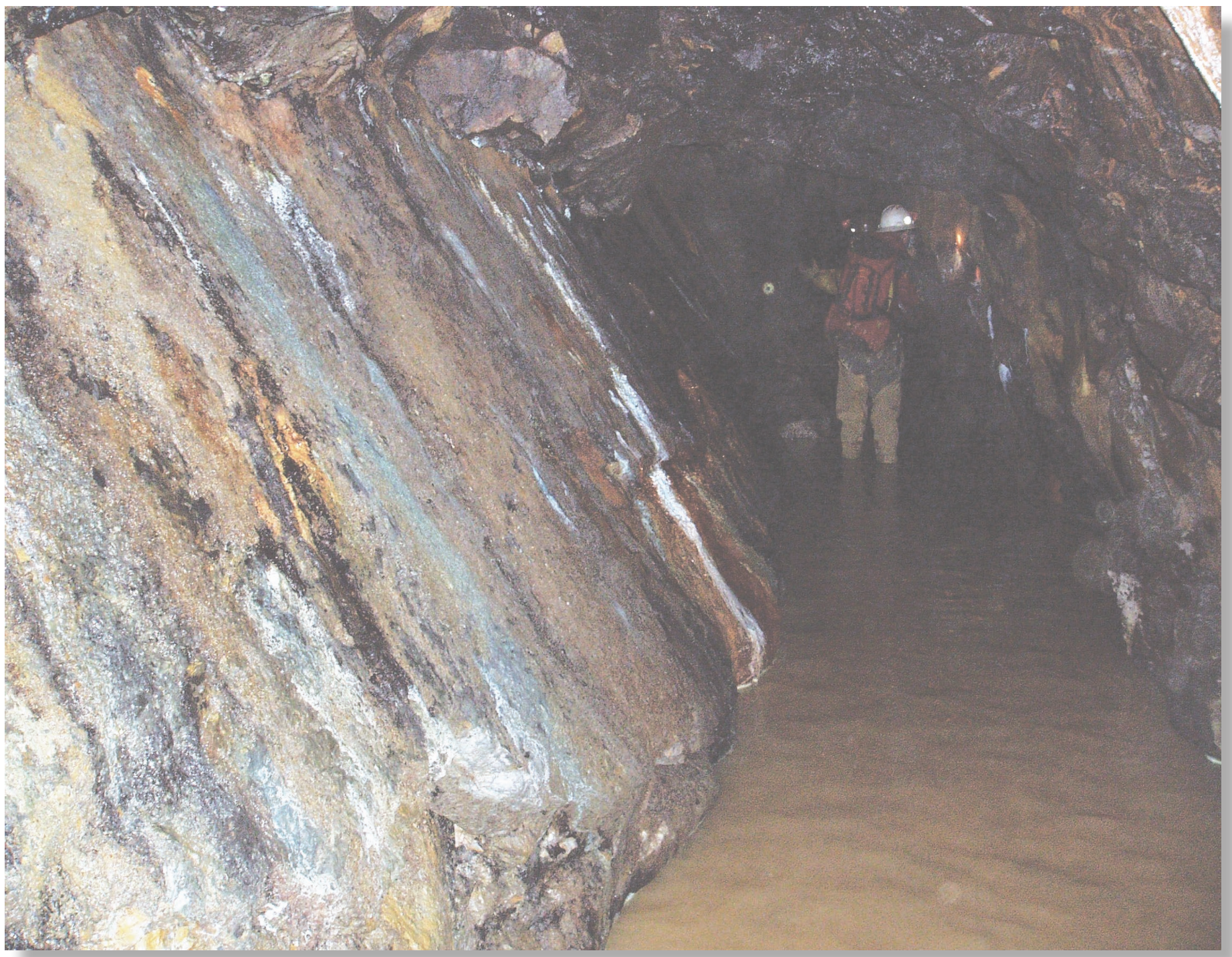

Scientific Investigations Report 2007-5265 



\section{Hydrogeochemical Investigation of the Standard Mine Vicinity, Upper Elk Creek Basin, Colorado}

By Andrew H. Manning, Philip L. Verplanck, M. Alisa Mast, and Richard B. Wanty

Prepared in Cooperation with the U.S. Environmental Protection Agency

Scientific Investigations Report 2007-5265 


\title{
U.S. Department of the Interior DIRK KEMPTHORNE, Secretary
}

\author{
U.S. Geological Survey \\ Mark D. Myers, Director
}

U.S. Geological Survey, Reston, Virginia: 2008

\begin{abstract}
About USGS Products
For product and ordering information:

World Wide Web: http://www.usgs.gov/pubprod

Telephone: 1-888-ASK-USGS

For more information on the USGS - the Federal source for science about the Earth, its natural and living resources, natural hazards, and the environment:

World Wide Web: http://www.usgs.gov

Telephone: 1-888-ASK-USGS
\end{abstract}

\section{About this Product}

For more information concerning this publication, contact:

Team Chief Scientist, USGS Central Region Earth Surface Processes Team

Box 25046

Denver Federal Center

MS 980

Denver, C0 80225-0046

(303) 236-5344

Or visit the Central Region Earth Surface Pocesses Team Web site at:

http://esp.cr.usgs.gov

This publication is available online at:

http://esp.cr.usgs.gov

Publishing support provided by:

Denver Publishing Service Center, Denver, Colorado

Manuscript approved for publication November 27, 2007

Edited by Mary-Margaret Coates, Contractor, ATA Services

Graphics by Andrew H. Manning and layout by Sharon Powers

Suggested citation:

Manning, A.H., Verplanck, P.L., Mast, M.A., and Wanty, R.B., 2008, Hydrogeochemical investigation of the Standard Mine vicinity, upper Elk Creek Basin, Colorado: U.S. Geological Survey Scientific Investigations Report 2007-5265, 131 p. 


\section{Contents}

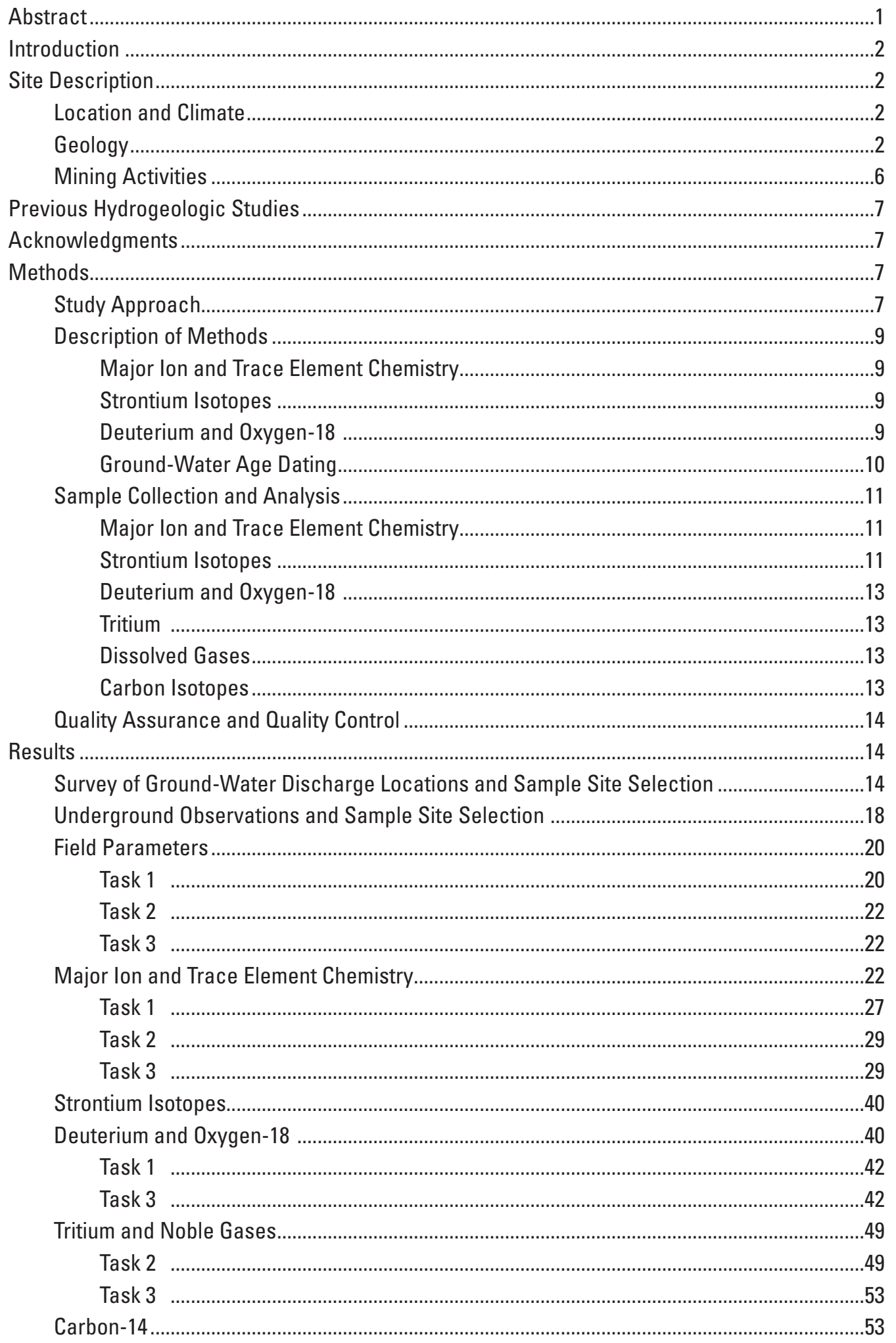




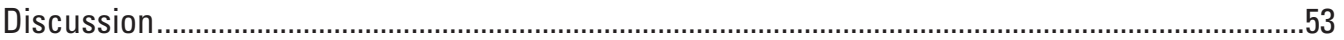

Distribution of Ground-Water Discharge and Potential Geologic Controls on Flow ..............53

Ground-Water Residence Times .........................................................................................

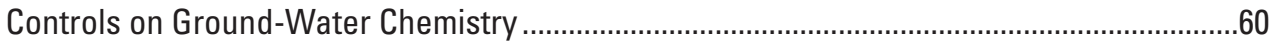

Controls on Metal Concentrations ...............................................................................60

Controls on Major Ion Chemistry ................................................................................60

Controls on Standard Mine Water Chemistry ……………...........................................61

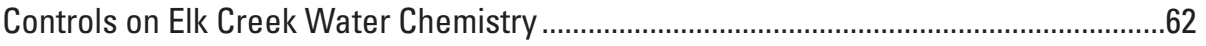

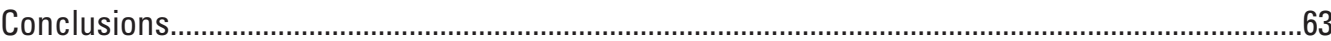

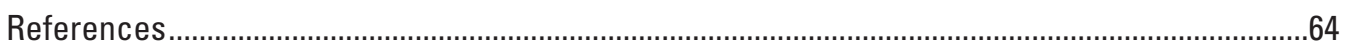

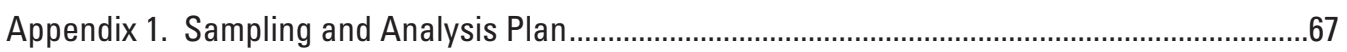

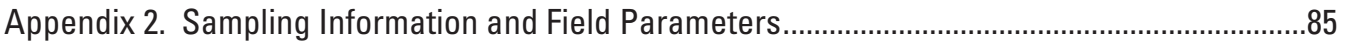

Appendix 3. Concentrations of Major lons and Selected Metals..................................................95

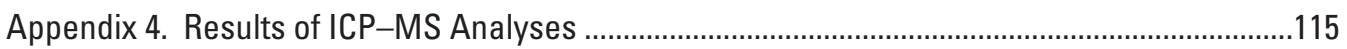

\section{Figures}

1. Index map showing location of Standard Mine, Colorado …...............................................

2. Topograghic map showing location of three sample areas in Standard

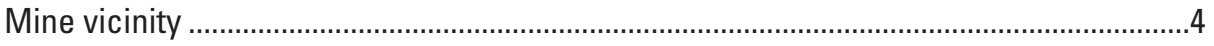

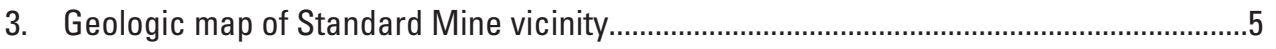

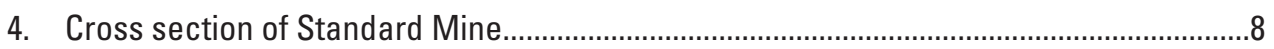

5. Aerial photograph showing location of aboveground samples sites within the three sample areas shown in figure 2 ...............................................................15

6. Cross section showing location of underground samples sites in Level 3 of Standard Mine.

7. Cross section showing location of underground samples sites in Level 5

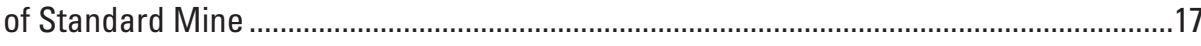

8. Geologic map showing location of aboveground sample sites ......................................19

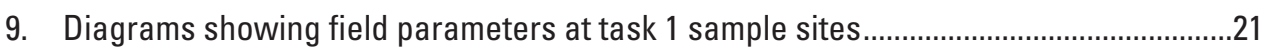

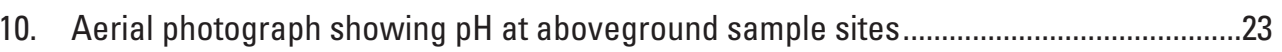

11. Aerial photograph showing specific conductance at aboveground sample sites..........24

12. Cross section showing field parameters at underground sample sites in

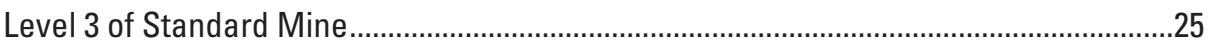

13. Cross section showing field parameters at underground sample sites in

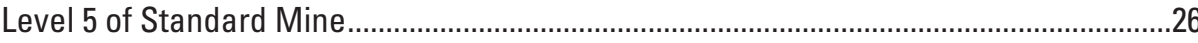

14-17. Diagrams showing:

14. Field parameters versus overburden thickness in underground samples................27

15. Comparison of analytical results by using ICP-AES and ICP-MS for barium, manganese, and strontium concentrations 
16. Calcium and sulfate ion concentrations at task 1 sample sites

17. Concentrations of zinc, lead, cadmium, copper, and manganese at task 1 samples sites

18-24. Aerial photographs annotated to show concentrations at aboveground sample sites of the following metals:

18. Calcium. .31

19. Sulfate . .32

20. Zinc ...33

21. Lead .34

22. Cadmium . .35

23. Copper

24. Manganese

25. Cross section showing concentrations of calcium, sulfate, and selected metals at underground sample sites in Level 3 of Standard Mine.

26. Cross section showing concentrations of calcium, sulfate, and selected metals at underground sample sites in Level 5 of the Standard Mine

27. Diagrams showing concentration of calcium and sulfate versus overburden thickness in underground samples.

28. Diagrams showing concentrations of zinc, lead, cadmium, copper, and manganese versus overburden thickness in underground samples

29. Aerial photograph annotated to show strontium concentration at aboveground sample sites

30. Aerial photograph annotated to show strontium isotope ratios $\left({ }^{87} \mathrm{Sr} r{ }^{86} \mathrm{Sr}\right)$

at aboveground sample sites. . .44

31. Diagram showing strontium concentration versus strontium isotope ratio $\left({ }^{87} \mathrm{Sr} /{ }^{86} \mathrm{Sr}\right) \ldots . .45$

32. Diagrams showing $\delta^{18} 0$ and $\delta^{2} \mathrm{H}$ concentration at task 1 sample sites .. .45

33. Cross section showing $\delta^{18} 0$ and $\delta^{2} \mathrm{H}$ concentration at underground sample sites in Level 3 of Standard Mine...

34. Cross section showing $\delta^{18} 0$ and $\delta^{2} \mathrm{H}$ concentration at underground samples sites in Level 5 of Standard Mine

35. Diagrams showing $\delta^{18} 0$ and $\delta^{2} \mathrm{H}$ concentrations versus overburden thickness for underground samples.

36. Aerial photograph annotated to show tritium concentration at aboveground sample sites

37. Aerial photograph annotated to show apparent ${ }^{3} \mathrm{H} /{ }^{3} \mathrm{He}$ age at aboveground sample sites

38. Cross section showing tritium concentration at underground sample sites in Level 3 of Standard Mine . .55

39. Cross section showing tritium concentration and apparent ${ }^{3} \mathrm{H} /{ }^{3} \mathrm{He}$ age at underground sample sites in Level 5 of Standard Mine. 
40-45. Diagrams showing:

40. Tritium concentration versus overburden thickness for underground

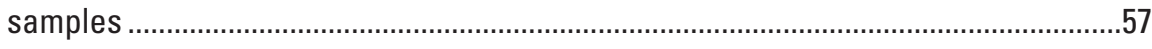

41. Precipitation ${ }^{3} \mathrm{H}$ records for Salt Lake City, Utah, and Albuquerque, N. Mex............58

42. Initial ${ }^{3} \mathrm{H}$ concentration of samples (measured ${ }^{3} \mathrm{H}+$ measured ${ }^{3} \mathrm{He}_{\text {trit }}$ )

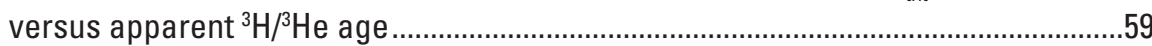

43. Quarterly precipitation ${ }^{3} \mathrm{H}$ concentration for Albuquerque, N. Mex., 1997-2002 ......59

44. Zinc concentration versus cadmium concentration ...............................................61

45. Sulfate concentration versus zinc concentration..................................................62

\section{Tables}

1. Methods of analysis and detection limits................................................................12

2. Strontium isotope content of selected water samples ...............................................42

3. Oxygen-18, deuterium, and carbon isotope content of selected water samples ............46

4. Dissolved gas and ${ }^{3} \mathrm{H}$ data and ${ }^{3} \mathrm{H} /{ }^{3} \mathrm{He}$ ages of samples ...............................................50 


\section{Abbreviations Used in This Report}

\begin{tabular}{|c|c|c|c|}
\hline & Units of measure & & Initialisms and other terms \\
\hline$\mu \mathrm{L}$ & microliter, microliters & AMS & accelerator mass spectrometry \\
\hline$\mu \mathrm{m}$ & micrometer, micrometers & ICP-AES & inductively coupled plasma-atomic emission \\
\hline$\mu \mathrm{S} / \mathrm{cm}$ & microsiemens per centimeter & ICP-MS & $\begin{array}{l}\text { inductively coupled plasma-mass } \\
\text { spectrometry }\end{array}$ \\
\hline $\mathrm{cfs}$ & cubic feet per second & IR-MS & isotope ratio-mass spectrometry \\
\hline $\mathrm{cm}^{3} \mathrm{STP} / \mathrm{g}$ & $\begin{array}{l}\text { cubic centimeters (of gas) at standard } \\
\text { temperature and pressure per gram of } \\
\text { water }\end{array}$ & MC-ICP-MS & $\begin{array}{l}\text { multicollector inductively coupled plasma } \\
\text { mass spectrometer }\end{array}$ \\
\hline Eh & redox potential & $\mathrm{TU}$ & $\begin{array}{l}\text { tritium unit; } 1 \mathrm{TU}=1 \text { atom of }{ }^{3} \mathrm{H} \text { per } 1,018 \\
\text { atoms of hydrogen }\end{array}$ \\
\hline $\mathrm{ft}$ & foot, feet & U.S. & United States \\
\hline gpm & gallons per minute & inby & on the tunnel-end side of \\
\hline h & hour, hours & outby & on the portal side of \\
\hline in./yr & inch (inches) per year & & \\
\hline Ma & mega-annum; millions of years ago & & \\
\hline $\mathrm{mg} / \mathrm{L}$ & milligram (milligrams) per liter & & \\
\hline $\mathrm{mg} / \mathrm{s}$ & milligram (milligrams) per second & & \\
\hline $\mathrm{mi}$ & mile, miles & & \\
\hline $\mathrm{pH}$ & $\begin{array}{l}\text { measure of concentration of hydrogen } \\
\text { ions }\end{array}$ & & \\
\hline $\mathrm{yr}$ & year, years & & \\
\hline
\end{tabular}




\section{Conversion Factors, Abbreviations, and Datums}

Inch/Pound to SI

\begin{tabular}{|c|c|c|}
\hline Multiply & By & To obtain \\
\hline \multicolumn{3}{|c|}{ Length } \\
\hline inch (in.) & 25.4 & centimeter $(\mathrm{cm}))$ \\
\hline foot $(\mathrm{ft})$ & 0.3048 & meter $(\mathrm{m})$ \\
\hline mile (mi) & 1.609 & kilometer $(\mathrm{km})$ \\
\hline \multicolumn{3}{|c|}{ Area } \\
\hline square meter $\left(\mathrm{m}^{2}\right)$ & 2.590 & square kilometer $\left(\mathrm{km}^{2}\right)$ \\
\hline \multicolumn{3}{|c|}{ Flow rate } \\
\hline gallon per minute (gal/min) & 0.06309 & liter per second $(\mathrm{L} / \mathrm{s})$ \\
\hline \multicolumn{3}{|c|}{ Pressure } \\
\hline atmosphere, standard (atm) & 101.3 & kilopascal $(\mathrm{kPa})$ \\
\hline \multicolumn{3}{|l|}{ SI to Inch/Pound } \\
\hline Multiply & By & To obtain \\
\hline \multicolumn{3}{|c|}{ Length } \\
\hline centimeter $(\mathrm{cm})$ & 0.3937 & inch (in.) \\
\hline meter $(\mathrm{m})$ & 3.281 & foot $(\mathrm{ft})$ \\
\hline \multicolumn{3}{|c|}{ Volume } \\
\hline liter $(\mathrm{L})$ & 33.82 & ounce, fluid (fl. oz) \\
\hline cubic centimeter $\left(\mathrm{cm}^{3}\right)$ & 0.06102 & cubic inch $\left(\mathrm{in}^{3}\right)$ \\
\hline \multicolumn{3}{|c|}{ Mass } \\
\hline $\operatorname{gram}(\mathrm{g})$ & 0.03527 & ounce $(\mathrm{oz})$ \\
\hline
\end{tabular}

Temperature in degrees Celsius $\left({ }^{\circ} \mathrm{C}\right)$ may be converted to degrees Fahrenheit $\left({ }^{\circ} \mathrm{F}\right)$ as follows:

$$
{ }^{\circ} \mathrm{F}=\left(1.8 \times^{\circ} \mathrm{C}\right)+32
$$

Temperature in degrees Fahrenheit $\left({ }^{\circ} \mathrm{F}\right)$ may be converted to degrees Celsius $\left({ }^{\circ} \mathrm{C}\right)$ as follows:

$$
{ }^{\circ} \mathrm{C}=\left({ }^{\circ} \mathrm{F}-32\right) / 1.8
$$

Vertical coordinate information is referenced to the North American Vertical Datum of 1988 (NAVD 88).

Horizontal coordinate information is referenced to the North American Datum of 1983 (NAD 83).

Altitude, as used in this report, refers to distance above the vertical datum. 


\title{
Hydrogeochemical Investigation of the Standard Mine Vicinity, Upper Elk Creek Basin, Colorado
}

\author{
By Andrew H. Manning, Philip L. Verplanck, M. Alisa Mast, and Richard B. Wanty
}

\section{Abstract}

Ground- and surface-water samples were collected in the vicinity of the Standard Mine in west-central Colorado in order to characterize the local ground-water flow system, determine metal concentrations in local ground water, and better understand factors controlling the discharge of metalrich waters from the mine. The sampling program included a one-time sampling of springs, mine adits, and exploration pits in Elk Basin and Redwell Basin; repeated sampling throughout one year of Standard Mine Level 1 discharge and Elk Creek near its confluence with Coal Creek; and a one-time sampling of underground sites in Levels 3 and 5 of the Standard Mine. Samples were analyzed for major ions and trace elements, stable isotopes of hydrogen $\left({ }^{2} \mathrm{H} /{ }^{1} \mathrm{H}\right)$ and oxygen $\left({ }^{18} \mathrm{O} /{ }^{16} \mathrm{O}\right)$, strontium isotopes, and tritium and dissolved noble gases (including helium isotopes) for tritium/helium-3 age dating.

No clear correlations were observed between natural ground-water discharge locations and map-scale faults and lithology. Surface observations and the location of groundwater discharge suggest that simple topography, rather than large-scale geologic features, primarily controls the occurrence and flow of shallow ground water in Elk Basin. Discrete inflows from cross faults or other features were not observed in Levels 3 and 5 of the Standard Mine. Instead, water entered the mine as relatively persistent dripping from gouge and breccia within the Standard fault, which both tunnels follow. Therefore, the Standard fault itself is probably the main pathway of ground-water flow from the shallow subsurface to the mine workings.

Low $\mathrm{pH}$ (as low as 3.2) and elevated concentrations of zinc, lead, cadmium, copper, and manganese (commonly exceeding water-quality standards for Elk Creek) were measured in samples located within or immediately downgradient of areas where sulfides are abundant, including the Standard fault, the Elk Lode portal, and the breccia pipe in Redwell Basin. Concentrations of these metals were typically low and $\mathrm{pH}$ values were circumneutral at surrounding locations. Metal concentrations in samples collected from underground workings in the Standard Mine were also generally higher than in samples collected at aboveground sites located outside of sulfide-rich areas. Metal concentrations in discharge from the Level 1 tunnel were among the highest measured in Elk Basin.
All of these observations suggest that sulfide-rich mineralized rock is the primary control on dissolved metal concentrations and $\mathrm{pH}$ in ground water in the Standard Mine vicinity. Wasterock piles apparently exert another major control on metal concentrations and $\mathrm{pH}$; the lowest $\mathrm{pH}$ and highest metal concentrations typically are found in discharge from waste-rock piles. Concentrations of several chemical constituents along with strontium isotope data indicate that none of the sampled waters could have been the primary source of metals in discharge from Level 1. Therefore, this study did not identify the primary source location for metals in Level 1 discharge. Possible sources must be located below Levels 3 and 5 or farther back into the mountainside than the ends of Levels 3 and 5 .

Apparent tritium/helium-3 ground-water ages ranged from 0 to $9 \mathrm{yr}$, and a considerable majority were $<1 \mathrm{yr}$. Tritium data and computed initial tritium values (measured tritium plus measured tritiogenic helium-3) suggest that much of the ground water in the Standard Mine vicinity was weeks to months old rather than years old. Tritium, $\delta^{2} \mathrm{H}$, and $\delta^{18} \mathrm{O}$ data from water entering into and discharging from the Standard Mine displayed spatial and temporal patterns indicating that these tracers were influenced by seasonal variations in their concentration in precipitation. The tracer data therefore suggest that ground water entering into and discharging from the Standard Mine was largely composed of water $<1$ yr old. Pronounced seasonal variations in geochemistry in Level 1 discharge also are consistent with short residence times for much of the water in the Standard Mine.

Metal concentrations in Elk Creek waters were consistently at least an order of magnitude lower than in Level 1 discharge, but they still commonly exceeded water quality standards for zinc, lead, cadmium, copper, and manganese. Estimated metal fluxes along with similar seasonal fluctuations in chemistry (field parameters, chemical constituents, and stable isotopes) observed in Level 1 discharge and Elk Creek are consistent with Level 1 discharge being the primary source of metals in Elk Creek. A prominent feature of the time-series data from both Level 1 discharge and Elk Creek was a "spring flush" during which $\mathrm{pH}$ dropped and metal concentrations rose in the early stages of spring runoff. 


\section{Introduction}

The U.S. Environmental Protection Agency has listed the Standard Mine in the Elk Creek drainage near Crested Butte, Colo., (fig. 1) as a Superfund site. Drainage from the Standard Mine enters Elk Creek, contributing dissolved and suspended loads of zinc, cadmium, lead, and other metals. Elk Creek is a tributary to Coal Creek, which is the main drinking-water supply for the town of Crested Butte. Dozens of abandoned mines and mining prospects cover both the north and south sides of Mount Emmons (fig. 1), but portals associated with Standard Mine are among the few that continually drain water. The Standard Mine has therefore become the focus of attention of concerned local citizens and the U.S. Environmental Protection Agency.

This study characterized the ground-water flow system in the vicinity of the Standard Mine, in order to assist the U.S. Environmental Protection Agency in evaluating remedial options for the mine. More specifically, the purpose of this study is to attempt to answer the following questions.

1. Where in the Standard Mine vicinity does metal-rich water discharge, and what are the concentrations of metals in these waters?

2. What is the primary source (for instance, geologic structure type or rock type) of the elevated metal concentrations?

3. Where is there sufficient permeability to allow substantial ground-water flow rates?

4. What are characteristic ground-water residence times and related temporal variations in ground-water flow and chemistry?

5. Within the Standard Mine, where does ground water discharge, and what is the chemical composition of the different waters contributing to mine outflow?

In order to answer these questions, ground-water and surface-water samples were collected from summer 2006 through spring 2007 from Elk Basin, upper Redwell Basin, lower Elk Creek, and within the Standard Mine (fig. 2). Samples were analyzed for major ions and trace elements, stable isotopes of hydrogen $\left({ }^{2} \mathrm{H} /{ }^{1} \mathrm{H}\right)$ and oxygen $\left({ }^{18} \mathrm{O} /{ }^{16} \mathrm{O}\right)$, strontium isotopes, and tritium and dissolved noble gases (including helium isotopes) for tritium/helium-3 age dating. The resulting chemical and isotopic data provide important information on the distribution and source of metal-rich waters in the Standard Mine vicinity as well as groundwater residence times and seasonal cycles in ground-water chemistry. The study is divided into three tasks. Task 1 consisted of repeated sampling of four locations throughout one year to discern seasonal cycles. Task 2 consisted of a onetime survey and sampling of ground-water discharge locations (springs, mine portals, and exploration pits) in Elk Basin and
Redwell Basin. Task 3 consisted of sampling ground water inside the Standard Mine.

\section{Site Description}

\section{Location and Climate}

The Standard Mine lies within the upper Elk Creek drainage basin (Elk Basin), a roughly $1 \mathrm{mi}^{2}$ alpine watershed located approximately $4 \mathrm{mi}$ west-northwest of the town of Crested Butte in west-central Colorado (fig. 1). Land surface elevations in Elk Basin ranged from 10,800 to 12,200 ft above sea level, and topographic gradients generally ranged from 0.2 to 0.6 , typical of rugged mountain settings (fig. 2). Vegetation is subalpine to alpine, dominantly mixed spruce and fir forest or tundra. The closest meteorological stations are in the town Crested Butte at an elevation of $8,860 \mathrm{ft}$ above sea level (http://www.wrcc.dri.edu) and at Crested Butte ski area approximately $6 \mathrm{mi}$ to the east at an elevation of $10,160 \mathrm{ft}$ (http://www.wcc.nrcs.usda.gov/snotel). Data from these stations suggest that Elk Basin has a mean annual air temperature of about $1{ }^{\circ} \mathrm{C}$ and mean annual precipitation of about $31 \mathrm{in./yr}$; approximately 65 percent of that precipitation typically falls as snow. Snow cover typically persists from November through May. Elk Basin is drained by Elk Creek, which is a perennial stream.

\section{Geology}

The dominant rock units exposed in the Standard Mine vicinity are the Tertiary Wasatch Formation (unit Tw) and Tertiary Ohio Creek Formation (unit Toc) (fig. 3; map taken from Gaskill and others (1967)). The Wasatch Formation consists of fine-grained to very coarse grained sandstone, siltstone, and mudstone, with thick lenses of conglomerate near its base. The Ohio Creek Formation is similar, consisting of sandstone (some conglomeratic), siltstone, shale, and carbonaceous shale, with massive pebbly sandstone beds near its base. These units are underlain by the Cretaceous Mesaverde Formation (unit Kmv), exposed on the north side of Scarp Ridge (north of Elk Basin), which consists of interbedded sandstone, shale, coal, and carbonaceous shale. These fluviolacustrine sedimentary units are intruded by mid-Tertiary sills, dikes, laccoliths, and stocks throughout the Mt. Emmons area. In the Standard Mine vicinity, quartz monzonite porphyry (unit qmp) sills are exposed as are a breccia pipe in Redwell Basin and an associated northeasttrending dike. Both the breccia pipe and dike were mapped as felsite (unit f) by Gaskill and others (1967) (fig. 3). More recent exploration drilling has indicated that the breccia pipe is more likely a composite of felsite, igneous breccia, and rubble breccia and has suggested that the pipe vented volcanic gases and fluids from an unexposed rhyolite-granite porphyry 


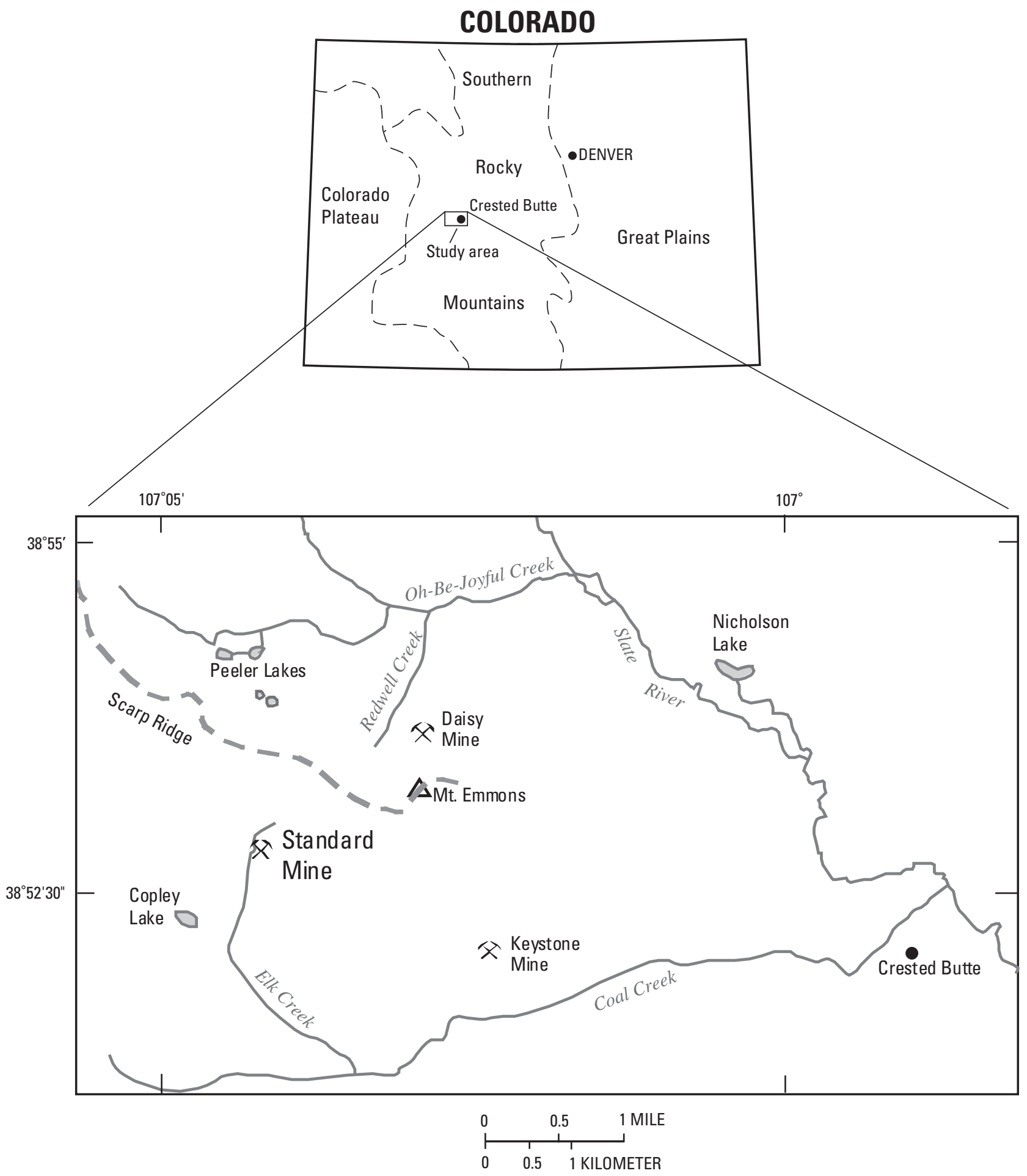

Figure 1. Location of Standard Mine. Dashed line, ridge crest. 


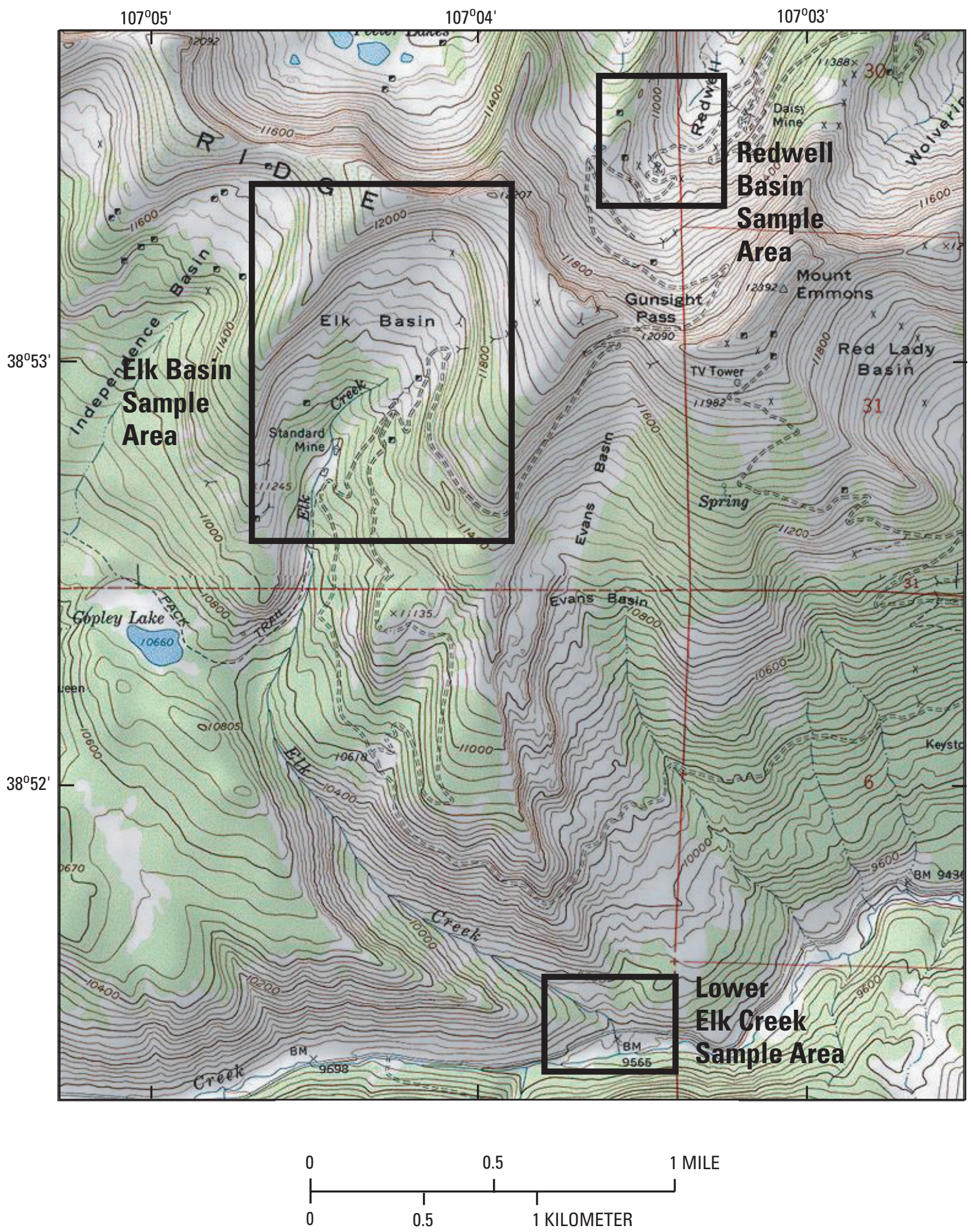

Figure 2. Location of three sample areas in Standard Mine vicinity. Base map compiled from U.S. Geological Survey 1:24,000 topographic maps of the Oh-Be-Joyful, Colo. and Mt. Axtell, Colo. quadrangles (1973). Contour interval, $40 \mathrm{ft}$. 


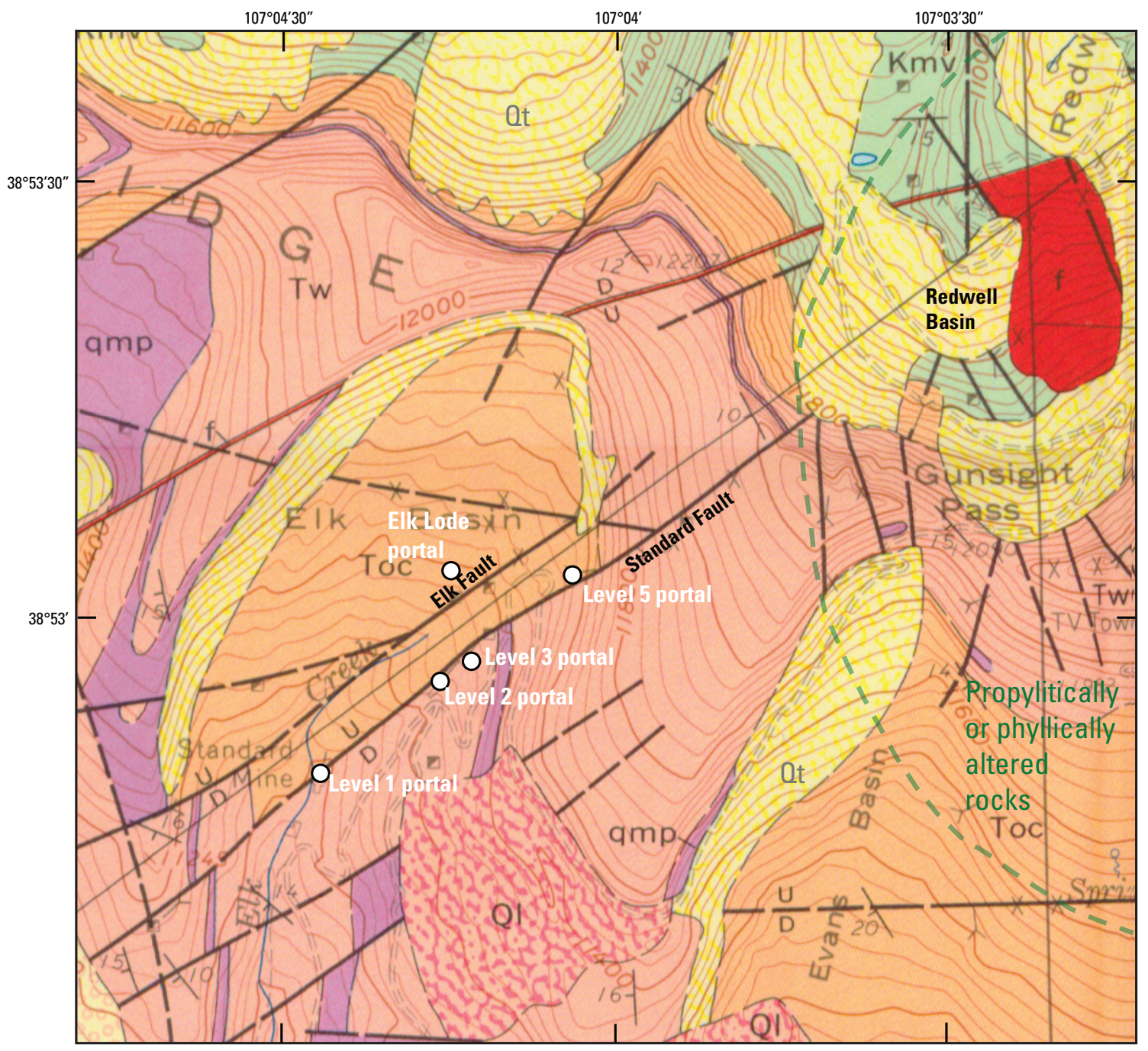

\section{EXPLANATION}

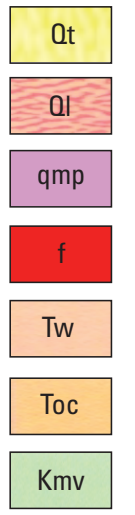
deposit

Quaternary landslide deposit

Tertiary quartz monzonite porphyry

Tertiary felsite

Tertiary Wasatch

Formation

Tertiary Ohio

Creek Formation

Cretaceous

Mesaverde Formation
Quaternary talus

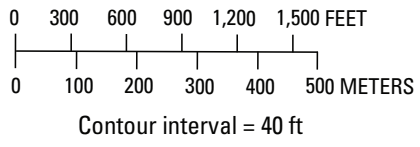

where inferred. U, upthrown

side; D, downthrown side.

Contact—Dashed where approximately

located

16 Strike and dip of beds

- - Extent of alteration zone

O Mine adit

Figure 3. Geology near Standard Mine. Adapted from Gaskill and others (1967). Base map is U.S. Geological Survey 1:24,000 topographic map of Oh-Be-Joyful, Colo. (1973). 
intrusive complex underlying Redwell Basin at depths greater than about 3,000 ft (Sharp, 1978). On the basis of additional exploration work, Thomas and Galey (1982) suggest that the stock underlying Redwell Basin (Redwell stock) is part of a much larger 16-18 million year old (Ma) granite porphyry stock that underlies Mt. Emmons and Red Lady Basin to the southeast (fig. 2).

The sedimentary units dip gently $\left(10^{\circ}-20^{\circ}\right)$ to the southwest. Faults in the area are generally steeply dipping, trend either northeast or north-northwest, and have trace lengths of 0.25 to $2 \mathrm{mi}$. Thomas and Galey (1982) report that the faults display relatively small normal-sense offsets of $<200 \mathrm{ft}$. However, more recently, Wanty and others (2003) have reported that the northeast trending faults are dominantly strike slip, on the basis of fault striation data, and that the two fault sets form a strike-slip extensional step-over (or duplex) in the Mt. Emmons area. Fault duplexes of this type form in transpressive tectonic settings. The age of the faulting is uncertain. Sharp (1978) suspects that that they predate intrusion of the granite porphyry stock underlying the area (dated at 16-18 Ma) and are associated instead with a preintrusion basement fabric manifested by the northeast-trending Colorado mineral belt (Tweto and Sims, 1963) and the northwest-trending Crested Butte lineament (Mutschler, 1968). However, the small displacements displayed by the faults, along with the fact that they do not contain granite porphyry, led Thomas and Galey (1982) to suspect that they are the result of late adjustments in the stock (before or contemporaneous with base metal mineralization), neither predating nor controlling the emplacement of the stock. Wanty and others (2003) also suggest that the faults are contemporaneous with the stock intrusion, but they believe that emplacement of the intrusion was accommodated by localized extension in the duplex, meaning that both faulting and intrusion were controlled by the same stress field. The faults then controlled the flow of mineralizing fluids associated with the intrusion. Wanty and others (2003) emphasize that the presence of hydrothermal veins and mineralization along the principal structures of the duplex indicate that these structures accommodated fluid flow in the geologic past because they were zones of enhanced permeability.

The portals associated with the Standard Mine (Levels 1, 2,3 , and 5 shown on fig. 3) lie on or very close to a northeasttrending fault transecting all of Elk Basin that will henceforth be referred to as the Standard fault. The Standard Mine workings generally follow the Standard fault (Colorado Division of Reclamation, Mining, and Safety, 2007). Thomas and Galey (1982) refer to this structure as the Standard vein. It is one of six subparallel faults mapped within Elk Basin and Independence Basin immediately to the northwest that together are referred to as the Elk Basin fault zone by Sharp (1978). The structure of the Standard fault is described in further detail in a draft underground assessment report by the Colorado Division of Reclamation, Mining, and Safety (2007). The fault immediately northwest of the Standard fault shall be referred to in this report as the Elk fault (fig. 3).
Hydrothermal alteration and mineralization occur in the Standard Mine vicinity as a result of the intrusion of the granite porphyry stock underlying the area. Pervasive propylitic alteration (a low-grade form of alteration) occurs in Redwell Basin and Evans Basin and barely extends into the northeasternmost part of Elk Basin (fig. 3). Propylitically altered rocks typically contain pyrite, epidote, calcite-siderite, and chlorite. Although they contain pyrite, these rocks typically do not produce low-pH and metal-rich waters owing to the buffering capacity of the other minerals present in the assemblage. Thomas and Galey (1982) report that the propylitically altered rocks exposed at the surface in the area contain $<1$ percent pyrite. Higher grade phyllic hydrothermal alteration occurs in the immediate vicinity of the breccia pipe in Redwell Basin, characterized by quartz, sericite, pyrite-pyrrhotite, fluorite, and calcite-siderite-rhodochrosite. Phyllically altered rocks commonly do produce low-pH and metal-rich waters owing to their high pyrite content and low buffering capacity.

Outside of the zone of pervasive alteration shown on figure 3 , hydrothermally altered and mineralized rocks are generally sparse and restricted to faults, veins, and rocks immediately adjacent to these features (Thomas and Galey, 1982). This distribution suggests that hydrothermal fluid flow associated with the intrusion was similarly restricted to faults outside of the immediate vicinity of the granite porphyry intrusion (Wanty and others, 2003). Sulfide minerals within the Standard fault and other faults and veins in the Mt. Emmons area include sphalerite, pyrite, pyrrhotite, argentiferous galena, and chalcopyrite. Fault and vein ores have produced base and precious metals. In addition to the altered and mineralized rock exposed at the surface, phyllic and higher grade potassic alteration have been identified at depth under both Redwell Basin and Red Lady Basin, closer to the granite porphyry stock. Three molybdenite deposits were discovered associated with this alteration, two beneath Redwell Basin (Sharp, 1978) and another higher grade deposit below Red Lady Basin (Thomas and Galey, 1982).

\section{Mining Activities}

The Standard Mine and other mines in the Mt. Emmons area are in the Ruby mining district. Ores within faults and veins in the Mt. Emmons area were mined for base and precious metals from the 1880 s to the early 1970s. The principal mines in the Mt. Emmons area include the Keystone Mine on the southern flank of Mt. Emmons between Evans and Red Lady Basins, the Daisy Mine in Redwell Basin, and the Standard Mine (fig. 1). A review of the history and development of the Standard Mine is provided in a draft underground assessment by the Colorado Division of Reclamation, Mining, and Safety (2007). Extensive exploration drilling in the 1970s identified and characterized the three molybdenite deposits beneath Redwell and Red Lady Basins. These deposits have not been mined. 
The workings of the Standard Mine are described in detail in a draft underground assessment (Colorado Division of Reclamation, Mining, and Safety, 2007). Briefly, the mine consists of four adits and several stopes and shafts that generally follow the Standard fault (fig. 4). The adits are designated Levels 1, 2, 3, and 5, in sequence from lowermost to uppermost. Levels 1, 2, and 3 are connected by stopes or raises. The level 5 tunnel is not connected to the other levels. The Level 1 and Level 5 portals are the only portals that consistently drain water. In August 2006, water was observed inside Level 3 that was draining to lower levels through raises. Level 1 discharges considerably more water than the other levels and is thus the largest potential source of metals in Elk Creek associated with the Standard Mine.

\section{Previous Hydrogeologic Studies}

We are aware of no prior hydrogeologic or geochemical investigations specifically of Elk Basin or the Standard Mine. However, surface- and ground-water geochemistry in the Mt. Emmons area has been studied by the U.S. Geological Survey in recent years, focused mainly in Redwell Basin. Verplanck and others (2004) present the results of chemical analysis of 43 water samples collected from springs, streams, and mine drainages within the Mt. Emmons area. These samples were analyzed for major and trace elements and strontium (Sr) isotopes. The major and trace element data indicate that the sampled waters can be divided into three main types. Type I waters, referred to as "Group 1-2 samples" (Verplanck and others, 2004), have circumneutral $\mathrm{pH}$ and are relatively dilute (iron concentrations on the order of 0.01 milligrams per liter $(\mathrm{mg} / \mathrm{L})$ and zinc concentrations on the order of $0.1 \mathrm{mg} / \mathrm{L}$ ). These samples were collected primarily from springs and stream sites within unmineralized (calcium-rich and sulfidepoor) sedimentary rocks. Type II waters ("Group 4-5 samples,” Verplanck and others, 2004) are acidic (pH typically 3-4) with elevated concentrations of several major elements (iron concentrations on the order of $1-10 \mathrm{mg} / \mathrm{L}$ ) and most trace metals (zinc concentrations on the order of $1 \mathrm{mg} / \mathrm{L}$ ). Many of these samples were collected from mine drainages and other sites within or immediately downgradient of basemetal mineralized rock, which generally is close to the breccia pipe in Redwell Basin or within faults and veins throughout the area. Type III waters ("Group 3 samples," Verplanck and others, 2004) are intermediate between Types I and II, owing either to mixing between Type I and Type II waters or to lesser degrees of water-rock interaction within mineralized rock (possibly shorter flow pathways). All samples collected from sites within base-metal mineralized rock have similar ${ }^{87} \mathrm{Sr} /{ }^{86} \mathrm{Sr}$ isotope ratios (0.7134-0.7143), whereas other samples have different and more widely varying ${ }^{87} \mathrm{Sr} /{ }^{86} \mathrm{Sr}$ isotope ratios (0.7114-0.7166). The study by Verplanck and others (2004) therefore suggests that acidic and metal-rich waters (Type II) near the Standard Mine may be closely associated with faults and veins, which apparently host mineralized rock, and that $\mathrm{Sr}$ isotopes may be a useful tool for identifying waters that have interacted with mineralized rock when flow paths are uncertain or other chemical parameters do not clearly indicate this interaction.

As previously noted, map-scale faults apparently controlled the flow of hydrothermal fluids in the Mt. Emmons area in the geologic past. An important question is whether or not these structures are zones of enhanced permeability and ground-water flow in the current hydrogeologic regime. Wanty and others (2003) performed a tracer dilution study in Redwell Creek to address this question. The tracer test was conducted by continuously injecting lithium chloride $(\mathrm{LiCl})$ into the headwaters of Redwell Creek for 24 hours (h) and collecting 68 synoptic samples from Redwell Creek and all its tributaries when the tracer had reached steady-state concentrations along the study reach. The concentration of the tracer decreased downstream of each tributary, as expected, but the tracer also decreased along the reach where Redwell Creek flows along a set of well-developed, laterally continuous north-south fractures. The dilution of the tracer within this fracture zone documented an input of water to Redwell Creek, although no surface tributaries existed in that reach. Groundwater discharge from the north-south fracture set is the most probable source of the additional water. Therefore the primary fractures in the duplex do appear to serve as preferential ground-water flow pathways in Redwell Basin. There is little reason to believe that the same is not true throughout the Standard Mine vicinity and thus that the Standard fault, Elk fault, and other map-scale faults in Elk Basin (fig. 3) may also serve as preferential ground-water-flow pathways.

\section{Acknowledgments}

This study was performed in cooperation with the U.S. Environmental Protection Agency. We greatly appreciate the efforts of Steve Renner, Jim Herron, and Jeff Graves of the Colorado Division of Reclamation, Mining, and Safety for escorting us into the mine. We thank Robert Runkel and David Borrok for their helpful reviews of this report.

\section{Methods}

\section{Study Approach}

This study was divided into three tasks. Task 1 consisted of repeated sampling of the Standard Mine Level 1 portal and of Lower Elk Creek near the confluence with Coal Creek during the course of one year. Of 8 sampling events, 4 were during spring runoff and 4 were spread throughout the rest of the year. In addition, two springs in Elk Basin were sampled twice, once in late summer (low flow period) and once in the 


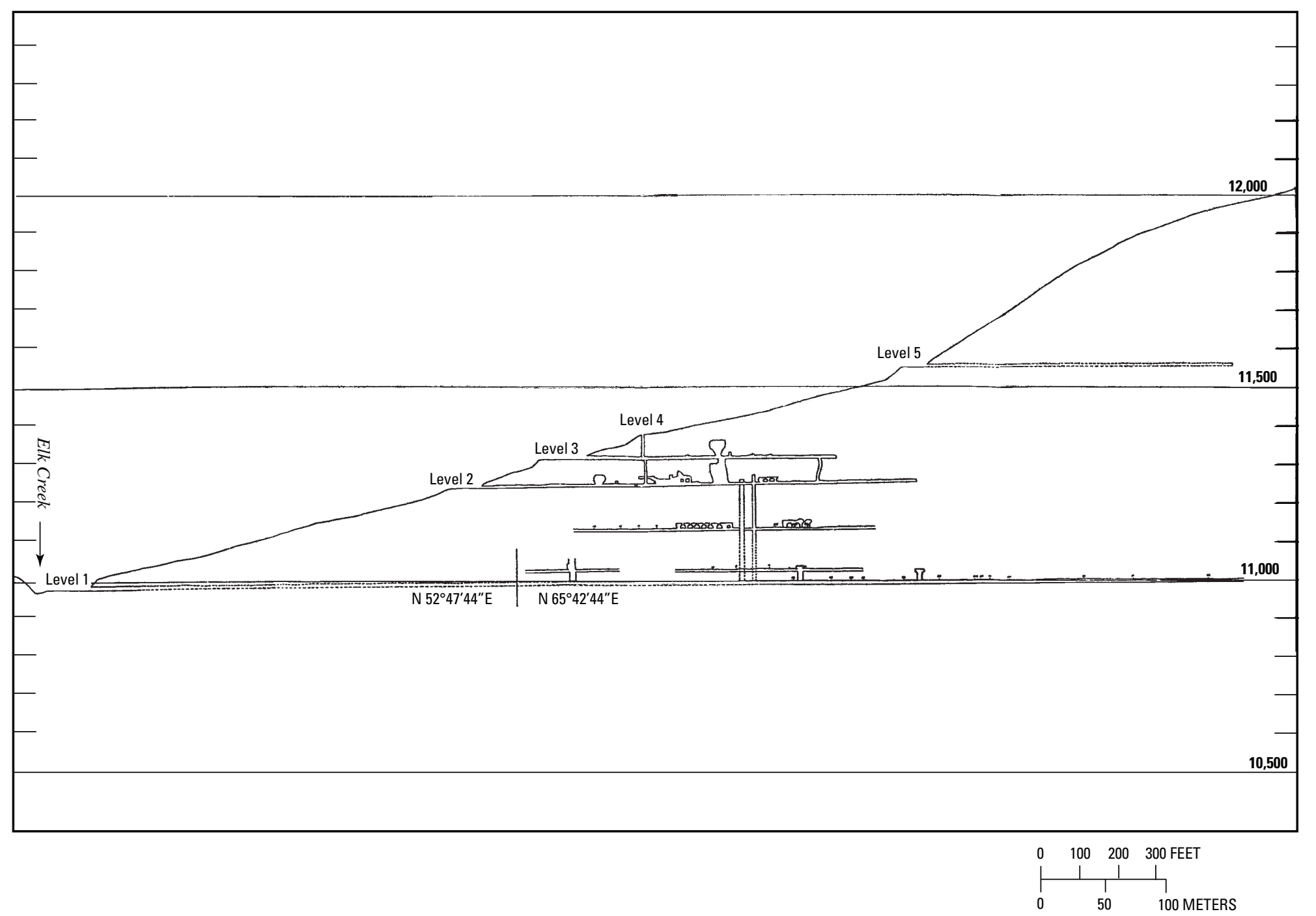

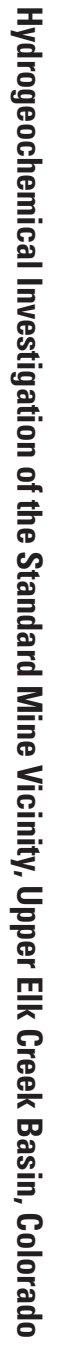

Figure 4. Cross section of Standard Mine. Adapted from Colorado Division of Reclamation, Mining, and Safety (2007). 
spring (high flow period). The objectives of task 1 were to observe seasonal variations in water chemistry in Standard Mine discharge and to compare these variations with those in Elk Creek and in ground water in the rest of Elk Basin. Task 2 consisted of a one-time survey and sampling of ground-water discharge locations (springs, mine workings, and wells) in the Standard Mine vicinity. The objectives of task 2 were to (1) determine the location of metal-rich ground water in the Standard Mine vicinity; (2) place metal concentrations in Standard Mine discharge in context with other ground water in Elk Basin; (3) determine the source of metal-rich water in Elk Basin; (4) assess possible geological controls on groundwater flow in the area; and (5) characterize ground-water residence times. Task 3 consisted of entering the Standard Mine, observing where and how ground water enters the mine, and sampling this water. The objective of task 3 was to better understand the source of ground water and dissolved metals discharging from the Level 1 portal.

\section{Description of Methods}

\section{Major Ion and Trace Element Chemistry}

Because alpine ground-water recharge is dilute precipitation, the primary source of solutes in ground water in the study area should be water-rock interactions. Major and trace element data therefore can be used to determine the mineral assemblages or rock types through which water has flowed. This approach has been used successfully in the Mt. Emmons area and other alpine settings to categorize waters on the basis of rock types with which they have interacted, thus providing important information on flow pathways and sources of high metal concentrations (Verplanck and others, 2004; Wanty and others, 2004). Major and trace element concentrations were measured in this study to determine metal concentrations in Standard Mine drainage, how these concentrations vary seasonally, and how they compare with ground water in the mine vicinity, as well as to discern possible ground-water flow pathways.

\section{Strontium Isotopes}

A comprehensive review of $\mathrm{Sr}$ isotope techniques is provided by Faure (1986). Strontium has four stable, naturally occurring isotopes $\left({ }^{84} \mathrm{Sr},{ }^{86} \mathrm{Sr},{ }^{87} \mathrm{Sr}\right.$, and $\left.{ }^{88} \mathrm{Sr}\right)$. The isotopic abundance of ${ }^{87} \mathrm{Sr}$ is variable because it is produced by the radioactive decay of naturally occurring ${ }^{87} \mathrm{Rb}$ with a half life of $\sim 4.8 \times 10^{10}$ years (yr). Strontium isotopes have been shown to be useful hydrologic tracers for three reasons: the strontium isotope composition of ground water is primarily controlled by the rock through which the ground water flows (in other words, by water-rock interactions); unlike lighter isotopes, strontium isotopes do not produce mass-dependent fractions; and high-precision measurements can be routinely made after only minor chemical separations. ${ }^{87} \mathrm{Sr} /{ }^{86} \mathrm{Sr}$ ratios differ in different rock types because rocks formed in different geologic environments can have different initial ${ }^{87} \mathrm{Sr} /{ }^{86} \mathrm{Sr}$, and rocks that are older or have a greater $\mathrm{Rb} / \mathrm{Sr}$ ratio will have more radiogenic ${ }^{87} \mathrm{Sr}$. As noted above, previous work in the Mt. Emmons area suggests that the strontium isotope signature $\left({ }^{87} \mathrm{Sr} /{ }^{86} \mathrm{Sr}\right)$ of ground water can differentiate waters that have interacted with mineralized or unmineralized rock (Verplanck and others, 2004). Strontium isotope compositions were therefore coupled with major and trace element data to help constrain the origin and evolution of discharging ground waters in the vicinity of the Standard Mine.

\section{Deuterium and 0xygen-18}

A comprehensive review of the use of ${ }^{2} \mathrm{H} /{ }^{1} \mathrm{H}$ and ${ }^{18} \mathrm{O} /{ }^{16} \mathrm{O}$ isotope ratios in ground-water studies is provided by Coplen and others (2000). Deuterium $\left({ }^{2} \mathrm{H}\right)$ and oxygen-18 $\left({ }^{18} \mathrm{O}\right)$ are stable isotopes of hydrogen and oxygen, respectively, that occur naturally in water. Because they are heavier than the dominant isotopes of hydrogen and oxygen $\left({ }^{1} \mathrm{H}\right.$ and $\left.{ }^{16} \mathrm{O}\right)$, they behave differently than ${ }^{1} \mathrm{H}$ and ${ }^{16} \mathrm{O}$ during evaporation and condensation (precipitation). As a result, ${ }^{2} \mathrm{H} /{ }^{1} \mathrm{H}$ and ${ }^{18} \mathrm{O} /{ }^{16} \mathrm{O}$ isotope ratios vary spatially and temporally in meteoric waters, reflecting varying pathways through the hydrologic cycle. Stable isotopic ratios are reported relative to a standard as $\delta$ values in units of per mil, defined as:

$$
\delta X=\left[\frac{R_{X}}{R_{\text {std }}}-1\right] \times 1,000
$$

where $R_{x}$ and $R_{\text {std }}$ are ${ }^{2} \mathrm{H} /{ }^{1} \mathrm{H}$ or ${ }^{18} \mathrm{O} /{ }^{16} \mathrm{O}$ of the sample and standard, respectively. As is customary, $\delta^{2} \mathrm{H}$ and $\delta^{18} \mathrm{O}$ are reported relative to Vienna Standard Mean Ocean Water in this study. The $\delta^{2} \mathrm{H}$ and $\delta^{18} \mathrm{O}$ values of meteoric waters are generally negative because ${ }^{2} \mathrm{H} /{ }^{1} \mathrm{H}$ and ${ }^{18} \mathrm{O} /{ }^{16} \mathrm{O}$ ratios in precipitation are lower than in sea water.

Precipitation $\delta^{2} \mathrm{H}$ and $\delta^{18} \mathrm{O}$ values typically follow a seasonal cycle. Cold winter precipitation has lower values (more negative, or "lighter") and warm summer precipitation has higher values (less negative, or "heavier"). As a result, $\delta^{2} \mathrm{H}$ and $\delta^{18} \mathrm{O}$ values in ground water that has followed short flow pathways (residence times of less than a year) vary with time, displaying the influence of these seasonal variations in precipitation. In contrast, $\delta^{2} \mathrm{H}$ and $\delta^{18} \mathrm{O}$ values in ground water that has followed longer flow pathways (residence times of years) are relatively constant through time, equal to the seasonal average of recharged precipitation. Seasonal variations in $\delta^{2} \mathrm{H}$ and $\delta^{18} \mathrm{O}$ (or lack thereof) are therefore potentially useful in determining the relative contribution of short-and-fast or longand-slow flow paths to a ground-water discharge location. Stable isotope data were obtained for samples collected as part of tasks 1 and 3 to discern the relative abundance of seasonal (younger) and base-flow (older) components in water entering into and discharging from the Standard Mine. 


\section{Ground-Water Age Dating}

The most direct way to determine flow pathway length and residence time is to use ground-water dating techniques. The tritium/helium-3 $\left({ }^{3} \mathrm{H} /{ }^{3} \mathrm{He}\right)$ method was used because it was expected that most waters would fall within the age range of the method, which is 0-50 yr. A comprehensive review of the ${ }^{3} \mathrm{H} /{ }^{3} \mathrm{He}$ method is provided by Solomon and Cook (2000). The method is generally considered to be the most robust of the techniques for dating young ground water because it is least affected by complications arising from degradation, contamination from anthropogenic sources, and mixing of ground waters of different ages (Manning and others, 2005). Tritium is a radioactive isotope of hydrogen that naturally occurs in water and decays to ${ }^{3} \mathrm{He}$ with a half-life of 12.32 yr. Natural concentrations of ${ }^{3} \mathrm{H}$ in precipitation are generally 4-8 tritium units (TU; $1 \mathrm{TU}=1$ atom of ${ }^{3} \mathrm{H}$ per 1,018 atoms of hydrogen). Atmospheric thermonuclear testing in the 1950s and early 1960s introduced large amounts of ${ }^{3} \mathrm{H}$ to the atmosphere, resulting in precipitation ${ }^{3} \mathrm{H}$ concentrations $>1,000 \mathrm{TU}$ and providing ample ${ }^{3} \mathrm{H}$ to allow ground water recharged after the early 1950s (postbomb water) to be dated using the ${ }^{3} \mathrm{H} /{ }^{3} \mathrm{He}$ method. Because both ${ }^{3} \mathrm{H}$ and ${ }^{3} \mathrm{He}$ are chemically inert in the ground-water system, their concentrations change only as a function of time in the subsurface. The age of a ground-water sample is determined by measuring both ${ }^{3} \mathrm{H}$ and tritiumderived (tritiogenic) ${ }^{3} \mathrm{He}$ concentrations and then using their ratio along with the radioactive decay equation to compute the time elapsed since the sampled water entered the saturated zone. Tritium $/{ }^{3} \mathrm{He}$ ground-water ages have proven very useful in developing conceptual models of alpine fractured-rock ground-water flow systems, which are typically highly complex (for example, Manning and Caine, 2007). Tritium $/{ }^{3} \mathrm{He}$ ground-water ages were obtained from the Standard Mine vicinity to help identify zones of high versus low flow velocities and short versus long flow pathways.

The tritiogenic component of ${ }^{3} \mathrm{He}$ in a sample $\left({ }^{3} \mathrm{He}_{\text {trit }}\right)$ is determined by calculating all other ${ }^{3} \mathrm{He}$ components, then subtracting them from the total measured ${ }^{3} \mathrm{He}$. These other ${ }^{3} \mathrm{He}$ components include solubility, excess air, and terrigenic components. The total ${ }^{3} \mathrm{He}$ concentration is determined by multiplying the measured total He concentration by the measured ${ }^{3} \mathrm{He} /{ }^{4} \mathrm{He}$ ratio (R). The measured ${ }^{3} \mathrm{He} /{ }^{4} \mathrm{He}$ ratio is expressed in the form $\mathrm{R} / \mathrm{R}_{\mathrm{a}}$, where $\mathrm{R}_{\mathrm{a}}$ is the ${ }^{3} \mathrm{He} /{ }^{4} \mathrm{He}$ ratio in air. The solubility ${ }^{3} \mathrm{He}$ component is acquired at the time of recharge from gas exchange between the sampled water and air in the unsaturated zone. It is governed by Henry's Law and is a function of the recharge temperature $\left(\mathrm{T}_{\mathrm{r}}\right)$ and recharge pressure, which are the temperature and air pressure at the water table at the point of recharge. The recharge pressure is a direct function of the recharge elevation $\left(\mathrm{H}_{\mathrm{r}}\right)$, which is typically well constrained and is thus assumed. In many cases, $\mathrm{T}_{\mathrm{r}}$ is more uncertain and is therefore computed from the concentration of other noble gases measured along with $\mathrm{He}-$ neon $(\mathrm{Ne})$, argon (Ar), krypton (Kr), and xenon (Xe). Excess air is a component of dissolved gas in excess of solubility concentrations that is ubiquitous in ground water and has an air-like composition. Kipfer and others (2002) provide a complete review of current models of excess air formation. Excess air is believed to originate from the entrapment and subsequent dissolution of air bubbles near the water table when the water table rises. The most current and widely used model for excess air entrainment, and that used in this study, is the closed equilibrium model. In this model, excess air concentrations are governed by two parameters, $\mathrm{A}_{\mathrm{e}}$ and $\mathrm{F}$. $\mathrm{A}_{\mathrm{e}}$ is the amount of air trapped when the water table rises, and $\mathrm{F}$ describes the degree to which gases become fractionated during partial bubble dissolution. $\mathrm{A}_{\mathrm{e}}$ and $\mathrm{F}$ also must be computed from the concentration of the other measured noble gases ( $\mathrm{Ne}, \mathrm{Ar}, \mathrm{Kr}$, and $\mathrm{Xe}$ ). In this study, the total excess air concentration is also reported for reference. This concentration is defined as the sum of the modeled excess components of nitrogen $\left(\mathrm{N}_{2}\right)$, oxygen $\left(\mathrm{O}_{2}\right)$, and Ar. After the recharge parameters $\mathrm{H}_{\mathrm{r}}, \mathrm{T}_{\mathrm{r}}, \mathrm{A}_{\mathrm{e}}$, and $\mathrm{F}$ are either assumed or computed, the solubility and excess air components of ${ }^{3} \mathrm{He}$ can be calculated.

After recharge, ground water can acquire terrigenic $\mathrm{He}$ $\left(\mathrm{He}_{\text {terr }}\right)$ as a result of either radioactive decay of $\mathrm{U}$ and $\mathrm{Th}$ in aquifer materials or from upward leakage of mantle gases and fluids. $\mathrm{He}_{\text {terr }}$ is determined by subtracting the solubility and excess air He components from the total measured He. The terrigenic component of ${ }^{3} \mathrm{He}$ is then computed by multiplying $\mathrm{He}_{\text {terr }}$ by an assumed ${ }^{3} \mathrm{He} /{ }^{4} \mathrm{He}$ ratio for $\mathrm{He}_{\text {terr }}$. If $\mathrm{He}_{\text {terr }}$ concentrations in a sample are too high (greater than about $5 \times 10^{-8}$ cubic centimeters of gas at standard temperature and pressure per gram of water $\left.\left(\mathrm{cm}^{3} \mathrm{STP} / \mathrm{g}\right)\right)$, then the magnitude of ${ }^{3} \mathrm{He}_{\text {trit }}$ becomes highly uncertain owing to uncertainty in the assumed ${ }^{3} \mathrm{He} /{ }^{4} \mathrm{He}$ ratio for $\mathrm{He}_{\text {terr, }}$, and a reliable ${ }^{3} \mathrm{H} /{ }^{3} \mathrm{He}$ age cannot be determined. Typically only samples with ages considerably greater than $50 \mathrm{yr}$ or samples collected in areas of active volcanism have elevated $\mathrm{He}_{\text {terr }}$ concentrations.

The age range of the carbon-14 age dating technique is $1,000-50,000$ yr. A comprehensive review of the carbon-14 method is provided by Kalin (2000). The method is based on the radioactive decay of the carbon-14 $\left({ }^{14} \mathrm{C}\right)$ isotope (half-life of 5,730 yr) in dissolved inorganic carbon in ground water. Carbon-14 is produced in the upper atmosphere and mixes into the lower atmosphere in the form of ${ }^{14} \mathrm{CO}_{2}$. Carbon-14 enters the ground-water system during recharge as soil $\mathrm{CO}_{2}$ produced by plant root respiration and microbial degradation of organic material that dissolves in infiltrating ground water. After entering the saturated zone, interaction with soil $\mathrm{CO}_{2}$ ceases and ${ }^{14} \mathrm{C}$ in the dissolved inorganic carbon decays with time. By convention, the modern pre-1950 (before open-air nuclear bomb testing) activity of atmospheric ${ }^{14} \mathrm{C}$ is 100 percent modern carbon. Two samples collected in this study were analyzed for carbon isotopes to determine whether some of the ground water near the Standard Mine might follow very long or slow flow pathways (or both) and might thus to a degree be disconnected from the active ground-water flow system. 


\section{Sample Collection and Analysis}

This section provides a general description of sample collection and analysis methods. Samples were collected and analyzed as described in appendix 1, Sampling and Analysis Plan, which provides additional details regarding collection and analytical methods.

\section{Major Ion and Trace Element Chemistry}

Onsite measurements of $\mathrm{pH}$, specific conductance, temperature, dissolved oxygen, and redox potential (Eh) were obtained. At each site the $\mathrm{pH}$ electrode calibration was checked and, when necessary, recalibrated using two buffers that bracketed the measured $\mathrm{pH}$. Samples were filtered onsite through a syringe filter having a pore size of $0.45 \mu \mathrm{m}$. Several sample aliquots were collected for determination of concentrations of inorganic constituents and redox species $\left(\mathrm{Fe}^{+2} / \mathrm{Fe}^{+3}\right)$. Container preparation and stabilization of filtered samples included an unfiltered, nitric-acid-acidified aliquot for totalrecoverable major cation and trace element determinations; a filtered, nitric-acid-acidified aliquot for dissolved major cation and trace element determinations; a filtered, nonacidified aliquot for anion and alkalinity determinations; and a filtered, hydrochloric-acid-acidified aliquot for iron redox species determinations. Bottles for both filtered and unfiltered nitricacid-acidified aliquots were soaked in nitric acid, rinsed in distilled water, and then rinsed with sample water. Bottles for filtered, nonacidified aliquots were soaked in distilled water and rinsed with sample water. Opaque bottles for iron redox aliquots were soaked in hydrochloric acid, rinsed in distilled water, and then rinsed with sample water. Appropriate aliquots were acidified with ultrapure acid and then stored on ice until refrigerated.

All analyses for major ion and trace element chemistry were performed at U.S. Geological Survey laboratories in Denver or Boulder, Colo. All reagents were of a purity at least equal to the reagent-grade standards of the American Chemical Society. Double-distilled deionized water and redistilled acids using a subboiling purification technique (Kuehner and others, 1972) were used in all preparations. The methods and detection limit for each analysis are summarized in table 1. U.S. Geological Survey standard reference water samples and blanks were included with each sample suite for inductively coupled plasma-atomic emission spectroscopy (ICP-AES) and inductively coupled plasma-mass spectrometry (ICP-MS). Major cations ( $\mathrm{Ca}, \mathrm{Mg}, \mathrm{K}$, and $\mathrm{Na}$ ) and silica and selected trace elements (aluminum, boron, barium, copper, iron, manganese, lead, strontium, and zinc) for totalrecoverable and dissolved samples were determined using a Perkin Elmer Optima 3000 ${ }^{\mathrm{TM}}$ ICP-AES (Briggs, 2002). Trace elements for total-recoverable and dissolved samples were analyzed with the ICP-MS using a method developed by the
U.S. Geological Survey (Meier and others, 1994; Lamothe and others, 2002). This method is used to directly determine the elements in the water samples without need for any preconcentration or dilution. Elemental detection limits for most trace metals are in the subparts per billion range (table 1), and the working linear range is six or more orders of magnitude.

Concentrations of major anions $\left(\mathrm{Cl}^{-}, \mathrm{F}^{-}, \mathrm{NO}_{3}^{-}\right.$and $\left.\mathrm{SO}_{4}^{-}\right)$ were determined by ion chromatography (Theodorakos and others, 2002); a Dionex DX500 ${ }^{\mathrm{TM}}$ ion chromatograph with 5 -microliter $(\mu \mathrm{L})$ and $10-\mu \mathrm{L}$ sample loops was used. Standards were prepared from compounds of the highest commercially available purity. U.S. Geological Survey standard reference water samples were used as independent quality-control standards. Alkalinity (as $\mathrm{HCO}_{3}^{-}$) was determined using an Orion $960^{\mathrm{TM}}$ autotitrator and standardized $\mathrm{H}_{2} \mathrm{SO}_{4}$ (Barringer and Johnsson, 1989). Samples were diluted as necessary to bring the analyte concentration within the optimal range of the method. Iron(II) redox species and total iron in filtered, $\mathrm{HCl}-$ acidified samples were determined by using a modification of the FerroZine ${ }^{\mathrm{TM}}$ colorimetric method (Stookey, 1970; To and others, 1999) with a Hewlett Packard 8453 ${ }^{\mathrm{TM}}$ diode array ultraviolet-visible spectrophotometer.

\section{Strontium Isotopes}

Measured aliquots of sample water were placed in Savillex ${ }^{\circledR}$ containers, evaporated, and the strontium was then separated for each sample using $\mathrm{SrSpec}^{\circledR}$ resin. During the study period total procedural blanks for strontium were $\leq 30 \mathrm{pg}$ and were negligible compared with the amount of strontium processed for a given sample. Isotopic analyses of strontium separates were performed at the U.S. Geological Survey in Denver, Colo., by using a Nu Instruments ${ }^{\circledR}$ double focusing, high-resolution multicollector inductively coupled plasma mass spectrometer (MC-ICP-MS) and at the University of Colorado, Boulder, by using a Finnigan-MAT 261, 6-collector thermal ionization mass spectrometer. By use of the MC-ICPMS, strontium samples were dissolved in 2 percent $\mathrm{HNO}_{3}$ and introduced into the argon plasma through a desolvating nebulizer system (Nu Instruments DSN100). Seven measurements of the standard SRM-987 during the study period yielded mean ${ }^{87} \mathrm{Sr} /{ }^{86} \mathrm{Sr}=0.71024 \pm 2$. By using the thermal ionization mass spectrometer, ${ }^{87} \mathrm{Sr} /{ }^{86} \mathrm{Sr}$ ratios were analyzed using fourcollector static mode measurements, and SRM-987 during the study period yielded mean ${ }^{87} \mathrm{Sr} /{ }^{86} \mathrm{Sr}=0.71031 \pm 1$. Because of the consistent difference in the measurements of SRM-987 between the two instruments, data from the MC-ICP-MS were normalized to SRM-987 of 0.71031. For two samples (EC-MSTDL32-01 and EC-MSTDL35-01), the same aliquot of strontium was analyzed on both instruments and, after the MC-ICP-MS data were normalized, the ${ }^{87} \mathrm{Sr} /{ }^{86} \mathrm{Sr}$ ratios were within analytical error. 
Table 1. Methods of analysis and detection limits.

\begin{tabular}{|c|c|c|c|c|c|}
\hline Element & $\begin{array}{c}\text { Detection } \\
\text { limit }\end{array}$ & Method & Element & $\begin{array}{l}\text { Detection } \\
\text { limit }\end{array}$ & Method \\
\hline $\mathrm{Ag}$ & $1 \mu \mathrm{g} / \mathrm{L}$ & ICP-MS & $\mathrm{Mn}$ & $10 \mu \mathrm{g} / \mathrm{L}$ & ICP-AES \\
\hline $\mathrm{Al}$ & $20 \mu \mathrm{g} / \mathrm{L}$ & ICP-AES & Mn & $0.2 \mu \mathrm{g} / \mathrm{L}$ & ICP-MS \\
\hline $\mathrm{Al}$ & $2 \mu \mathrm{g} / \mathrm{L}$ & ICP-MS & Mo & $2 \mu \mathrm{g} / \mathrm{L}$ & ICP-MS \\
\hline As & $1 \mu \mathrm{g} / \mathrm{L}$ & ICP-MS & $\mathrm{Na}$ & $0.1 \mu \mathrm{g} / \mathrm{L}$ & ICP-AES \\
\hline B & $5 \mu \mathrm{g} / \mathrm{L}$ & ICP-AES & $\mathrm{Nb}$ & $0.2 \mu \mathrm{g} / \mathrm{L}$ & ICP-MS \\
\hline $\mathrm{Ba}$ & $1 \mu \mathrm{g} / \mathrm{L}$ & ICP-AES & $\mathrm{Nd}$ & $0.01 \mu \mathrm{g} / \mathrm{L}$ & ICP-MS \\
\hline $\mathrm{Ba}$ & $0.2 \mu \mathrm{g} / \mathrm{L}$ & ICP-MS & $\mathrm{Ni}$ & $0.4 \mu \mathrm{g} / \mathrm{L}$ & ICP-MS \\
\hline $\mathrm{Be}$ & $0.05 \mu \mathrm{g} / \mathrm{L}$ & ICP-MS & $\mathrm{NO}_{3}^{-}$ & $0.05 \mathrm{mg} / \mathrm{L}$ & IC \\
\hline $\mathrm{Bi}$ & $0.2 \mu \mathrm{g} / \mathrm{L}$ & ICP-MS & $\mathrm{P}$ & $10 \mu \mathrm{g} / \mathrm{L}$ & ICP-MS \\
\hline $\mathrm{Ca}$ & $0.1 \mu \mathrm{g} / \mathrm{L}$ & ICP-AES & $\mathrm{Pb}$ & $50 \mu \mathrm{g} / \mathrm{L}$ & ICP-AES \\
\hline $\mathrm{Cd}$ & $0.02 \mu \mathrm{g} / \mathrm{L}$ & ICP-MS & $\mathrm{Pb}$ & $0.05 \mu \mathrm{g} / \mathrm{L}$ & ICP-MS \\
\hline $\mathrm{Ce}$ & $0.01 \mu \mathrm{g} / \mathrm{L}$ & ICP-MS & $\operatorname{Pr}$ & $0.01 \mu \mathrm{g} / \mathrm{L}$ & ICP-MS \\
\hline $\mathrm{Cl}^{-}$ & $0.03,0.05 \mathrm{mg} / \mathrm{L}^{1}$ & IC & $\mathrm{Rb}$ & $0.01 \mu \mathrm{g} / \mathrm{L}$ & ICP-MS \\
\hline $\mathrm{Co}$ & $0.02 \mu \mathrm{g} / \mathrm{L}$ & ICP-MS & $\mathrm{Sb}$ & $0.3 \mu \mathrm{g} / \mathrm{L}$ & ICP-MS \\
\hline $\mathrm{Cr}$ & $1 \mu \mathrm{g} / \mathrm{L}$ & ICP-MS & $\mathrm{Sc}$ & $0.6 \mu \mathrm{g} / \mathrm{L}$ & ICP-MS \\
\hline $\mathrm{Cs}$ & $0.02 \mu \mathrm{g} / \mathrm{L}$ & ICP-MS & $\mathrm{Se}$ & $1 \mu \mathrm{g} / \mathrm{L}$ & ICP-MS \\
\hline $\mathrm{Cu}$ & $10 \mu \mathrm{g} / \mathrm{L}$ & ICP-AES & $\mathrm{SiO}_{2}$ & $0.1 \mu \mathrm{g} / \mathrm{L}$ & ICP-AES \\
\hline $\mathrm{Cu}$ & $0.5 \mu \mathrm{g} / \mathrm{L}$ & ICP-MS & $\mathrm{SiO}_{4}^{-}$ & $0.1,0.05 \mathrm{mg} / \mathrm{L}^{1}$ & IC \\
\hline Dy & $0.005 \mu \mathrm{g} / \mathrm{L}$ & ICP-MS & $\mathrm{Sm}^{4}$ & $0.01 \mu \mathrm{g} / \mathrm{L}$ & ICP-MS \\
\hline $\mathrm{Er}$ & $0.005 \mu \mathrm{g} / \mathrm{L}$ & ICP-MS & $\mathrm{Sr}$ & $1 \mu \mathrm{g} / \mathrm{L}$ & ICP-AES \\
\hline $\mathrm{Eu}$ & $0.005 \mu \mathrm{g} / \mathrm{L}$ & ICP-MS & $\mathrm{Sr}$ & $0.5 \mu \mathrm{g} / \mathrm{L}$ & ICP-MS \\
\hline $\mathrm{F}^{-}$ & $0.03,0.05 \mathrm{mg} / \mathrm{L}^{1}$ & IC & $\mathrm{Ta}$ & $0.02 \mu \mathrm{g} / \mathrm{L}$ & ICP-MS \\
\hline $\mathrm{Fe}$ & $20 \mu \mathrm{g} / \mathrm{L}$ & ICP-AES & $\mathrm{Tb}$ & $0.005 \mu \mathrm{g} / \mathrm{L}$ & ICP-MS \\
\hline $\mathrm{Fe}$ & $2 \mu \mathrm{g} / \mathrm{L}$ & FerroZine & Th & $0.2 \mu \mathrm{g} / \mathrm{L}$ & ICP-MS \\
\hline $\mathrm{Fe}(\mathrm{II})$ & $2 \mu \mathrm{g} / \mathrm{L}$ & FerroZine & $\mathrm{Ti}$ & $0.5 \mu \mathrm{g} / \mathrm{L}$ & ICP-MS \\
\hline $\mathrm{Ga}$ & $0.05 \mu \mathrm{g} / \mathrm{L}$ & ICP-MS & $\mathrm{Tl}$ & $0.15 \mu \mathrm{g} / \mathrm{L}$ & ICP-MS \\
\hline $\mathrm{Gd}$ & $0.005 \mu \mathrm{g} / \mathrm{L}$ & ICP-MS & $\mathrm{Tm}$ & $0.005 \mu \mathrm{g} / \mathrm{L}$ & ICP-MS \\
\hline $\mathrm{Ge}$ & $0.05 \mu \mathrm{g} / \mathrm{L}$ & ICP-MS & $\mathrm{U}$ & $0.1 \mu \mathrm{g} / \mathrm{L}$ & ICP-MS \\
\hline Ho & $0.005 \mu \mathrm{g} / \mathrm{L}$ & ICP-MS & V & $0.5 \mu \mathrm{g} / \mathrm{L}$ & ICP-MS \\
\hline $\mathrm{K}$ & $0.1 \mu \mathrm{g} / \mathrm{L}$ & ICP-AES & $\mathrm{W}$ & $0.5 \mu \mathrm{g} / \mathrm{L}$ & ICP-MS \\
\hline $\mathrm{K}$ & $30 \mu \mathrm{g} / \mathrm{L}$ & ICP-MS & $\mathrm{Y}$ & $0.01 \mu \mathrm{g} / \mathrm{L}$ & ICP-MS \\
\hline $\mathrm{La}$ & $0.01 \mu \mathrm{g} / \mathrm{L}$ & ICP-MS & $\mathrm{Yb}$ & $0.005 \mu \mathrm{g} / \mathrm{L}$ & ICP-MS \\
\hline $\mathrm{Li}$ & $0.2 \mu \mathrm{g} / \mathrm{L}$ & ICP-MS & $\mathrm{Zn}$ & $20 \mu \mathrm{g} / \mathrm{L}$ & ICP-AES \\
\hline $\mathrm{Lu}$ & $0.1 \mu \mathrm{g} / \mathrm{L}$ & ICP-MS & $\mathrm{Zn}$ & $0.5 \mu \mathrm{g} / \mathrm{L}$ & ICP-MS \\
\hline $\mathrm{Mg}$ & $0.1 \mathrm{mg} / \mathrm{L}$ & ICP-AES & $\mathrm{Zr}$ & $0.2 \mu \mathrm{g} / \mathrm{L}$ & ICP-MS \\
\hline
\end{tabular}

${ }^{1}$ Detection limit changed January 2007. 


\section{Deuterium and 0xygen-18}

Samples for ${ }^{2} \mathrm{H}$ and ${ }^{18} \mathrm{O}$ analysis were collected in borosilicate glass vials (unfiltered, unpreserved). Analyses were performed at the U.S. Geological Survey Stable Isotope Laboratory in Denver, Colo. Samples were prepared for ${ }^{2} \mathrm{H}$ analysis offline by zinc reduction as described by Kendall and Coplen (1985). Sample $\mathrm{H}_{2}$ gas was admitted to a mass spectrometer and $\delta^{2} \mathrm{H}$ measured by dual-inlet viscous flow. Analytical uncertainty $(1 \sigma)$ is \pm 2.0 per mil. Sample preparation for ${ }^{18} \mathrm{O}$ analysis was performed by online equilibration with $\mathrm{CO}_{2}$ as described by Epstein and Mayeda (1953), with slight modification to accommodate automated sample preparation and analysis. Following equilibration with the sample, headspace $\mathrm{CO}_{2}$ was extracted, purified, and admitted to a mass spectrometer and $\delta^{18} \mathrm{O}$ measured by dual inlet viscous flow. Analytical uncertainty $(1 \sigma)$ is \pm 0.15 per mil. Final reported $\delta^{2} \mathrm{H}$ and $\delta^{18} \mathrm{O}$ values were scaled against Vienna Standard Mean Ocean Water.

\section{Tritium}

Tritium samples were collected in $500 \mathrm{~mL}$ high-density polyethylene bottles (unfiltered, unpreserved). Tritium analyses were performed by the U.S. Geological Survey Noble Gas Laboratory in Denver, Colo., using the ${ }^{3} \mathrm{He}$ ingrowth method described by Bayer and others (1989). A portion of the sample is placed in an airtight tritium extraction flask, degassed, sealed, and then stored for approximately 100 days to allow the accumulation of tritiogenically produced ${ }^{3} \mathrm{He}$. The accumulated ${ }^{3} \mathrm{He}$ is then measured using a magnetic-sector mass spectrometer. The original ${ }^{3} \mathrm{H}$ concentration at the time of sampling is calculated from the measured ${ }^{3} \mathrm{He}$ concentration using a known decay constant $\left(0.05621 \mathrm{yr}^{-1}\right)$. The detection limit is approximately $0.05 \mathrm{TU}$. Analytical uncertainty $(1 \sigma)$ ranges from $0.05 \mathrm{TU}$ at low concentrations $(<1 \mathrm{TU})$ to $0.2 \mathrm{TU}$ at higher concentrations ( $>5 \mathrm{TU})$.

\section{Dissolved Gases}

Dissolved gas samples were collected following the general guidelines described in Stute and Schlosser (2000). Samples were collected in approximately 18-in.-long sections of 3/8-in.-diameter copper tube. Ground water was pumped directly from the discharge point through a copper tube using a peristaltic pump, preventing any contact between the pumped water and the atmosphere upstream of the copper tube. Back pressure was maintained on the pumped water using a flowregulating valve at the downstream end of a length of clear plastic tube attached to the downstream end of the copper tube. The clear plastic tube was monitored to ensure that the flowing water was free of bubbles. After sufficient purging, the sample was sealed in the copper tube using stainless steal pinch-off clamps.

Dissolved gas analyses were performed at the U.S. Geological Survey Noble Gas Laboratory in Denver, Colo. Dissolved gases were extracted from samples by using an ultra high vacuum extraction line. Major component gases (nitrogen, oxygen, carbon dioxide, and methane) were measured on a quadrupole mass spectrometer in dynamic operation mode. Major component gases were then removed by chemical reaction with a heated titanium and zirconium sponge, and remaining noble gases were separated cryogenically. Noble gas concentrations and isotope compositions ( $\mathrm{He}, \mathrm{Ne}, \mathrm{Ar}, \mathrm{Kr}, \mathrm{Xe}$, and the ${ }^{3} \mathrm{He} /{ }^{4} \mathrm{He}$ ratio reported as $\mathrm{R} / \mathrm{R}_{\mathrm{a}}$ ) were measured using separate aliquots on a magnetic-sector mass spectrometer run in static operation mode. All gas concentrations are reported in units of cubic centimeters at standard temperature $\left(0^{\circ} \mathrm{C}\right)$ and pressure (1 atmosphere) per gram of water $\left(\mathrm{cm}^{3} \mathrm{STP} / \mathrm{g}\right)$. Measurement uncertainties $(1 \sigma)$ are 2 percent for nitrogen, 2 percent for $\mathrm{He}, 1$ percent for ${ }^{3} \mathrm{He} /{ }^{4} \mathrm{He}$ ratio, 3 percent for $\mathrm{Ne}, 2$ percent for Ar, 3 percent for $\mathrm{Kr}$, and 3 percent for Xe.

\section{Carbon Isotopes}

Carbon isotope samples were collected in $1 \mathrm{~L}$ safetycoated glass bottles with septum caps. A peristaltic pump was used to pump ground water directly from the discharge point through an inline $0.45-\mu \mathrm{m}$ disposable filter and into the sample bottle. The discharge end of the tube from the pump and filter was placed at the bottom of the sample bottle allowing the bottle to fill from the bottom, minimizing contact between the sampled water and the atmosphere. The bottle was allowed to overflow and continue overflowing for at least 1 minute, purging the bottle. After purging, the tube was slowly removed from the bottle and the bottle was immediately capped. The septum cap was secured with electrical tape.

$\delta^{13} \mathrm{C}$ and ${ }^{14} \mathrm{C}$ activity of dissolved inorganic carbon were measured at the University of Waterloo Environmental Isotope Laboratory (Ontario, Canada) by isotope ratio-mass spectrometry (IR-MS) and at the University of Arizona using accelerator mass spectrometry (AMS), respectively. Dissolved inorganic carbon was extracted from solution in the form of $\mathrm{CO}_{2}$ gas by acidification under vacuum by the University of Waterloo Environmental Isotope Laboratory, and the $\mathrm{CO}_{2}$ gas was sealed in glass breakseals. $\delta^{13} \mathrm{C}$ was determined for the $\mathrm{CO}_{2}$ gas on the Vienna Pee Dee Belemnite scale. One of the breakseals was then sent to the University of Arizona for graphite target preparation and ${ }^{14} \mathrm{C}$ measurement. Details regarding methods used by the University of Arizona AMS facility for ${ }^{14} \mathrm{C}$ determinations can be found in Donahue and others (1990). Analytical errors $(1 \sigma)$ typically are 0.15 per mil for $\delta^{13} \mathrm{C}$ and 0.5 percent modern carbon for ${ }^{14} \mathrm{C}$.

All ${ }^{14} \mathrm{C}$ activity measurements are reported as the ${ }^{14} \mathrm{C}$ activity ratio, ${ }^{14} a$, expressed in percent modern carbon at the time of sampling, not normalized for ${ }^{13} \mathrm{C}$ fractionation, and defined as:

$$
\text { pm } C={ }^{14} a \times 100=\left(\frac{{ }^{14} A_{\text {sample }}}{{ }^{14} A_{\text {reference }}}\right) \times 100
$$

where ${ }^{14} A_{\text {sample }}$ is the absolute (specific) ${ }^{14} \mathrm{C}$ activity of the sample (in disintegrations per minute per gram of carbon), and 
${ }^{14} A_{\text {reference }}$ is the standard activity defined as 95 percent of the activity of National Bureau of Standards oxalic acid

(Ox 1) in the year A.D. 1950. Further explanation of these reporting units in comparison to other common reporting units for ${ }^{14} \mathrm{C}$ activity measurements is provided by Plummer and others (2004).

\section{Quality Assurance and Quality Control}

A complete description of quality assurance and quality control methods is presented in appendix 1. For stable water isotope ratios $\left(\delta^{2} \mathrm{H}\right.$ and $\left.\delta^{18} \mathrm{O}\right),{ }^{3} \mathrm{H}$, dissolved gases, and carbon isotopes, quality control included collecting sample replicates at a rate of 1 in 10 and comparing differences in measurements between replicate pairs with the analytical error reported for the method. Replicate samples are two field-collected samples from the same location that are considered to be essentially identical in composition. Each replicate sample was collected immediately following the original (replicated) sample and was processed through all the same steps. For filtered samples, a new filter was used for the replicate. Replicate samples were analyzed using the same instruments as the original samples.

For major ions and trace elements, quality control methods were more extensive and included replicate samples, field equipment blanks, analyses by alternative methods, and calculation of charge imbalance. A field equipment blank is a sample prepared using deionized water passed through all the sampling and processing equipment. This type of sample is used to check for potential contamination of samples during collection, processing, handling, and analysis. Concentrations of cations were determined by ICP-AES and ICP-MS, allowing comparison of cation concentrations measured using two different methods. Barium, manganese, and strontium were chosen for this comparison because the range in concentrations of these elements was within the working range of both analytical techniques. Data for all samples with complete analyses were checked using the computer program WATEQ4F (Ball and Nordstrom, 1991) for charge imbalance in percent, by using the following calculation:

\section{Charge imbalance $=100 \times($ sum cations - sum anions $)$}

(sum cations + sum anions)

where sum cations is the sum of the cations in milliequivalents per liter, and sum anions is the sum of the anions in milliequivalents per liter. The percent charge imbalance reflects how well the major anions and cations balance and is an independent measure of the accuracy of the analytical techniques.

\section{Results}

Sixty-six samples were collected from 33 sample sites located in 3 sample areas near the Standard Mine (fig. 2). All sample information, including analyses performed on each sample, is shown in appendix 2. Analytical results for replicate samples are included in the analytical results tables referred to below (denoted with a sample name ending with R), and they are listed immediately following their corresponding original sample. Sample site locations are shown in figures 5, 6, and 7. Aboveground sample data shown in map-view figures referred to below were collected in August 2006, except for data from the Elk Creek and Level 2 waste rock sites, which were collected in July 2006.

\section{Survey of Ground-Water Discharge Locations and Sample Site Selection}

Before samples were collected, ground-water discharge points in Elk Basin were surveyed in August 2006 as part of task 2 to discern any patterns in the distribution of discharge points and to select sample sites. The survey was not intended to be comprehensive, but it was undertaken in sufficient detail to include most discharge locations in Elk Basin and thus permit a representative sample set. It is unlikely that any high-flow discharge points (major contributors to Elk Creek) were missed in the survey, because they generally produce tributaries and vegetation patterns that are easily seen. Of the observed waters, those that were not sampled were dilute (specific conductance $<100$ microsiemens per centimeter $(\mu \mathrm{S} / \mathrm{cm}))$, had a circumneutral $\mathrm{pH}(5.5-8.0)$, and had average to low discharge rates $(<2$ gallons per minute $(\mathrm{gpm}))$.

Ground-water in Elk Basin discharges from springs and mine adits and is observed in exploration pits. Estimated spring discharge rates ranged from $<1$ gpm (seeps) to about 10 gpm; typical discharge rates are $<2$ gpm (appendix 2). Seventeen spring discharge locations were observed, including three broad areas of either diffuse discharge or multiple discharge points. From these 17 locations, 13 discrete springs were selected as sample sites (springs 1-12 and Level 2 waste rock, fig. 5). Spring sampling sites were selected on the basis of three guidelines: all waters that were somewhat acidic $(\mathrm{pH}$ $<6$ ) or chemically evolved (specific conductance over about $100 \mu \mathrm{S} / \mathrm{cm}$ ) were sampled; good areal distribution was sought; and if several discharge points with similar field parameters were closely spaced, the one with the highest discharge rate was selected. Springs 1 and 11 are located at the toe of waste rock piles outside of the Level 5 and Elk Lode portals, respectively; they were chosen to characterize water that had filtered through this waste rock. Discharge at the Level 2 waste rock site passes through waste rock outside of the Level 2 portal, so it serves the same purpose. Spring 10 is located at the bottom of the meadow into which spring 1 water reinfiltrates shortly after discharging; water from spring 10 was collected to determine the degree to which the chemistry of spring 1 water changes after flowing as very shallow ground water through this meadow.

Three tributaries of Elk Creek (tributaries 1-3, fig. 5) were sampled to complement the spring samples. Tributaries 1 and 2 collect water discharging from the northwest and 


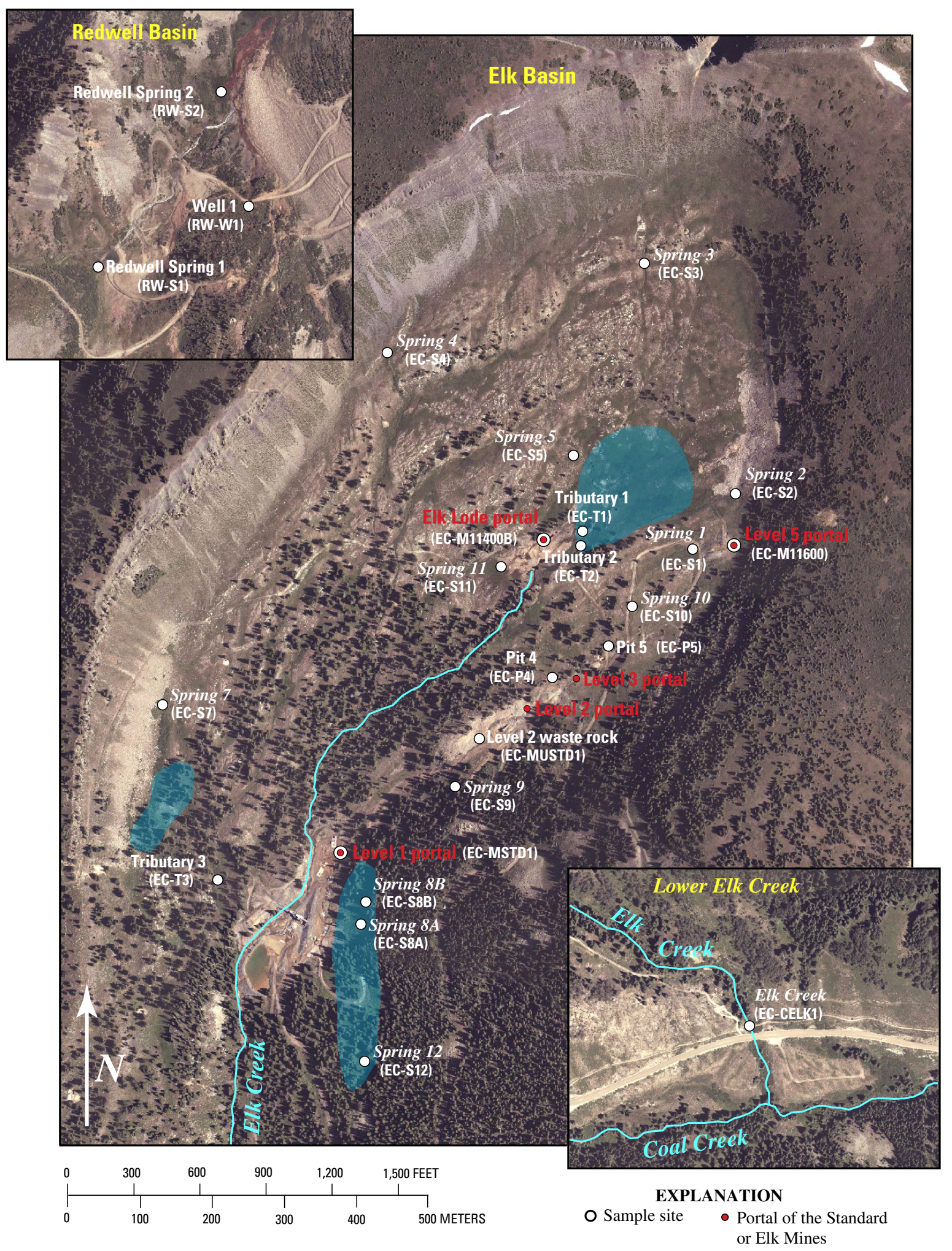

Figure 5. Location of aboveground samples sites (white type; site ID in parentheses) within the three samples areas shown in figure 2. Blue regions, zones of diffuse spring discharge; red type, Standard Mine portal. 


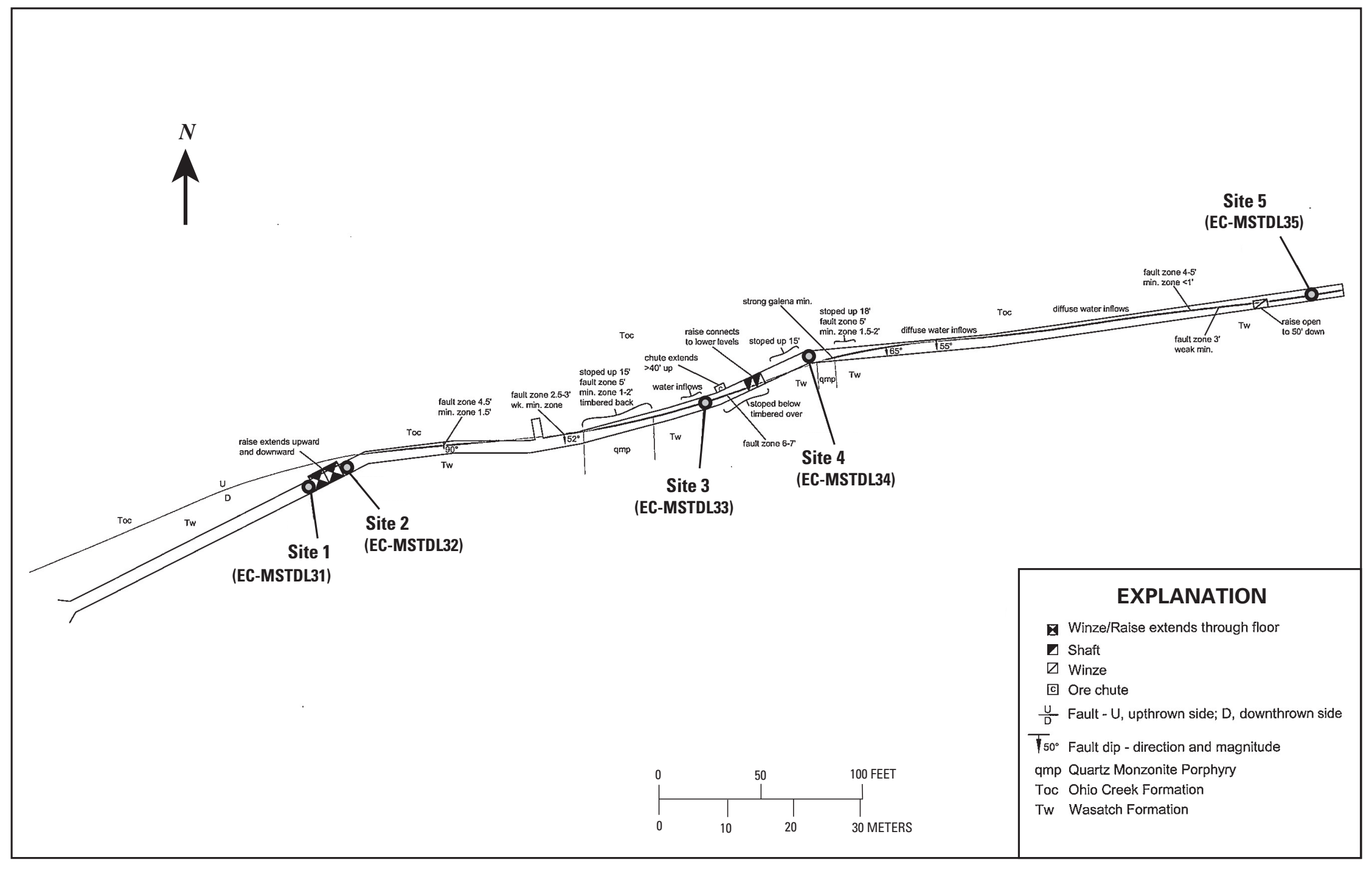

Figure 6. Location of underground samples sites in Level 3 of Standard Mine (site ID in parentheses). Adapted from Colorado Division of Reclamation, Mining, and Safety (2007). min., mineralized or mineralization; wk. min., weakly mineralized. 


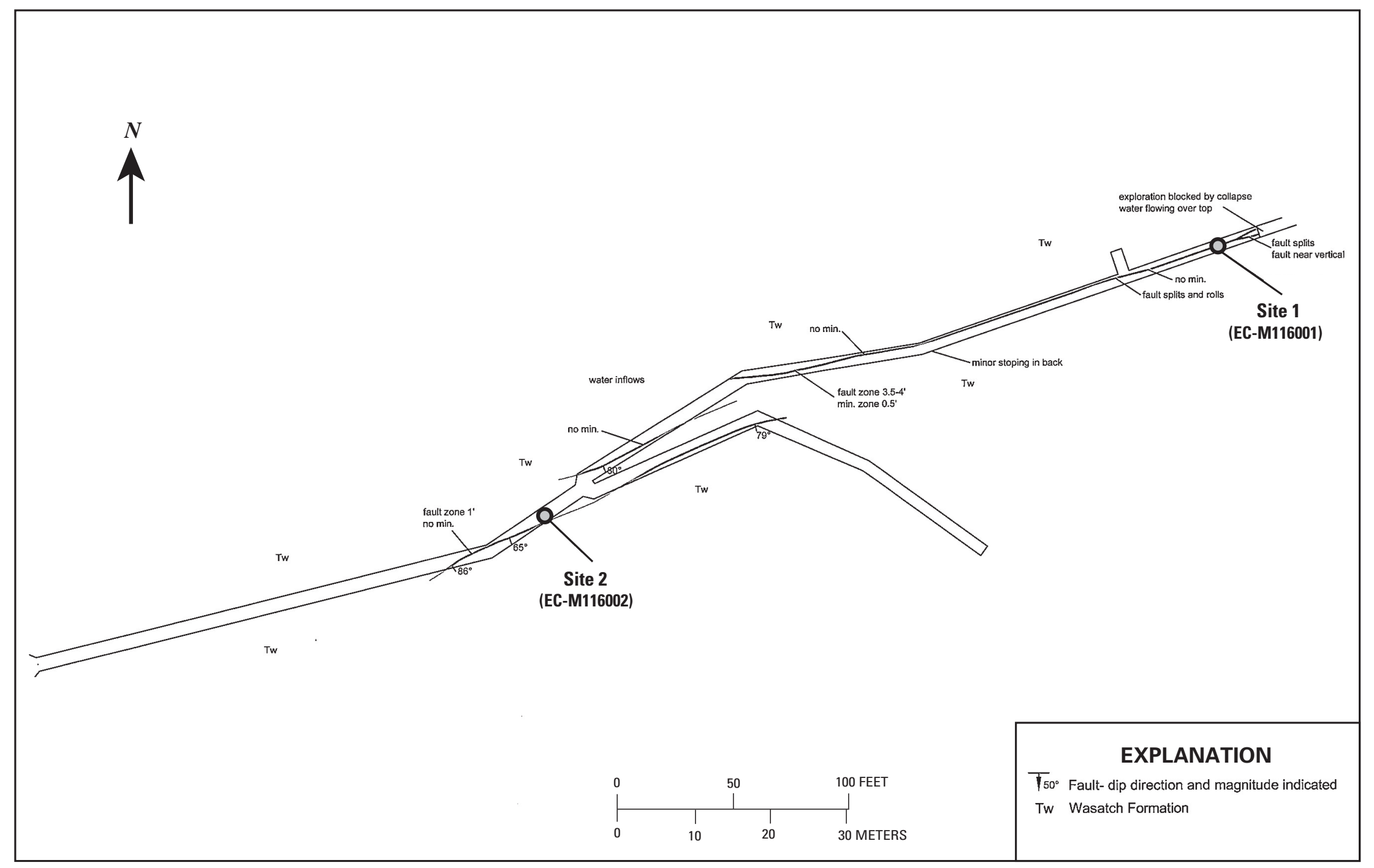

Figure 7. Location of underground samples sites in Level 5 of Standard Mine (site ID in parentheses). Adapted from Colorado Division of Reclamation, Mining, and Safety (2007). min., mineralized or mineralization; wk. min., weakly mineralized. 
southeast sides, respectively, of a broad area of diffuse discharge between springs 2 and 5 (fig. 5). These two tributaries were therefore sampled to characterize ground water discharging within this zone. Similarly, tributary 3 collects water discharging from a zone of multiple springs downhill from spring 7 (fig. 5); water from the tributary was collected to characterize this zone.

Nine mine adits were observed, 3 dry and 6 draining water at estimated rates of 1-10 gpm. Four of the observed adits are part of the Standard Mine (Levels 1, 2, 3, and 5). At the time of task 2 sampling in August 2006, Levels 1 and 5 were draining water and Levels 2 and 3 were dry. Of the observed adits, Level 1 had the highest estimated discharge rate, about $10 \mathrm{gpm}$, and the other adits discharged $<5 \mathrm{gpm}$ (typically $<2 \mathrm{gpm}$ ). Adit lengths, aside from those associated with the Standard Mine, ranged from $<20 \mathrm{ft}$ to several tens of feet at least-sufficiently long that the end could not be seen from the portal. Three of the draining adits, the Level 1 , Level 5, and Elk Lode portals, were selected as sampling sites (fig. 5). All adit discharge waters that were somewhat acidic $(\mathrm{pH}<6.0)$ or chemically evolved (specific conductance over about $100 \mu \mathrm{S} / \mathrm{cm}$ ) were sampled.

Eleven exploration pits, typically $5-10 \mathrm{ft}$ deep and 5-10 ft wide, were observed. Nine of the 11 contained water, and depth to water was $1-8 \mathrm{ft}$ in all 9 pits. The flooded pits were all located on the basin floor, whereas the 2 dry pits were located uphill of the Level 5 portal on the basin headwall. Water in the pits was dilute (specific conductance $<100 \mu \mathrm{S} / \mathrm{cm}$ ) and had circumneutral $\mathrm{pH}(>5.5)$. Pits 4 and 5 were selected as sample sites (fig. 5). Pit 4 was sampled because it appeared to contain the most intensely mineralized rock and is located on the Standard fault so, of all the observed pits, it was suspected to contain water with the highest metal concentrations. Pit 5 was sampled as a substitute for pit 4 after we learned that Colorado Division of Reclamation, Mining, and Safety personnel, about $4 \mathrm{~h}$ before sample collection, had entered Level 3 and then washed their muddy waders in pit 4.

Ground water was not observed on the headwall of Elk Basin (on the ridges rimming the basin) but was observed only at the foot of the headwall or on the basin floor (fig. 5). This spatial distribution is the only trend apparent in ground-water occurrence and discharge. The greater density of sample points near the Standard and Elk faults is a function of the mining activity there (and the desire to characterize waters potentially affected by that activity), not of a greater density of groundwater discharge points.

As part of the survey of ground-water discharge locations, outcrop-scale faults, veins, and mineralization were also noted. As expected, the adits and pits are commonly associated with faults and veins, the loci of mineralized rock. These faults, veins, and silicified zones generally trend either east to east-northeast or north to north-northwest. Sulfide minerals including pyrite, sphalerite, galena, and chalcopyrite are the most abundant in outcrops and waste rock located along the Standard fault and in the breccia pipe in Redwell Basin (unit $\mathrm{f}$ in fig. 3). These sulfide minerals are also present, although in lower abundance, in outcrops and waste rock at the Elk Lode portal. The Elk Lode portal is located within (and apparently follows) a well-defined, mineralized fault similar in scale and orientation to exposed sections of the Standard fault. This fault is located within about $200 \mathrm{ft}$ of the mapped location of the Elk fault (fig. 3). It thus may be a splay or conjugate of the Elk fault, or perhaps the Elk fault itself if the mapped location is slightly off. Sulfide minerals are considerably less abundant in outcrops and waste rock in locations other than the Standard fault, Elk Lode portal, and Redwell Basin breccia pipe. Outside of these areas, mineralization takes the form of sparsely disseminated and veinlet pyrite. Springs generally emanate from float, so the bedrock geology at the spring locations could not be observed.

In addition to the Elk Basin sites, three sample sites were selected in Redwell Basin, the basin adjacent to the northeast (fig. 5). Redwell spring 1 was chosen because it was the ground-water discharge location closest to being on-trend with the Standard fault, yet outside of the zone of intense alteration associated with the breccia pipe exposed in Redwell Basin (fig. 8). The purpose of this sample site was to determine if mineralized rock in the Standard fault might be influencing ground water in Redwell Basin. Redwell spring 2, also known as "The Red Well," was selected because the large volume of ferricrete deposited by the spring and its low dissolved-oxygen concentration suggest that this water may have circulated more deeply and be older than other ground water in the Standard Mine vicinity. The purpose of this sample was therefore to characterize the older, more deeply circulating component of ground water in the area. Well 1 is an uncapped mineral exploration drill hole that forms an artesian well flowing at an estimated rate of 10-20 gpm. Extensive Fe oxide deposits (rust-colored strand extending northward from the well in fig. 5) and a low dissolved-oxygen concentration suggest that water from well 1 , like that from Redwell spring 2 , is deep-circulating and older. However, sampling conditions for dissolved gases were better at well 1 than at Redwell spring 2; the focused, rapidly discharging water was free of bubbles, whereas bubbles were visible in the more slowly emerging water at Redwell spring 2, suggesting some gas loss in the large spring pool. A sample for dissolved gas and ${ }^{3} \mathrm{H}$ was therefore collected at well 1 to more confidently characterize the age of what appeared to be the oldest component of ground water in the area.

\section{Underground Observations and Sample Site Selection}

Levels 3 and 5 of the Standard Mine (fig. 4) were entered with Colorado Division of Reclamation, Mining, and Safety personnel in August 2006 as part of task 3 in order to make hydrologic and geologic observations, select sample sites, and collect water samples. Collapses at or near the portals of Levels 1 and 2 prevented entry into these tunnels. A draft underground assessment report by Colorado Division 


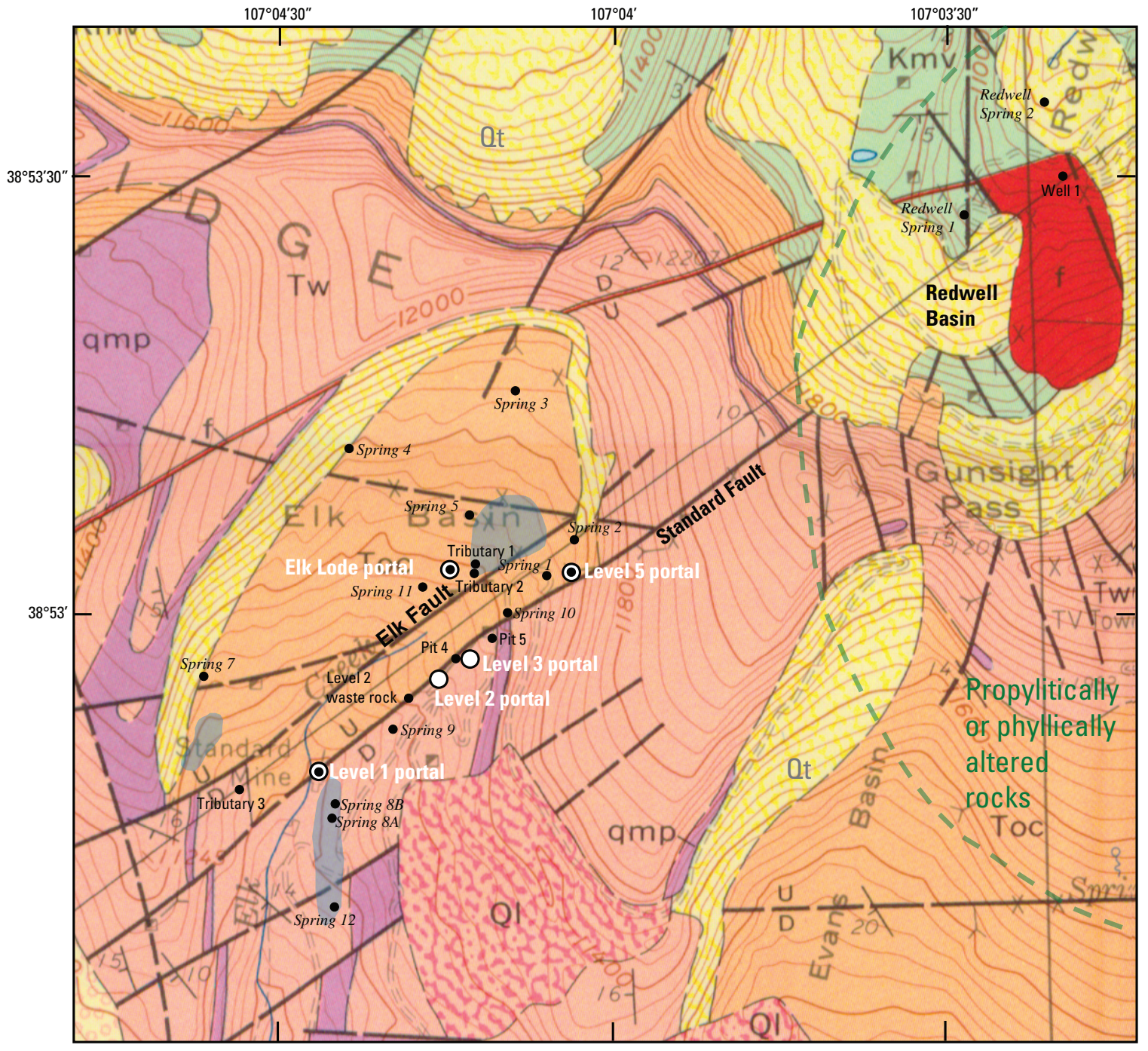

\section{EXPLANATION}

\begin{tabular}{|c|c|c|c|}
\hline Qt & Quaternary talus & $\mathrm{U}$ & Fault or shear zone-Dashed \\
\hline Q1 & Quaternary landslide & & side; $\mathrm{D}$, downthrown side. \\
\hline qmp & $\begin{array}{l}\text { Tertiary quartz } \\
\text { monzonite porphyry }\end{array}$ & 16 & $\begin{array}{l}\text { located } \\
\text { Strike and dip of beds }\end{array}$ \\
\hline$f$ & Tertiary felsite & -- & $\begin{array}{l}\text { Extent of alteration zone } \\
\text { Mine adit }\end{array}$ \\
\hline Tw & $\begin{array}{l}\text { Tertiary Wasatch } \\
\text { Formation }\end{array}$ & - & Sample site \\
\hline Toc & $\begin{array}{l}\text { Tertiary Ohio } \\
\text { Creek Formation }\end{array}$ & & \\
\hline $\mathrm{Kmv}$ & $\begin{array}{l}\text { Cretaceous } \\
\text { Mesaverde Formation }\end{array}$ & & \\
\hline
\end{tabular}

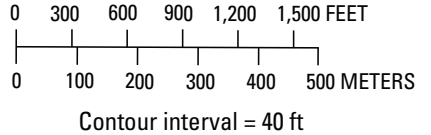

Contour interval $=40 \mathrm{ft}$ 
of Reclamation, Mining, and Safety (2007) describes in detail tunnel features (such as layout, raises, and stopes) and geology. Tunnel features relevant to the hydrogeologic system and sample site selection are discussed below.

Level 3 follows the Standard fault along nearly the entire tunnel (fig. 6). The fault zone is typically $3-5 \mathrm{ft}$ wide, contains sulfide mineralization, strikes N. $70^{\circ}-80^{\circ}$ E. and dips $50^{\circ}-70^{\circ}$ E. No discrete inflows were observed. Instead, water entered the tunnel by dripping from the ceiling and walls. The fault zone material (gouge and breccia) in the ceiling appeared to be the primary source of the inflowing water, which dripped to the floor or trickled down the footwall (northwest) side of the tunnel where the footwall surface formed the northwest wall of the tunnel. Therefore, the footwall (northwest) side of the tunnel was commonly wet, and the hanging-wall (southeast) side of the tunnel was commonly dry. The dripping was pervasive throughout the tunnel, though its intensity varied. No obvious correlations were noted between zones of more intense dripping and geologic features. Water was on the floor throughout the tunnel, but flow was either nonexistent or imperceptibly slow. Water flowed down the two raises to Level 2 on both the outby (portal) side and inby (tunnel end) side of each raise, indicating at least some inward and outward flow on the tunnel floor toward the raises.

Five sample sites were selected in Level 3 (fig. 6). Sites 1 and 2 were chosen because of the relatively low $\mathrm{pH}$ values $(<5)$ of their water and to characterize water flowing toward and down the first raise from outby and inby sides, respectively. Site 3 was chosen because it was the location of the most intense dripping. Site 4 was chosen to characterize water flowing toward and down the second raise from the inby side. Site 5 was chosen to characterize inflow at the end of the tunnel. The sample from site 3 was collected directly from water dripping into the tunnel. Samples from the remainder of the sites were collected from water on the tunnel floor and thus integrate local and upstream inflows (indby or outby, depending on the site).

Level 5 also follows the Standard fault, or segments of the fault, along most of the length of the tunnel (fig. 7). Exposed fault zones are typically $1-4 \mathrm{ft}$ wide, contain sulfide minerals, strike N. $65^{\circ}-85^{\circ}$ E., and dip $60^{\circ}-80^{\circ}$ E. As with Level 3, water entered the tunnel pervasively as diffuse drips and we observed no discrete inflows. Also as with Level 3, the fault zone material appeared to be the primary source of inflowing water, resulting in the footwall (northwest) side of the tunnel commonly being wet and the hanging-wall (southeast) side commonly being dry when the footwall surface formed the northwest wall of the tunnel. Two cross faults striking approximately perpendicular to Standard fault segments were observed, both $1-2 \mathrm{ft}$ wide and dipping $80^{\circ}-85^{\circ}$ W. Water dripped from material within these faults, as with the Standard fault segments, but no increase in tunnel inflows were noted near these cross faults. No correlations were noted between the rate of dripping and geologic features in the tunnel. Water was on the floor throughout the tunnel and flowed slowly toward the portal (no raises are present).
Two sample sites were selected in Level 5 (fig. 7). Site 1 at the end of the accessible portion of the tunnel was chosen to characterize inflow at this point and inby the collapse blocking the tunnel. The sample was collected from a pool at the base of the collapse. Site 2 was selected because it was the largest single inflow (but still $<0.2 \mathrm{gpm}$ ), in the form of a thin stream of water spouting from the ceiling apparently under pressure. The sample was collected directly from the inflow.

\section{Field Parameters}

Measured field parameters included $\mathrm{pH}$, redox potential, discharge temperature, dissolved oxygen, and specific conductance (appendix 2). Temperature, dissolved oxygen, and specific conductance were measured for all samples except those collected as part of task 1 in winter and early spring, when snow cover made accurate dissolved oxygen measurements unfeasible. Eh and pH were not remeasured for samples collected within a week of a previous sample at the same site. Eh was measured only on selected samples to observe representative Eh values for the site. Only $\mathrm{pH}$ and specific conductance measurements are discussed below because these parameters are typically the best indicators of metal-rich waters.

\section{Task 1}

Values of pH ranged from 3.4 to 6.7 at the Level 1 portal, and from 6.1 to 7.4 at Elk Creek, spring 2, and spring 8A (fig. 9A). Measurements at Elk Creek and the Level 1 portal showed the same general seasonal trend of climbing or remaining similar through summer, fall, and winter; peaking in late winter to early spring (during base flow); then dropping during the spring snowmelt runoff. The pattern was more muted for Elk Creek than for the Level 1 portal. Measurements at springs 2 and $8 \mathrm{~A}$ in the late summer, fall, and spring showed little variation. Specific conductance measurements ranged from 442 to $613 \mu \mathrm{S} / \mathrm{cm}$ at the Level 1 portal and from 52 to180 $\mu \mathrm{S} / \mathrm{cm}$ at Elk Creek, spring 2, and spring 8A (fig. 9B). As with $\mathrm{pH}$, specific conductance measurements at Elk Creek and the Level 1 portal showed the same general seasonal trend of climbing or remaining similar through summer, fall, and winter; peaking in late winter; then dropping during the spring snowmelt runoff. However, the seasonal variation in specific conductance was less pronounced than variation in $\mathrm{pH}$. Again, measurements at springs 2 and $8 \mathrm{~A}$ in late summer, fall, and spring showed relatively little seasonal variation. No data were collected from springs 2 and 8A during the period of greatest variation in specific conductance and $\mathrm{pH}$ at the Level 1 portal and Elk Creek (late February through early June), owing to an inability to access the springs under the snowpack. Therefore, $\mathrm{pH}$ and specific conductance at the spring sites may have varied seasonally in a manner similar to the Level 1 portal and Elk Creek, but this possible variation cannot be resolved by the data. 

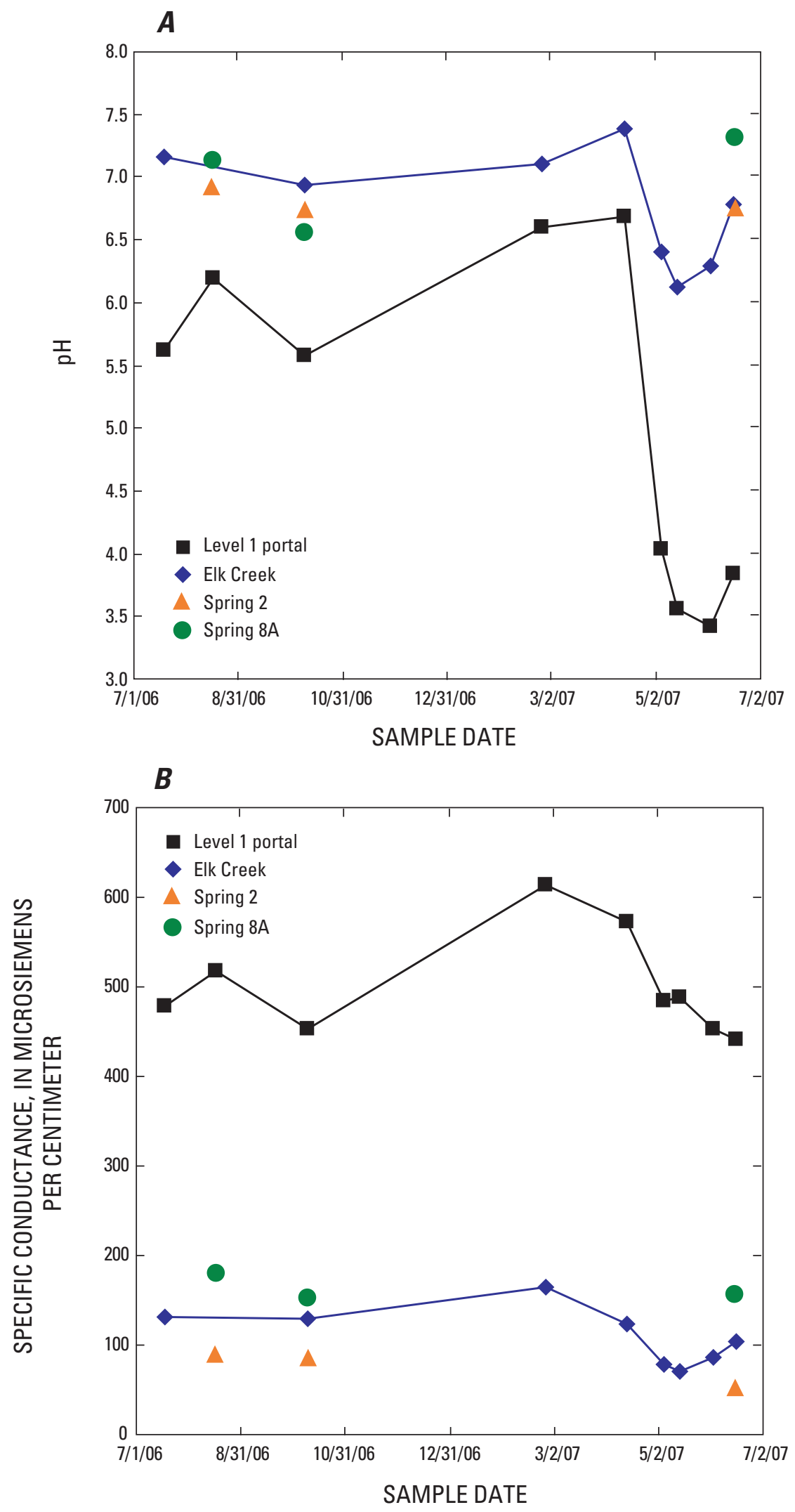

Figure 9. $\mathrm{pH}(A)$ and specific conductance $(B)$ at task 1 sample sites plotted versus sample date. 


\section{Task 2}

Field $\mathrm{pH}$ and specific conductance at the aboveground sample sites are shown in figures 10 and 11, respectively. Measured $\mathrm{pH}$ values were generally circumneutral (6.2-7.7) except at sites near the Standard fault, where they were as low as 3.0, and at Redwell spring 2 (3.7). Mineralized rocks in the Standard fault and the breccia pipe immediately upgradient of Redwell spring 2 contain the most abundant sulfide minerals observed in the study area. The two lowest $\mathrm{pH}$ values were measured at the Level 2 waste rock site and at spring 1, both locations of waste-rock discharge. Of the sites with circumneutral waters located away from the Standard fault, those near the Elk Lode portal, another location of mineralized rock relatively high in sulfides, had the lowest $\mathrm{pH}$ values (6.2-6.3).

Measured specific conductance values were generally low (30-108 $\mu \mathrm{S} / \mathrm{cm}$ ) except in three instances: (1) sites near the Standard fault, where they were as high as $840 \mu \mathrm{S} / \mathrm{cm}$;

(2) well 1 and Redwell spring 2 (618 and $249 \mu \mathrm{S} / \mathrm{cm}$, respectively); and (3) springs in the area of diffuse discharge south of the Level 1 portal (180-230 $\mu \mathrm{S} / \mathrm{cm})$. The two highest SC values (773 and $840 \mu \mathrm{S} / \mathrm{cm}$ ) were measured at locations having the two lowest $\mathrm{pH}$ values (Level 2 waste rock site and spring 1), suggesting that specific conductance is controlled by $\mathrm{pH}$ or by factors that also control $\mathrm{pH}$ (mineralogy and redox conditions). However, specific conductance values were also elevated $(>180 \mu \mathrm{S} / \mathrm{cm})$ at some locations where the water was circumneutral, namely the Levels 1 and 5 portals and the area of diffuse discharge south of the Level 1 portal. The fact that water from the Levels 1 and 5 portals is expected to be some of the oldest at the site, because these tunnels penetrate deeply into the subsurface, suggests that specific conductance may also be controlled by ground-water residence time.

\section{Task 3}

Figures 12 and 13 show $\mathrm{pH}$ and specific conductance values measured at the underground sites. Measured $\mathrm{pH}$ values were circumneutral (6.7-7.2) in both tunnels except at Level 3 sites 1 and 2 (4.3 and 3.3, respectively). Specific conductance values at the underground sites ranged from 153 to $424 \mu \mathrm{S} / \mathrm{cm}$. As with the aboveground samples, the highest specific conductance value was measured at the location with the lowest pH (Level 3 site 2).

Clearly apparent, systematic variations in geology were not observed in Levels 3 or 5 or at the surface above these tunnels, suggesting that systematic relationships between the chemistry and overburden thickness for the underground samples are probably not caused by such geologic variations (fig. 14). A more likely explanation is that the residence time of ground water at the underground sites generally increases with overburden thickness. The specific conductance data along with other data in following sections are therefore plotted against overburden thickness to evaluate potential relationships between ground-water residence time and chemistry. Of course, flow paths can be highly irregular and flow rates highly heterogeneous in fractured-rock ground-water-flow systems, so a strong correlation between overburden and residence time is not expected. Nevertheless, the broad range of overburden thicknesses for the underground sites (50-350 ft) means that flow pathway lengths and residence times on average should be longer for the deeper sites than for the shallower sites. Further, assuming a rough correlation between overburden thickness and residence time is reasonable given that ground water was not observed entering Levels 3 and 5 by discrete fracture-controlled inflows (clearly indicative of highly variable flow rates to the tunnel) but, instead, by pervasive and diffuse dripping from gouge and breccia in the Standard fault zone (consistent with more uniform flow contained largely within the Standard faultzone material). Aside from the two samples with the thinnest overburden having the lowest $\mathrm{pH}$ values, $\mathrm{pH}$ varied little with overburden thickness (fig. 14A). However, if Level 3 site 2 is considered an outlier, specific conductance generally increased with overburden thickness (fig. 14B). Similar to the aboveground data, the underground specific conductance data therefore suggest that specific conductance is controlled in part by residence time.

\section{Major Ion and Trace Element Chemistry}

Fifty samples were analyzed for major and trace element chemistry (appendixes 3 and 4). Most major, minor, and trace element replicate concentrations were within \pm 10 percent of the value obtained for the corresponding original sample. Analytical results for equipment blanks (appendixes 3 and 4) and are designated as EB-01 through EB-05. All analytes in the equipment blanks were below analytical detection limits except for bicarbonate alkalinity, which was consistently measured at $2 \mathrm{mg} / \mathrm{L}$, just above the reporting limit. Good agreement between ICP-AES and ICP-MS results was observed for cations measured at concentrations at least three times the detection limit (fig. 15). The percent-charge imbalance was low (less than 10 percent) for all samples (appendix 3).

Discussion of results of major ion and trace element analyses in this report focuses on calcium $(\mathrm{Ca})$, sulfate $\left(\mathrm{SO}_{4}\right)$, zinc $(\mathrm{Zn})$, lead $(\mathrm{Pb})$, cadmium $(\mathrm{Cd})$, copper $(\mathrm{Cu})$, and manganese $(\mathrm{Mn})$. Calcium and $\mathrm{SO}_{4}$ were chosen because they were typically the most abundant major cation and anion, respectively, and their spatial and temporal trends generally represented the trends of other major ions. Nine contaminants of concern were identified in a recent ecological risk assessment of the site (Syracuse Research Corporation, 2007): $\mathrm{Zn}, \mathrm{Pb}, \mathrm{Cd}, \mathrm{Cu}, \mathrm{Mn}$, aluminum, silver, nickel, and calcium. Of these, concentrations $\mathrm{Zn}, \mathrm{Pb}, \mathrm{Cd}, \mathrm{Cu}$, and $\mathrm{Mn}$ exceeded water quality standards in the Elk Creek samples collected as part of this study, so these five metals are discussed in this report. Water quality standards for Elk Creek (segment 11, upper Gunnison River Basin) were computed from table value standard equations for chronic exposure specified in the Colorado Department of Public Health and Environment 

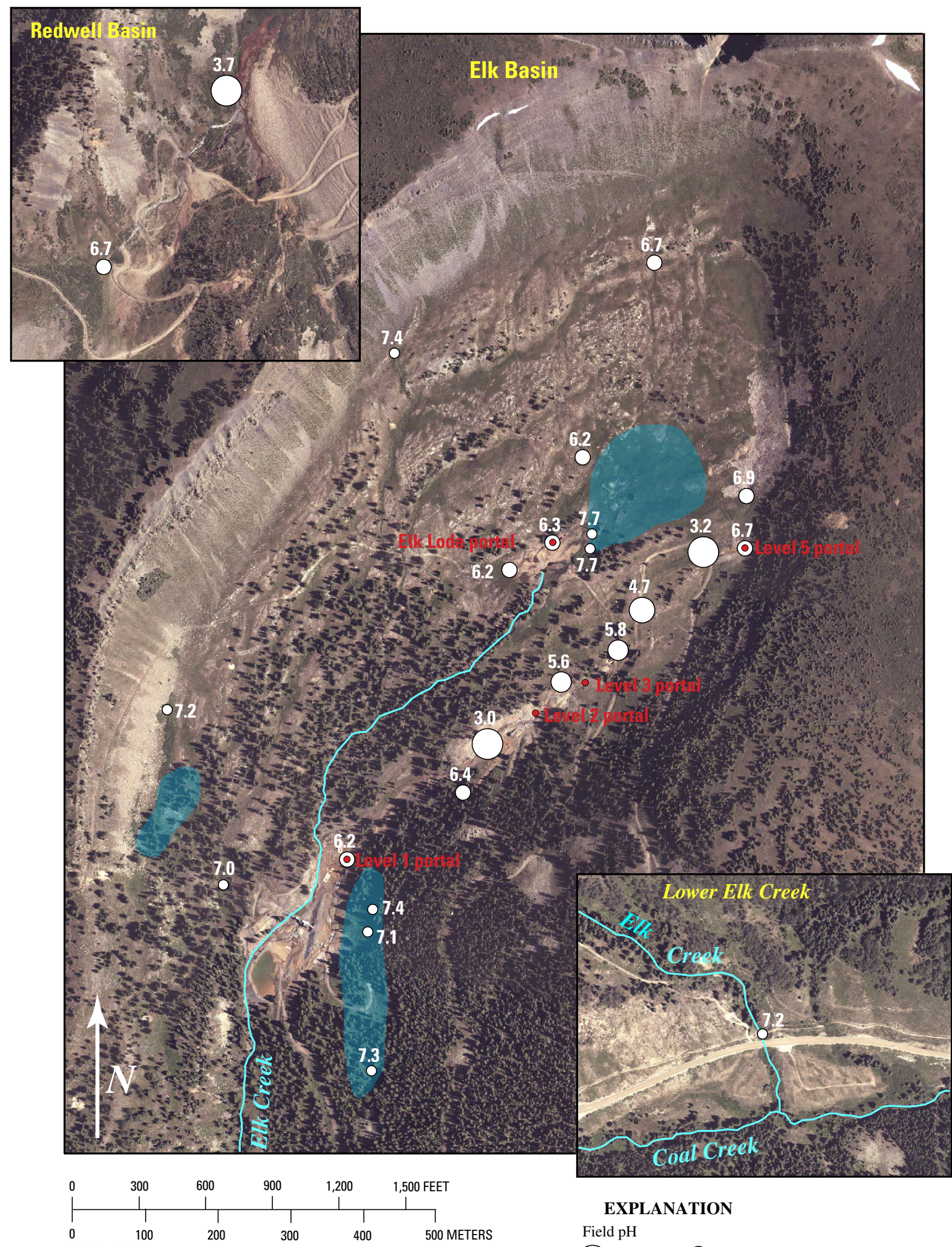

EXPLANATION

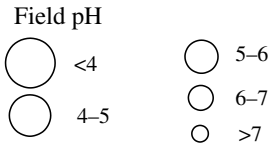

Figure 10. pH (white type) at aboveground sample sites. Blue regions, zones of diffuse spring discharge; red type, Standard Mine portal. 


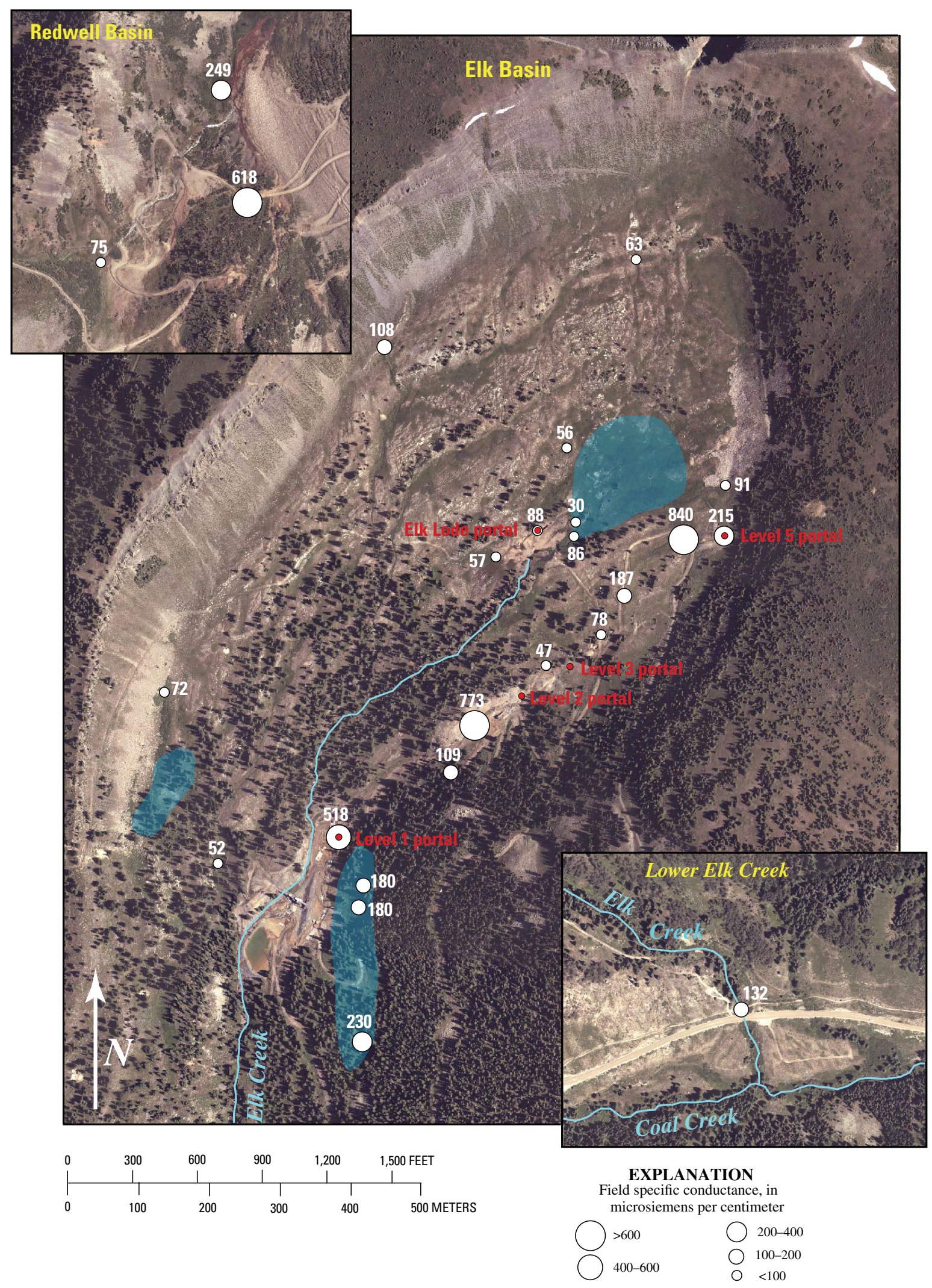

Figure 11. Specific conductance (white type) at aboveground sample sites. Blue regions, zones of diffuse spring discharge; red type, Standard Mine portal. 


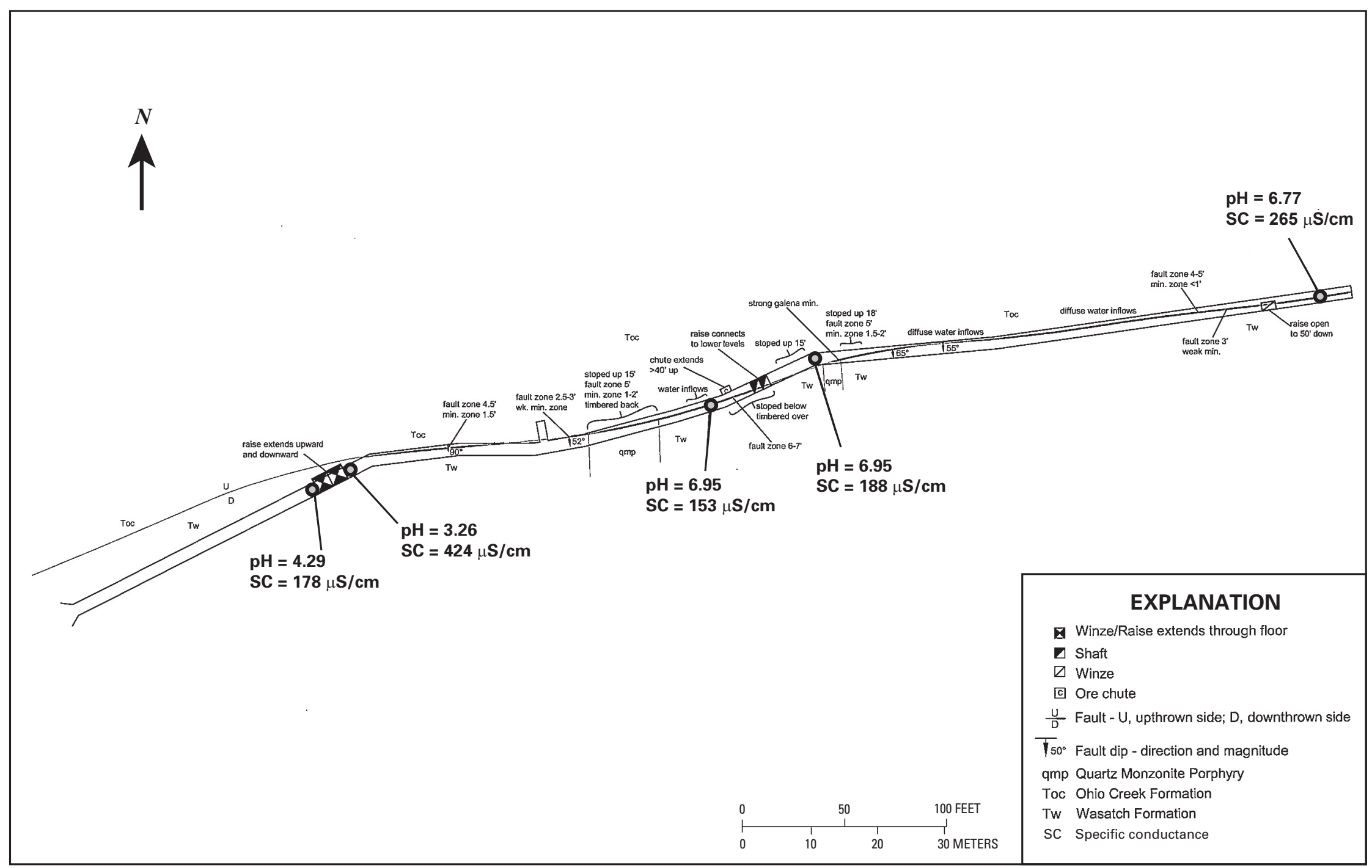

Figure 12. Field parameters at underground sample sites in Level 3 of Standard Mine. Adapted from Colorado Division of Reclamation, Mining, and Safety (2007). min., mineralized or mineralization; wk. min., weakly mineralized. 


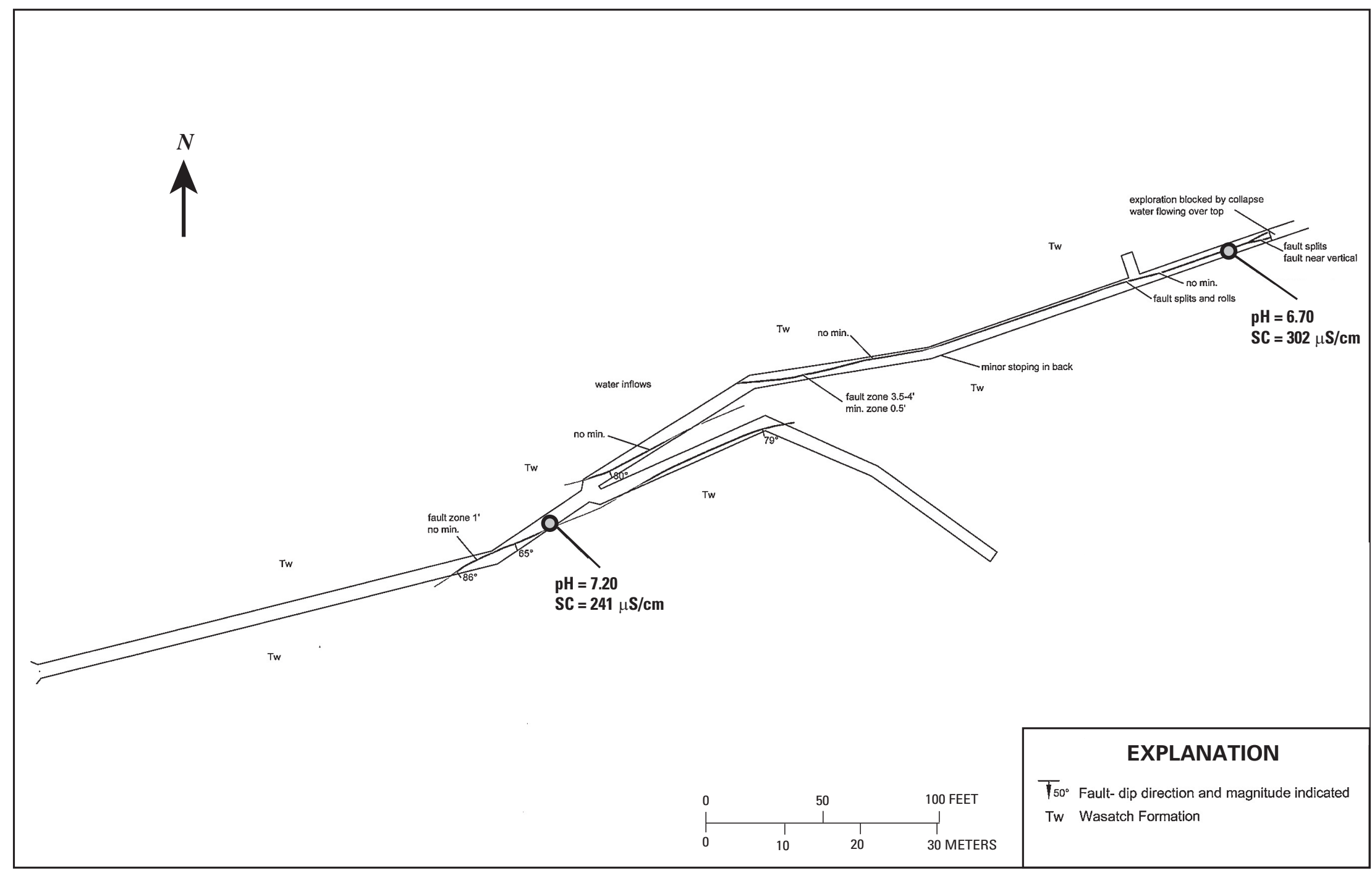

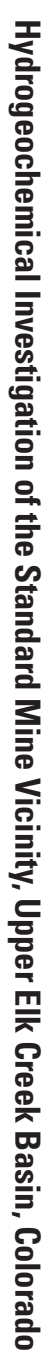

Figure 13. Field parameters at underground sample sites in Level 5 of Standard Mine. Adapted from Colorado Division of Reclamation, Mining, and Safety (2007). min., mineralized or mineralization. 

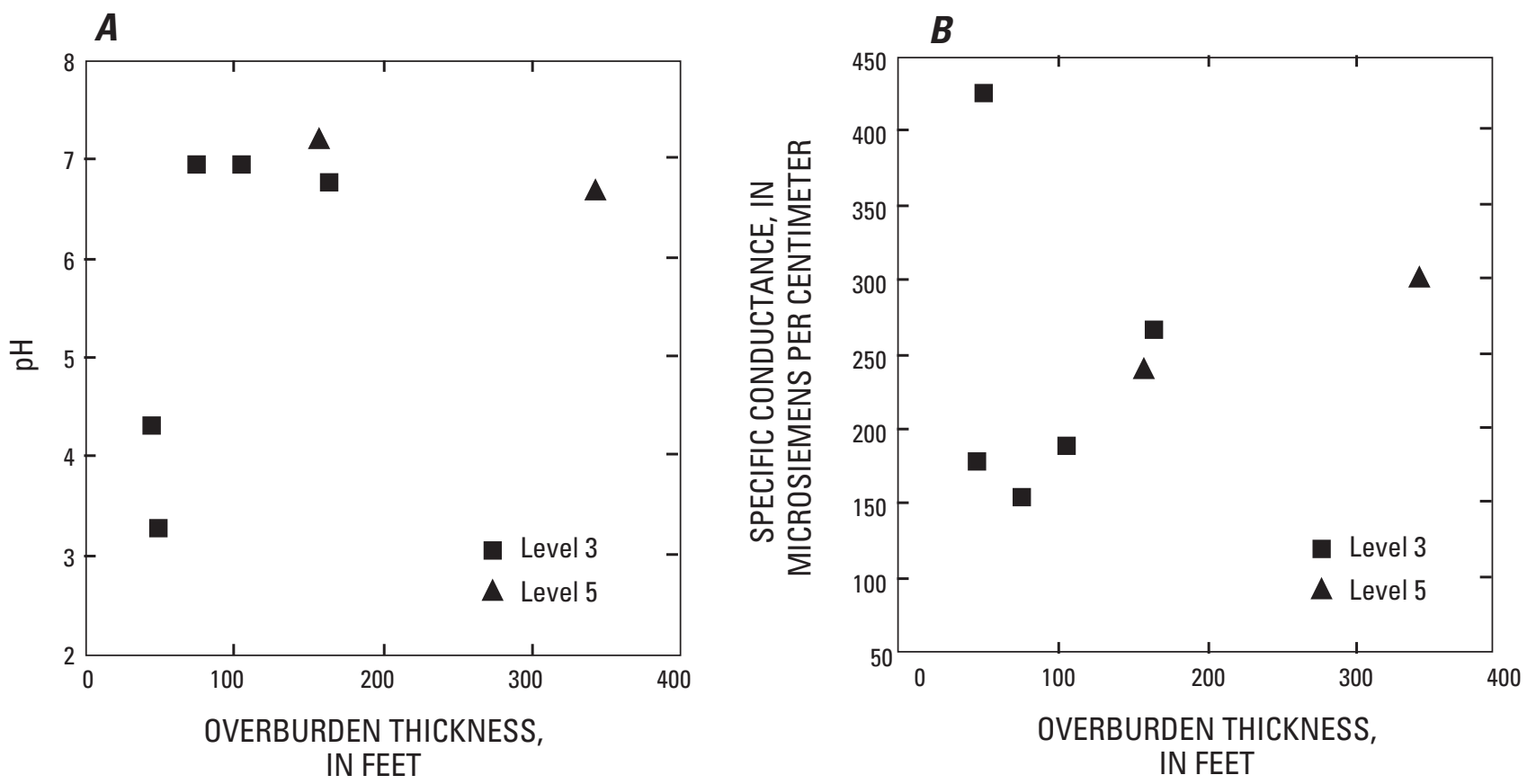

Figure 14. $\mathrm{pH}(A)$ and specific conductance $(B)$ of underground samples plotted versus overburden thickness.

Water Quality Control Commission Regulation Number 35 (5 CCR 1002-35), Classifications and Numeric Standards for Gunnison and Lower Dolores River Basins. Table value standards are computed from a water hardness value. The hardness value used was the average hardness of the eight samples collected from Elk Creek as part of this study (47.4 mg/L as calcium carbonate, appendix 3). Computed water quality standards for Elk Creek are $\mathrm{Zn}, 0.066 \mathrm{mg} / \mathrm{L}$; $\mathrm{Pb}, 0.0011 \mathrm{mg} / \mathrm{L} ; \mathrm{Cd}, 0.00024 \mathrm{mg} / \mathrm{L} ; \mathrm{Cu}, 0.0047 \mathrm{mg} / \mathrm{L}$; and $\mathrm{Mn}, 0.050 \mathrm{mg} / \mathrm{L}$. Note that the $\mathrm{Mn}$ standard is the value specified for surface waters used for water supply. No nickel concentrations measured in this study exceeded the water quality standard for Elk Creek (0.028 mg/L). Aluminum and $\mathrm{Ca}$ are not discussed as contaminants in this report because no appropriate water quality standards were found for these constituents. Silver is not discussed because its detection limit $(0.001 \mathrm{mg} / \mathrm{L})$ exceeds the water quality standard for Elk Creek $(0.00002 \mathrm{mg} / \mathrm{L})$. Unless noted otherwise, all references to chemical constituent concentrations below are to the dissolved concentration (measured in filtered samples) rather than to total concentration (measured in unfiltered samples).

\section{Task 1}

At the Level 1 portal, Ca concentrations in the time-series samples ranged from 38.7 to $83.2 \mathrm{mg} / \mathrm{L}$ and $\mathrm{SO}_{4}$ concentrations from 166 to $280 \mathrm{mg} / \mathrm{L}$ (fig. 16). Calcium and $\mathrm{SO}_{4}$ concentrations were lower at Elk Creek spring 2 and spring
$8 \mathrm{~A}$; they ranged from 6.69 to $28.9 \mathrm{mg} / \mathrm{L}$ and from 12.8 to $46.7 \mathrm{mg} / \mathrm{L}$, respectively. Concentrations at Elk Creek and the Level 1 portal showed the same general seasonal trend as specific conductance (fig. 9B) - increasing through summer, fall, and winter; peaking in late winter at base flow; then decreasing during the spring snowmelt runoff. Again as with specific conductance, concentrations at springs 2 and $8 \mathrm{~A}$ showed relatively little seasonal variation, although at spring 2 they were slightly lower in the spring than in the summer and fall.

Seasonal concentrations of all five metals consistently exceeded water quality standards for Elk Creek at the Level 1 portal (fig. 17). $\mathrm{Zn}$ ranged from 18.3 to $26.3 \mathrm{mg} / \mathrm{L}, \mathrm{Pb}$ from 0.101 to $1.70 \mathrm{mg} / \mathrm{L}, \mathrm{Cd}$ from 0.121 to $0.155 \mathrm{mg} / \mathrm{L}, \mathrm{Cu}$ from 0.0826 to $0.801 \mathrm{mg} / \mathrm{L}$, and $\mathrm{Mn}$ from 5.62 to $10.6 \mathrm{mg} / \mathrm{L}$. Metals concentrations at Elk Creek were an order of magnitude or more below those at the Level 1 portal; $\mathrm{Zn}$ ranged from 0.428 to $0.986 \mathrm{mg} / \mathrm{L}, \mathrm{Pb}$ from 0.0003 to $0.0066 \mathrm{mg} / \mathrm{L}, \mathrm{Cd}$ from 0.00220 to $0.00517 \mathrm{mg} / \mathrm{L}, \mathrm{Cu}$ from 0.0018 to $0.0124 \mathrm{mg} / \mathrm{L}$, and $\mathrm{Mn}$ from 0.0072 to $0.175 \mathrm{mg} / \mathrm{L}$. Zinc and Cd at Elk Creek consistently exceeded water-quality standards, whereas the other three metals exceeded water quality standards during only part of the year, commonly in the spring. Metals concentrations were typically lower still at springs 2 and $8 \mathrm{~A}$ and generally remained near or below water-quality standards for Elk Creek. Lead and $\mathrm{Cu}$ concentrations at the Level 1 portal and at Elk Creek displayed a pronounced increase during spring snowmelt runoff, mirroring the pronounced decrease in $\mathrm{pH}$ (fig. 9A), and they reached their highest concentrations of 

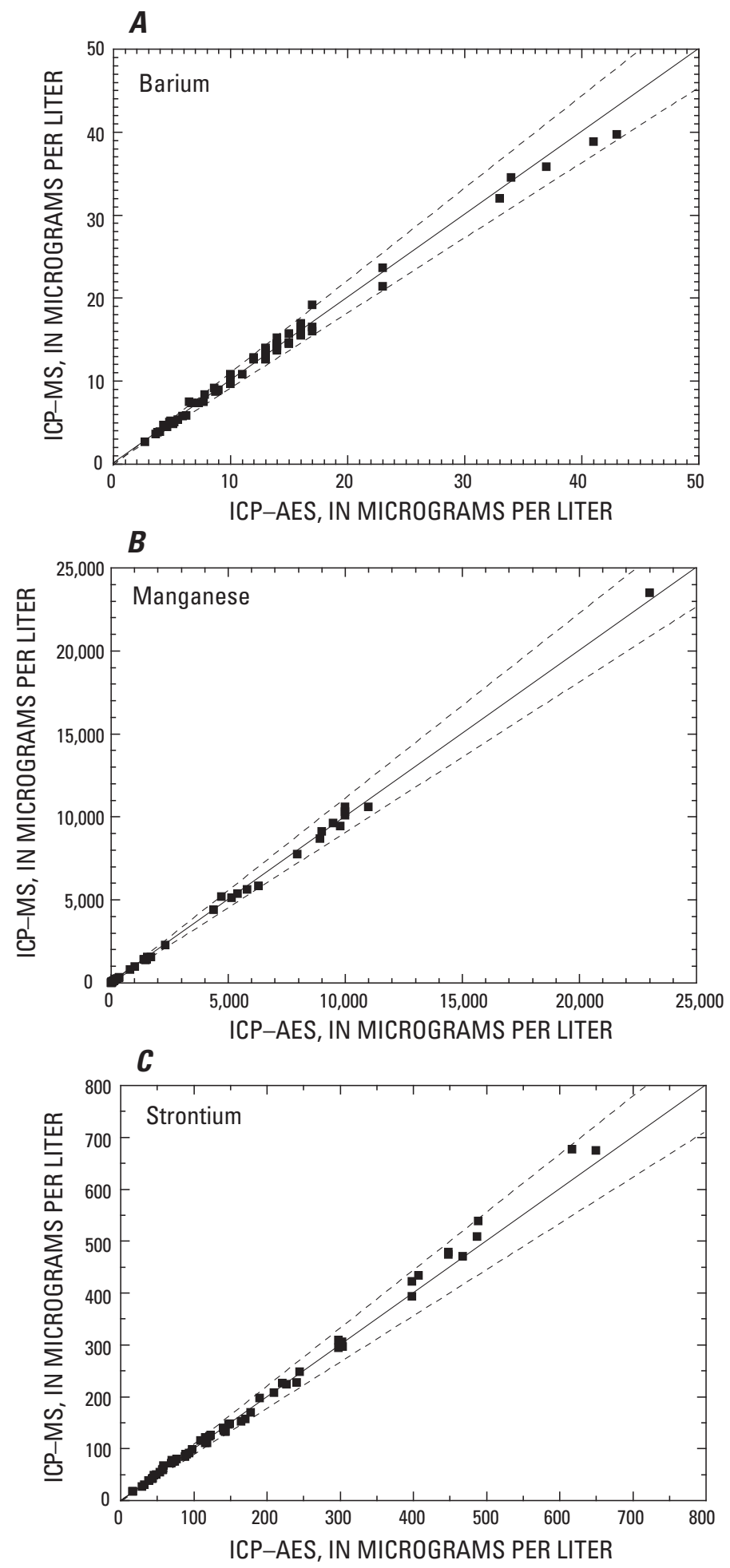

Figure 15. Comparison of analytical results by using ICP-AES (inductively coupled plasma-atomic emission spectroscopy) and ICP-MS (inductvely coupled plasma-mass spectrometry). Barium $(A)$, manganese $(B)$, and strontium $(C)$ concentration. Solid diagonal line, 1:1 correspondence; dashed line, 10 percent variation. 

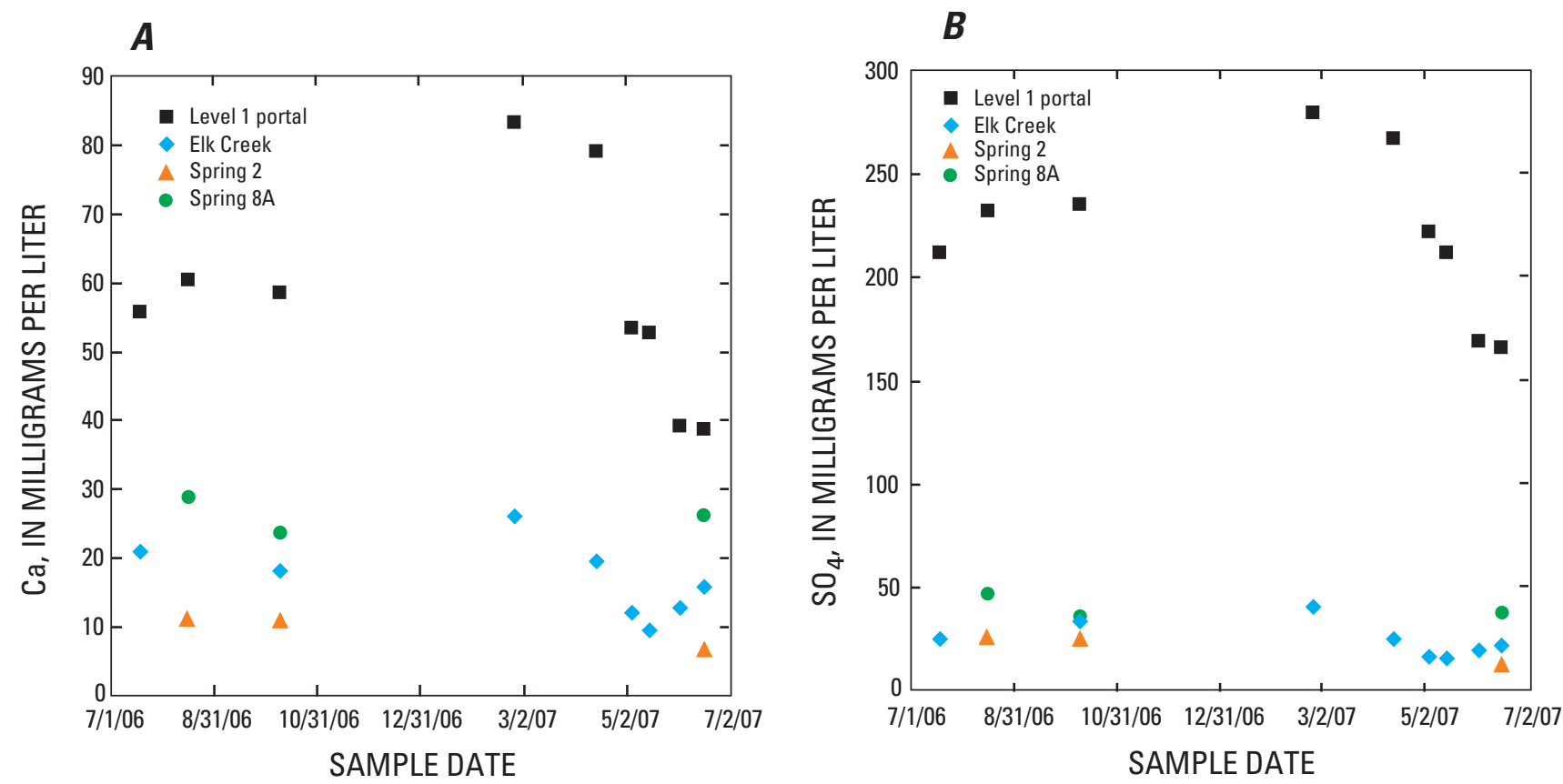

Figure 16. Calcium $(A)$ and sulfate $(B)$ concentration at task 1 sample sites plotted versus sample date. Only samples with concentrations above detection limits are shown.

the year in May or early June. At Elk Creek, Zn, Cd, and Mn concentrations also increased sharply during spring runoff, although high concentrations were also observed in the fall. At the Level 1 portal, $\mathrm{Zn}, \mathrm{Cd}$, and Mn concentrations increased between the May 5 and May 15, 2007, sampling events, but this increase was superimposed on an overall trend of decreasing concentration through the spring, similar to the trend of major ion concentrations. Concentrations of all five metals showed relatively minor seasonal variations at springs 2 and $8 \mathrm{~A}$.

\section{Task 2}

Concentrations of chemical constituents at the aboveground sample sites varied spatially as well as temporally (figs. 18-24). Calcium and $\mathrm{SO}_{4}$ concentrations (figs. 18 and 19) ranged from 4.09 to $60.4 \mathrm{mg} / \mathrm{L}$ and from 2.99 to $318 \mathrm{mg} / \mathrm{L}$, respectively, and had a distribution similar to specific conductance (fig. 11). Higher concentrations of $\mathrm{Ca}$ and $\mathrm{SO}_{4}$ occurred in discharge from tunnels and waste rock associated with the Standard Mine, in samples from the zone of diffuse discharge south of the Level 1 portal, and at Redwell spring 2 ( $\mathrm{SO}_{4}$ only). Zinc concentrations (fig. 20) ranged from 0.0005 to $25.6 \mathrm{mg} / \mathrm{L}, \mathrm{Pb}$ concentrations (fig. 21) from $<0.00005$ to $1.73 \mathrm{mg} / \mathrm{L}, \mathrm{Cd}$ concentrations (fig. 22) from $<0.00002$ to $0.197 \mathrm{mg} / \mathrm{L}, \mathrm{Cu}$ concentrations (fig. 23) from $<0.0005$ to $1.08 \mathrm{mg} / \mathrm{L}$, and $\mathrm{Mn}$ concentrations (fig. 24) from $<0.0002$ to $23.5 \mathrm{mg} / \mathrm{L}$. Concentrations of all five metals commonly exceeded water quality standards for Elk Creek at sites located along the Standard fault, near the Elk Lode portal, and in Redwell Basin. Elsewhere, metals concentrations seldom exceeded water quality standards for Elk Creek and were typically near detection limits. Metals concentrations typically were highest at locations of tunnel and waste rock discharge associated with the Standard and Elk Lode Mines and at Redwell spring 2. The distribution of these metals therefore generally mirrored the $\mathrm{pH}$ distribution (fig. 10).

\section{Task 3}

Concentrations of chemical constituents at the underground sample sites also varied similarly (figs. 25 and 26). Calcium and $\mathrm{SO}_{4}$ concentrations ranged from 11.1 to $38.4 \mathrm{mg} / \mathrm{L}$ and from 31.7 to $111 \mathrm{mg} / \mathrm{L}$, respectively. Zinc concentrations ranged from 0.556 to $7.70 \mathrm{mg} / \mathrm{L}, \mathrm{Pb}$ concentrations from 0.0012 to $2.19 \mathrm{mg} / \mathrm{L}, \mathrm{Cd}$ concentrations from 0.00008 to $0.112 \mathrm{mg} / \mathrm{L}, \mathrm{Cu}$ concentrations from $<0.0005$ to $1.67 \mathrm{mg} / \mathrm{L}$, and $\mathrm{Mn}$ concentrations from 0.0133 to 4.38 $\mathrm{mg} / \mathrm{L}$. With the exception of $\mathrm{Mn}$, metal concentrations were generally higher in Level 3 than in Level 5, and were typically the highest at sites 1 and 2 in Level 3, the two sites with the lowest $\mathrm{pH}$. The concentrations of some chemical constituents bore some relation to overburden thickness (figs. 27 and 28). Similar to specific conductance (fig. 14), $\mathrm{Ca}$ and $\mathrm{SO}_{4}$ generally increased with overburden thickness, the main exception being $\mathrm{SO}_{4}$ at Level 3 site 2 (fig. 27). However, similar to $\mathrm{pH}$ (fig. 14), metal concentrations showed little correlation with overburden thickness aside from concentrations at the two 

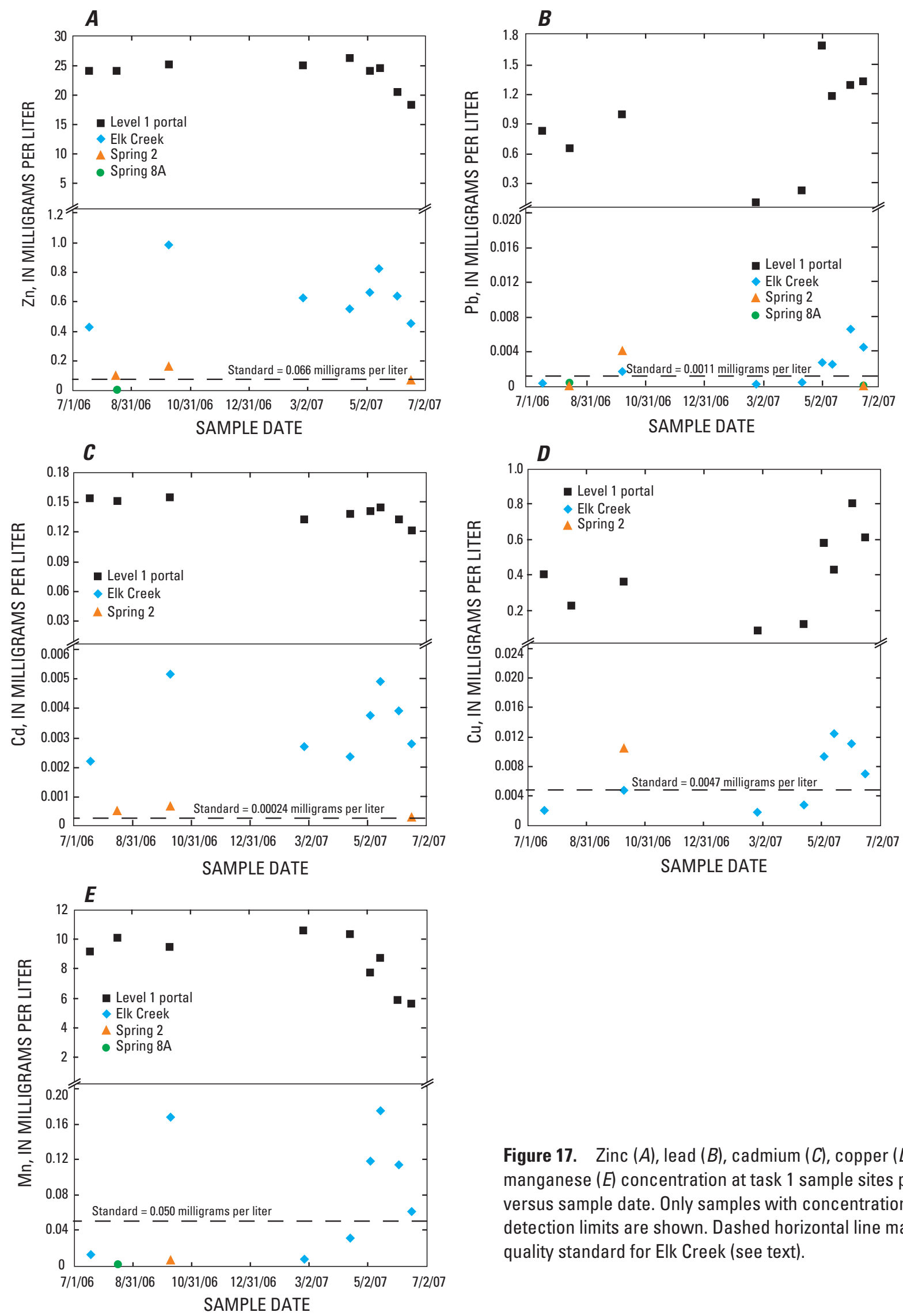

Figure 17. Zinc $(A)$, lead $(B)$, cadmium $(C)$, copper $(D)$, and manganese $(E)$ concentration at task 1 sample sites plotted versus sample date. Only samples with concentrations above detection limits are shown. Dashed horizontal line marks water quality standard for Elk Creek (see text). 

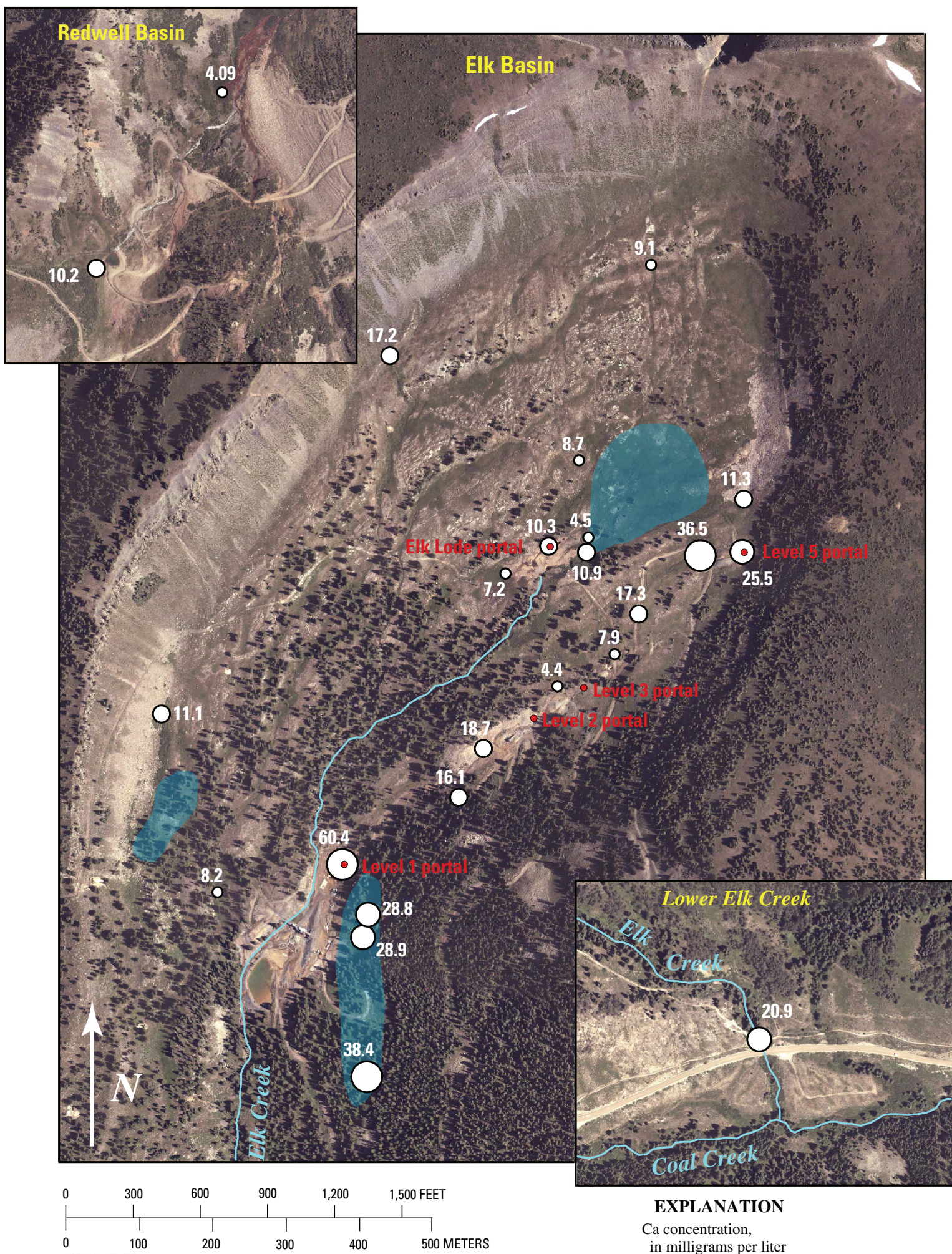

EXPLANATION

Ca concentration,

in milligrams per liter

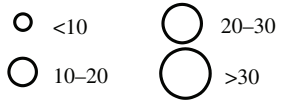

Figure 18. Calcium concentration (white type) at aboveground sample sites. Blue regions, zones of diffuse spring discharge; red type, Standard Mine portal. 


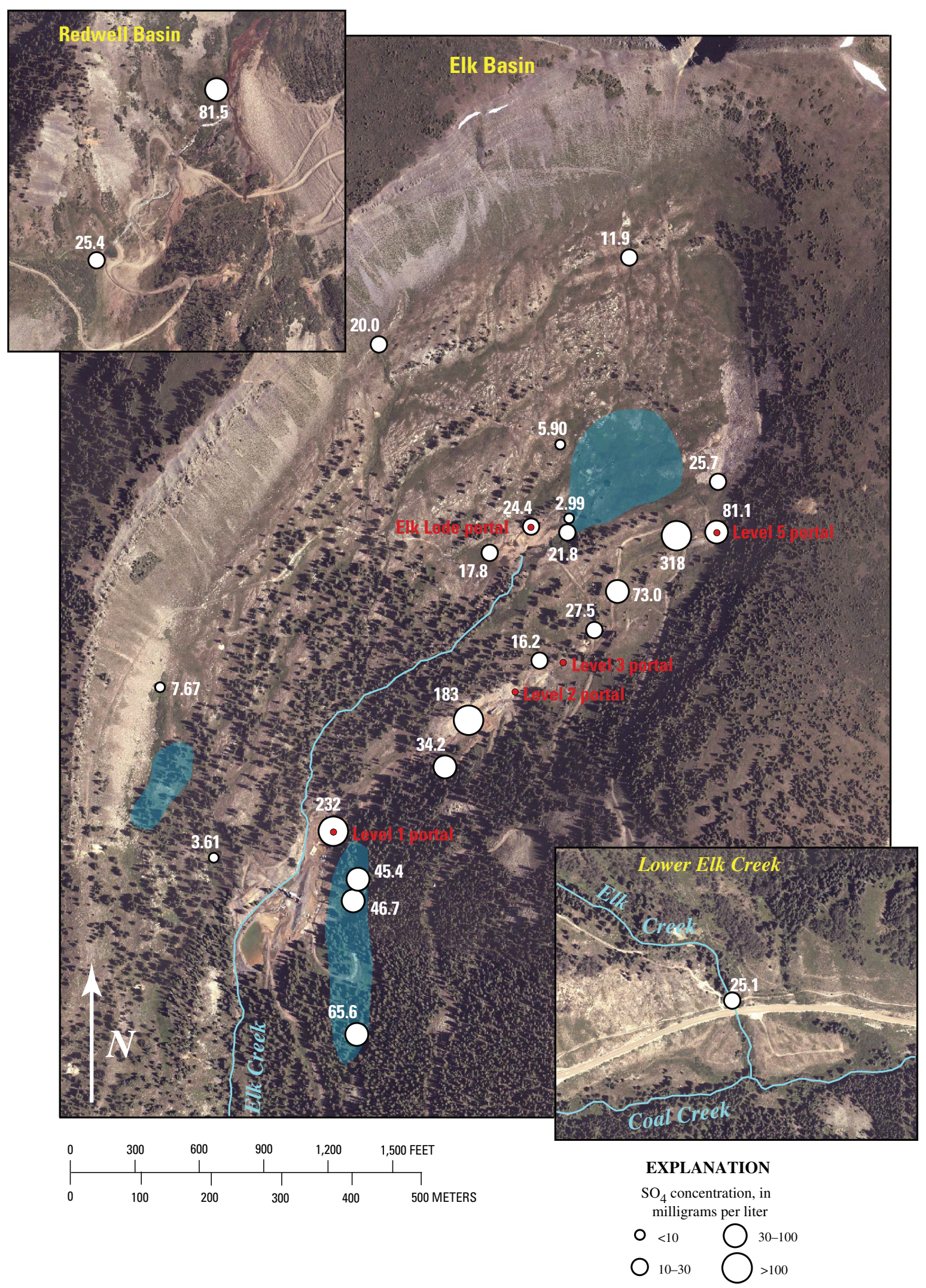

Figure 19. Sulfate concentration (white type) at aboveground sample sites. Blue regions, zones of diffuse spring discharge; red type, Standard Mine portal. 


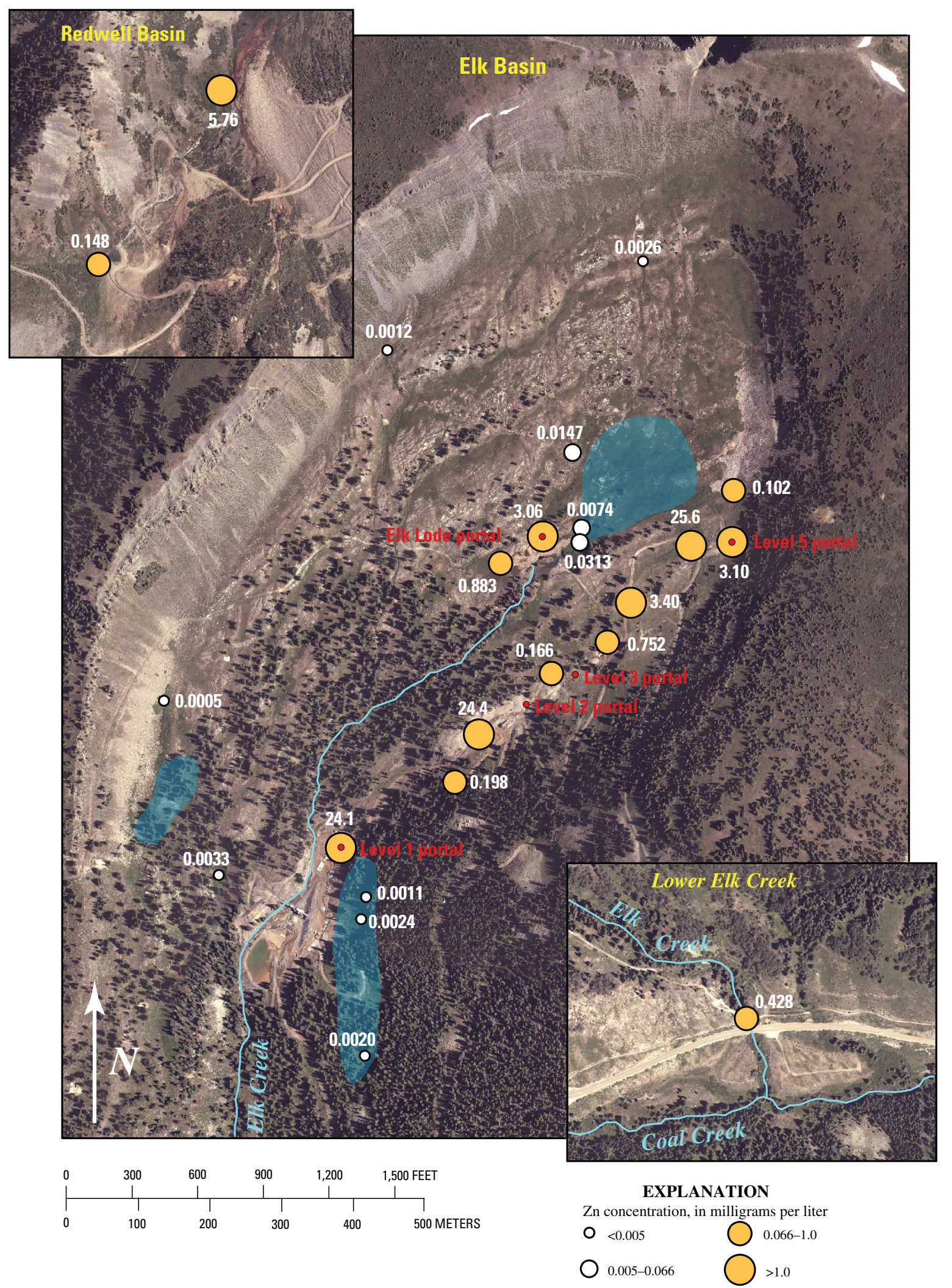

Figure 20. Zinc concentration (white type) at aboveground sample sites. Orange symbols mark sites at which zinc concentration exceeds water quality standard for Elk Creek of $0.066 \mathrm{mg} / \mathrm{L}$ (see text). Blue regions, zones of diffuse spring discharge; red type, Standard Mine portal. 

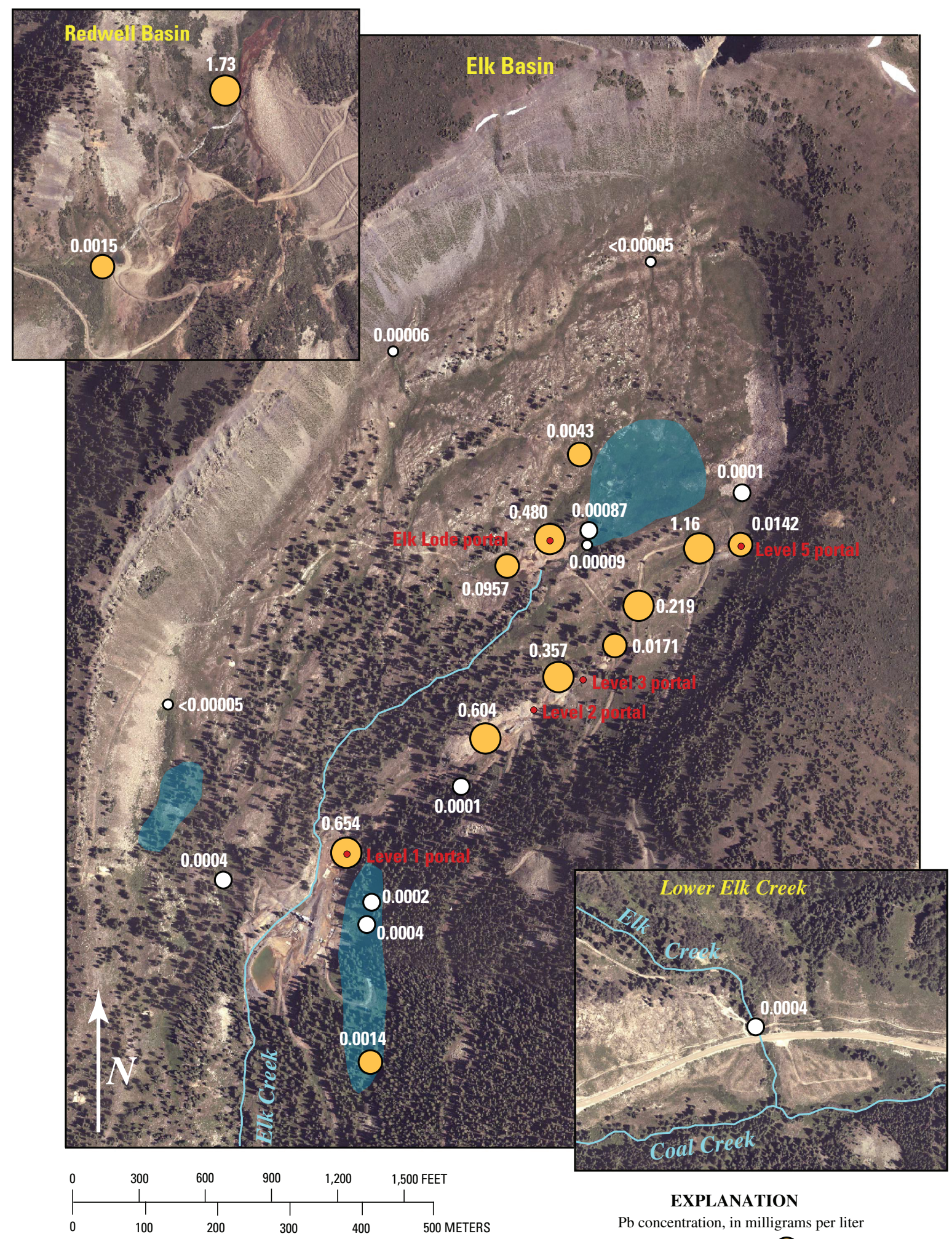

\section{EXPLANATION}

$\mathrm{Pb}$ concentration, in milligrams per liter
○<0.0001
0.0011-0.1
0.0001-0.0011
$\bigcirc>0.1$

Figure 21. Lead concentration (white type) at aboveground sample sites. Orange symbols mark sites at which zinc concentration exceeds water quality standard for Elk Creek of $0.0011 \mathrm{mg} / \mathrm{L}$ (see text). Blue regions, zones of diffuse spring discharge; red type, Standard Mine portal. 

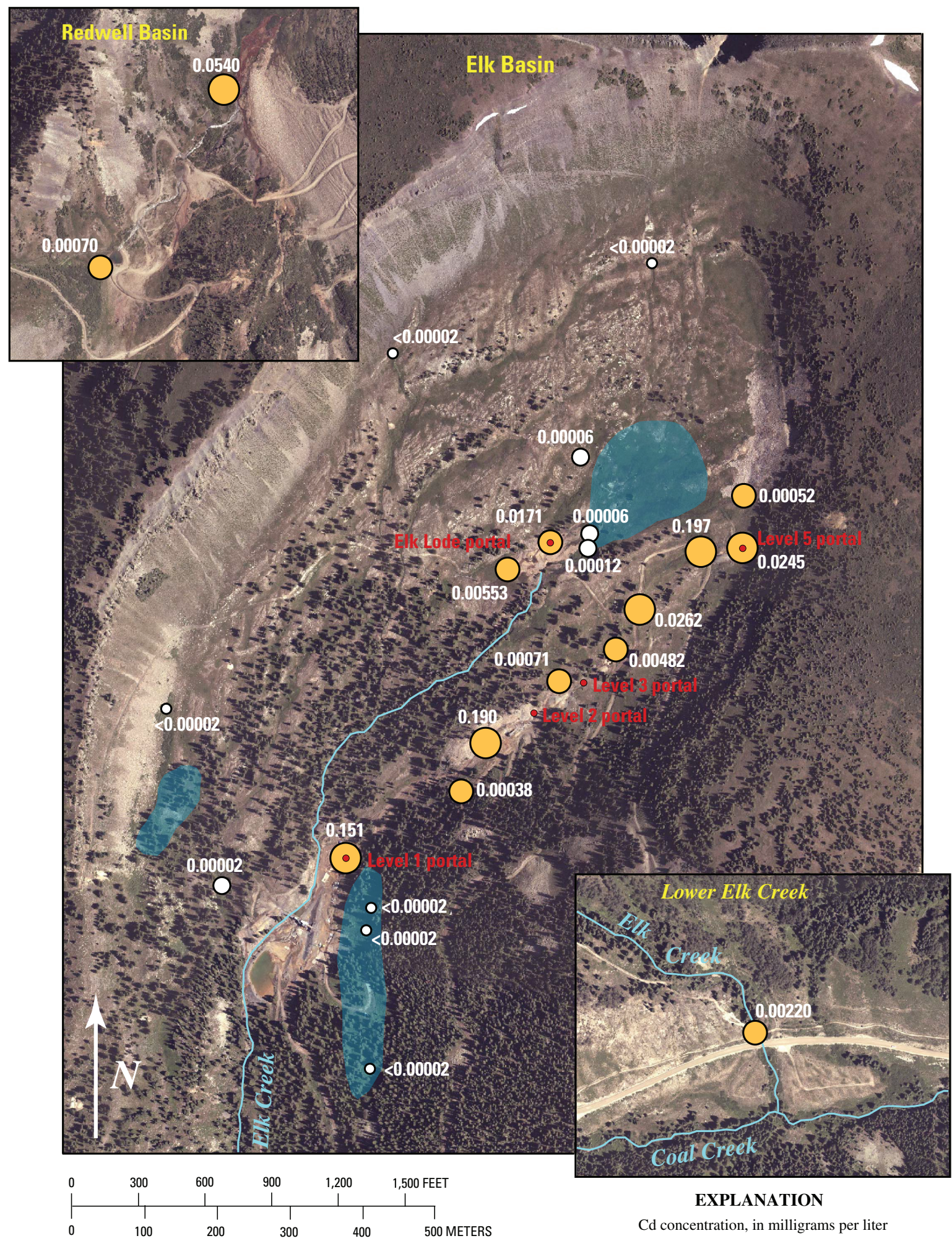

\section{EXPLANATION}

$\mathrm{Cd}$ concentration, in milligrams per liter
O $<0.00002$
0.00024-0.02
0.00002-0.00024
$\bigcirc_{0.02}$

Figure 22. Cadmium concentration (white type) at aboveground sample sites. Orange symbols mark sites at which cadmium concentration exceeds water quality standard for Elk Creek of $0.00024 \mathrm{mg} / \mathrm{L}$ (see text). Blue regions, zones of diffuse spring discharge; red type, Standard Mine portal. 


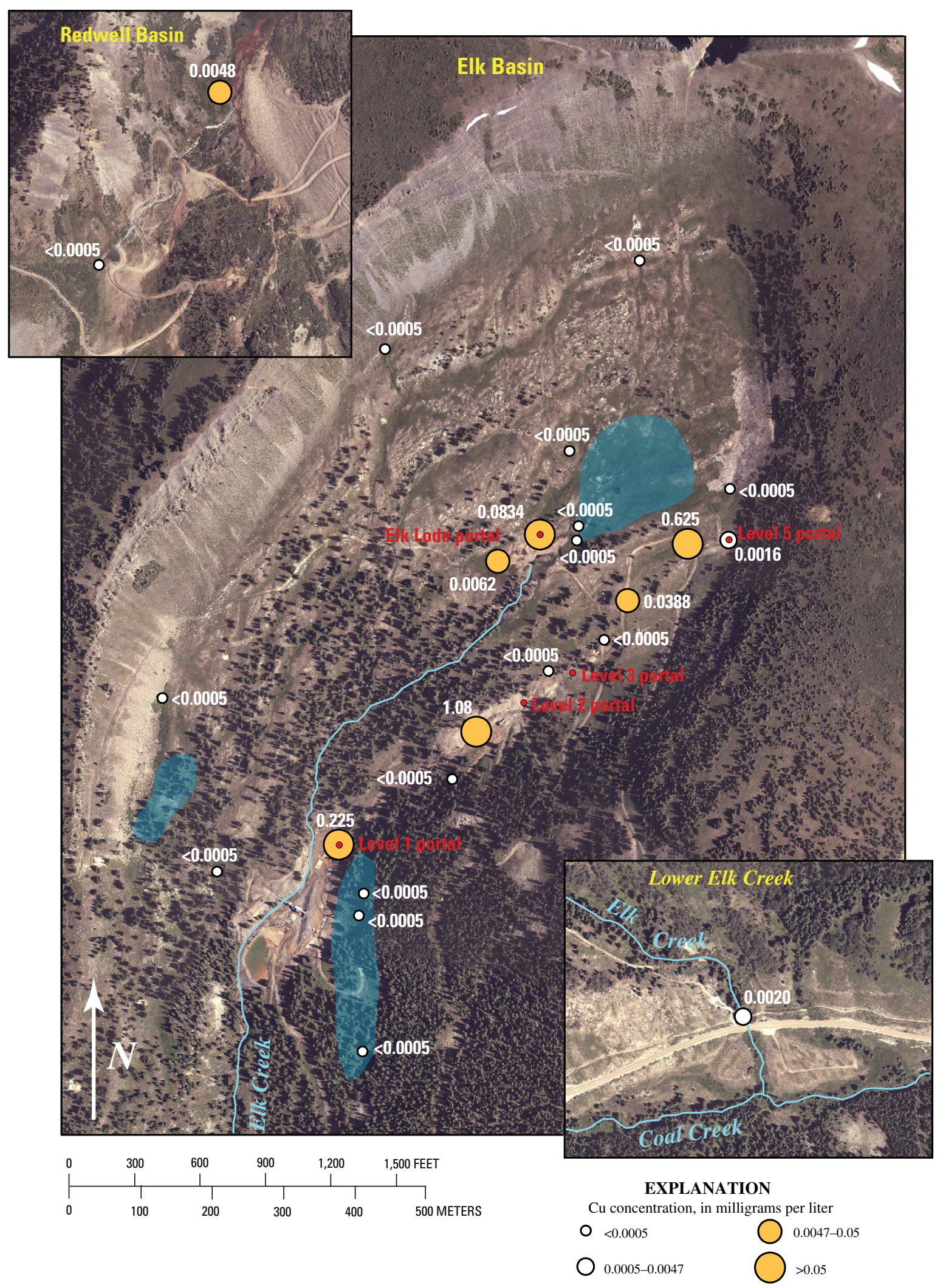

Figure 23. Copper concentration (white type)at aboveground sample sites. Orange symbols mark sites at which copper concentration exceeds water quality standard for Elk Creek of $0.0047 \mathrm{mg} / \mathrm{L}$ (see text). Blue regions, zones of diffuse spring discharge; red type, Standard Mine portal. 

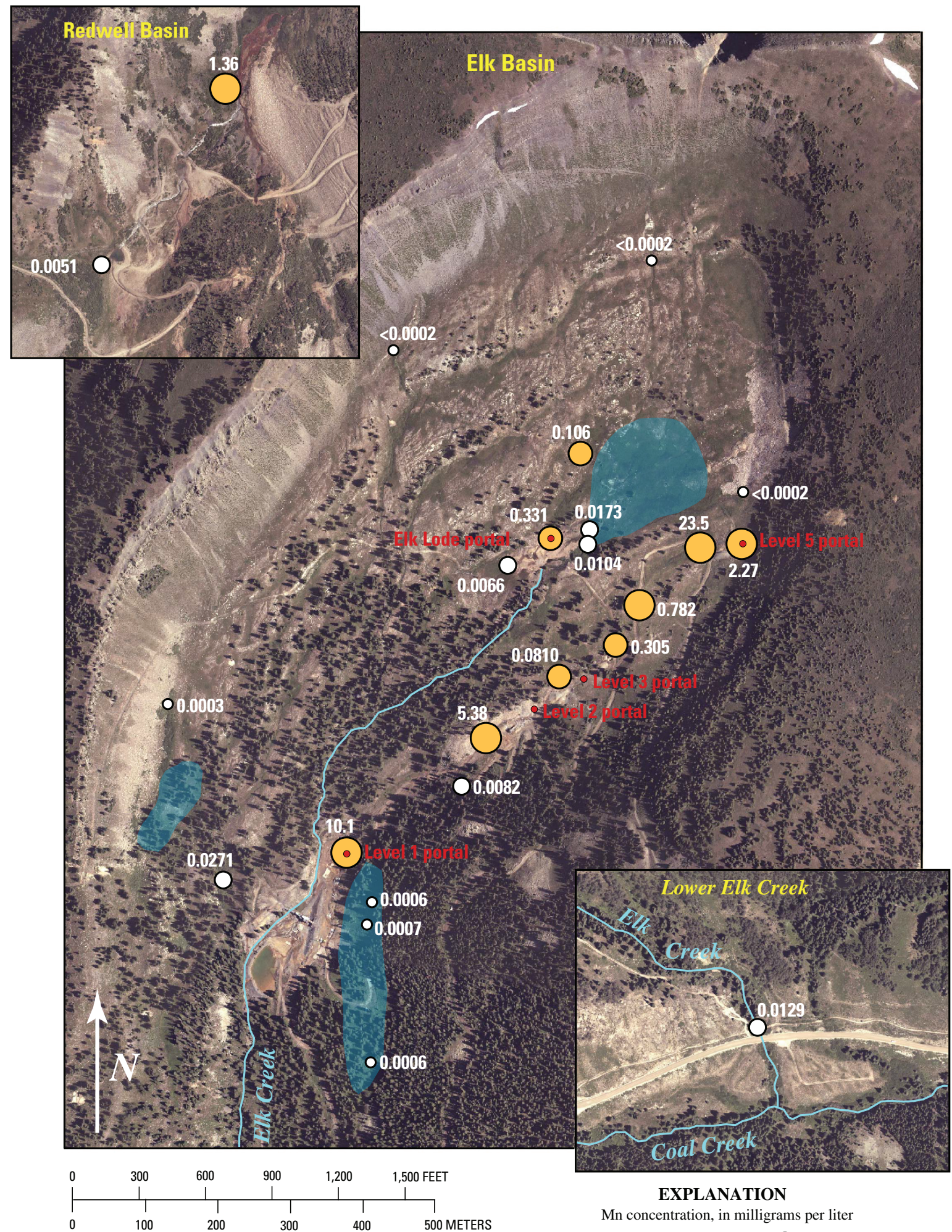

EXPLANATION

Mn concentration, in milligrams per liter
O $<0.005$
$\bigcirc 0.05-0.5$
0.005-0.05

Figure 24. Manganese concentration (white type) at aboveground sample sites. Orange symbols mark sites at which manganese concentration exceeds water quality standard for Elk Creek of $0.05 \mathrm{mg} / \mathrm{L}$ (see text). Blue regions, zones of diffuse spring discharge; red type, Standard Mine portal. 


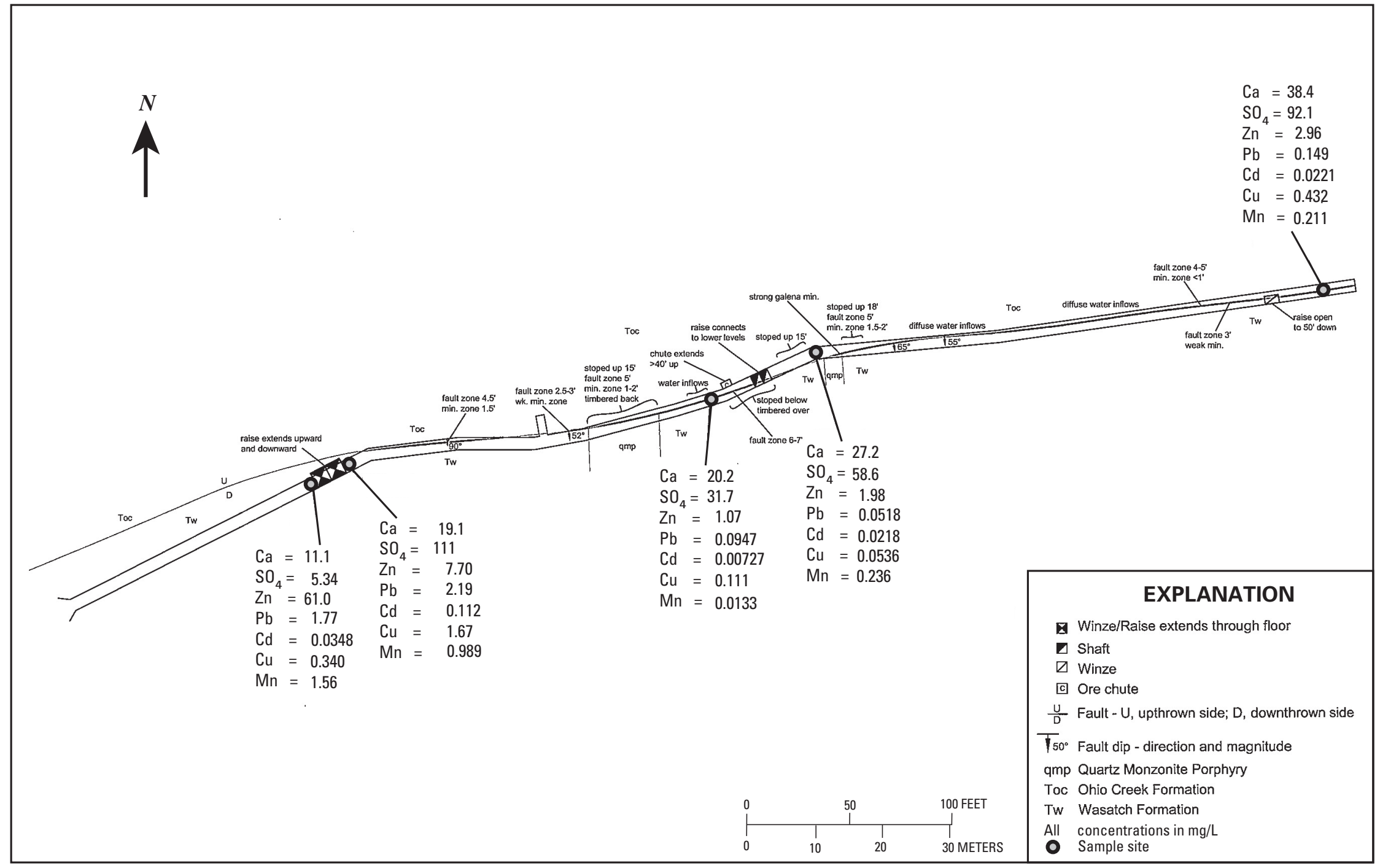

Figure 25. Concentrations of calcium, sulfate, and selected metals at underground sample sites in Level 3 of Standard Mine. Adapted from Colorado Division of Reclamation, Mining, and Safety (2007). min., mineralized or mineralization; wk. min., weakly mineralized. 


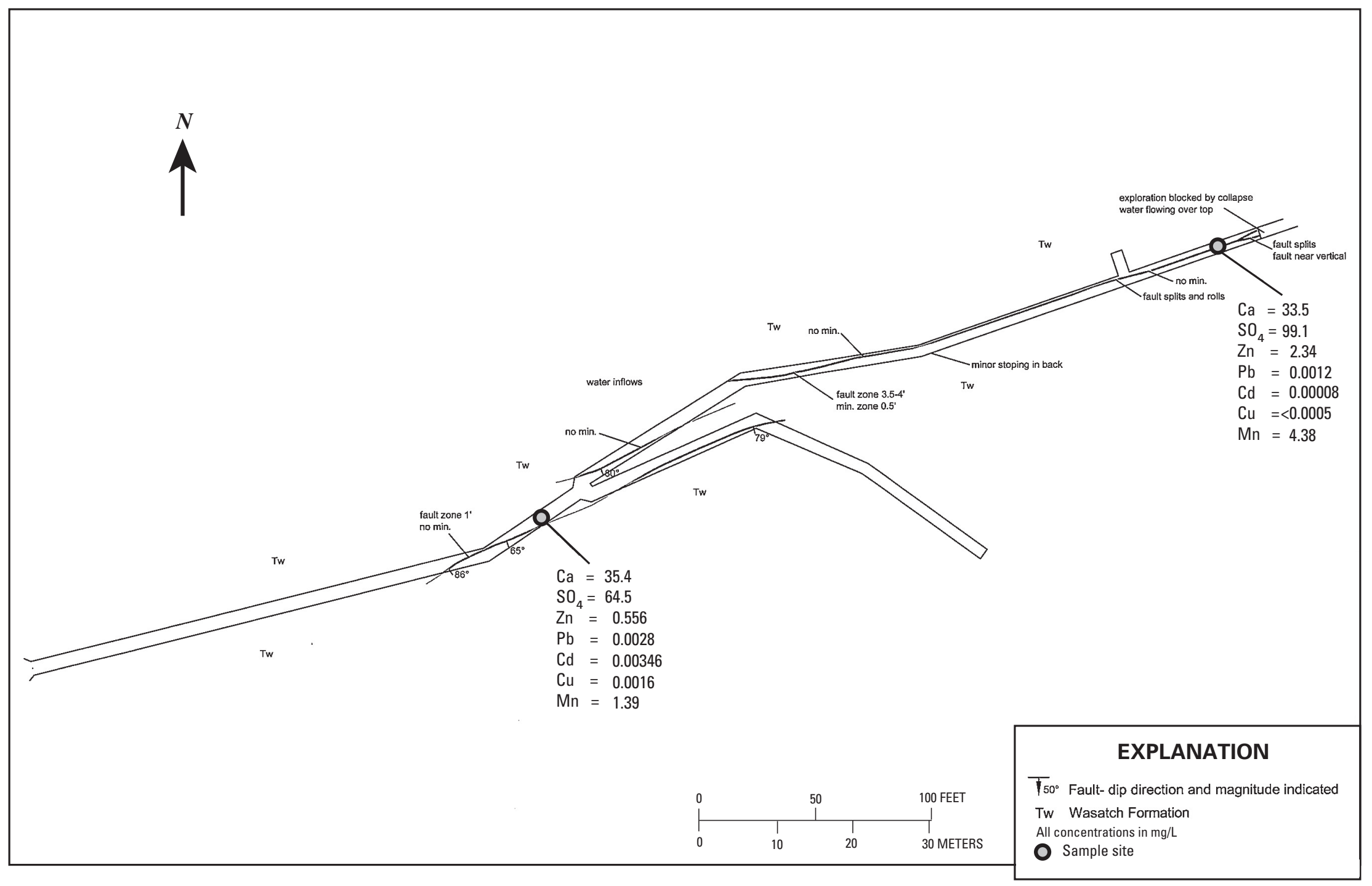

Figure 26. Concentrations of calcium, sulfate, and selected metals at underground sample sites in Level 5 of the Standard Mine. Adapted from Colorado Division of Reclamation, Mining, and Safety (2007). min., mineralized or mineralization. 

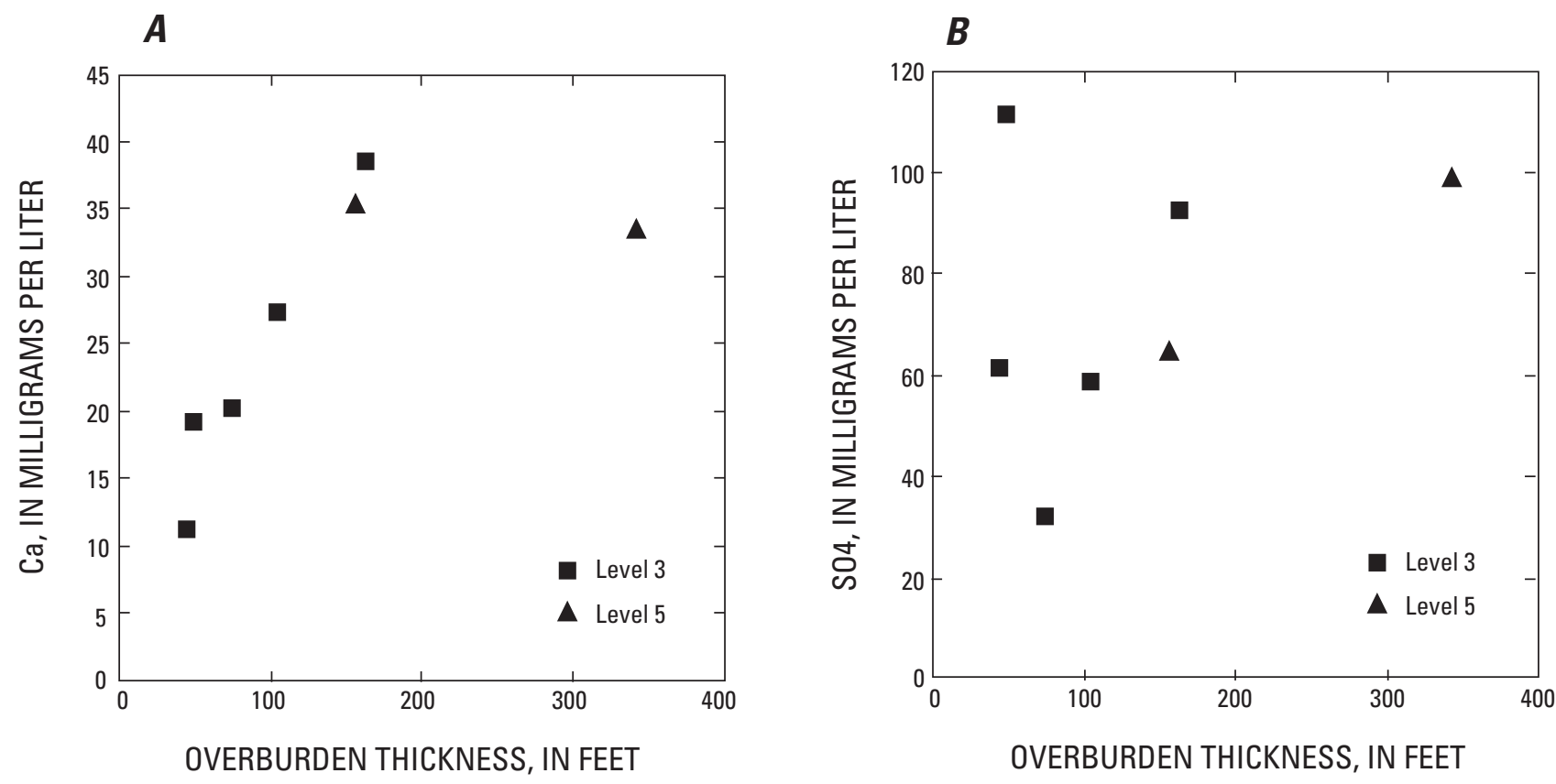

Figure 27. Concentrations of calcium $(A)$ and sulfate $(B)$ in underground samples plotted versus overburden thickness.

sites with thinnest overburden (Level 3 sites 1 and 2) that typically had the highest (fig. 28).

\section{Strontium Isotopes}

A total of 37 samples were analyzed for strontium $(\mathrm{Sr})$ isotopes (table 2). Measured $\mathrm{Sr}$ isotope ratios $\left({ }^{87} \mathrm{Sr} /{ }^{86} \mathrm{Sr}\right)$ for two of three replicated pairs agreed within the $2 \sigma$ analytical error of 0.00002 , and the third replicate pair agreed within 0.00004 .

Measured Sr concentrations ranged from 0.016 to $0.650 \mathrm{mg} / \mathrm{L}$. The distribution of concentrations at the aboveground sample sites (fig. 29) was similar to the distributions of specific conductance and the major ions (figs. 11, 18, and 19); higher concentrations were found in discharge from tunnels and waste rock associated with the Standard Mine as well as in samples from the zone of diffuse discharge south of the Level 1 portal. Notably, however, Redwell spring 2 had the lowest $\mathrm{Sr}$ concentration measured in this study $(0.016 \mathrm{mg} / \mathrm{L})$. Samples from the Level 1 portal generally had the highest $\mathrm{Sr}$ concentrations, which reached a maximum of $0.650 \mathrm{mg} / \mathrm{L}$ during late winter (base flow), as did specific conductance (fig. $9 B$ ) and the major ions (fig. 16). Samples from Levels 3 and 5 ranged from 0.074 to $0.398 \mathrm{mg} / \mathrm{L}$ and from 0.210 to $0.227 \mathrm{mg} / \mathrm{L}$, respectively. The $\mathrm{Sr}$ concentration of the Level 3 samples increased with distance in from the portal.
Measured ${ }^{87} \mathrm{Sr} /{ }^{86} \mathrm{Sr}$ ratios ranged from 0.70969 to 0.71406 (table 2). The distribution of ${ }^{87} \mathrm{Sr} /{ }^{86} \mathrm{Sr}$ ratios at aboveground sample sites (fig. 30) was similar to that of the metal concentrations (figs. 20-24); the highest ratios generally were found at tunnel and waste-rock discharge sites associated with the Standard and Elk Lode Mines. Strontium concentration versus ${ }^{87} \mathrm{Sr} /{ }^{86} \mathrm{Sr}$ ratio is plotted on figure 31 . Samples from areas with little or no mineralized rock (denoted in fig. 3 as "other") generally had lower ${ }^{87} \mathrm{Sr} /{ }^{86} \mathrm{Sr}$ ratios $(<0.7120)$, and samples from areas with abundant mineralized rock generally had higher ratios $(>0.7120)$. The highest ${ }^{87} \mathrm{Sr} /{ }^{86} \mathrm{Sr}$ ratio $(0.71406)$ was measured in the sample from the Elk Lode portal. Ratios in Level 1 samples were consistently among the highest measured and ranged from 0.71313 to $0.71365 \mathrm{mg} / \mathrm{L}$. The three repeat sampling events at springs 2 and $8 \mathrm{~A}$ displayed little variation in $\mathrm{Sr}$ isotope ratios. Underground samples from Levels 3 and 5 had $\mathrm{Sr}$ isotope ratios that ranged from 0.71279 to $0.71344 \mathrm{mg} / \mathrm{L}$ and from 0.71149 to $0.71255 \mathrm{mg} / \mathrm{L}$, respectively.

\section{Deuterium and 0xygen-18}

Thirty-one samples were analyzed for $\delta^{2} \mathrm{H}$ and $\delta^{18} \mathrm{O}$ (table 3 ). Measured $\delta^{18} \mathrm{O}$ values of four replicate pairs agreed within the $2 \sigma$ analytical error of 0.30 per mil. For $\delta^{2} \mathrm{H}$, three of four replicate pairs agreed within the $2 \sigma$ analytical error of 4.0 per mil, and the fourth agreed within 4.2 per mil. 

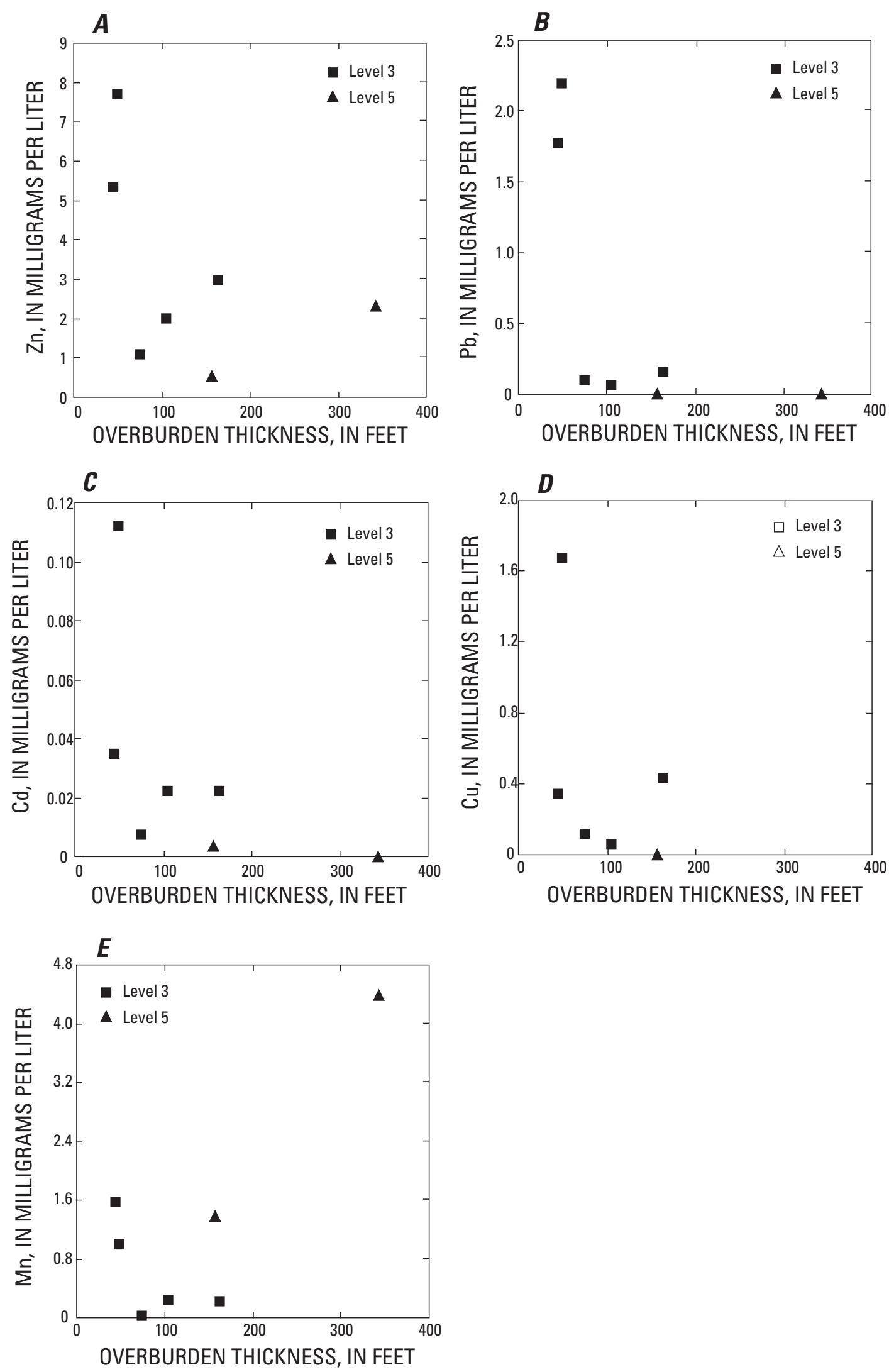

Figure 28. Concentrations of zinc $(A)$, lead $(B)$, cadmium $(C)$, copper $(D)$, and manganese $(E)$ in underground samples plotted versus overburden thickness. Only samples with concentrations above detection limits are shown. 
Table 2. Strontium isotope content of selected water samples.

[mg/L, milligrams per liter; $-\mathrm{R}$ (appended to sample name), replicate sample]

\begin{tabular}{|c|c|c|c|}
\hline $\begin{array}{l}\text { Sample } \\
\text { name }\end{array}$ & $\begin{array}{c}\mathrm{Sr} \\
(\mathrm{mg} / \mathrm{L})\end{array}$ & ${ }^{87} \mathrm{Sr} /{ }^{86} \mathrm{Sr}$ & $\begin{array}{l}\text { Uncertainty } \\
\qquad(1 \sigma)\end{array}$ \\
\hline EC-S1-01 & 0.221 & 0.71328 & 0.00004 \\
\hline $\mathrm{EC}-\mathrm{S} 2-01$ & 0.091 & 0.71158 & 0.00001 \\
\hline $\mathrm{EC}-\mathrm{S} 2-03$ & 0.077 & 0.71159 & 0.00001 \\
\hline EC-S2-04 & 0.049 & 0.71153 & 0.00001 \\
\hline EC-S3-01 & 0.046 & 0.71110 & 0.00001 \\
\hline EC-S4-01 & 0.141 & 0.71038 & 0.00001 \\
\hline EC-S7-01 & 0.054 & 0.70969 & 0.00001 \\
\hline $\mathrm{EC}-\mathrm{S} 8 \mathrm{~A}-01$ & 0.143 & 0.71100 & 0.00001 \\
\hline EC-S8A-03 & 0.116 & 0.71143 & 0.00001 \\
\hline $\mathrm{EC}-\mathrm{S} 8 \mathrm{~B}-01$ & 0.143 & 0.71100 & 0.00001 \\
\hline EC-S9-01 & 0.094 & 0.71095 & 0.00004 \\
\hline EC-S10-01 & 0.118 & 0.71265 & 0.00001 \\
\hline EC-S11-01-R & 0.038 & 0.71277 & 0.00001 \\
\hline EC-S12-01 & 0.171 & 0.71095 & 0.00001 \\
\hline EC-MUSTD1-01 & 0.148 & 0.71212 & 0.00001 \\
\hline EC-P4-01 & 0.033 & 0.71182 & 0.00001 \\
\hline EC-P5-01 & 0.058 & 0.71133 & 0.00001 \\
\hline EC-T1-01 & 0.029 & 0.71270 & 0.00001 \\
\hline EC-T2-01 & 0.088 & 0.71153 & 0.00001 \\
\hline EC-MSTD1-01 & 0.448 & 0.71343 & 0.00001 \\
\hline EC-MSTD1-02 & 0.487 & 0.71348 & 0.00001 \\
\hline EC-MSTD1-02-R & 0.489 & 0.71349 & 0.00001 \\
\hline EC-MSTD1-03 & 0.468 & 0.71344 & 0.00001 \\
\hline EC-MSTD1-03-R & 0.448 & 0.71343 & 0.00001 \\
\hline EC-MSTD1-04 & 0.650 & 0.71364 & 0.00001 \\
\hline EC-MSTD1-05 & 0.617 & 0.71365 & 0.00001 \\
\hline EC-MSTD1-06 & 0.407 & 0.71353 & 0.00001 \\
\hline EC-MSTD1-07 & 0.398 & 0.71347 & 0.00001 \\
\hline EC-MSTD1-08 & 0.304 & 0.71315 & 0.00001 \\
\hline EC-MSTD1-09 & 0.303 & 0.71315 & 0.00001 \\
\hline EC-MSTDL31-01 & 0.074 & 0.71149 & 0.00001 \\
\hline EC-MSTDL32-01 & 0.140 & 0.71209 & 0.00001 \\
\hline EC-MSTDL33-01 & 0.144 & 0.71193 & 0.00001 \\
\hline EC-MSTDL34-01 & 0.241 & 0.71241 & 0.00001 \\
\hline EC-MSTDL35-01 & 0.398 & 0.71255 & 0.00001 \\
\hline EC-M11400B-01 & 0.069 & 0.71402 & 0.00001 \\
\hline EC-M11400B-01-R & 0.069 & 0.71406 & 0.00001 \\
\hline EC-M11600-01 & 0.178 & 0.71344 & 0.00001 \\
\hline EC-M116001-01 & 0.210 & 0.71301 & 0.00001 \\
\hline EC-M116002-01 & 0.227 & 0.71279 & 0.00001 \\
\hline
\end{tabular}

\section{Task 1}

Figure 32 shows the $\delta^{18} \mathrm{O}$ and $\delta^{2} \mathrm{H}$ data for the timeseries samples. Measured values ranged from -16.61 to -15.14 per mil for $\delta^{18} \mathrm{O}$ and from -125.3 to -110.0 per mil for $\delta^{2} \mathrm{H}$. Measured $\delta^{18} \mathrm{O}$ and $\delta^{2} \mathrm{H}$ values for all of the sites (except perhaps $\delta^{2} \mathrm{H}$ at the Level 1 portal) displayed a firstorder seasonal trend: heavier in the fall and lighter in the spring and early summer. The trend was most pronounced for Elk Creek and more muted for the three ground-water sites (Level 1 portal and springs 2 and 8A). Precipitation $\delta^{18} \mathrm{O}$ and $\delta^{2} \mathrm{H}$ values are typically heavier in rain than they are in snow. The first-order trend in the time-series samples is therefore consistent with precipitation patterns, suggesting that fall samples contained more summer and fall rain and that spring and early summer samples contained more snowmelt. This pattern would be expected at Elk Creek but not necessarily at the ground-water sites. Elk Creek and the Level 1 portal displayed a clear second-order trend (or first-order for $\delta^{2} \mathrm{H}$ at the Level 1 portal) in which both $\delta^{18} \mathrm{O}$ and $\delta^{2} \mathrm{H}$ values rapidly increased and then decreased during spring snowmelt runoff. $\delta^{18} \mathrm{O}$ and $\delta^{2} \mathrm{H}$ values might have spiked in the spring at springs 2 and $8 \mathrm{~A}$ also, but the sample density was insufficient to resolve it.

\section{Task 3}

Measured $\delta^{18} \mathrm{O}$ and $\delta^{2} \mathrm{H}$ values for underground samples ranged from -17.02 to -15.65 per mil and from -124.3 to -114.1 per mil, respectively (figs. 33 and 34 ). These ranges are similar to those of ground-water samples collected aboveground during the same month $(-16.63$ to -15.93 per mil for $\delta^{18} \mathrm{O}$ and -122.2 to -113.9 per mil for $\delta^{2} \mathrm{H}$; table 3 ). Both $\delta^{18} \mathrm{O}$ and $\delta^{2} \mathrm{H}$ generally became lighter with increasing overburden thickness (fig. 35). The exception was Level 5 site 1 , at which $\delta^{18} \mathrm{O}$ and $\delta^{2} \mathrm{H}$ values were heavier than at most other underground sites despite also having the greatest overburden thickness. Ground-surface elevations above the tunnel increase with overburden thickness (fig. 4), and $\delta^{18} \mathrm{O}$ and $\delta^{2} \mathrm{H}$ in precipitation typically decrease with elevation (Coplen and others, 2000). However, precipitation $\delta^{18} \mathrm{O}$ and $\delta^{2} \mathrm{H}$ values typically decrease with elevation at a rate of only about -0.05 per mil/100 ft for $\delta^{18} \mathrm{O}$ and about 0.4 per mil/100 ft for $\delta^{2} \mathrm{H}$ in the southern Rocky Mountains (Adams and others, 1995; Manning and Solomon, 2004). Given a 


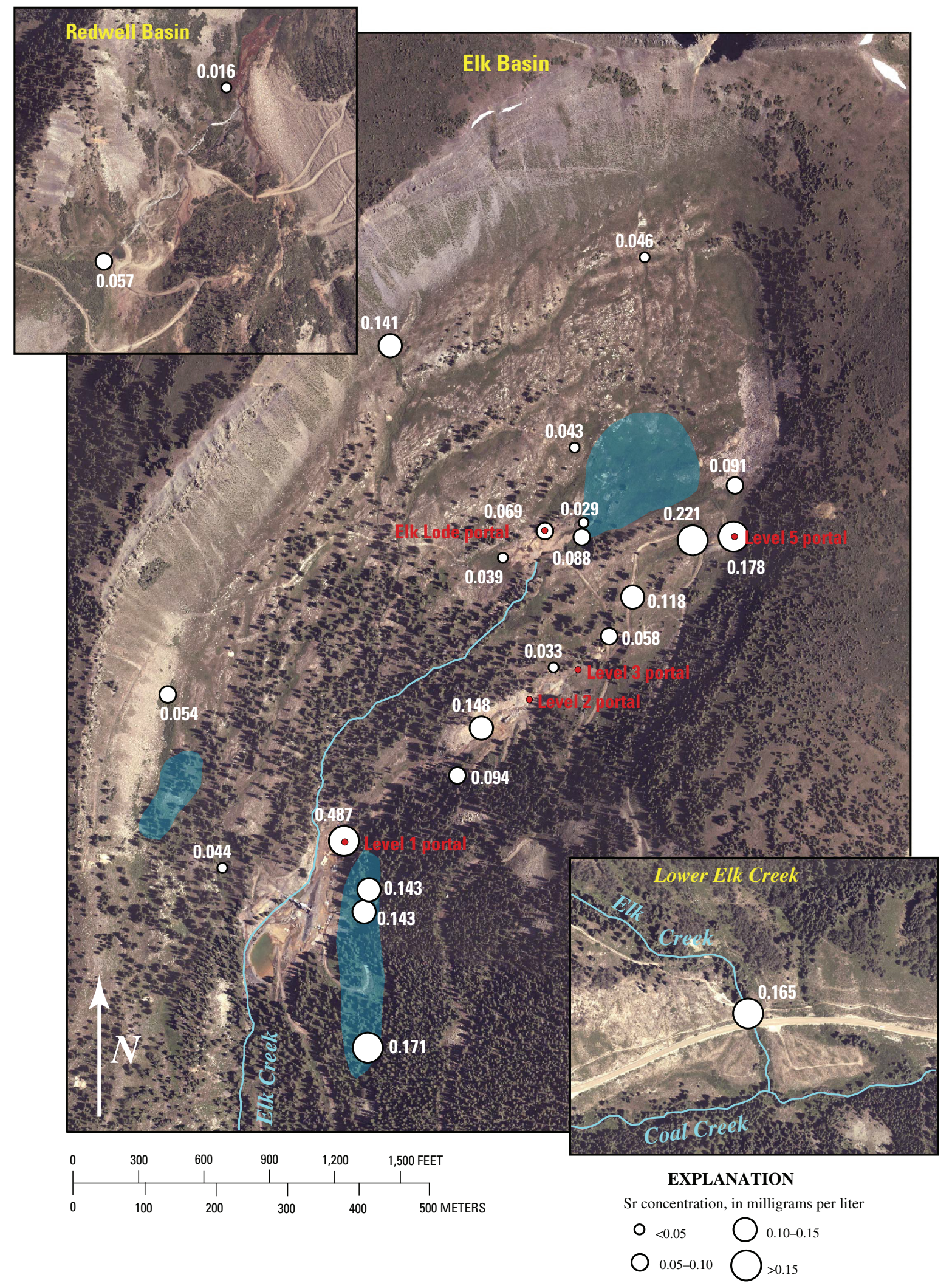

Figure 29. Strontium concentration (white type) at aboveground sample sites. Blue regions, zones of diffuse spring discharge; red type, Standard Mine portal. 


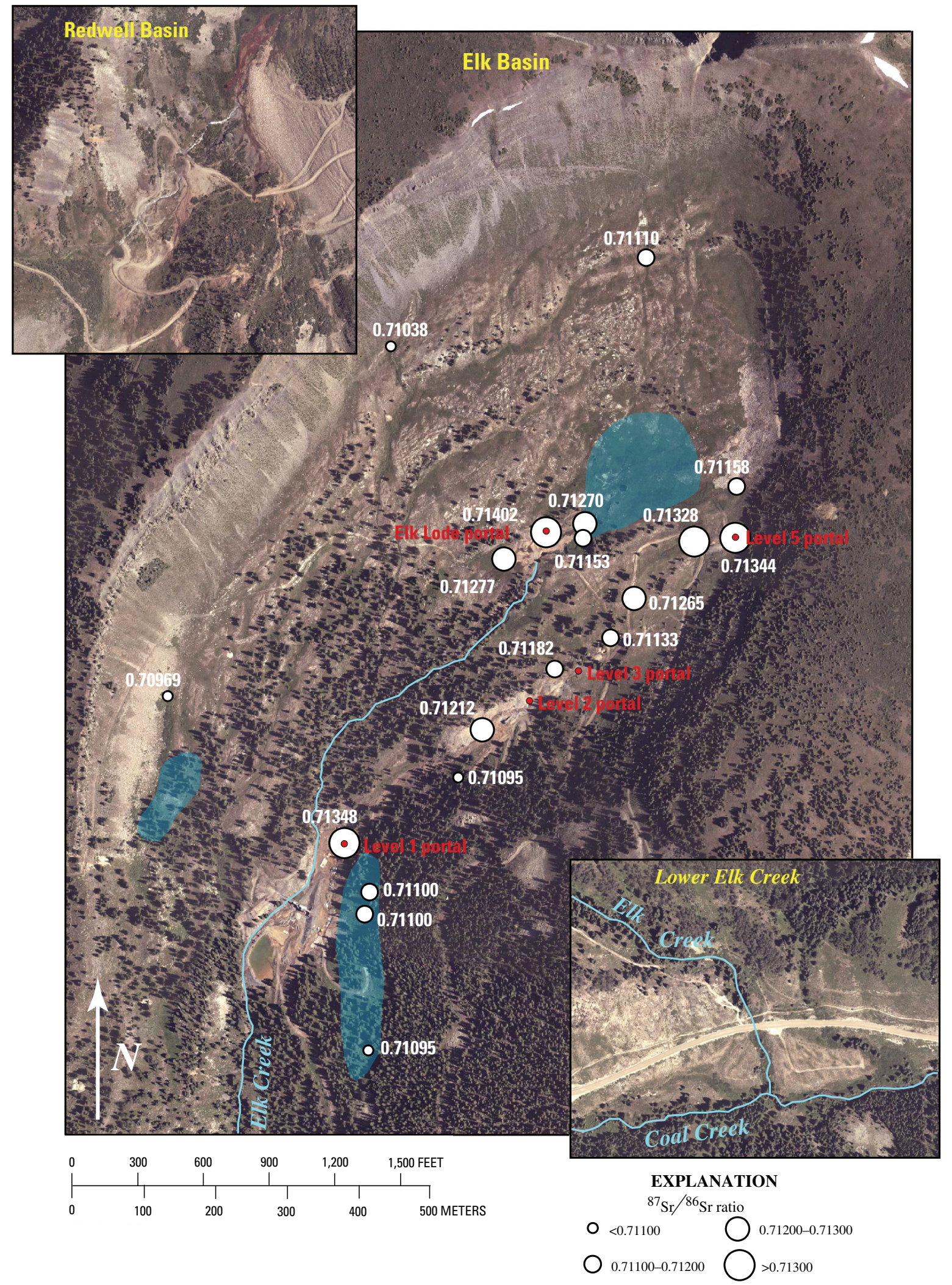

Figure 30. Strontium isotope ratios $\left({ }^{87} \mathrm{Sr} /{ }^{86} \mathrm{Sr}\right.$ ) (white type) at aboveground sample sites. Blue regions, zones of diffuse spring discharge; red type, Standard Mine portal. 


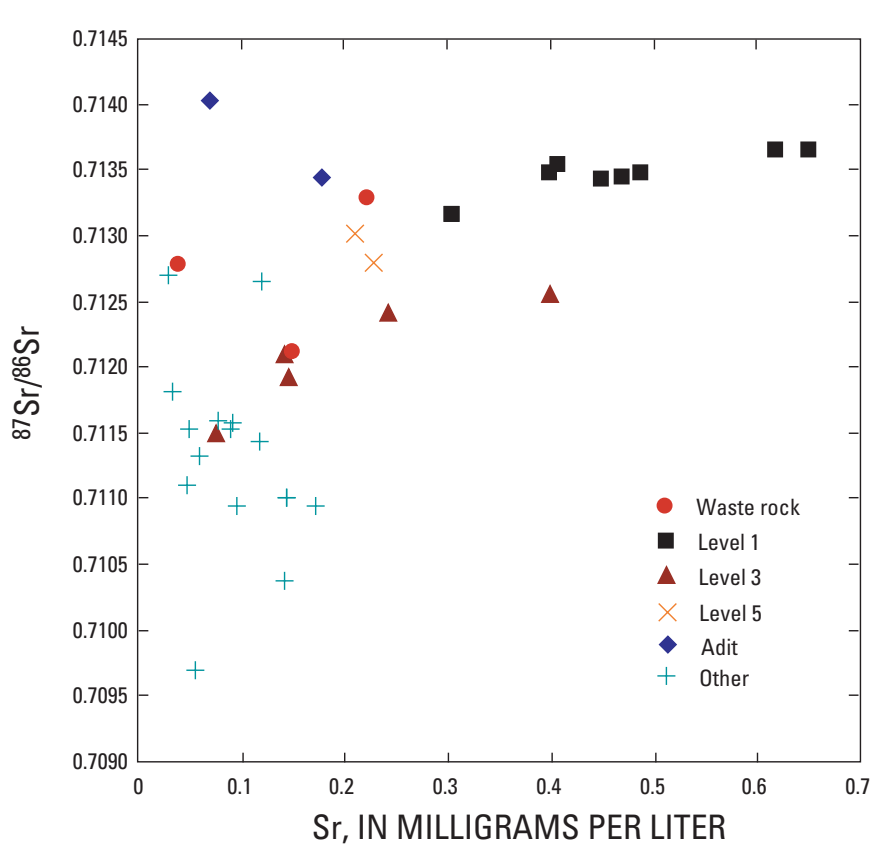

Figure 31. Strontium concentration at all sample sites plotted versus strontium isotope ratio $\left({ }^{87} \mathrm{Sr} /{ }^{86} \mathrm{Sr}\right)$.
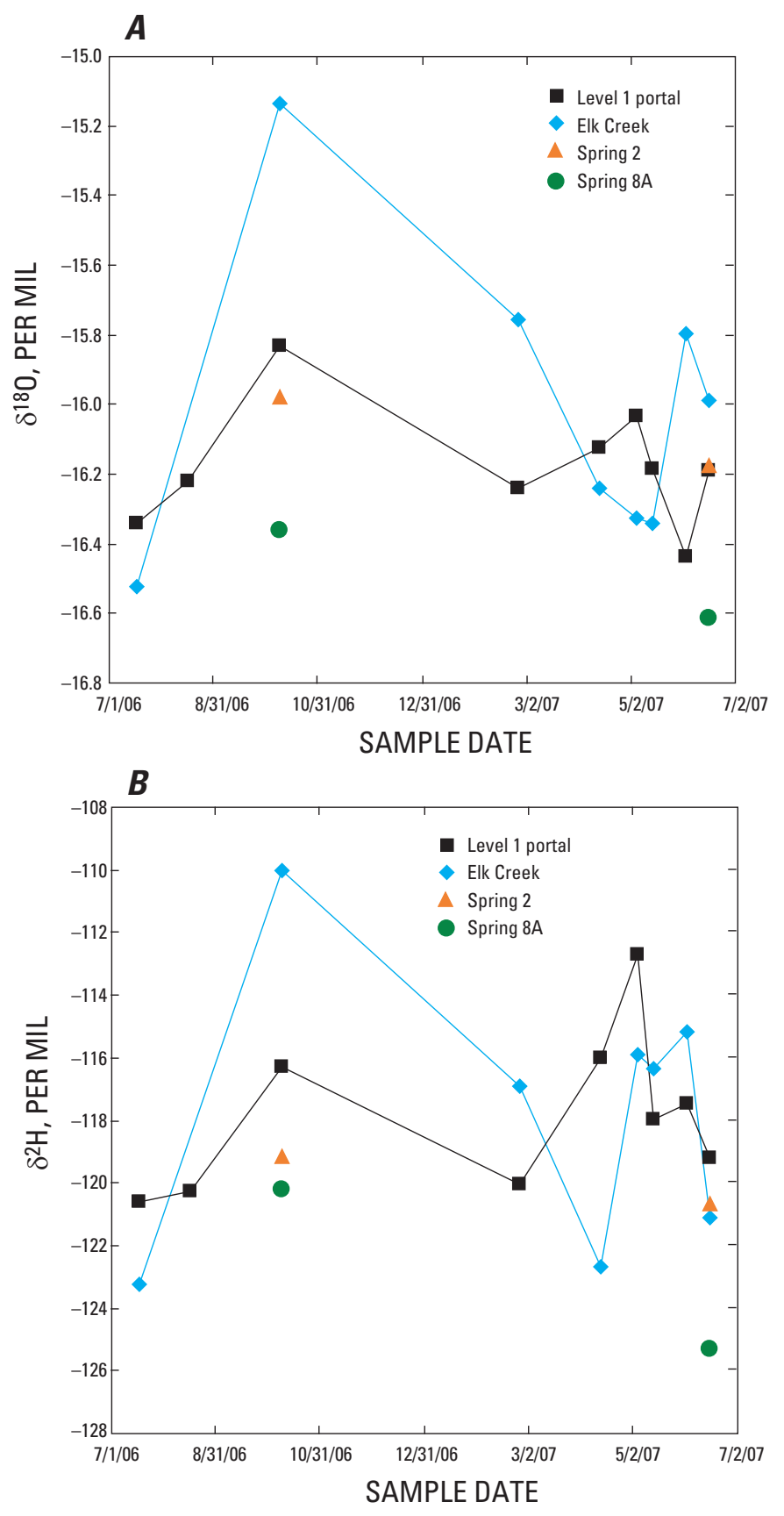

Figure 32. $\quad \delta^{18} \mathrm{O}(A)$ and $\delta^{2} \mathrm{H}(B)$ concentrations at task 1 sample sites plotted versus sample date. 
Table 3. Oxygen-18, deuterium, and carbon isotope content of selected water samples.

[NA, not applicable; NC, not computed; NM, not measured; pmC, parts modern carbon; $-\mathrm{R}$ (appended to sample name), replicate sample]

\begin{tabular}{|c|c|c|c|c|c|c|}
\hline $\begin{array}{l}\text { Sample } \\
\text { name }\end{array}$ & $\begin{array}{c}\text { Sample } \\
\text { date }\end{array}$ & $\begin{array}{c}\delta^{18} 0 \\
\text { (per mil) }\end{array}$ & $\begin{array}{c}\delta^{2} \mathbf{H} \\
\text { (per mil) }\end{array}$ & $\begin{array}{c}\delta^{13} \mathbf{C} \\
\text { (per mil) }\end{array}$ & $\begin{array}{l}{ }^{14} \mathrm{C} \\
(\mathrm{pmC})\end{array}$ & $\begin{array}{l}\text { Unadjusted } \\
{ }^{14} \mathrm{C} \text { age } \\
\text { (years) }\end{array}$ \\
\hline EC-CELK1-01 & $7 / 18 / 06$ & -16.52 & -123.2 & NM & NM & $\mathrm{NC}$ \\
\hline EC-CELK1-02 & $10 / 9 / 06$ & -15.14 & -110.0 & NM & NM & $\mathrm{NC}$ \\
\hline EC-CELK1-03 & $2 / 25 / 07$ & -15.76 & -116.9 & NM & NM & $\mathrm{NC}$ \\
\hline EC-CELK1-04 & $4 / 14 / 07$ & -16.24 & -122.7 & NM & NM & $\mathrm{NC}$ \\
\hline EC-CELK1-05 & $5 / 5 / 07$ & -16.33 & -115.9 & NM & NM & $\mathrm{NC}$ \\
\hline EC-CELK1-06 & $5 / 15 / 07$ & -16.34 & -116.4 & NM & NM & $\mathrm{NC}$ \\
\hline EC-CELK1-07 & $6 / 3 / 07$ & -15.80 & -115.2 & NM & NM & $\mathrm{NC}$ \\
\hline EC-CELK1-08 & $6 / 17 / 07$ & -15.99 & -121.1 & NM & NM & $\mathrm{NC}$ \\
\hline $\mathrm{EC}-\mathrm{S} 2-03$ & $10 / 9 / 06$ & -15.98 & -119.1 & NM & NM & $\mathrm{NC}$ \\
\hline EC-S2-04 & $6 / 17 / 07$ & -16.18 & -120.7 & NM & NM & $\mathrm{NC}$ \\
\hline EC-S8A-03 & $10 / 9 / 06$ & -16.36 & -120.2 & NM & NM & $\mathrm{NC}$ \\
\hline EC-S8A-04 & $6 / 17 / 07$ & -16.61 & -125.3 & NM & NM & $\mathrm{NC}$ \\
\hline EC-S8A-04-R & $6 / 17 / 07$ & -16.73 & -121.1 & NM & NM & $\mathrm{NC}$ \\
\hline EC-MUSTD1-01 & $8 / 17 / 06$ & -16.50 & -122.2 & NM & NM & $\mathrm{NC}$ \\
\hline RW-S1-01 & $8 / 18 / 06$ & -16.63 & -121.7 & -8.8 & 98.62 & 58 \\
\hline RW-S2-01 & 8/18/06 & -15.93 & -113.9 & -8.3 & 34.27 & 8550 \\
\hline RW-S2-01-R & 8/18/06 & -15.77 & -115.5 & -8.0 & 35.92 & 8172 \\
\hline EC-MSTD1-01 & 7/18/06 & -16.34 & -120.6 & NM & NM & $\mathrm{NC}$ \\
\hline EC-MSTD1-02 & $8 / 16 / 06$ & -16.22 & -120.3 & NM & NM & $\mathrm{NC}$ \\
\hline EC-MSTD1-02-R & 8/16/06 & -16.24 & -121.1 & $\mathrm{NM}$ & NM & $\mathrm{NC}$ \\
\hline EC-MSTD1-03 & $10 / 9 / 06$ & -15.83 & -116.3 & NM & NM & $\mathrm{NC}$ \\
\hline EC-MSTD1-03-R & $10 / 9 / 06$ & -15.87 & -116.4 & NM & NM & $\mathrm{NC}$ \\
\hline EC-MSTD1-04 & $2 / 25 / 07$ & -16.24 & -120.0 & NM & NM & $\mathrm{NC}$ \\
\hline EC-MSTD1-05 & $4 / 14 / 07$ & -16.12 & -116.0 & NM & NM & $\mathrm{NC}$ \\
\hline EC-MSTD1-06 & $5 / 5 / 07$ & -16.03 & -112.7 & NM & NM & $\mathrm{NC}$ \\
\hline EC-MSTD1-07 & $5 / 15 / 07$ & -16.19 & -118.0 & NM & NM & $\mathrm{NC}$ \\
\hline EC-MSTD1-08 & $6 / 3 / 07$ & -16.44 & -117.5 & $\mathrm{NM}$ & NM & $\mathrm{NC}$ \\
\hline EC-MSTD1-09 & $6 / 17 / 07$ & -16.19 & -119.2 & NM & NM & $\mathrm{NC}$ \\
\hline EC-MSTDL31-01 & $8 / 17 / 06$ & -15.65 & -114.1 & NM & NM & $\mathrm{NC}$ \\
\hline EC-MSTDL32-01 & 8/17/06 & -16.46 & -119.9 & NM & NM & $\mathrm{NC}$ \\
\hline EC-MSTDL33-01 & $8 / 17 / 06$ & -16.55 & -121.7 & NM & NM & $\mathrm{NC}$ \\
\hline EC-MSDTL34-01 & $8 / 17 / 06$ & -16.82 & -121.9 & NM & NM & $\mathrm{NC}$ \\
\hline EC-MSTDL35-01 & $8 / 17 / 06$ & -16.74 & -122.9 & NM & NM & $\mathrm{NC}$ \\
\hline EC-M116001-01 & $8 / 17 / 06$ & -16.08 & -118.8 & NM & NM & $\mathrm{NC}$ \\
\hline EC-M116002-01 & $8 / 17 / 06$ & -17.02 & -124.3 & NM & NM & $\mathrm{NC}$ \\
\hline
\end{tabular}




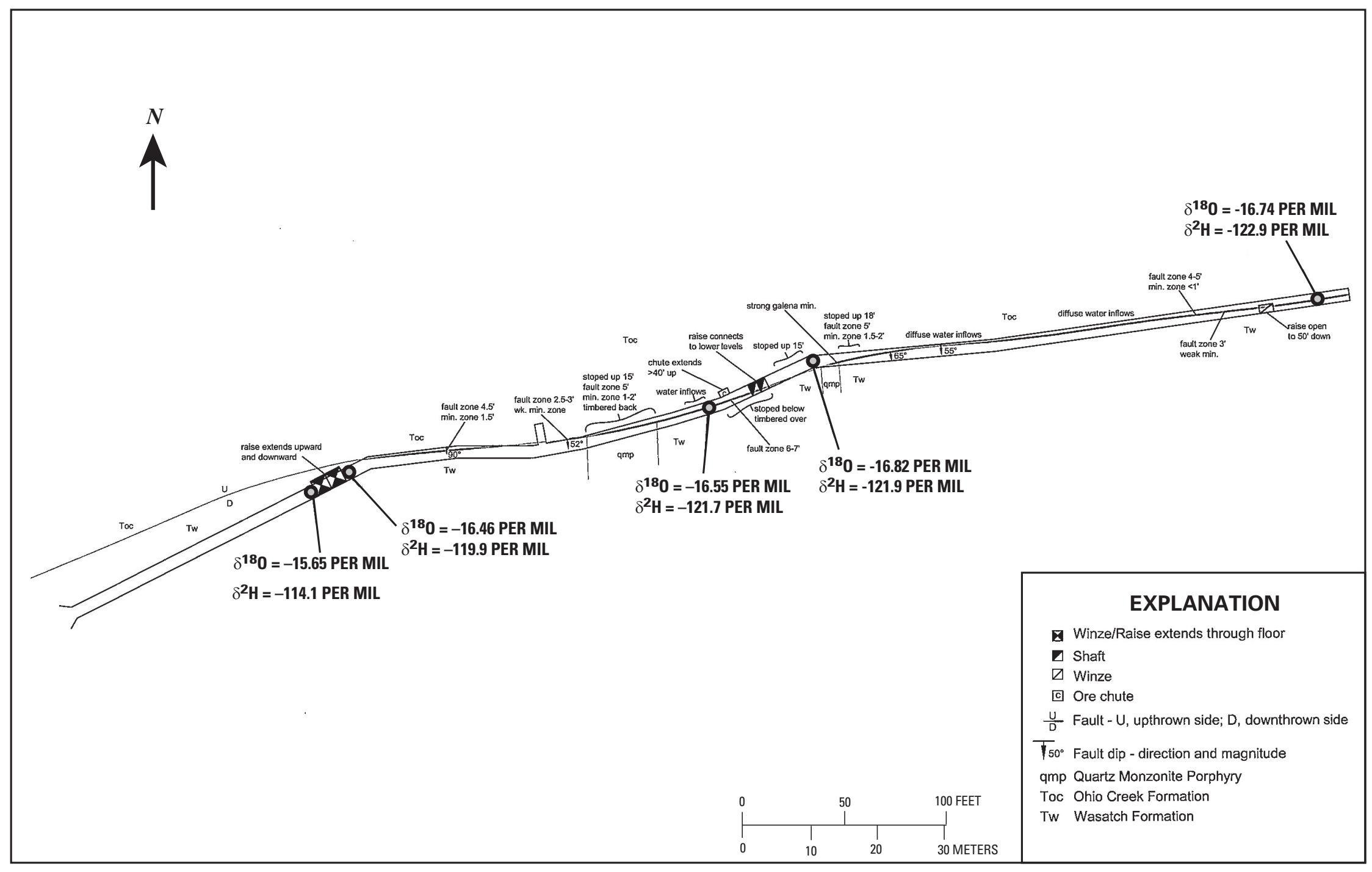

Figure 33. $\delta^{18} 0$ and $\delta^{2} \mathrm{H}$ at underground sample sites in Level 3 of Standard Mine. Adapted from Colorado Division of Reclamation, Mining, and Safety (2007). min., mineralized or mineralization; wk. min., weakly mineralized. 


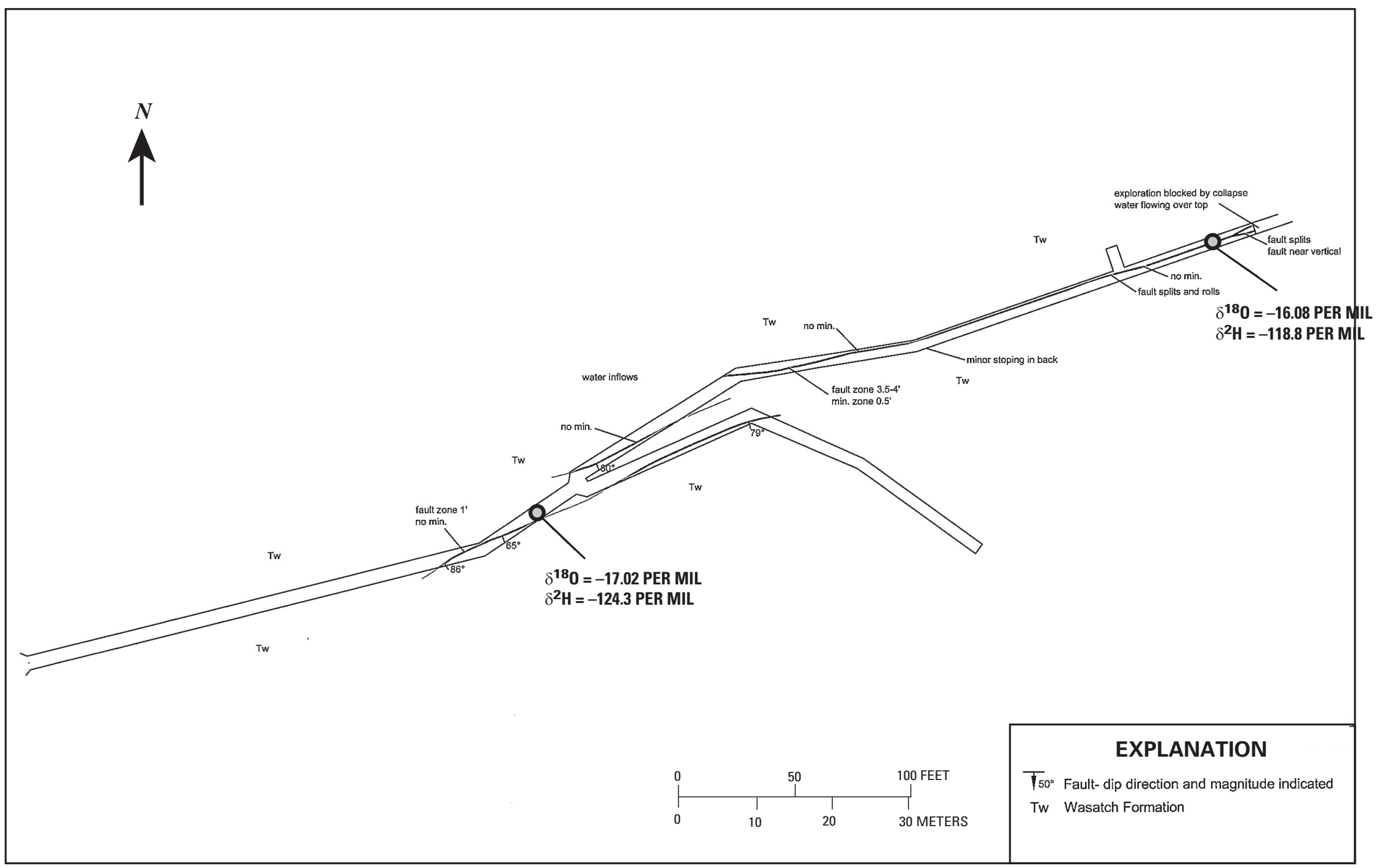

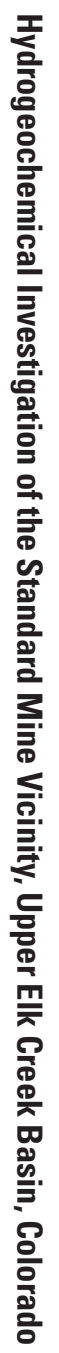

Figure 34. $\delta^{18} 0$ and $\delta^{2} \mathrm{H}$ at underground sample sites in Level 5 of Standard Mine. Adapted from Colorado Division of Reclamation, Mining, and Safety (2007). min., mineralized or mineralization. 

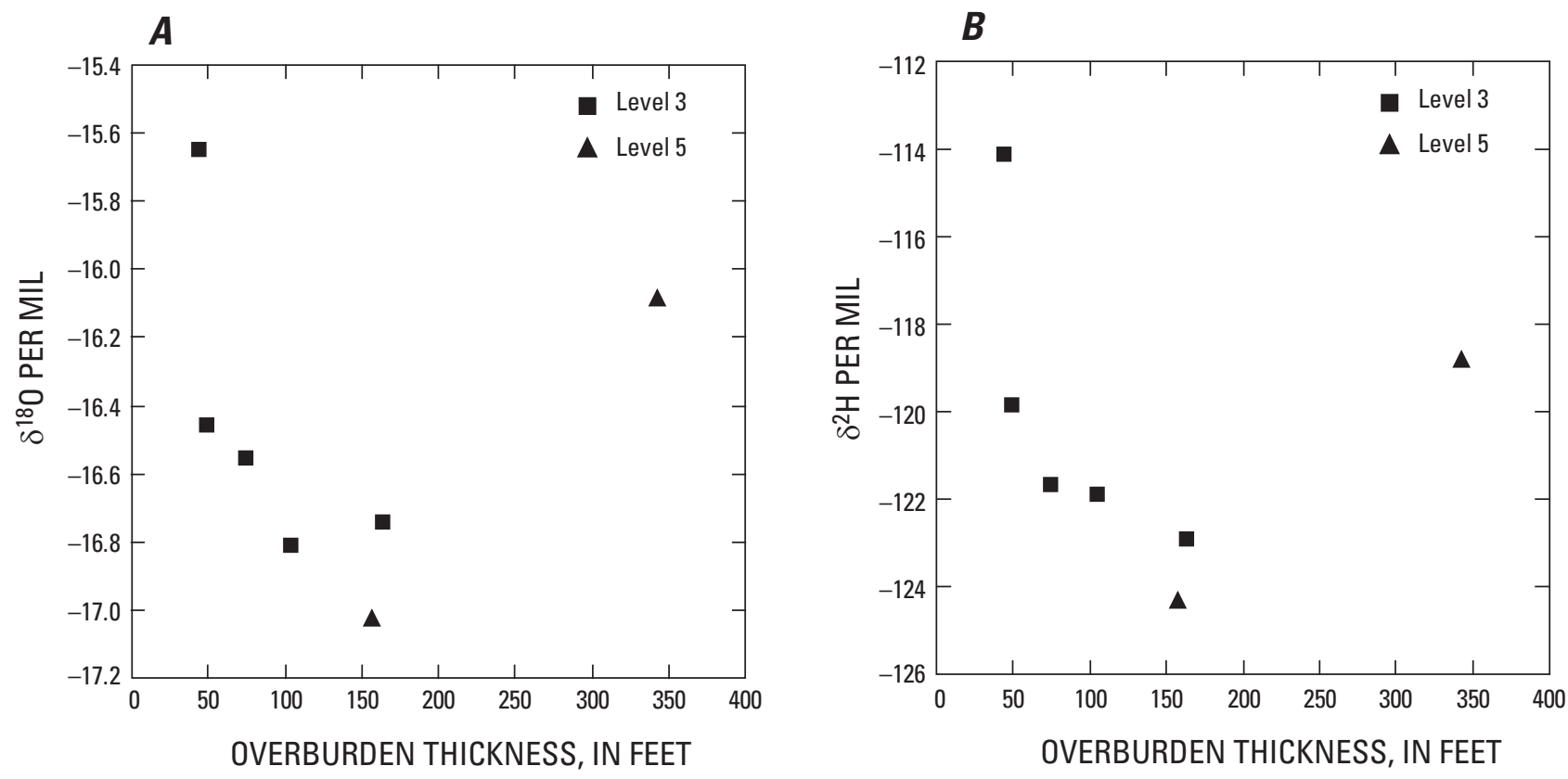

Figure 35. $\delta^{18} O(A)$ and $\delta^{2} H(B)$ of underground samples plotted versus overburden thickness.

surface elevation increase of about $400 \mathrm{ft}$ above the sampled sections of Levels 3 and 5, elevation effects can account for only about 0.2 per mil of the observed 1.4 per mil change in $\delta^{18} \mathrm{O}$, and only about 1.6 per mil of the observed 10 per mil change in $\delta^{2} \mathrm{H}$. The general decrease in $\delta^{18} \mathrm{O}$ and $\delta^{2} \mathrm{H}$ with overburden thickness must therefore primarily be caused by another factor, the most likely of which is increasing flowpathway length and residence time as discussed further in the Discussion section below.

\section{Tritium and Noble Gases}

Twenty-five samples were analyzed for ${ }^{3} \mathrm{H}$ and 14 samples were analyzed for dissolved gases (table 4). Up to 25 dissolved gas samples were initially planned, but only 14 were collected because sampling conditions precluded the collection of additional reliable samples. In most cases, intended samples were not collected because of the obvious potential for gas exchange between the sampled water and the atmosphere upstream of the sample point. Measured ${ }^{3} \mathrm{H}$ concentrations of three replicate pairs agreed within the $2 \sigma$ analytical error (see Methods section above). Likewise, measured dissolved gas concentrations and the ${ }^{3} \mathrm{He} /{ }^{4} \mathrm{He}$ ratio (reported as $\mathrm{R} / \mathrm{R}_{\mathrm{a}}$ ) of two replicate pairs agreed within the $2 \sigma$ analytical error for each gas (see Methods section above). Tritium concentrations are not reported for samples collected from tributary 2 (EC-T2-02) or from Level 3 site 2 (EC-MSTDL32-01), because the flasks used to store these samples for ${ }^{3} \mathrm{He}$ ingrowth leaked, making ${ }^{3} \mathrm{H}$ analysis impossible.

\section{Task 2}

Measured ${ }^{3} \mathrm{H}$ concentrations in aboveground samples were all similar and ranged from 6.61 to $11.01 \mathrm{TU}$; most were 8-10 TU (fig. 36). No clear spatial patterns were apparent in the ${ }^{3} \mathrm{H}$ distribution. However, the aboveground samples with the four highest ${ }^{3} \mathrm{H}$ concentrations (EC-M11600-02, EC-MSTD2-01, EC-M11400B-02, and RW-S2-01) were collected from four of the five sites where the oldest water was expected on the basis of either field parameters and observations (Redwell spring 2 and well 1) or the fact that the sampled water discharged from a mine tunnel either known or believed to penetrate deeply into the subsurface (Level 5 portal, Level 1 site 2, and Elk Lode portal).

Recharge elevations were assumed to be the approximate mean elevation of the portion of the watershed up-gradient of the sample location and have an uncertainty of $\pm 500 \mathrm{ft}$ or less (table 4). Variations in $\mathrm{H}_{\mathrm{r}}$ of this magnitude result in variations in the apparent ${ }^{3} \mathrm{H} /{ }^{3} \mathrm{He}$ age of \pm 0.2 years or less for samples in this study. Chi-squared $\left(\chi^{2}\right)$ misfit values were unacceptably high (probability $<0.05$ ) for only two sample (EC-S8A-02 and EC-S8B-02), which were from springs 8A and $8 \mathrm{~B}$. Measured gas concentrations for these samples did not fit the closed equilibrium model because lighter gases ( $\mathrm{He}$ and $\mathrm{Ne}$ ) were overly depleted and the heavier gases (Xe and $\mathrm{Kr}$ ) were overly enriched. This pattern suggests that gas was lost from the sampled water during discharge (these samples were "stripped"). Such loss can occur when the sampled water is high in excess air and, as it emerges from the ground and the hydrostatic load is lost, bubbles form and gas (including ${ }^{3} \mathrm{H}_{\text {trit }}$ ) escapes. Modeled recharge parameters and apparent ${ }^{3} \mathrm{H} /{ }^{3} \mathrm{He}$ 
Table 4. Dissolved gas and ${ }^{3} \mathrm{H}$ data and ${ }^{3} \mathrm{H} /{ }^{3} \mathrm{He}$ age results.

$\left[\chi^{2}\right.$, model misfit; ${ }^{\circ} \mathrm{C}$, degrees Celsius; $\mathrm{cm}^{3} \mathrm{STP} / \mathrm{g}$, cubic centimeters at standard temperature and pressure per gram of water; ft asl, feet above sea level; $\mathrm{mg} / \mathrm{L}$, milligrams per liter; yr, year; $\mathrm{A}_{\mathrm{e}}$ and $\mathrm{F}$, excess air parameters defined in text; DO, dissolved oxygen; EA, excess air, defined as the sum of the modeled excess air components of $\mathrm{N}_{2}, \mathrm{O}_{2}$, and $\mathrm{Ar} ; \mathrm{H}_{\mathrm{r}}$, recharge elevation; ${ }^{3} \mathrm{He}_{\text {triti }}$, tritiogenic ${ }^{3} \mathrm{He} ; \mathrm{He}_{\text {terr, }}$, terrigenic $\mathrm{He}$ component; $\mathrm{NC}$, not computed; NM, not measured; -R (appended to sample name), replicate sample; $\mathrm{R},{ }^{3} \mathrm{He} /{ }^{4} \mathrm{He}$ ratio in sample; $\mathrm{R}_{\mathrm{a}},{ }^{3} \mathrm{He} /{ }^{4} \mathrm{He}$ ratio in air; $\mathrm{T}$, discharge temperature; $\mathrm{T}_{\mathrm{r}}$, recharge temperature; $\mathrm{TU}$, tritium units].

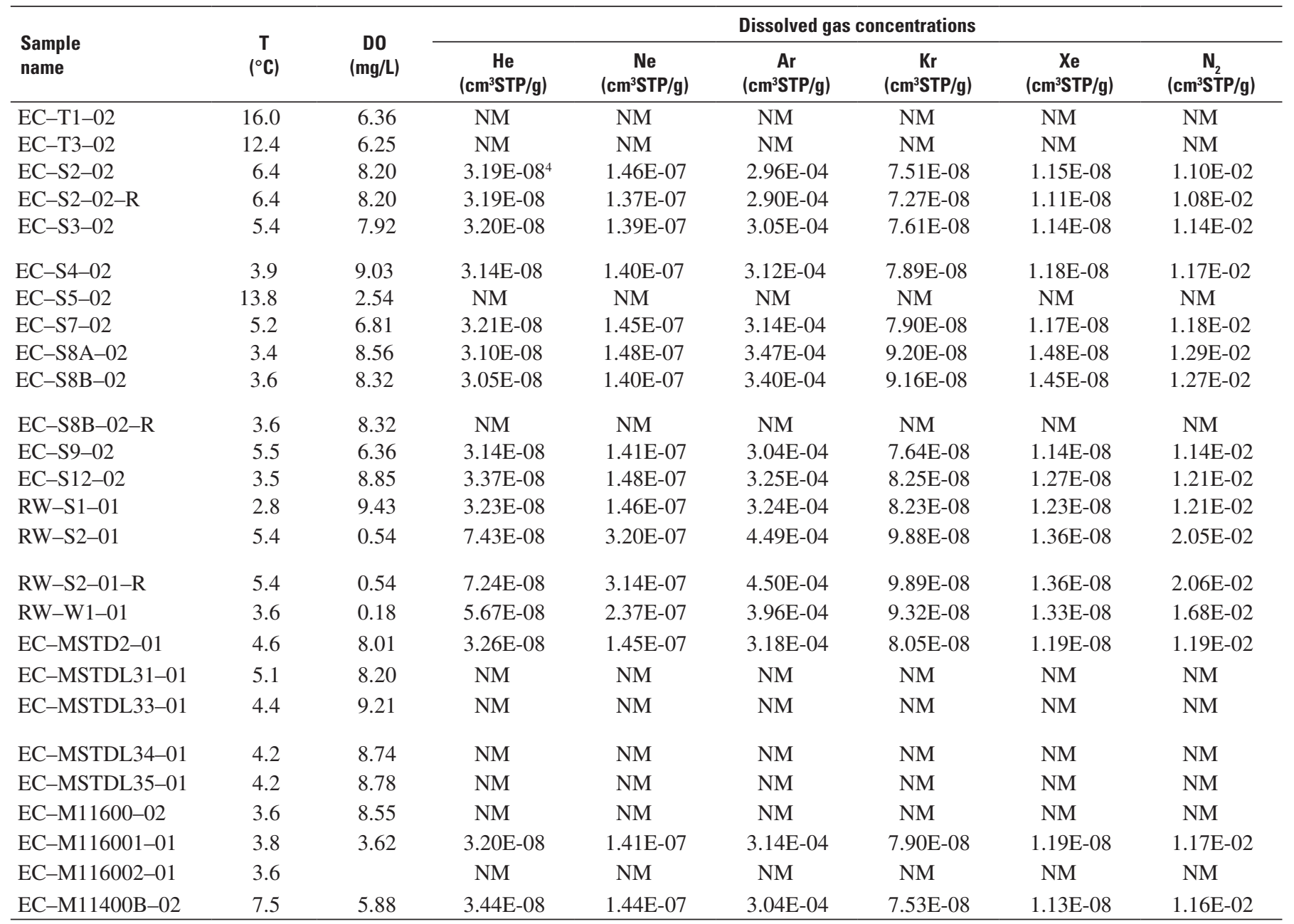

${ }^{1}$ Assumed value, see text.

${ }^{2}$ Chi-squared value unacceptably high.

${ }^{3} \mathrm{He}$ excluded in derivation of recharge parameters because stripped.

${ }^{4}$ Read $3.19 \mathrm{E}-08$ as $3.19 \times 10^{-8}$.

${ }^{5}$ Samples with negative ${ }^{3} \mathrm{He}_{\text {trit }}$ values assigned age of $0 \mathrm{yr}$. 
Table 4. Dissolved gas and ${ }^{3} \mathrm{H}$ data and ${ }^{3} \mathrm{H} /{ }^{3} \mathrm{He}$ age results.-Continued

$\left[\chi^{2}\right.$, model misfit; ${ }^{\circ} \mathrm{C}$, degrees Celsius; $\mathrm{cm}^{3} \mathrm{STP} / \mathrm{g}$, cubic centimeters at standard temperature and pressure per gram of water; ft asl, feet above sea level; mg/L, milligrams per liter; yr, year; $\mathrm{A}_{\mathrm{e}}$ and $\mathrm{F}$, excess air parameters defined in text; DO, dissolved oxygen; EA, excess air, defined as the sum of the modeled excess air components of $\mathrm{N}_{2}, \mathrm{O}_{2}$, and $\mathrm{Ar} ; \mathrm{H}_{\mathrm{r}}$, recharge elevation; ${ }^{3} \mathrm{He}_{\text {triti }}$, tritiogenic ${ }^{3} \mathrm{He} ; \mathrm{He}_{\text {terr }}$, terrigenic $\mathrm{He}$ component; $\mathrm{NC}$, not computed; NM, not measured; $-\mathrm{R}$ (appended to sample name), replicate sample; $\mathrm{R},{ }^{3} \mathrm{He} /{ }^{4} \mathrm{He}$ ratio in sample; $\mathrm{R}_{\mathrm{a}},{ }^{3} \mathrm{He} /{ }^{4} \mathrm{He}$ ratio in air; $\mathrm{T}$, discharge temperature; $\mathrm{T}_{\mathrm{r}}$, recharge temperature; $\mathrm{TU}$, tritium units].

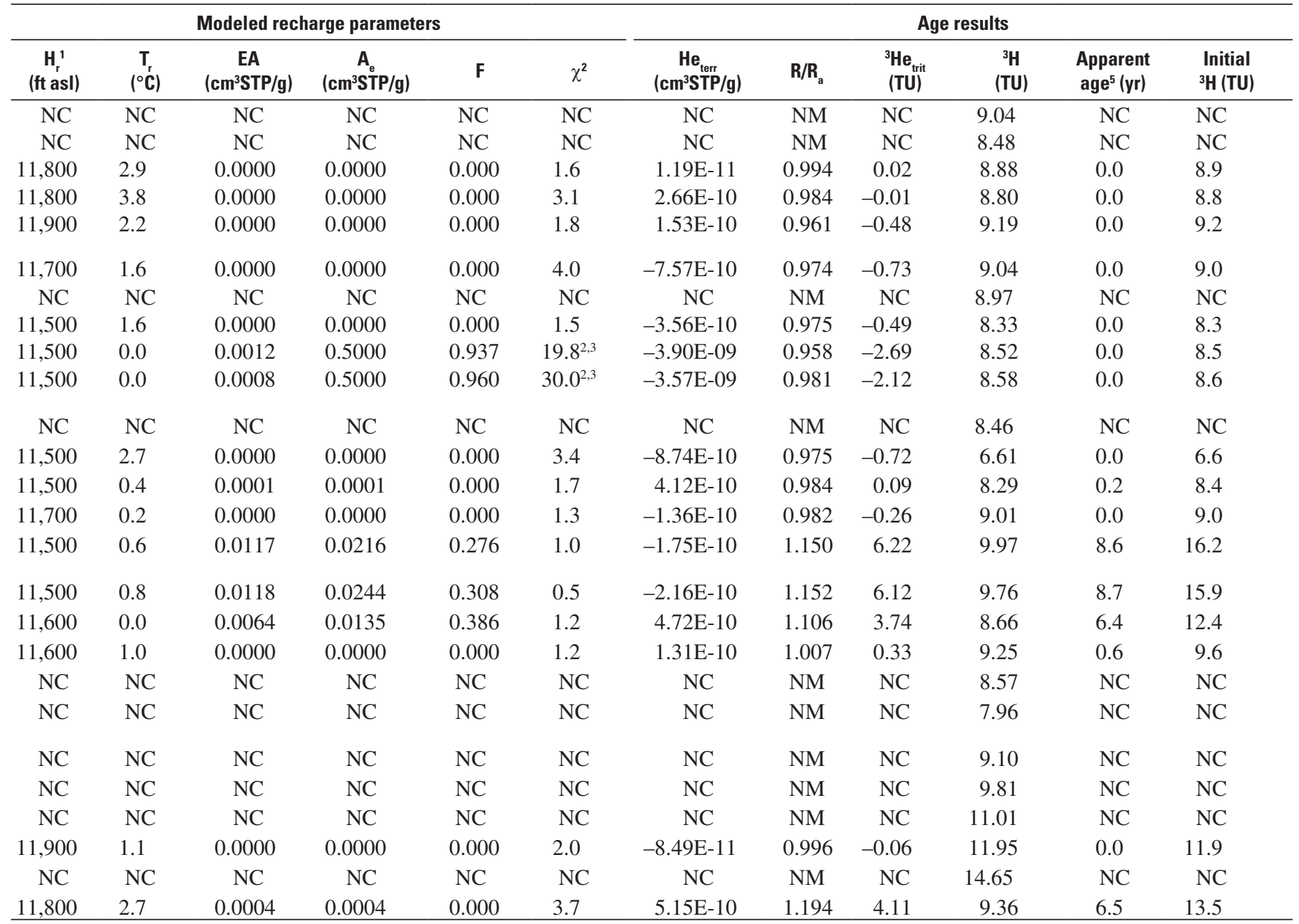




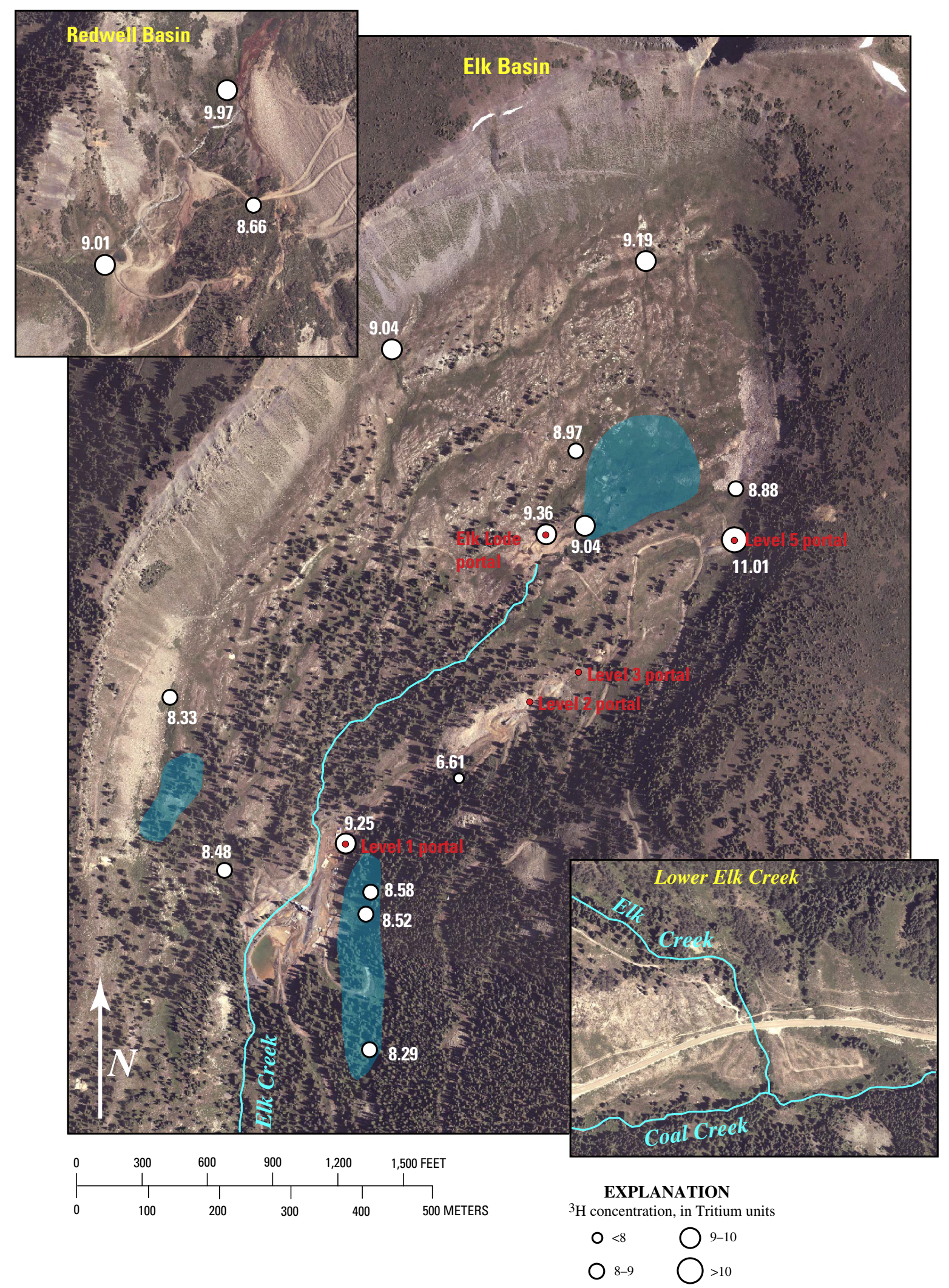

Figure 36. Tritium concentration (white type) at aboveground sample sites. Blue regions, zones of diffuse spring discharge; red type, Standard Mine portal. 
ages of such samples are not reliable. Modeled $\mathrm{T}_{\mathrm{r}}$ values were $0^{\circ}-4^{\circ} \mathrm{C}$, consistent with a mean annual air temperature of about $1^{\circ} \mathrm{C}$ and discharge temperatures of $3^{\circ}-5^{\circ} \mathrm{C}$ from the largest springs and the underground sites. Excess air concentrations were generally low, most $\leq 0.001 \mathrm{~cm}^{3} \mathrm{STP} / \mathrm{g}$. Samples from Redwell spring 2 and well 1 were clear exceptions; they had excess air values of 0.0117 and $0.0064 \mathrm{~cm}^{3} \mathrm{STP} / \mathrm{g}$, respectively.

Apparent ${ }^{3} \mathrm{H} /{ }^{3} \mathrm{He}$ ages for the aboveground samples ranged from 0.0 to $8.6 \mathrm{yr}$, and all but three (from the Elk Lode portal, Redwell spring 2 , and well 1) had apparent ages $<1.0 \mathrm{yr}$ (fig. 37). Uncertainty in the apparent age is approximately \pm 1 yr for samples in this data set, given their low ${ }^{4} \mathrm{He}_{\text {terr }}$ concentrations $\left(<10^{-8} \mathrm{~cm}^{3} \mathrm{STP} / \mathrm{g}\right)$, low apparent ages, low to intermediate excess air concentrations, and well-constrained $\mathrm{H}_{\mathrm{r}}$ values (Manning and Caine, 2007). The four oldest apparent ages at aboveground sample sites (Redwell spring 2, well 1, Elk Lode portal, and Level 1 site 2) were from four of the five sites where the oldest water was expected, as with the ${ }^{3} \mathrm{H}$ concentrations (see above). Apparent ages considered unreliable (from springs $8 \mathrm{~A}$ and $8 \mathrm{~B}$ and Level 1 site 2) are shown in green on fig. 37. The first two are unreliable because they were probably stripped (as explained above), and thus their apparent ages are probably erroneously young owing to loss of ${ }^{3} \mathrm{He}_{\text {trit }}$. Inspection of table 4 reveals a correlation between excess air and age: two of the three samples have apparent ages $>1 \mathrm{yr}$ and contain considerably more excess air than samples with apparent ages $<1 \mathrm{yr}$. This positive correlation between excess air and age has been observed at other mountain locations (Manning and Caine, 2007). The high probability that samples from springs $8 \mathrm{~A}$ and $8 \mathrm{~B}$ contained elevated excess air prior to discharge (causing them to become stripped) further supports the notion that the apparent ages of these samples are erroneously young. The sample at Level 1 site 2 was collected on the outby side of the collapse in the Level 1 tunnel, and it is unknown whether or not water inby the collapse had undergone considerable exchange with the atmosphere. If so, then the apparent age is again erroneously young.

\section{Task 3}

Tritium concentrations in underground samples ranged from 8.0 to 14.7 TU (figs. 38 and 39), higher than concentrations in aboveground samples. Tritium concentrations generally increased with overburden thickness (fig. 40), suggesting a positive correlation between ${ }^{3} \mathrm{H}$ concentration and flow-pathway length and thus residence time. However, the ${ }^{3} \mathrm{H}$ concentration at Level 5 site 1 was lower than at Level 5 site 2, counter to the overall trend.

Only one dissolved gas sample was collected in Levels 3 and 5; it came from Level 5 site 1 on the outby side of the collapse near the end of Level 5. As at Level 1 site 2, it is unknown whether water inby the collapse had undergone gas exchange with the atmosphere. Its apparent age of $0.0 \mathrm{yr}$ is therefore considered unreliable. If gas exchange did occur, the apparent age is erroneously young.

\section{Carbon-14}

Two samples were analyzed for ${ }^{13} \mathrm{C}$ and ${ }^{14} \mathrm{C}$ in dissolved inorganic carbon (table 3). For the one replicate pair, $\delta^{13} \mathrm{C}$ agreed within the reported $2 \sigma$ analytical error of 0.3 per mil. The ${ }^{14} \mathrm{C}$ activity of the replicate pair differed by 1.6 percent modern carbon, more than the typical $2 \sigma$ analytical error of 1.0 percent modern carbon. This larger-than-expected discrepancy is probably a result of the very low dissolved inorganic carbon concentration in the replicated sample $(\mathrm{pH}=3.68)$.

The sample from Redwell spring 1 (RW-S1-01) was collected to characterize the carbon isotope signature of young ground water at the site, information that is necessary in interpreting the ${ }^{14} \mathrm{C}$ age of older ground water. As expected, the ${ }^{14} \mathrm{C}$ activity was high (98.62 percent modern carbon), indicating an unadjusted age of $58 \mathrm{yr}$. Note that under the best circumstances, ${ }^{14} \mathrm{C}$ ages seldom have uncertainties less than $\pm 1,000$ yr. A sample was collected from Redwell spring 2 because it was suspected, on the basis of field parameters and observations, that water discharging from this spring was the oldest near the Standard Mine. The sample from Redwell spring 2 (RW-S2-01) had a ${ }^{14} \mathrm{C}$ activity of 34.27 percent modern carbon, indicating an unadjusted age of 8,550 yr. However, the unadjusted age does not take into account possible changes in the ${ }^{14} \mathrm{C}$ activity of dissolved inorganic carbon resulting from chemical reactions with dissolved inorganic carbon in the unsaturated and saturated zone or from mixing with other fluids. The chemical mass balance would have to be modeled in detail to quantify the influence of these processes and compute an adjusted age. Age adjustments typically reduce the unadjusted age 0 to $10,000 \mathrm{yr}$. Tritium and ${ }^{3} \mathrm{He}$ data indicated that water from Redwell spring 2 was about 9 yr old, and computed initial ${ }^{3} \mathrm{H}$ concentrations confirmed that it contained little water recharged prior to the early 1950s (see Discussion section below). These data confirm that processes other than radioactive decay almost certainly have markedly reduced the ${ }^{14} \mathrm{C}$ activity of water discharging from Redwell spring 2 and that the unadjusted age has essentially no meaning. Given the low $\mathrm{pH}$ of water from Redwell spring 2, the large unadjusted age is most likely due to the dissolution of calcite along flow pathways; calcite has a low ${ }^{14} \mathrm{C}$ activity. The $\delta^{13} \mathrm{C}$ value for the sample ( -8.0 per mil) was greater than that at Redwell spring 1 (-8.8 per mil), consistent with some dissolution of calcite, which typically has $\delta^{13} \mathrm{C}$ values of 0 to -6 per mil.

\section{Discussion}

\section{Distribution of Ground-Water Discharge and Potential Geologic Controls on Flow}

The only clear trend in the spatial distribution of groundwater discharge (aboveground) is that discharge was not observed on the ridges rimming Elk Basin but only at the 


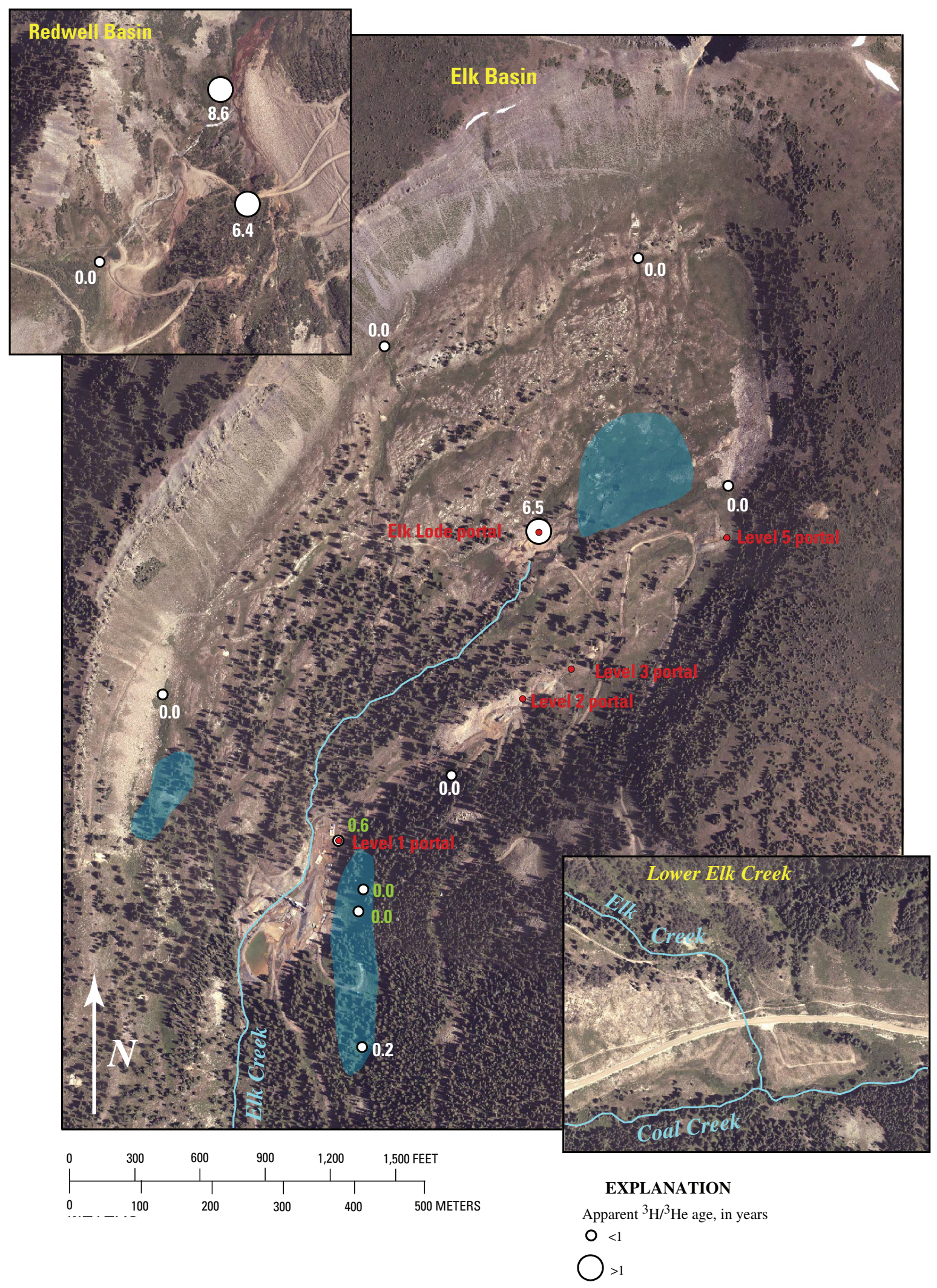

Figure 37. Apparent ${ }^{3} \mathrm{H} /{ }^{3} \mathrm{He}$ age (white and green type) at aboveground sample sites. Values in green considered unreliable (see text). Blue regions, zones of diffuse spring discharge; red type, Standard Mine portal. 


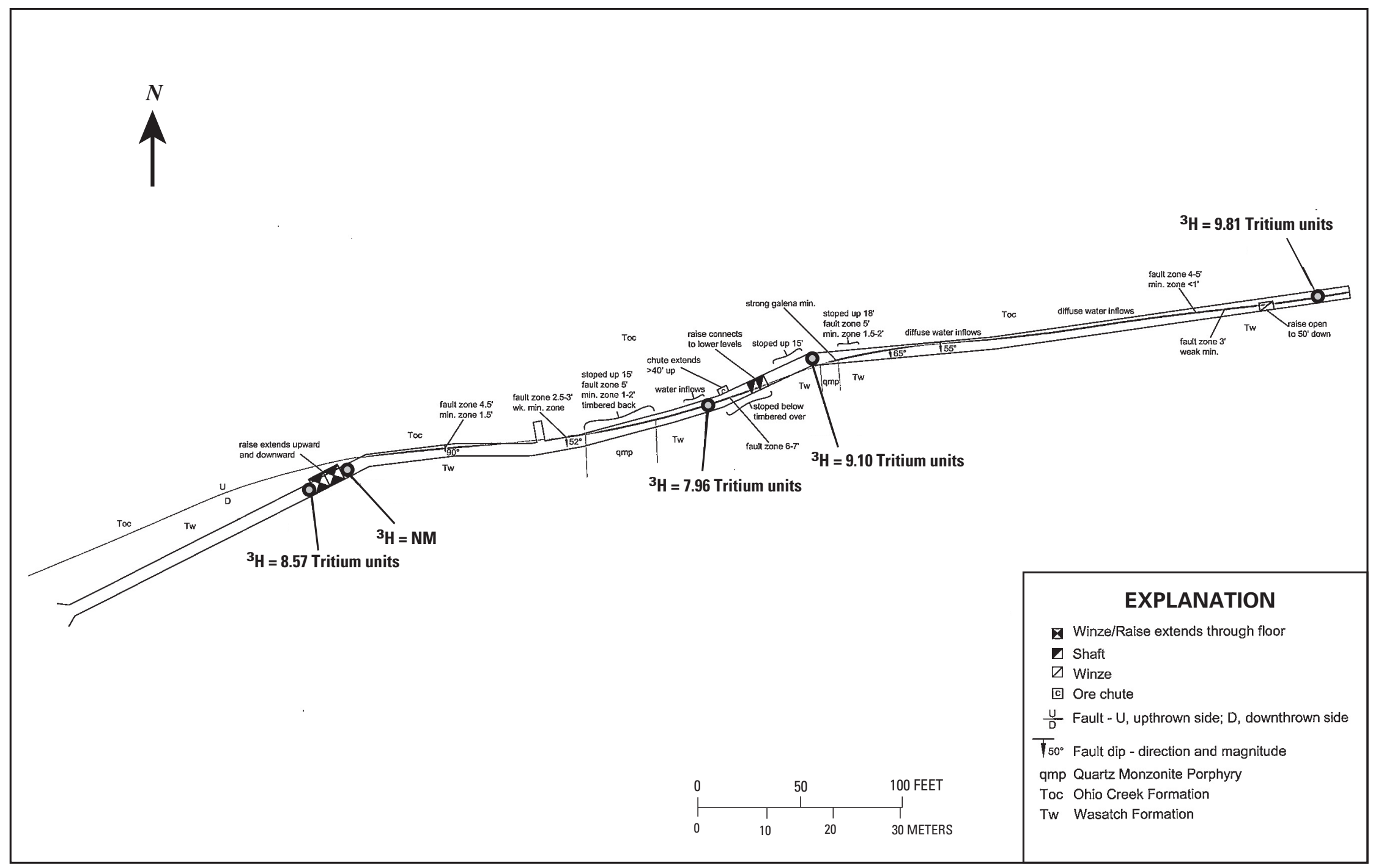

Figure 38. Tritium concentration at underground sample sites in Level 3 of the Standard Mine. Adapted from Colorado Division of Reclamation, Mining, and Safety (2007). NM, not measured; min., mineralized or mineralization; wk. min., weakly mineralized. 


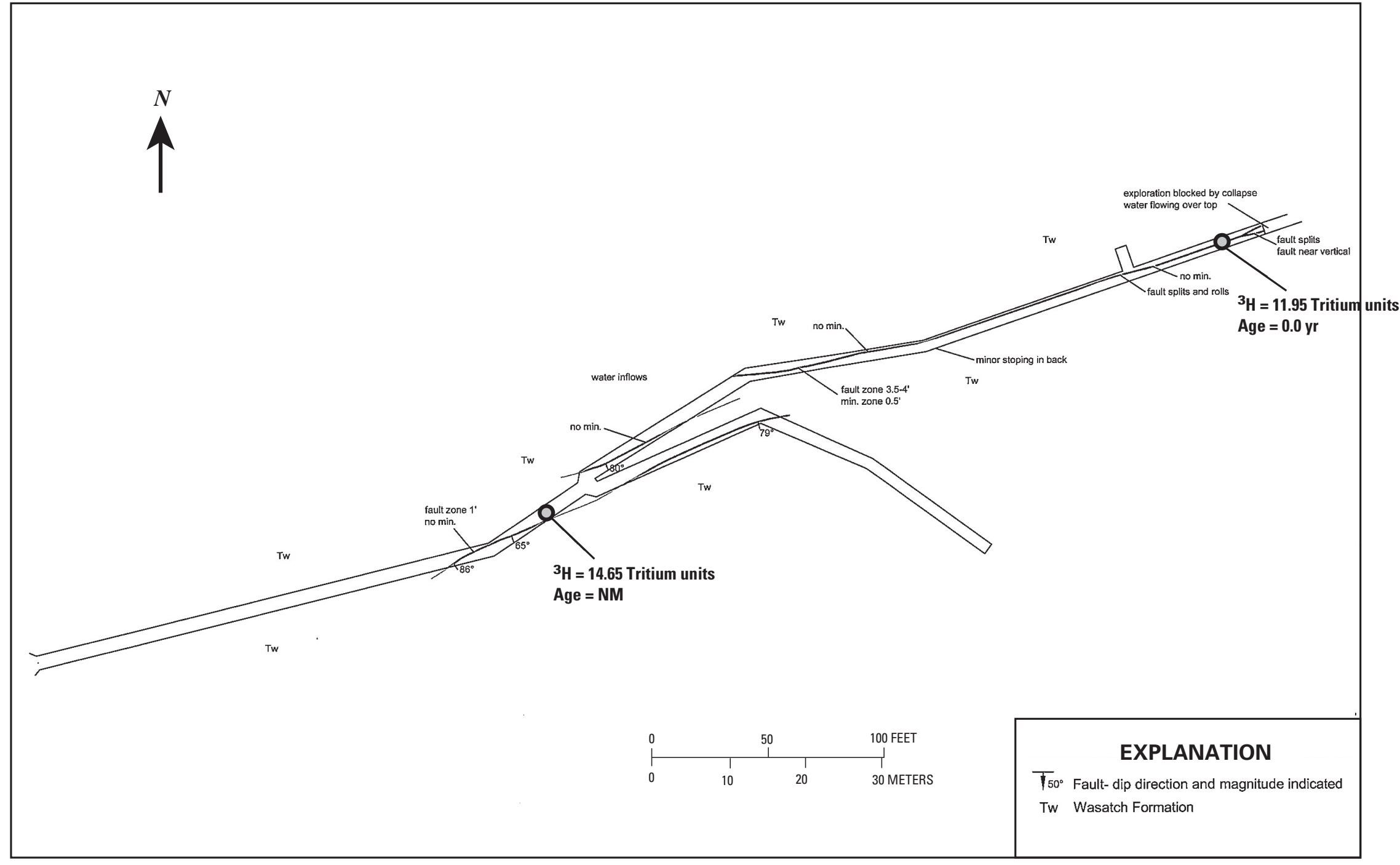

Figure 39. Tritium concentration and apparent ${ }^{3} \mathrm{H} / 3 \mathrm{He}$ age at underground sample sites in Level 5 of the Standard Mine. Apparent age at site 1 (fig. 7) is considered unreliable for reasons explained in text. Adapted from Colorado Division of Reclamation, Mining, and Safety (2007). NM, not measured; min., mineralized or mineralization. 


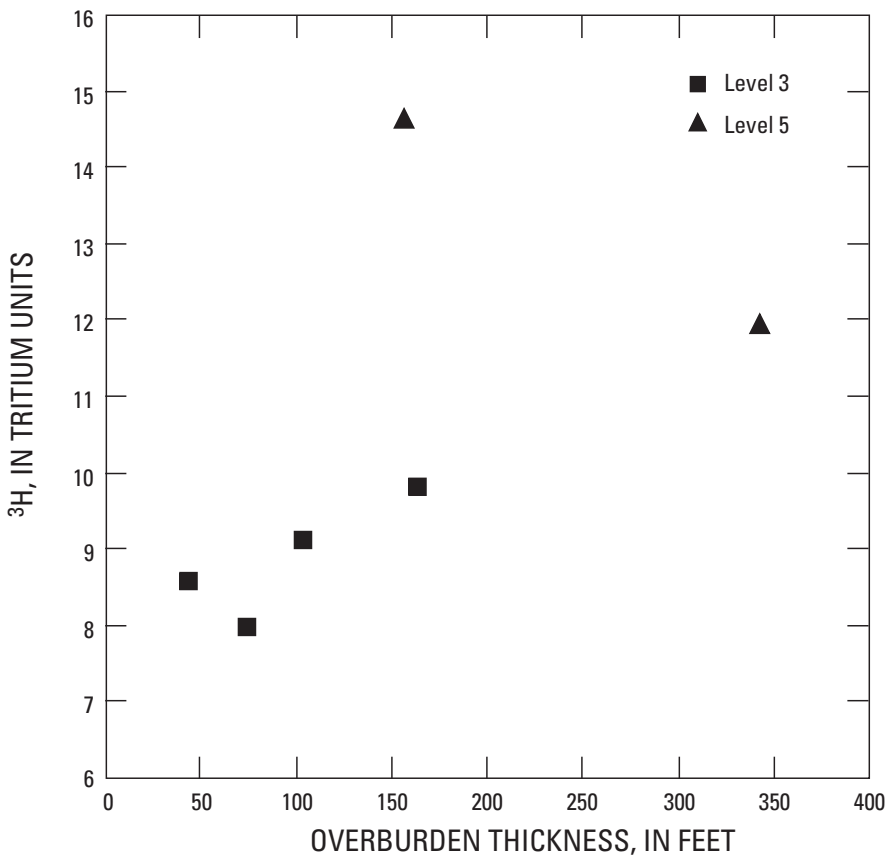

Figure 40. Tritium concentration in underground samples plotted versus overburden thickness.

foot of the headwall or on the basin floor (fig. 5). The water observed in the exploration pits is probably shallow ground water, and the elevation of the surface of that water probably reflects the water-table elevation. However, the shallow ground-water system may be perched, in which case water levels in the pits would be unrelated to water levels in the deeper, watershed-scale to regional-scale ground-water system. Shallow water levels $(<8 \mathrm{ft})$ in basin-floor pits and extensive ground-water discharge on the basin floor both suggest that the water table is generally near the ground surface on the basin floor. Dry exploration pits and an absence of any ground-water discharge above the basin floor suggest that the water table is deeper under the ridges rimming the basin. This relation is expected, given that water tables are typically muted expressions of the topography, hence deeper under ridges.

More sample sites are located in the Ohio Creek Formation than in the Wasatch Formation (fig. 8). However, this difference in number is probably due to the location of these units in the basin rather than to systematic permeability contrasts between them; the Ohio Creek Formation underlies most of the basin floor (where ground water discharges), whereas the Wasatch Formation underlies most of the ridges rimming the basin (where ground-water does not discharge). Ground water does discharge where the Wasatch Formation underlies the basin floor at springs $9,8 \mathrm{~A}, 8 \mathrm{~B}$, and 12 . No clear correlation exists between natural ground-water discharge locations and map-scale faults; several springs lie in the general vicinity of a fault, but few are located directly on a fault as would be expected if ground water flowed to the discharge location primarily through the fault. The greater density of sample sites along the Standard fault is due to the mine workings there, not to more sites of natural groundwater discharge. The lack of correlation between spring discharge and the map-scale faults suggests that these structures exert little influence on shallow ground-water flow, although they may strongly influence deeper ground-water flow. The degree to which outcrop-scale geologic structures control ground-water flow cannot be assessed on the basis of surface observations, because the springs generally discharge in float. In short, surface observations suggest that simple topography, rather than large-scale geologic features (mapscale faults and lithology), primarily controls the occurrence and flow of shallow ground-water in Elk Basin.

Because the primary source of water flowing into the Standard Mine appeared to be gouge and breccia in the Standard fault, the Standard fault itself is probably the main pathway of ground-water flow from the shallow subsurface to the mine workings. The fact that material in cross faults was saturated and dripping suggests that these cross faults may also contribute some flow to the mine. However, the lack of increased inflow rates where these cross-faults intersect Level 5 suggests that such contributions are relatively minor. Inflows throughout Levels 3 and 5 present the possibility that ground-water commonly circulates to depths of at least 500 feet throughout Elk Basin. However, the fact that the fault material was the primary source of inflowing water suggests that most of the ground-water flow at these depths, if it does occur elsewhere in the basin, is likely localized within map-scale fault zones such as the Standard fault. The mine workings might allow ground water to circulate far deeper in the Standard fault than it would naturally, by providing a drain and drawing water down to the tunnel elevations. The installation of monitoring wells would be required to further characterize deeper ground-water flow in Elk Basin and the manner in which ground-water flows to the Standard Mine workings.

\section{Ground-Water Residence Times}

The ${ }^{3} \mathrm{H}$ and ${ }^{3} \mathrm{He}$ data along with measured $\delta^{18} \mathrm{O}$ and $\delta^{2} \mathrm{H}$ values provide important information on ground-water residence times within the Standard Mine and surrounding area. Water recharged prior to the early 1950 s (prebomb water) would have had a ${ }^{3} \mathrm{H}$ concentration $<0.5 \mathrm{TU}$ in the year 2006. Because measured ${ }^{3} \mathrm{H}$ concentrations were $\geq 6.61 \mathrm{TU}$, all samples were composed partly or completely of water recharged after the early 1950s (postbomb water). Mean annual precipitation ${ }^{3} \mathrm{H}$ concentrations were computed from monthly and quarterly precipitation ${ }^{3} \mathrm{H}$ data for the period 1970 to 2006 at Salt Lake City, Utah, and Albuquerque, N. Mex., the two cities closest to the site with extended precipitation ${ }^{3} \mathrm{H}$ records (fig. 41). Both records are shown because it is uncertain which record is more representative of precipitation at the site. Concentrations for 
years with no data were estimated on the basis of correlations with complete records from other cities as described by Manning and others (2005). Precipitation ${ }^{3} \mathrm{H}$ concentrations decayed to 2006 levels are also shown in fig. 41. Tritium concentrations for samples in this study were similar to expected current concentrations in precipitation recharged within the past $35 \mathrm{yr}(5-15 \mathrm{TU})$, suggesting that, if the sampled waters were unmixed, they were $<35 \mathrm{yr}$ old. Apparent ${ }^{3} \mathrm{H} /{ }^{3} \mathrm{He}$ ages further constrain ground-water residence times: if sampled waters again were unmixed, they were $<9$ years old and most were $<1$ yr old.

However, actual ground-water ages can be considerably older than apparent ${ }^{3} \mathrm{H} /{ }^{3} \mathrm{He}$ ages for samples that are mixtures of postbomb and prebomb water, and such mixing cannot be ruled out on the basis of ${ }^{3} \mathrm{H}$ concentration or apparent ${ }^{3} \mathrm{H} /{ }^{3} \mathrm{He}$ age alone. Potential mixing can be evaluated by comparing computed initial ${ }^{3} \mathrm{H}$ concentrations (measured ${ }^{3} \mathrm{H}+$ measured ${ }^{3} \mathrm{He}_{\text {trit }}$; table 4) with precipitation ${ }^{3} \mathrm{H}$ concentrations at the apparent time of recharge (fig. 42). Tritium concentrations in precipitation vary seasonally, but initial ${ }^{3} \mathrm{H}$ values are commonly compared with mean annual concentrations in precipitation (fig. 42) because dispersion along ground-water flow pathways is expected to erase seasonal signals in water $>1 \mathrm{yr}$ old. The three samples with apparent ages $>1 \mathrm{yr}$ all plot close to the Salt Lake City record (fig. 42), suggesting that this record represents precipitation at the site better than the Albuquerque record. Initial ${ }^{3} \mathrm{H}$ values from Handcart Gulch in Park County in the Front Range, the only other alpine site in Colorado where extensive ${ }^{3} \mathrm{H} /{ }^{3} \mathrm{He}$ ground-water age data have been collected, are also more consistent with the Salt Lake City record than the Albuquerque record (Manning and Caine, 2007). The fact that these three samples do not plot below either record suggests that they contained little or no prebomb water and that the apparent age closely approximates the true mean age.

Samples with apparent ages $<1$ yr mostly plot below the Salt Lake City record and closer to the Albuquerque record. There are three possible explanations: these samples contained some prebomb water; the Albuquerque record better represents precipitation at the site; or these samples were affected by seasonal variations in precipitation ${ }^{3} \mathrm{H}$ concentrations. The first explanation is unlikely. It is difficult to imagine a groundwater flow configuration for the site area that would consistently produce large fractions of prebomb water in samples with the youngest apparent ages but no prebomb water in samples with older apparent ages. Further, we are not aware of any published ground-water age data sets that show evidence of such a mixing pattern. The second explanation is also unlikely, given how well the three samples with apparent ages $>1$ yr match the Salt Lake City record. The third explanation is the most likely. Quarterly precipitation ${ }^{3} \mathrm{H}$ concentrations for Albuquerque, N. Mex., from 1997 to 2002 (the final five years that data were collected at this station) show a seasonal cycle in which concentrations are higher in winter and spring and lower in summer and fall (fig. 43). This pattern is common throughout North America. If the samples with apparent ages

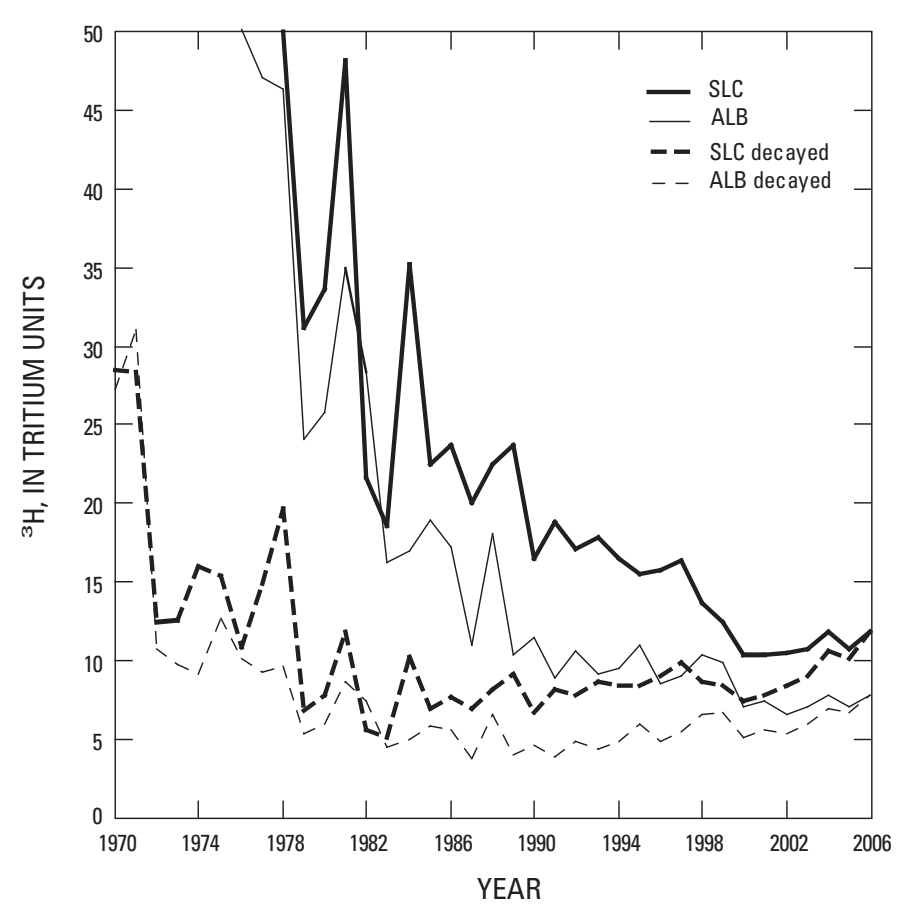

Figure 41. Precipitation ${ }^{3} \mathrm{H}$ records for Salt Lake City, Utah (SLC), and Albuquerque, N. Mex. (ALB). Precipitation tritium concentrations decayed to 2006 levels (SLC decayed and ALB decayed) are also shown.

$<1 \mathrm{yr}$ contained a large component of water only weeks to months old, then they contained a large component of summer precipitation having ${ }^{3} \mathrm{H}$ concentrations below the annual mean, thus explaining their low initial ${ }^{3} \mathrm{H}$ concentrations. The ${ }^{3} \mathrm{H}$ and He data therefore suggest that much of the ground water in the Standard Mine vicinity is extremely young and has residence times of weeks or months rather than years.

The spatial distribution of ${ }^{3} \mathrm{H}$ concentration is consistent with much of the water at the site being $<1 \mathrm{yr}$ old. The aboveground samples with the four highest ${ }^{3} \mathrm{H}$ concentrations are from four of the five locations where the oldest water was expected on the basis of either field parameters and observations or the fact that the sampled water discharged from a mine tunnel (fig. 36). More important, ${ }^{3} \mathrm{H}$ concentrations in underground samples generally increased with overburden thickness (fig. 40). Both of these trends suggest that older samples generally have higher ${ }^{3} \mathrm{H}$ concentrations than younger samples. All ${ }^{3} \mathrm{H}$ samples were collected in late summer. A positive correlation between ${ }^{3} \mathrm{H}$ concentration and age is therefore consistent with much of the water at the site being months old. Younger samples containing mostly water $<2$ months old would contain a larger fraction of summer rain and thus have lower ${ }^{3} \mathrm{H}$ concentrations (fig. 43). Older samples containing mostly water $>2$ months old would contain a larger fraction of spring snowmelt and thus have higher ${ }^{3} \mathrm{H}$ concentrations. 


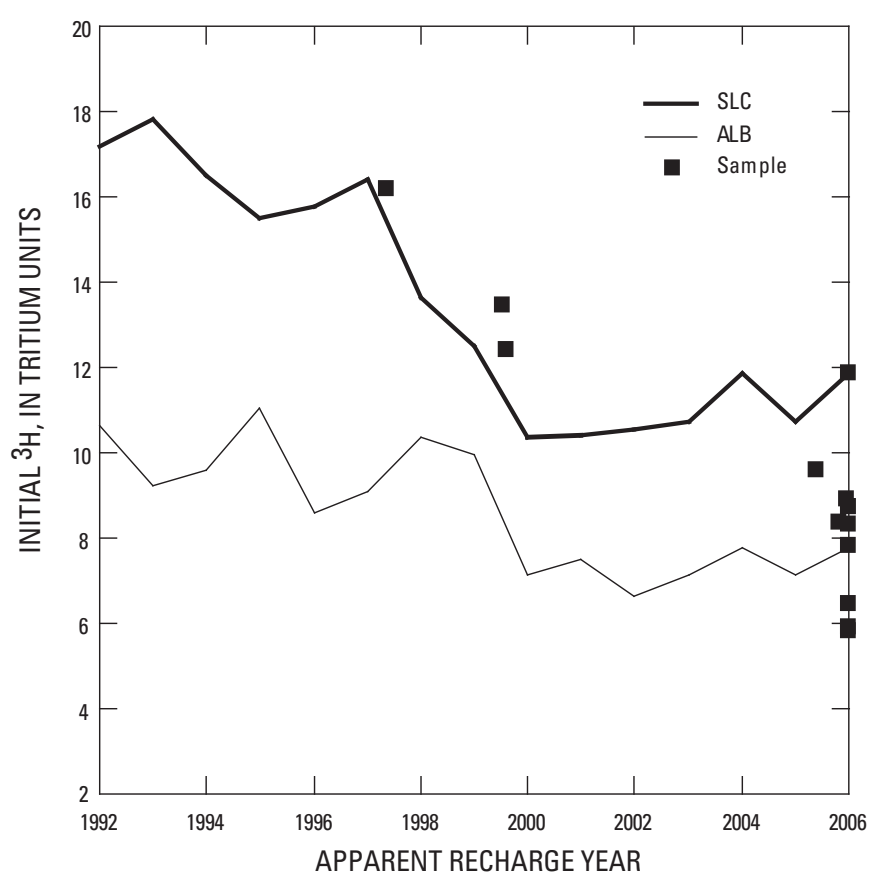

Figure 42. Initial ${ }^{3} \mathrm{H}$ concentration (measured ${ }^{3} \mathrm{H}+$ measured ${ }^{3} \mathrm{He}_{\text {trit }}$ ) in samples plotted versus apparent recharge year (determined from apparent ${ }^{3} \mathrm{H} /{ }^{3} \mathrm{He}$ age). Precipitation ${ }^{3} \mathrm{H}$ records for Salt Lake City, Utah (SLC), and Albuquerque, N. Mex. (ALB) are also shown.

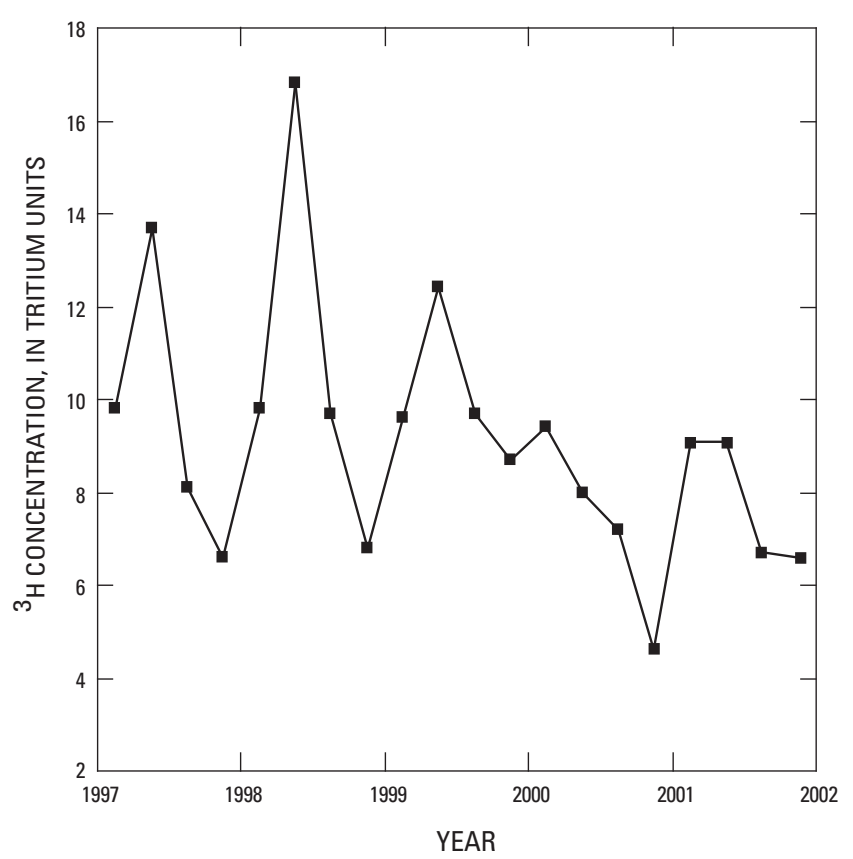

Figure 43. Quarterly ${ }^{3} \mathrm{H}$ concentration in precipitation at Albuquerque, N. Mex., 1997-2002.
If instead the youngest water at the site were about 1 yr old (recall that the uncertainty in the apparent ${ }^{3} \mathrm{H} /{ }^{3} \mathrm{He}$ age is $\pm 1 \mathrm{yr}$ ), then older samples would have ${ }^{3} \mathrm{H}$ concentrations similar to or lower than the younger samples (fig. 41) - if the oldest water at the site were $<10 \mathrm{yr}$ old (as suggested by the maximum apparent age of $9 \mathrm{yr}$ at Redwell spring 2).

Another important feature of the underground ${ }^{3} \mathrm{H}$ distribution is that the concentration decreased from 14.65 TU at Level 5 site 2 in the middle of the tunnel to 11.95 TU at Level 5 site 1 near the end of the tunnel, which is the reverse of the general trend of ${ }^{3} \mathrm{H}$ concentration increasing with overburden thickness (and age). It is possible that water at site 1 was younger than water at site 2 . However, no shafts connect Level 5 to higher tunnels or to the surface (fig. 4), and thus no obvious fast-flow pathways preferentially connect site 1 to the surface. Furthermore, specific conductance is higher at site 1 than at site 2 , and specific conductance is apparently positively correlated with age in waters with circumneutral pH (fig. 14B). Therefore, a more likely explanation is that water at site 1 was indeed older than water at site 2 , but its ${ }^{3} \mathrm{H}$ concentration was lower because its age was $\geq 1$ yr. Assuming that the Salt Lake City precipitation ${ }^{3} \mathrm{H}$ record is representative of the site, ground water with an age of $1-10 \mathrm{yr}$ should have a ${ }^{3} \mathrm{H}$ concentration of 8-12 TU (fig. 41). The sample at site 2 had a ${ }^{3} \mathrm{H}$ concentration above this range (14.65 TU), suggesting that it contained a substantial fraction of snowmelt water (water 2-4 months old). The sample at site 1 had a ${ }^{3} \mathrm{H}$ concentration within this range (11.95 TU), consistent with being 1-10 yr old.

The $\delta^{18} \mathrm{O}$ and $\delta^{2} \mathrm{H}$ data are also consistent with much of the water at the site being $<1 \mathrm{yr}$ old. Seasonal variations in $\delta^{18} \mathrm{O}$ and $\delta^{2} \mathrm{H}$ were more muted at the Level 1 portal than at Elk Creek (fig. 32). This lesser variation is expected given that ground water is generally older than creek water, much of which resides only hours to days (if at all) in the groundwater system. However, the fact that $\delta^{18} \mathrm{O}$ and $\delta^{2} \mathrm{H}$ values did vary seasonally at the Level 1 portal means that the portal discharge must have contained an appreciable fraction of water $<1 \mathrm{yr}$ old. If all portal discharge were $>1 \mathrm{yr}$ old, such seasonal isotopic variations (particularly of those isotopes that closely track seasonal variations in precipitation) would be unlikely given natural dispersion in the ground-water system, and $\delta^{18} \mathrm{O}$ and $\delta^{2} \mathrm{H}$ values would remain relatively constant throughout the year. $\delta^{18} \mathrm{O}$ and $\delta^{2} \mathrm{H}$ data from the Level 1 portal therefore also suggest that a large mine pool extending above the elevation of Level 1 does not exist in the Standard Mine. If such a large reservoir of water did exist, most ground water entering into the mine presumably would reside within the mine for well over one year. The substantial seasonal variations in $\delta^{18} \mathrm{O}$ and $\delta^{2} \mathrm{H}$ suggest that such is not the case. Furthermore, the apparent ${ }^{3} \mathrm{H} /{ }^{3} \mathrm{He}$ age for the sample collected just inside the portal at Level 1 site 2 was 0.6 yr. This apparent age could be erroneously young owing to unseen gas exchange inby the collapse where the sample was collected. However, such gas exchange would require 
that the mine tunnel be filled largely with air inby this collapse, a requirement that is inconsistent with the mine being flooded inby the collapse (in other words, with a large mine pool extending above Level 1).

Measured $\delta^{18} \mathrm{O}$ and $\delta^{2} \mathrm{H}$ values for underground samples generally decreased with overburden thickness (fig. 35), and elevation changes at the ground surface above can account for only a small fraction of this decrease (see Results section above). This correlation with overburden thickness is consistent with samples from shallower tunnel sites that contain larger fractions of summer rain (water $<2$ months old) and samples from deeper tunnel sites that contain larger fractions of snowmelt water (water 2-4 months old). Again, if all ground water entering Levels 3 and 5 were $>1$ yr old, $\delta^{18} \mathrm{O}$ and $\delta^{2} \mathrm{H}$ values should vary little throughout the tunnels owing to natural dispersion. As with ${ }^{3} \mathrm{H}$, the general trend reversed between Level 5 site 2 and Level 5 site 1 (fig. 35); $\delta^{18} \mathrm{O}$ and $\delta^{2} \mathrm{H}$ were heavier rather than lighter with greater overburden thickness. Samples from Redwell spring 2 and the Level 1 portal at base flow (EC-MSTD1-04, collected in February) provide the best estimation of the $\delta^{18} \mathrm{O}$ of water that is $1-10 \mathrm{yr}$ old, because the former had an apparent ${ }^{3} \mathrm{H} /{ }^{3} \mathrm{He}$ age in this range (the only such sample for which $\delta^{18} \mathrm{O}$ was measured) and the latter was presumably the oldest of the other samples for which $\delta^{18} \mathrm{O}$ was measured. $\delta^{18} \mathrm{O}$ values for these two samples (table 3 ) suggest that water $1-10 \mathrm{yr}$ old had a $\delta^{18} \mathrm{O}$ of approximately -15.9 to -16.2 per mil. Water at Level 5 site 2 had a $\delta^{18} \mathrm{O}$ well below this range $(-17.02$ per mil) and likely contained a large fraction of snowmelt water (water 2-4 months old). Water at site 1 had a $\delta^{18} \mathrm{O}$ of -16.08 per mil, consistent with water $1-10$ yr old.

\section{Controls on Ground-Water Chemistry}

\section{Controls on Metal Concentrations}

The presence of sulfide-rich mineralized rock is the primary control on dissolved metal concentrations and $\mathrm{pH}$ in ground water in the Standard Mine vicinity. Ground-water $\mathrm{pH}$ was consistently low and $\mathrm{Zn}, \mathrm{Pb}, \mathrm{Cd}, \mathrm{Cu}$, and $\mathrm{Mn}$ concentrations were consistently elevated at aboveground sample sites located within or immediately downgradient of areas where sulfides are abundant (figs. 10, 20-24), namely the Standard fault, the Elk Lode portal, and the breccia pipe in Redwell Basin. Metal concentrations in underground samples in the Standard Mine, which follows mineralized rock in the Standard fault, were also generally higher than in aboveground samples located outside of the sulfide-rich areas (figs. 28, 20-24). Metal concentrations in discharge from the Level 1 portal were among the highest measured in Elk Basin, and the time-series data indicate that they remained so throughout the year (fig. 17). The $\mathrm{pH}$ at underground sites and at the Level 1 portal was as low as 3.3 (fig. $9 A$ and $14 A$ ), whereas samples from locations outside sulfide-rich areas were consistently circumneutral.
Whether or not sulfide-rich rock occurs in waste-rock piles appears to be another major control on ground-water metal concentrations and $\mathrm{pH}$. Spring 1 and the Level 2 waste rock site had the lowest $\mathrm{pH}$ and, typically, the highest metal concentrations, and both are sites where the sampled water discharged directly from waste rock. The waste-rock piles at these sites are associated with the Standard Mine workings (fig. 5). The interior of the piles could not be observed, and it is possible that they contain rock that is more sulfide rich than at other sites. However, the fact that the waste rock came from the Standard Mine means that its sulfide content should be similar to that of mineralized rock still in place within the mine. More likely, waste-rock piles allow greater water-rock interaction than sulfide-bearing rocks still in place because the piles are a porous medium rather than a fractured-rock medium; thus, the total surface area per unit volume of rock where water can directly contact and react with minerals is far greater. Furthermore, the exposed mineral surfaces may be fresher (tens of years old), and thus more reactive, than those along well established flow pathways in the native ground (at least thousands of years old). It is also possible that more oxygen is available for sulfide oxidation because saturated portions of the waste-rock piles may be thin and highly transient, allowing considerable oxygen exchange between ground-water and air. Regardless of the actual controlling mechanism, waste-rock piles appear to be the source of some of the lowest$\mathrm{pH}$ and most metal-rich ground water near the Standard Mine.

\section{Controls on Major Ion Chemistry}

As with metal concentrations, major ion concentrations are controlled in part by the presence of sulfide-rich rock, and whether or not this rock is in waste-rock piles. Ca and $\mathrm{SO}_{4}$ concentrations and specific conductance were commonly elevated where $\mathrm{pH}$ was low and metal concentrations were high (figs. 11, 18, and 19). Further, samples from spring 1 (waste rock discharge) and the Level 2 waste rock site, which had the lowest $\mathrm{pH}$ values and typically the highest metal concentrations, also had the highest specific conductance values (fig. 11). Major ion concentrations were probably high in areas with abundant sulfides because the low $\mathrm{pH}$ caused by sulfide dissolution increased the dissolution of other minerals.

However, major ion concentrations are apparently controlled by another factor as well: residence time. Specific conductance and $\mathrm{Ca}$ and $\mathrm{SO}_{4}$ concentrations in the underground samples all generally increased with overburden thickness (figs. $14 B$ and 27), which is presumably correlated with flow-pathway length and thus residence time. Major ion concentrations probably increase with increasing residence time owing to progressive dissolution of more easily dissolved minerals such as calcite and gypsum along ground-water flow pathways within the sedimentary rocks underlying most of the site, which have undergone only low-grade alteration. Note that, although the Standard fault zone contains abundant sulfides, the circumneutral $\mathrm{pH}$ of most of the underground samples suggests that the grade of alteration in the fault zone 
(or in much of the fault zone) was not high enough to remove all the carbonate. Residence time had little apparent influence on the $\mathrm{pH}$ and metal concentrations. Metal concentrations did not systematically increase and $\mathrm{pH}$ did not systematically decrease with overburden thickness in the underground samples (figs. 14A and 28). Further, metal concentrations were high and $\mathrm{pH}$ was low in older aboveground samples (for example, at Redwell spring 2) and in presumably very young aboveground samples (for example, pit 5).

Specific conductance, $\mathrm{Ca}$, and $\mathrm{SO}_{4}$ were all somewhat elevated in the area of diffuse spring discharge south of the Level 1 portal where springs 8A, 8B, and 12 are located (figs. 11, 18, and 19). Older ground water in this area could produce higher specific conductance. This speculation is consistent with the probable high excess air levels at springs 8A and 8B (see Results section above), but inconsistent with the apparent age at spring 12 of only $0.2 \mathrm{yr}$ (fig. 37). It could also be the result of mineralogical differences between the Wasatch Formation, which underlies this area south of the Level 1 portal, and the Ohio Creek Formation, which underlies the rest of the sampled portion of Elk Basin (spring 9 excepted; fig. 8). The cause of elevated major ion concentrations in this part of the study site remains unclear.

\section{Controls on Standard Mine Water Chemistry}

The likely sources of $\mathrm{Zn}, \mathrm{Pb}, \mathrm{Cd}$, and $\mathrm{Cu}$ in ground water in and near the Standard Mine are sphalerite (ZnS), galena $(\mathrm{PbS})$, and chalcopyrite $\left(\mathrm{CuFeS}_{2}\right)$, which are commonly observed in mineralized zones in the Standard fault and in waste-rock piles associated with the Standard Mine. Sphalerite is the likely source of $\mathrm{Cd}$ and $\mathrm{Zn}$. Cadmium can substitute for $\mathrm{Zn}$ in the sphalerite crystal lattice because its atomic size is similar to that of $\mathrm{Zn}$, so sphalerite regularly contains small percentages of $\mathrm{Cd}$. The $\mathrm{Zn} / \mathrm{Cd}$ ratio was relatively constant in the sampled waters (fig. 44). Ratios were generally in the range of 100-300, similar to ratios measured by Plumlee and others (2005) in sphalerite in the Questa porphyry molybdenum deposit in northern New Mexico, further supporting sphalerite as the source of $\mathrm{Cd}$. Manganese enrichment is common in porphyry-type molybdenum deposits such as that underlying Mt. Emmons. Siderite $\left(\mathrm{FeCO}_{3}\right)$ is commonly associated with such deposits and is a potential source of Mn because Mn commonly substitutes for Fe. Siderite is therefore a possible source of $\mathrm{Mn}$ in ground water near the Standard Mine, although the presence of siderite in and near the Standard fault was not confirmed.

The location within the flow system where these metals become dissolved in the ground water (the source location) remains unknown. To evaluate possible mixing among different sampled waters, zinc was plotted against $\mathrm{SO}_{4}$ (fig. 45). Zinc and $\mathrm{SO}_{4}$ were chosen because they were among the most abundant constituents in the sampled waters and because, when waters of differing $\mathrm{pH}$ are mixed, neither will precipitate unless the $\mathrm{pH}$ rises above about 8 . Level 1 portal discharge had the highest concentrations of $\mathrm{Zn}$ and

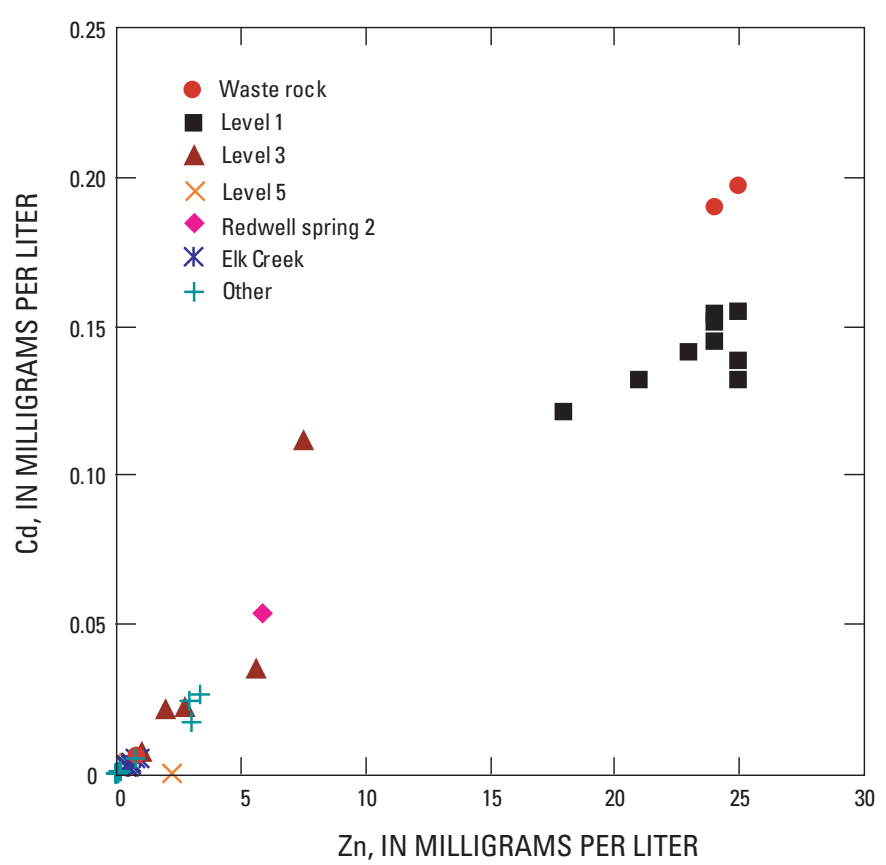

Figure 44. Zinc concentration at all sample sites plotted versus cadmium concentration.

$\mathrm{SO}_{4}$ of all waters sampled except the waste-rock waters from spring 1 and the Level 2 waste rock site (fig. 45). Thus, none of the sampled waters, other than those from spring 1 and the Level 2 waste rock site, could have been the primary source of metals in Level 1 discharge. It is emphasized that sulfides in the immediate vicinity of Levels 3 and 5 were not the primary source of metals in Level 1 discharge. Although it is chemically possible that the sampled waste-rock waters were the source, it is highly unlikely because the volume of water observed discharging from the waste rock (and thus, presumably, flowing through the waste rock) was small in comparison to the volume of water discharging from Level 1. In addition to $\mathrm{Zn}$ and $\mathrm{SO}_{4}$, concentrations of other constituents (for example, $\mathrm{Cd}$ and $\mathrm{Ca}$ ), were greater in Level 1 discharge than in waters from Levels 3 and 5 (appendix 3). Measured ${ }^{87} \mathrm{Sr} /{ }^{86} \mathrm{Sr}$ ratios were also higher in Level 1 discharge than in samples from Levels 3 and 5 (fig. 31). Therefore, in short, the primary source location of metals in Level 1 discharge was not found in this study.

Two types of sources are possible for metals in Level 1 discharge. The first is an unseen mineralized zone that is substantially richer in ore minerals than any encountered in the observable portions of the Standard fault. Unsampled water draining this zone could be more metal-rich than water sampled in Levels 3 and 5 and could mix with water similar to that sampled in Levels 3 and 5 to form Level 1 discharge. Such a zone would need to be located below Level 3 or farther back into the mountain than the ends of the Levels 3 and 5 tunnels. The fact that Level 1 extends an unknown distance under the 


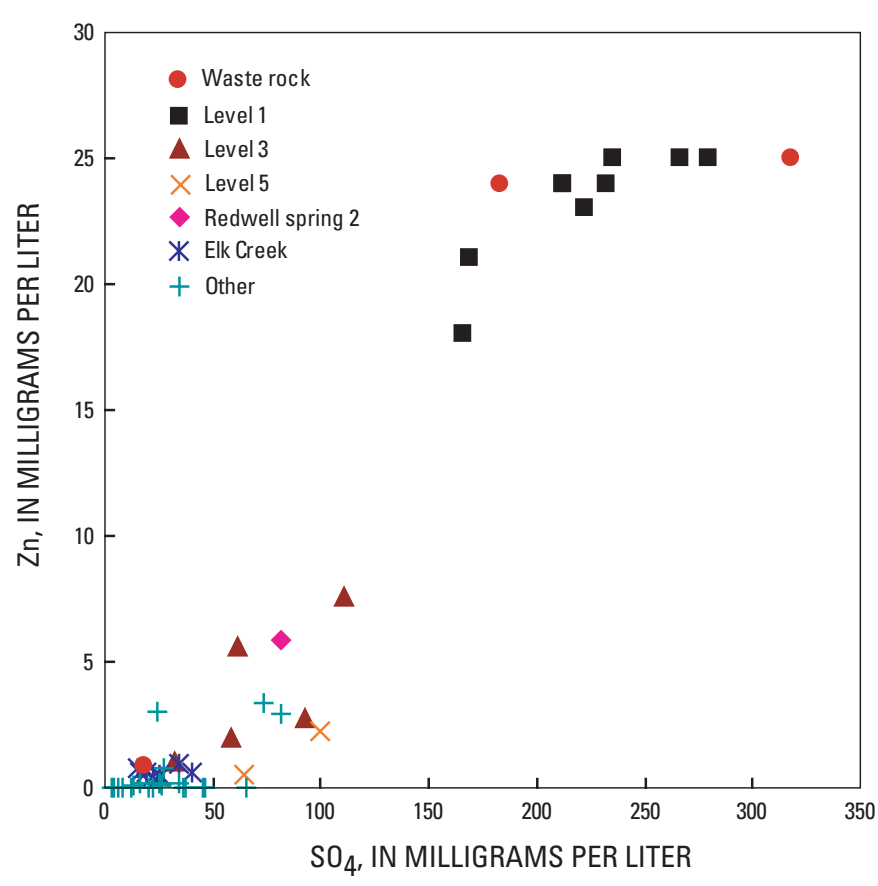

Figure 45. Sulfate concentration at all sample sites plotted versus zinc concentration.

ridge between Elk and Redwell Basins presents the possibility that mineralization associated with the breccia pipe in Redwell Basin could be the source. However, this mineralized area is the source of metals at Redwell spring 2, and concentrations of $\mathrm{Zn}$ and $\mathrm{SO}_{4}$ at Redwell spring 2 are clearly too low to suggest that this same area is the source of metals in Level 1 discharge (fig. 45).

The second possible type of source zone contains rock with the same degree of mineralization as that observed but under conditions more favorable for the dissolution of metals. Waters similar to those observed in Levels 3 and 5 could flow through such a zone and acquire higher metal concentrations to become similar to Level 1 discharge. Given the high metal concentrations observed in the waste-rock waters, a reasonable possibility is that the mineralized rock in a source zone of this type would form a porous medium, such as an extensive pile of rubble or debris within the mine workings below Level 3. As explained above, several factors might allow rock in such a porous medium to produce metal concentrations higher than those observed in Levels 3 and 5. Determining which type of source is responsible for the metals in Level 1 discharge is not possible without further investigation.

\section{Controls on Elk Creek Water Chemistry}

The patterns of seasonal variations in field parameters, chemical constituents, and stable isotopes were very similar in Level 1 discharge and in Elk Creek (figs. 9, 16, 17, and
32), suggesting that Level 1 discharge may be the primary source of metals in Elk Creek. At the time of preparation of this report, flow data from September 2006 were the only flow data available for the Level 1 portal and for Elk Creek (Christina Progess, U.S. Environmental Protection Agency, oral communication, September 2007). A flow rate of 0.021 cubic feet per second (cfs) was measured on September 13, 2006, at the Level 1 portal site, and a flow rate of $1.29 \mathrm{cfs}$ was measured on September 12, 2006, approximately $200 \mathrm{ft}$ downstream from the Elk Creek sample site (no tributaries enter the creek between the sample site and the flow measurement location). These flow rates were used in combination with metal concentrations measured in the summer of 2006 (figs. 20-24) to calculate mass fluxes for $\mathrm{Zn}, \mathrm{Pb}, \mathrm{Cd}, \mathrm{Cu}$, and $\mathrm{Mn}$ at the Level 1 portal and at the Elk Creek sample site for the times when flow data were collected. Calculated mass fluxes are only estimates because the metal concentrations used were collected several weeks before the flow measurements. Estimated mass fluxes for the Level 1 portal are $\mathrm{Zn}$, 14 milligrams per second (mg/s); Pb, $0.39 \mathrm{mg} / \mathrm{s} ; \mathrm{Cd}$, $0.090 \mathrm{mg} / \mathrm{s} ; \mathrm{Cu}, 0.13 \mathrm{mg} / \mathrm{s}$; and Mn, $6.0 \mathrm{mg} / \mathrm{s}$. Estimated mass fluxes for the Elk Creek sample site are Zn, $16 \mathrm{mg} / \mathrm{s}$; $\mathrm{Pb}, 0.015 \mathrm{mg} / \mathrm{s}$; Cd, $0.080 \mathrm{mg} / \mathrm{s} ; \mathrm{Cu}, 0.073 \mathrm{mg} / \mathrm{s}$; and Mn, $0.47 \mathrm{mg} / \mathrm{s}$. Mass fluxes at the Elk Creek sample site are approximately the same as $(\mathrm{Zn}$ and $\mathrm{Cd})$ or lower than $(\mathrm{Pb}, \mathrm{Cu}$, and $\mathrm{Mn}$ ) those at the Level 1 portal, consistent with Level 1 discharge being the primary source of metals in Elk Creek.

A prominent feature of the time-series data is that $\mathrm{pH}$ dropped and metals concentrations rose during the early stages of spring runoff (figs. 9 and 17) in Elk Creek and in Level 1 discharge. Rapid infiltration of snowmelt water in the spring therefore must have mobilized a low-pH, metal-rich component of ground water in and near the Standard Mine. $\delta^{18} \mathrm{O}$ and $\delta^{2} \mathrm{H}$ values became heavier during spring runoff at both sample sites (fig. 32) before dropping back down to lighter values representative of spring snowmelt. The stable isotope data suggest that the seasonal low-pH, metal-rich component (spring flush water) contained a large fraction of summer and fall rainwater. One hypothesis is that the spring flush water originated from a location where ground-water flow ceased as water levels fell over the winter, such that water recharged mainly in the late summer or fall became immobile. Reasonable candidate locations include pockets of high capillarity material (finegrained fault gouge or intensely microfractured rock) within the seasonally saturated zone (unsaturated in the winter, saturated in spring) near the ground surface or within parts of the mine workings that become saturated only during spring high flow. Immobilized water in these pockets could have acquired particularly low $\mathrm{pH}$ values and high metal concentrations during the winter given the lack of flow, high mineral surface contact area, and high oxygen availability (the pockets would be surrounded by air). One complication for this hypothesis is that increases in concentrations of $\mathrm{Zn}, \mathrm{Cd}$, and $\mathrm{Mn}$ in Level 1 discharge were minor to nonexistent during the early stages of spring runoff, suggesting that the spring flush water was high 
in $\mathrm{Pb}$ and $\mathrm{Cu}$, but not in $\mathrm{Zn}, \mathrm{Cd}$, and $\mathrm{Mn}$. A reason for this discrepancy in the metal concentrations is not clear.

Although increases in $\mathrm{Zn}, \mathrm{Cd}$, and $\mathrm{Mn}$ concentrations during spring runoff were minor to nonexistent in Level 1 discharge, concentrations of these three metals increased sharply in Elk Creek. One possible explanation is that the Level 1 portal water (assuming it is the source of these metals in Elk Creek) simply composed a larger fraction of Elk Creek water during spring runoff. However, this possibility seems unlikely given the presumed increase in overland flow to the creek owing to rapid snowmelt in the spring. Another possible explanation is that the slight drop in $\mathrm{pH}$ of Elk Creek water during spring runoff was sufficient to dissolve $\mathrm{Zn}, \mathrm{Cd}$, and Mn sorbed to suspended sediment particles under higher $\mathrm{pH}$ conditions. This effect would not have been observed at the Level 1 portal because portal discharge is essentially free of suspended sediment all year. A third possible explanation is that the increase in suspended sediment in Elk Creek during spring runoff resulted in an increase in colloids smaller than $0.45 \mu \mathrm{m}$, sufficiently small to pass through the sample filters used in this study (Kimball and others, 1995). Zinc, Cd, and Mn sorbed to such colloids could have caused an apparent increase in the dissolved concentrations of these metals in Elk Creek samples but not in portal discharge samples, which were free of suspended sediment. Further study would be required to better understand the potentially complex processes controlling metal concentrations in Elk Creek.

\section{Conclusions}

1. No clear correlation was observed between natural ground-water discharge locations and map-scale faults and lithology. Surface observations and the location of ground-water discharge suggest that simple topography, rather than large-scale geologic features, primarily controls the occurrence and flow of shallow ground water in Elk Basin.

2. Discrete inflows from cross faults or other features were not observed in Levels 3 and 5 of the Standard Mine. Instead, water entered the mine as persistent dripping from gouge and breccia within the Standard fault, which both tunnels follow. Therefore, the Standard fault itself is probably the main pathway of ground-water flow from the shallow subsurface to the mine workings.

3. Apparent tritium/helium-3 ground-water ages ranged from 0 to $9 \mathrm{yr}$, and the considerable majority were $<1 \mathrm{yr}$. The tritium data and computed initial tritium values (measured tritium plus measured tritiogenic helium-3) suggest that much of the ground water in the Standard Mine vicinity was weeks to months old rather than years old.

4. Tritium, $\delta^{18} \mathrm{O}$, and $\delta^{2} \mathrm{H}$ data from ground water entering into and discharge from the Standard Mine all displayed spatial and temporal patterns indicating that they were influenced by seasonal variations in their concentration in precipitation. These data therefore suggest that ground water entering into and discharging from the Standard Mine was largely composed of water $<1$ yr old. Short residence times for much of the water in the Standard Mine are consistent with the pronounced seasonal variations in geochemistry observed in Level 1 discharge. The short residence times are not consistent with a large mine pool that extends above the Level 1 tunnel.

5. The $\mathrm{pH}$ was consistently low and metal concentrations were consistently elevated in aboveground samples located within or immediately down-gradient of areas where sulfides are abundant, including the Standard fault, the Elk Lode portal, and the breccia pipe in Redwell Basin. Metal concentrations in underground samples from the Standard Mine, which follows mineralized rock in the Standard fault, were also generally higher than aboveground samples located outside of the sulfide-rich areas. Metal concentrations in Level 1 discharge were among the highest measured in Elk Basin. All of these observations suggest that the presence of sulfide-rich mineralized rock is the primary control on dissolved metal concentrations and $\mathrm{pH}$ in ground water in the Standard Mine vicinity.

6. Waste-rock piles exert another major control on metal concentrations and $\mathrm{pH}$. The lowest $\mathrm{pH}$ values and highest metal concentrations were typically observed in ground water discharging from waste-rock piles.

7. In addition to the control exerted by sulfide-rich bedrock, and waste rock piles, residence time also controlled major ion concentrations: higher specific conductance and major ion concentrations occur in older ground water.

8. Concentrations of many chemical constituents in addition to strontium isotope data indicate that the metals in sampled waters cannot be the primary source of metals in Level 1 discharge. Therefore, the primary source location of metals in Level 1 discharge was not found in this study. Possible source locations include either a zone of rock more highly mineralized than any observed in this study or a zone of mineralized rock similar to that observed but in a form that is highly conducive to metals dissolution, such as rubble or debris in the mine workings. Either source must be located below Levels 3 and 5 or farther back into the mountainside than the ends of Levels 3 and 5 .

9. The patterns of seasonal variations in field parameters, chemical constituents, and stable isotopes in Level 1 discharge and Elk Creek are very similar. Estimated metal fluxes in Elk Creek in September 2006 are similar to or less than those in Level 1 discharge. Both of these observations are consistent with Level 1 discharge being the primary source of metals in Elk Creek. 
10. A prominent feature of the time-series data from both Level 1 discharge and Elk Creek was a "spring flush" during which $\mathrm{pH}$ dropped and metal concentrations rose in the early stages of spring runoff. $\delta^{18} \mathrm{O}$ and $\delta^{2} \mathrm{H}$ data along with the fact that the flush occurred during spring high flow suggest that the spring flush water originated from a shallow portion of the ground-water flow system or within the mine workings themselves. Reasonable candidate locations include pockets of high capillarity material (fine-grained fault gouge or intensely microfractured rock) within the seasonally saturated zone (unsaturated in winter, saturated in spring) near the ground surface or within portions of the mine workings that become saturated only during spring high flow.

\section{References}

Adams, A.I., Goff, F., and Counce, D., 1995, Chemical and isotopic variations of precipitation in the Los Alamos region, New Mexico: Los Alamos National Laboratory Report LA-12895-MS, 35 p.

Ball, J.W., and Nordstrom, D.K., 1991, User's manual for WATEQ4F, with revised thermodynamic data base and test cases for calculating speciation of major, trace, and redox elements in natural waters: U.S. Geological Survey OpenFile Report 91-183, 189 p.

Barringer, J.L., and Johnsson, P.A., 1989, Theoretical considerations and a simple method for measuring alkalinity and acidity in low-pH waters by Gran titration: U.S. Geological Survey Water-Resources Investigations Report 89-4029, $35 \mathrm{p}$.

Bayer, Reinhold, Schlosser, P., Bönisch, G., Rupp, H., Zaucker, F., and Zimmek, G., 1989, Performance and blank components of a mass spectrometric system for routine measurement of helium isotopes and tritium by the ${ }^{3} \mathrm{He}$ ingrowth method, in Sitzungsberichte der Heidelberger Akademie der Wissenschaften, Mathematisch-naturwissenschaftliche Klasse, vol. 5: Heidelberg, Springer Verlag, p. 241-279.

Briggs, P.H., 2002, The determination of twenty-seven elements in aqueous samples by inductively coupled plasmaatomic emission spectrometry, in Taggart, J.E., Jr., ed., Analytical methods for chemical analysis of geologic and other materials, U.S. Geological Survey: U.S. Geological Survey Open-File Report 02-223, chap. F, 11 p.

Colorado Division of Reclamation, Mining, and Safety, 2007, Draft underground assessment, Standard Mine Superfund site, Gunnison County, Colorado: Denver, Colorado, 37 p.
Coplen, T.B., Herczeg, A.L., and Barnes, C., 2000, Isotope engineering-Using stable isotopes of the water molecule to solve practical problems, in Cook, P.G., and Herczeg, A.L., eds., Environmental tracers in subsurface hydrology: Boston, Kluwer Academic Publishers, p. 349-377.

Donahue, D.J., Linick, T.W., and Jull, A.J., 1990, Isotope-ratio and background corrections for accelerator mass spectrometry radiocarbon measurements: Radiocarbon, v. 32, p. $135-142$.

Epstein, Samuel, and Mayeda, T., 1953, Variation of ${ }^{18} \mathrm{O}$ content of waters from natural sources: Geochimica et Cosmochimica Acta, v. 4, p. 213-224.

Faure, Gunter, 1986, Principles of isotope geology (2d ed.): New York, John Wiley, 589 p.

Gaskill, D.L., Godwin, L.H., and Mutschler, F.E., 1967, Geologic map of the Oh-Be-Joyful quadrangle, Gunnison County, Colorado: U.S. Geological Survey Geologic Quadrangle Map GQ-578, scale 1:24,000.

Kalin, R.M., 2000, Radiocarbon dating of groundwater systems, in Cook, P.G., and Herczeg, A.L., eds., Environmental tracers in subsurface hydrology: New York, New York, Kluwer Academic Publishers, p. 111-144.

Kendall, Carol, and Coplen, T.B., 1985, Multisample conversion of water to hydrogen by zinc for stable isotope determination: Analytical Chemistry, v. 57, p.1437-1440.

Kimball, B.A., Callender, E., and Axtmann, E.V., 1995, Effects of colloids on metal transport in a river receiving acid mine drainage, upper Arkansas River, Colorado, U.S.A.: Applied Geochemistry, v. 10, p. 285-306.

Kipfer, Rolf, Aeschbach-Hertig, W., Peeters, F., and Stute, M., 2002, Noble gases in lakes and ground waters, in Porcelli, Donald, Ballentine, C.J., and Wieler, R., eds., Reviews in Mineralogy and Geochemsitry, v. 47, Noble gases in geochemistry and cosmochemistry: Chantilly, Virginia, Mineralogical Society of America, p. 615-700.

Kuehner, E.C., Alvarez, R., Paulsen, P.J., and Murphy, T.J., 1972, Production and analysis of special high-purity acids purified by sub-boiling distillation: Analytical Chemistry, v. 44, p. 2050-2056.

Lamothe, P.J., Meier, A.L., and Wilson, S.A., 2002, The determination of forty-four elements in aqueous samples by inductively coupled plasma-mass spectrometry, in Taggart, J.E., Jr., ed., Analytical methods for chemical analysis of geologic and other materials, U.S. Geological Survey: U.S. Geological Survey Open-File Report 02-223, chap. H, 13 p. 
Manning, A.H., and Caine, J.S., 2007, Groundwater noble gas, age, and temperature signatures in an alpine watershed-Valuable tools in conceptual model development: Water Resources Research, v. 43, W04404, doi:10.1029/2006WR005349.

Manning, A.H., and Solomon, D.K., 2004, Constraining mountain-block recharge to the eastern Salt Lake Valley, Utah, with dissolved noble gas and tritium data, in Hogan, J.F., Phillips, F.M., and Scanlon, B.R., eds., Groundwater recharge in a desert environment-The southwestern United States: Washington, D.C., American Geophysical Union, p. 139-158.

Manning, A.H., Solomon, D.K., and Thiros, S.A., 2005, ${ }^{3} \mathrm{H} /{ }^{3} \mathrm{He}$ age data in assessing the susceptibility of wells to contamination: Ground Water, vol. 43, p. 353-367.

Meier, A.L., Grimes, D.J., and Ficklin, W.H., 1994, Inductively coupled plasma-mass spectrometry-A powerful analytical tool for mineral resource and environmental studies [abs.], in Carter, L.M.H., Toth, M.I., and Day, W.C., eds., U.S. Geological Survey Research on Mineral Resources, 1994, Part A, Program and Abstracts, V.E. McKelvey Forum on Mineral and Energy Resources, 9th: U.S. Geological Survey Circular 1103-A, p. 67-68.

Mutschler, F.E., 1968, Geology of the Treasure Mountain dome and vicinity: Boulder, University of Colorado, Ph.D. dissertation, $240 \mathrm{p}$.

Plumlee, G.S., Lowers, H., Ludington, S., Koenig, A., and Briggs, P.H., 2005, Questa baseline and pre-mining groundwater quality investigation. 13. Mineral microscopy and chemistry of mined and unmined porphyry molybdenum mineralization along the Red River, New MexicoImplications for ground- and surface-water: U.S. Geological Survey Open-File Report 2005-1442, 95 p.

Plummer, L.N., Bexfield, L.M., Anderholm, S.K., Sanford, W.E., and Busenberg, E., 2004, Geochemical characterization of ground-water flow in the Santa Fe Group aquifer system, Middle Rio Grande Basin, New Mexico: U.S. Geological Survey Water Resources Investigations Report 03-4131, $395 \mathrm{p}$.

Sharp, J.E., 1978, A molybdenum mineralized breccia pipe complex, Redwell Basin, Colorado: Economic Geology, v. 73, p. 369-382.

Stookey, L.L., 1970, FerroZine-A new spectrophotometric reagent for iron: Analytical Chemistry, v. 42, p. 779-781.
Solomon, D.K., and Cook, P.G., 2000, ${ }^{3} \mathrm{H}$ and ${ }^{3} \mathrm{He}$, in Cook, P.G., and Herczeg, A.L., eds., Environmental tracers in subsurface hydrology: New York, New York, Kluwer Academic Publishers, p. 397-424.

Stute, Martin, and Schlosser, P., 2000, Atmospheric noble gases, in Cook, P.G., and Herczeg, A.L., eds., Environmental tracers in subsurface hydrology: New York, New York, Kluwer Academic Publishers, p. 349-377.

Syracuse Research Corporation, 2007, Baseline ecological risk assessment for the Standard Mine site, Gunnison County, CO: Denver, Colo., Syracuse Research Corp.

Theodorakos, P.M., d'Angelo, W.M., and Ficklin, W.H., 2002, Fluoride, chloride, nitrate, and sulfate in aqueous solution utilizing auto suppression chemically suppressed ion chromatography, in Taggart, J.E., Jr., ed., Analytical methods for chemical analysis of geologic and other materials, U.S. Geological Survey: U.S. Geological Survey Open-File Report 02-223, chapter V, 7 p.

Thomas, J.A., and Galey, J.T., Jr., 1982, Exploration and geology of the Mt. Emmons molybdenite deposits, Gunnison County, Colorado: Economic Geology, v. 77, p. 1085-1104.

To, T.B., Nordstrom, D.K., Cunningham, K.M., Ball, J.W., and McCleskey, R.B., 1999, New method for direct determination of dissolved $\mathrm{Fe}(\mathrm{III})$ concentrations in acid mine waters: Environmental Science and Technology, v. 33, p. 807-813.

Tweto, Ogden, and Sims, P.K., 1963, Precambrian ancestry of the Colorado mineral belt: Geological Society of America Bulletin, v. 74, p. 991-1014.

Verplanck, P.L., Wanty, R.B., Berger, B.R., Tuttle, M.L., Kimball, B.A., and Farmer, G.L., 2004, Hydrogeochemistry of an acidic, alpine watershed, Redwell Basin, Colorado, in Wanty, R.B., and Seal, R.R. II, eds., International Symposium on Water-Rock Interaction, 11th, Proceedings: London, Taylor and Francis, p. 1649-1653.

Wanty, R.B., Berger, B.R., Kimball, B.A., Verplanck, P.L., and Tuttle, M.L., 2003, Delineation of environmental tracts in mineralized areas using geologic criteria, in European Congress on Regional Geoscientific Cartography, 4th, Proceedings: Bologna, Italy, Servizio Geologoco, Sismico e Suoli.

Wanty, R.B., Verplanck, P.L., Kimball, B.A., Tuttle, M.L., Runkel, R.L., and Berger, B.R., 2004, Resolving natural and anthropogenic sources of solutes to a watershed from historic mining, in Wanty, R.B., and Seal, R.R. II, eds., International Symposium on Water-Rock Interaction, 11th, Proceedings: London, Taylor and Francis, p. 1659-1663. 


\section{Appendix 1. Sampling and Analysis Plan}


SAMPLING AND ANALYSIS PLAN

GEOHYDROLOGIC INVESTIGATIONS OF THE STANDARD MINE VICINITY GUNNISON COUNTY, COLORADO

\author{
May 30, 2006 \\ Prepared by: \\ Andrew Manning, Ph.D. \\ Phillip Verplanck, Ph. D. \\ U.S. Geological Survey \\ P.O. Box 25046, Mail Stop 964 \\ Denver, CO 80225
}




\section{Introduction}

This Sampling and Analysis Plan (SAP) describes ground- and surface-water sampling and analysis that will be conducted as part of a geohydrologic investigation of the Standard Mine site. Ground-water sampling will occur and surface-water sampling will begin during Summer 2006. Surface-water sampling will continue through Spring 2007.

\section{Problem Statement}

The U.S. Environmental Protection Agency (USEPA) has listed the Standard Mine in the Elk Creek drainage near Crested Butte, Colorado as a Superfund Site (Figure 1). Drainage from the Standard Mine enters Elk Creek, contributing loads of zinc, cadmium, copper and other metals. Elk Creek is a tributary to Coal Creek, which is part of the drinking-water supply for the town of Crested Butte. The Standard Mine is one of dozens of mines and prospects that cover both the north and south sides of Mount Emmons, but is among the few mine portals from which water continually drains. It has therefore become the focus of attention of concerned local citizens and the USEPA.

Decisions on remedial options will require an understanding of: (1) the source(s) of the high metal loads in ground-water discharge from the Standard Mine, and potentially other parts of the upper Elk Creek basin; (2) ground-water flow paths leading to, and in the vicinity of, the Standard Mine; and (3) the residence time of ground water following these flow paths. Ground-water residence time is particularly important because it controls the degree to which mine discharge volumes and chemistry will vary in response to the dramatic seasonal and climatic cycles characteristic of alpine settings. These variations are a critical factor in formulating remediation strategies and treatment plant design. The geohydrologic investigation is designed to gain the greatest understanding of the metals source(s), ground-water flow paths, and residence times in the vicinity of the Standard Mine that is possible within assumed cost limitations.

\section{Data Quality Objectives}

1. Determine where in the Elk Creek basin metal-rich water discharges, the concentrations of metals in these waters, and how these compare to metal concentrations in the Standard Mine discharge.

2. Determine the primary source(s) of the elevated metal concentrations, and where and how the Standard Mine intersects the metal source(s).

3. Determine where in the basin there is sufficient permeability and fracture connectivity to allow significant groundwater flow, how/where these high-flow zones are connected and associated with metal sources, and how/where the Standard Mine intersects these high-flow zones.

4. Determine characteristic ground-water residence times and related temporal variations in the flow regime.

5. Determine the chemical signatures of the different waters that discharge into the Standard Mine.

\section{Data Management}

Data for the Standard Mine geohydrologic investigation will be obtained from a combination of sources, including field and laboratory measurements. The process of collecting and managing data is a coordinated effort and will be conducted by project staff and laboratories working closely together. Analytical results will be provided in an electronic spreadsheet format and will be tabulated in report form. All raw analytical data will be archived in an electronic format. Data quality will be examined before results are presented or used in subsequent activities. The laboratory will confirm sample receipt, sample condition, and required analyses. 


\section{Types, Numbers, and Locations of Samples to Be Collected}

Table 1 summarizes information on the different sample types, including bottle sizes, filtration, and types of analyses to be performed.

Table 1. Sample Types.

\begin{tabular}{|c|c|c|c|}
\hline Type of sample & Bottle Size & Filtration & Analyses \\
\hline Raw, acidified (RA) & $30 \mathrm{~mL}$ & None & Total recoverable metals \\
\hline Filtered, unacidified (FU) & $125 \mathrm{~mL}$ & $\begin{array}{l}\text { Field filtered, } \\
0.45 \mu \mathrm{m}\end{array}$ & Anions, alkalinity \\
\hline Filtered, $\mathrm{HNO}_{3}$ acidified (FA) & $125 \mathrm{~mL}$ & $\begin{array}{l}\text { Field filtered, } \\
0.45 \mu \mathrm{m}\end{array}$ & $\begin{array}{l}\text { Dissolved metals, } \\
\text { Strontium isotopes }\end{array}$ \\
\hline Filtered, $\mathrm{HCl}$ acidified(FAHCl) & $60 \mathrm{~mL}$ & $\begin{array}{l}\text { Field filtered } \\
0.45 \mu \mathrm{m}\end{array}$ & Dissolved iron species \\
\hline Filtered, unacidified (C isotopes) & $1 \mathrm{~L}$ & $\begin{array}{l}\text { Field filtered } \\
0.45 \mu \mathrm{m}\end{array}$ & Carbon isotopes \\
\hline Raw, unacidified (HO isotopes) & $10 \mathrm{~mL}$ & None & Water isotopes \\
\hline Raw, unacidified (Tritium) & $500 \mathrm{~mL}$ & None & Tritium \\
\hline Raw, unacidified (Dissolved gases) & $15 \mathrm{ml}$ (clamped copper tube) & None & Dissolved gases \\
\hline
\end{tabular}

Field sampling has been broken into three different tasks. Task 1 will involve collecting surface- and ground-water samples from 4 different sites multiple times over the course of a year. These sites include the portal of the Standard Mine, Elk Creek just above its confluence with Coal Creek, and two additional ground-water sampling sites located in upper Elk Creek Basin. These two additional ground-water sites will most likely be springs, and their specific locations will be determined in the field. Table 2 lists which types of samples will collected and when from the 4 different sites. 
Table 2. Task 1 Sample Collection Schedule.

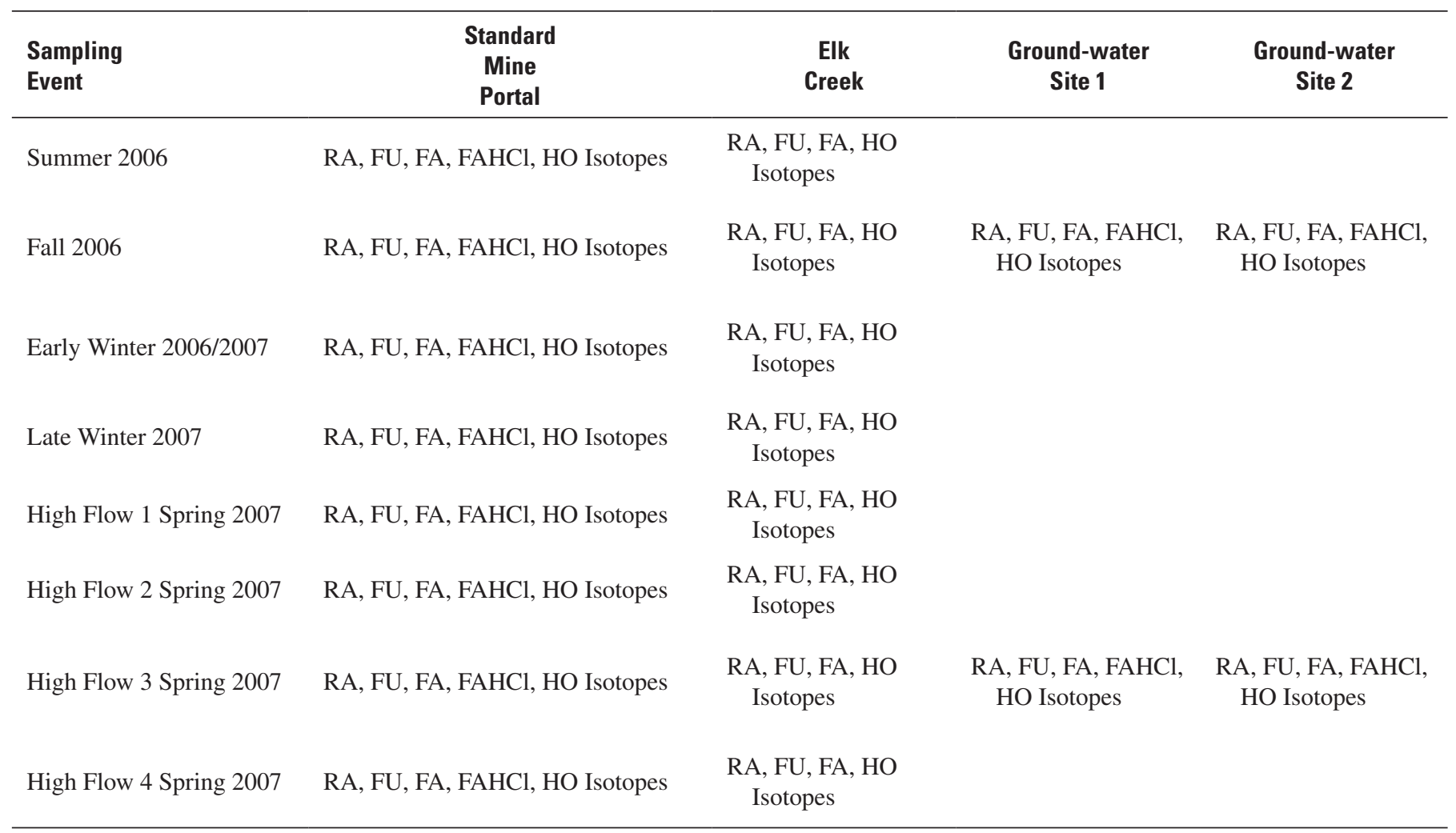

Task 2 will involve collecting ground-water samples (one-time) from about 20-30 locations in the upper Elk Creek Basin. Sampling sites will include springs, discharging mines, and flooded shafts, the locations of which will be determined in the field. The number and type of samples to be collected include: 20 to 30 samples for major and trace constituents (RA, FU, FA, FAHCl); 20 samples for Sr isotopes (FA); 20 samples for tritium and dissolved gases; and up to 2 samples for C isotopes.

Task 3 will involve collecting ground-water samples (one-time) from 5-10 locations within the Standard Mine. Specific sampling locations will be determined in the field. The number and type of samples to be collected include: 10 samples for major and trace constituents (RA, FU, FA, FAHCl); 7 samples for Sr isotopes (FA); and 5 samples for tritium and dissolved gases.

Field duplicate samples and equipment blanks will be collected at a rate of one for every ten locations sampled. Equipment blanks will be collected on filters.

\section{Sample Identification and Labeling}

Each water sample will be clearly labeled for easy identification. An adhesive label will be affixed to each sample container. All labels will be written with permanent, waterproof markers. The label will convey the following information:

- sample identification code

- sample date and time

- filtered or unfiltered sample

- preservative used, if any 
The label will contain an identification code that is unique for each sample. The identification code on the label will convey the following information: Site name, site type, number of times site has been sampled, and replicate information. The form of the identification code is "EC-XXXXX-00-X," where X and 0 denote letter and numeric symbols, respectively.

Identification codes are created as follows:

EC indicates: $\quad$ Drainage where site is located, in this case Elk Creek.

XXXXX indicates: $\quad$ Site name, which may include letters or numbers. The first character will always be a letter indicating the site type: $\mathrm{C}=$ creek; $\mathrm{S}=$ spring; $\mathrm{M}=$ mine discharge; etc.

00 indicates: $\quad$ Number in a sequence referring to how many times the site has been sampled: $01=$ first time; 02 = second time; etc.

X indicates: $\quad$ Replicate information: $\mathrm{A}=$ first replicate; $\mathrm{B}=$ second replicate (sample locations with no replicates will not get an A or B).

Identification codes for equipment blank samples will have the form "EB-00", where "EB" indicates "equipment blank" and " 00 " is the number in a sequence to be created as sample collection progresses.

The type of analysis or analyses to be conducted on the sample will also be noted on the sample label. All other sample collection information will be written on field sheets with the same ID code (see Attachment A).

\section{Field Sampling Protocols}

\section{Sample Site Selection}

For Task 1, the sampling site at the portal of the Standard Mine will be located as close to the portal as possible. The Elk Creek stream sample location will be located as close to the confluence with Coal Creek as possible, and will afford safe, convenient sample collection from the stream bank (without wading) during all seasons.

Task 2 sample sites will be selected based on several criteria. An attempt will be made to spatially distribute sites as evenly as possible throughout the Standard Mine vicinity, and to distribute sites among the different geologic features (rock types, faults, etc.) potentially controlling ground-water flow. If different types of water become evident based on field parameters, an attempt will be made to include sites representing all observed water types. If different site types can be sampled (different types of springs, mine discharge waters, and open mine shafts), an attempt will be made to include different site types. All sites must allow safe and relatively convenient access. Samples will only be collected from those sites that allow for the collection of a quality sample (for example, a quality dissolved gas sample cannot be collected from a very low-flow spring or seep). If field observations suggest that a site located in a drainage adjacent to Elk Creek would be useful, then this site might be selected.

In selecting Task 3 sample sites, the highest priority will be given to inflows with the highest flow rates and the lowest $\mathrm{pH}$ values. If multiple types of geologic features appear to be controlling inflows, then an attempt will be made to select inflows associated with the different features. An attempt will also be made to spread the sites as evenly as possible spatially. The most significant inflows, based on flow rate and $\mathrm{pH}$, will be selected for the sampling of integrated mine drainage water immediately upstream and downstream of the inflow.

\section{Field Parameters}

At each sample location, field measurements of $\mathrm{pH}$, specific conductance, dissolved oxygen, and temperature will be made at the time of sample collection. All field measurements will be recorded in a dedicated field notebook or on sample field sheets. All field monitoring equipment will be operated according to manufacturer's instructions. 


\section{Hydrogeochemical Investigation of the Standard Mine Vicinity, Upper Elk Creek Basin, Colorado}

\section{Sample Collection}

Table 3 lists the types and sizes of bottles used for sample collection, the bottle cleaning methods, filtration, and preservation for analytes. All bottles other than those cleaned by rinsing with sample water will be cleaned at the USGS laboratories. Sample filtration and preservation will be performed at the sampling site.

Table 3. Bottle type and size, cleaning, filtration, and preservation for analytes.

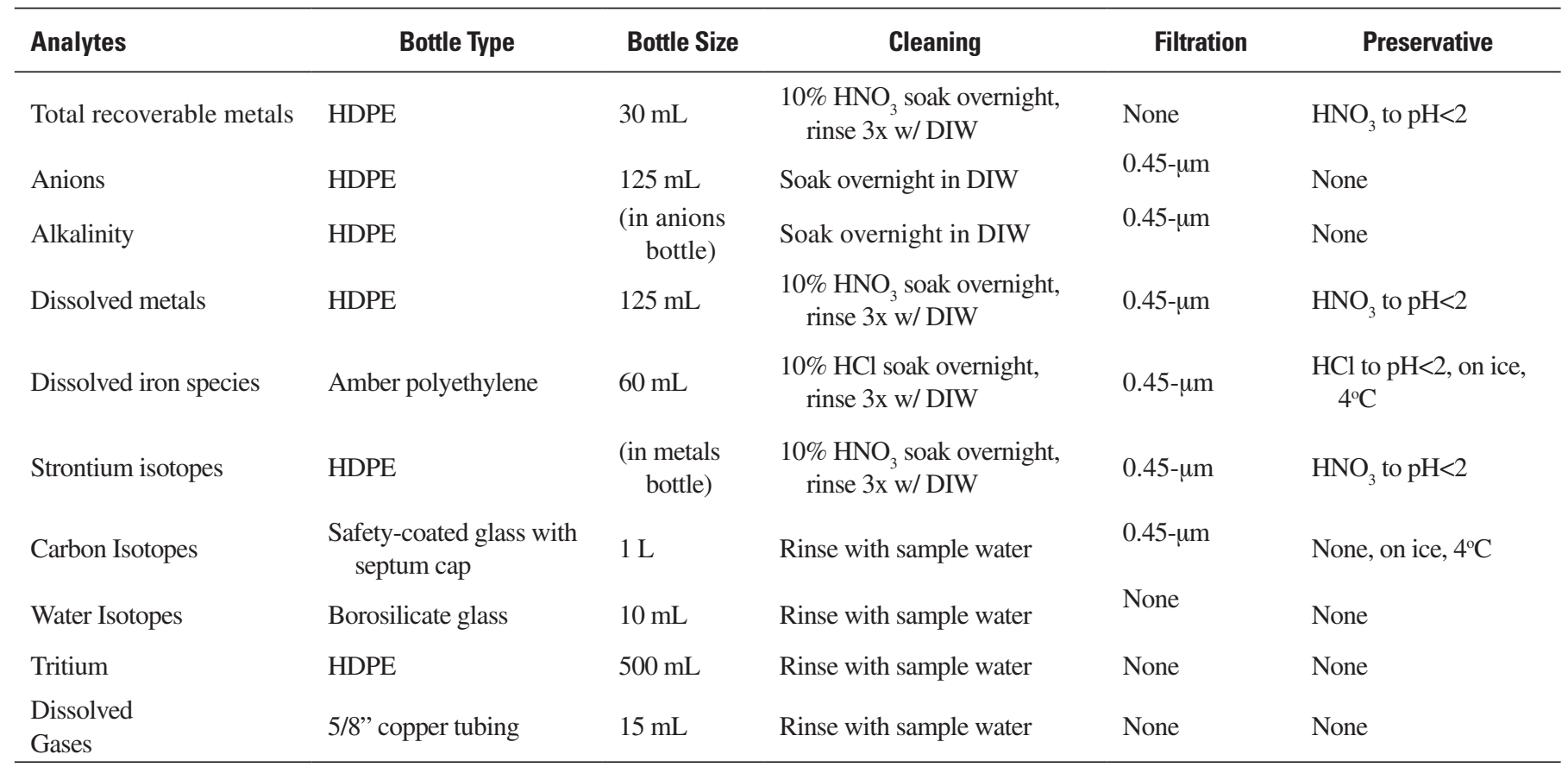

HDPE = high density polyethylene

DIW = distilled water

Samples collected from springs and discharging mines will be collected as close as possible to the emanation point - i.e., the actual orifice through which water discharges from the ground. Sampling gloves will be worn while sample bottles are being filled. For all samples except dissolved gas samples, bottles will be triple-rinsed using the following procedure:

1. open bottle and partially fill it with the water to be sampled (filtered if necessary)

2. close the cap and shake it vigorously

3. empty bottle downstream of the sample location

4. repeat 2 more times.

An effort will be made to minimize all physical contact with the water to be sampled while bottles are being filled. If entering the water is necessary in order to fill bottles, the person collecting the sample will stand downstream of the point where sample bottles are filled. Sample filtration procedures are described in section 7.4.

C isotope bottles will be filled using the following procedure.

1. Use a peristaltic or small submersible (centrifugal) pump to transfer water from the sampling point to the bottle. Submerge pump intake at the sample point, keeping it off the bottom so as to avoid pumping in sediment.

2. Turn on pump and allow to run for at least 2 minutes to purge the sample tubing. 
3. Turn off pump and install a disposable $0.45 \mu \mathrm{m}$ in-line filter in the sample line. Turn pump back on and allow to run at least 15 seconds to purge the filter. After sample line is purged, triple rinse sample bottle with filtered water.

4. Place discharge end of the sample tubing at the bottom of the sample bottle, thus allowing the bottle to fill from the bottom. Let the bottle overflow and continue overflowing for at least 1 minute.

5. Carefully remove the discharge end of the sample tubing from the bottle. Leave a 1-2mm head space.

6. Cap bottle with septum cap. Secure the cap by wrapping with electrical tape.

7. Affix a sample label with all required information. In addition to the standard information, the sample label will list the field $\mathrm{pH}$ and alkalinity. Field alkalinity will be obtained immediately before or after sample collection using a standard field alkalinity test kit, following all manufacturer's instructions.

8. Repeat for a second bottle that is to be archived as a back-up in case of sample breakage. Use a cone-cap for this back-up sample instead of a septum cap.

9. Place bottles in cooler as soon as possible after filling.

Dissolved gas samples will be collected following the general guidelines described in Stute and Schlosser (2000). Samples will be collected in approximately 18 " long sections of $3 / 8$ " diameter copper tubing. Water is sealed in the copper tubing with stainless steel pinch-off clamps. The following procedure will be used.

1. Use a peristaltic, small submersible (centrifugal), or vacuum hand pump to transfer water from the sampling point to the copper tube. This can also be done by siphoning. Submerge pump or intake tube at the sample point, keeping it off the bottom so as to avoid pumping in sediment.

2. Attach a pre-cut section of copper tubing at the end of the discharge tube. Attach a section of clear plastic tubing to the downstream end of the copper tubing. All fittings must create a tight seal to prevent leakage. Preset pinch-off clamps on the copper tubing so they are in place and ready to close.

3. Turn on pump or begin siphoning. Immediately tip copper tube upright (downstream-end up) and tap the copper tubing gently and repeatedly along its length with a wrench (or something similar) to force any trapped air bubbles to dislodge and flow out.

4. Allow water to run through the sample line for at least 1 minute to purge the copper tube. While purging, check the clear plastic tubing downstream of copper tubing to ensure that it is free of bubbles.

5. After purging, turn down the pump to low speed (unless siphoning) and close off the downstream end of the sample line by clamping the clear plastic tubing (alternately, a pre-installed valve in the plastic tubing can be closed).

6. Immediately close the downstream pinch-off clamp on the copper tube using a wrench. Alternate between the two bolts on either side of the clamp to avoid closing the clamp unevenly, which can cut the tube in a scissor-like fashion. After closing the downstream clamp completely, close the upstream clamp in the same way.

7. Remove the copper tubing from the sample line, fill the ends with sample water, and install end-caps.

8. Affix a sample label with all required information.

9. Care will be taken to not to bend the ends of the copper tubing that extend beyond the pinch-off clamps after the clamps are closed. These ends are delicate and will be handled with care during sample transport and storage.

\section{Sample Filtration}

Samples other than $\mathrm{C}$ isotope samples requiring filtration will be filtered at the sampling site using a disposable $0.45 \mu \mathrm{m}$ syringe filter. Syringe filtration will be performed using the following procedure:

1. Put on disposable powderless gloves.

2. Fill syringe with sampling water and expel. 
3. Fill syringe with sampling water, connect syringe filter, and pass approximately $30 \mathrm{mls}$ through filter.

4. Rinse each sampling bottle that will receive filtered sample with filtered water. Cap bottle, shake to coat inner surfaces, remove cap, and empty out contents.

5. Fill bottles in the following order, leaving sufficient space in bottles for addition of preservative, if required:
a. Anions/alkalinity
b. Dissolved metals/Sr isotope
c. Dissolved iron species

6. If the filter medium clogs before the needed volume of water is filtered, replace with a new filter and note on field sheet. Repeat filter-rinsing process (step 3) with each new filter.

7. Add preservatives, as needed (see Table 3). Cap each bottle immediately and invert to incorporate preservative into sample.

8. Dry off sample bottles, complete labels, and affix appropriate labels to bottles.

9. Place each sample bottle in a sealable bag and place in cooler or box, depending on required preservation.

10. Discard the used filter.

11. Document on field forms and in field notes any modifications to the filtration procedures used.

\section{Preparation of Equipment Blanks}

Equipment blanks will be prepared at a rate of 1 blank per 10 samples collected. Equipment blanks will be analyzed for total recoverable metals, anions (excluding alkalinity), dissolved metals, and dissolved iron species. Equipment blanks will be collected using the following procedure:

1. Put on disposable powderless gloves.

2. Fill syringe with double distilled water (DDW) and expel.

3. Fill syringe with DDW water, connect syringe filter, and pass approximately $30 \mathrm{mls}$ through filter.

4. Rinse each blank bottle that will receive filtered sample with filtered DDW. Cap bottle, shake to coat inner surfaces, remove cap, and empty out contents

5. Fill one bottle for each set of analytes to be determined.

6. Add preservatives, as needed (see Table 3). Cap each bottle immediately and invert to incorporate preservative into sample.

7. Dry off sample bottles, complete labels, and affix appropriate labels to bottles.

8. Place each sample bottle in a sealable bag and place in cooler or box, depending on required preservation.

\section{Duplicate Samples}

Duplicate samples will be prepared at a rate of one per 10 locations sampled, Duplicate samples will be collected using the same procedure as the sample being duplicated, and will be analyzed for the same analytes.

\section{Field Documentation}

The field sampling team will document its sampling activities in dedicated, paginated, bound field notebooks. Entries will be made in waterproof ink, and corrections will be made with a single line through the error accompanied by the correction date and corrector's initials. The notebook(s) will be kept in possession of the field sampling team at all times in the field. At the 
conclusion of the field investigation, the notebook(s) will be stored in a secure office location. Information recorded in the field notebook will include:

- a general description of activities performed on site, including personnel on site and times and locations of work activities

- work conditions, including weather and any difficulties encountered

- observations and data not related to sampling, such as geologic observations, structural measurements, etc.

- any additional information relevant to sampling that is not recorded on sample sheets (see below)

Prepared sample sheets (see Attachment A) will be used by the sampling team. The following information will be recorded at each sample site either in the field notebook(s) or on the sample sheets:

- site and project name

- each person's name in the sampling crew

- date and time of sample collection, weather conditions

- description of sample location using available landmarks and GPS-measured coordinates

- description of sample site characteristics, including surface stream characteristics, spring flow characteristics, etc.

- identification number(s) of sample(s) collected and the container (volume, type) used for each sample

- field parameter measurements

- any difficulties encountered or necessary deviations from the SAP during sample collection

- a description of each photograph taken

- any other pertinent field observations.

After each day's field sampling, the notes will be reviewed by the sampler and any necessary corrections will be made. Photographs of each sample location will be taken.

\section{Sample Preservation, Storage, Shipping and Custody}

\section{Preservation and Storage}

Requirements for sample preservation are given in Table 3. All samples will be collected and stored in pre-cleaned sample bottles. Ultrapure nitric and hydrochloric acid will be used for preservation of metals samples.

\section{Shipping and Custody}

All sample bottles will be placed in resealable plastic storage bags. Samples will be stored on ice at $4^{\circ} \mathrm{C}$, if required, until samples are transported to the laboratories. Total and dissolved metals/cations samples may be transported at either ambient temperatures or $4^{\circ} \mathrm{C}$, as needed to conserve cooler space. For transport to the laboratory, samples will be placed in a cooler with ice (double bagged using plastic trash bags or ziplock bags) or a box, as required for preservation. Protective packing material will be used if appropriate to ensure that no breakage occurs during shipment.

The field sampler is personally responsible for the care and custody of the samples until they are transferred to storage coolers. Samples will be stored in storage coolers in a locked room until they are transported to the laboratories. Samples will be transported to the USGS laboratories in Denver in locked field vehicles. C isotope samples will be shipped via FedEx from the USGS 
office in Denver to the University of Waterloo Laboratory, who performs the carbon extractions. The University of Waterloo then ships the extracted carbon samples to the University of Arizona for analysis.

\section{Analytical Measurements}

\section{Major and Trace Constituent Chemistry}

Analyses for total recoverable metals, anions and alkalinity, dissolved metals, and dissolved iron species will be performed in USGS laboratories in Denver or Boulder, Colorado. The following parameters will be measured: (1) major cations and anions; (2) total and dissolved trace and minor metals; and (3) dissolved iron species. The analytical method, reference, and detection limit for each parameter is listed in Table 4A and 4B.

Table 4A. Analytical methods and reporting limits in $\mathrm{mg} / \mathrm{L}$.

$\begin{array}{lccc}\text { Parameter } & \text { Method } & \text { Reference } & \begin{array}{c}\text { Reporting Limit } \\ \text { (mg/L) }\end{array} \\ \text { Calcium }(\mathrm{Ca}) & \text { ICP } & \text { Taggart, 2002 } & 0.1 \\ \text { Magnesium }(\mathrm{Mg}) & \text { ICP } & \text { Taggart, 2002 } & 0.1 \\ \text { Strontium }(\mathrm{Sr}) & \text { ICP } & \text { Taggart, 2002 } & 0.001 \\ \text { Barium }(\mathrm{Ba}) & \text { ICP } & \text { Taggart, 2002 } & 0.001 \\ \text { Sodium }(\mathrm{Na}) & \text { ICP } & \text { Taggart, 2002 } & 0.1 \\ \text { Aluminum }(\mathrm{Al}) & \text { ICP } & \text { Taggart, 2002 } & 0.01 \\ \text { Silica }\left(\mathrm{SiO}_{2}\right) & \text { ICP } & \text { Taggart, 2002 } & 0.1 \\ \text { Alkalinity } & \text { Titration } & \text { Taggart, 2002 } & 1.0 \\ \text { Chloride }(\mathrm{Cl}) & \text { IC } & \text { Taggart, 2002 } & 0.4 \\ \text { Fluoride }(\mathrm{F}) & \text { IC } & \text { Taggart, 2002 } & 0.4 \\ \text { Sulfate }\left(\mathrm{SO}_{4}\right) & \text { IC } & \text { Taggart, 2002 } & 0.8 \\ \text { Iron (total) }(\mathrm{Fe}) & \text { Colorimetric } & \text { To et al., 1999 } & 0.001 \\ \text { Iron (II) } & \text { Colorimetric } & \text { To et al., 1999 } & 0.002 \\ \text { ICP = inductively coupled argon plasma } & & & \\ \text { IC = Ion chromatography } & & & \end{array}$

\section{Sr Isotopes}

Strontium isotopic analyses will be performed at the USGS in Denver, Colorado. In a clean environment, an aliquot of the water sample will be poured into a Teflon beaker and evaporated to dryness. The residue will be redissolved in ultrapure $2 \mathrm{~N}_{\mathrm{HNO}_{3}}$ and eluted on a cation exchange column to separate the $\mathrm{Sr}$ from the other constituents in the sample. The Sr separate will be 
Table 4B. Analytical methods and reporting limits in $\mu \mathrm{g} / \mathrm{L}$.

\begin{tabular}{|c|c|c|c|}
\hline Parameter & Method & Reference & $\begin{array}{c}\text { Reporting Limit } \\
(\mu \mathrm{g} / \mathrm{L})\end{array}$ \\
\hline Lithium (Li) & ICP-MS & Taggart, 2002 & 0.9 \\
\hline Beryllium (Be) & ICP-MS & Taggart, 2002 & 0.05 \\
\hline Aluminum (Al) & ICP-MS & Taggart, 2002 & 2 \\
\hline Phosphorous (P) & ICP-MS & Taggart, 2002 & 10 \\
\hline Potassium (K) & ICP-MS & Taggart, 2002 & 30 \\
\hline Scandium $(\mathrm{Sc})$ & ICP-MS & Taggart, 2002 & 0.6 \\
\hline Titanium (Ti) & ICP-MS & Taggart, 2002 & 0.5 \\
\hline Vanadium (V) & ICP-MS & Taggart, 2002 & 0.5 \\
\hline Chromium (Cr) & ICP-MS & Taggart, 2002 & 1 \\
\hline Manganese (Mn) & ICP-MS & Taggart, 2002 & 0.2 \\
\hline Cobalt (Co) & ICP-MS & Taggart, 2002 & 0.02 \\
\hline Nickel (Ni) & ICP-MS & Taggart, 2002 & 0.4 \\
\hline Copper $(\mathrm{Cu})$ & ICP-MS & Taggart, 2002 & 0.5 \\
\hline Zinc (Zn) & ICP-MS & Taggart, 2002 & 0.5 \\
\hline Arsenic (As0 & ICP-MS & Taggart, 2002 & 1 \\
\hline Rubidium (Rb) & ICP-MS & Taggart, 2002 & 0.01 \\
\hline Strontium (Sr) & ICP-MS & Taggart, 2002 & 0.5 \\
\hline Yttrium (Y) & ICP-MS & Taggart, 2002 & 0.01 \\
\hline Niobium (Nb) & ICP-MS & Taggart, 2002 & 0.2 \\
\hline Molybdenum (Mo) & ICP-MS & Taggart, 2002 & 2 \\
\hline Silver (Ag) & ICP-MS & Taggart, 2002 & 0.3 \\
\hline Cadmium (Cd) & ICP-MS & Taggart, 2002 & 0.02 \\
\hline Antimony (Sb) & ICP-MS & Taggart, 2002 & 0.3 \\
\hline Cesium (Cs) & ICP-MS & Taggart, 2002 & 0.02 \\
\hline Barium (Ba) & ICP-MS & Taggart, 2002 & 0.2 \\
\hline Lanthanum (La) & ICP-MS & Taggart, 2002 & 0.01 \\
\hline Cerium $(\mathrm{Ce})$ & ICP-MS & Taggart, 2002 & 0.01 \\
\hline Praseodymium (Pr) & ICP-MS & Taggart, 2002 & 0.01 \\
\hline Neodymium (Nd) & ICP-MS & Taggart, 2002 & 0.01 \\
\hline Samarium (Sm) & ICP-MS & Taggart, 2002 & 0.01 \\
\hline Europium (Eu) & ICP-MS & Taggart, 2002 & 0.005 \\
\hline Terbium (Tb) & ICP-MS & Taggart, 2002 & 0.005 \\
\hline Gadolinium (Gd) & ICP-MS & Taggart, 2002 & 0.005 \\
\hline Dysprosium (Dy) & ICP-MS & Taggart, 2002 & 0.005 \\
\hline Holmium (Ho) & ICP-MS & Taggart, 2002 & 0.005 \\
\hline Erbium (Er) & ICP-MS & Taggart, 2002 & 0.005 \\
\hline Thulium (Tm) & ICP-MS & Taggart, 2002 & 0.005 \\
\hline Ytterbium (Yb) & ICP-MS & Taggart, 2002 & 0.005 \\
\hline Lutetium (Lu) & ICP-MS & Taggart, 2002 & 0.1 \\
\hline Tantalum (Ta) & ICP-MS & Taggart, 2002 & 0.02 \\
\hline Tungsten (W) & ICP-MS & Taggart, 2002 & 0.5 \\
\hline Thallium (Tl) & ICP-MS & Taggart, 2002 & 0.1 \\
\hline Lead $(\mathrm{Pb})$ & ICP-MS & Taggart, 2002 & 0.05 \\
\hline Bismuth (Bi) & ICP-MS & Taggart, 2002 & 0.2 \\
\hline Thorium (Th) & ICP-MS & Taggart, 2002 & 0.2 \\
\hline Uranium (U) & ICP-MS & Taggart, 2002 & 0.1 \\
\hline
\end{tabular}


collected in a Teflon beaker. The strontium isotopic composition of each separate will be measured on a Nu Instruments HR multi-collector ICP-MS. During each analytical run, a Sr standard reference (SRM987) will be measured periodically. Precision is generally less than $+/-0.00003$. At least one duplicate will be prepared and analyzed with each set of samples.

\section{Isotopes}

Carbon isotope analyses will be performed at the University of Arizona Accelerator Mass Spectrometry Laboratory in Tucson, Arizona. Samples will be analyzed for carbon-14 and carbon-13/carbon-12 ratio by accelerator mass spectrometry. Analytical methods are described in Donahue et al. (1990). Measurement precision for carbon-14 is typically less than $+/-0.5$ percent modern carbon.

\section{Water Isotopes}

Water isotope analyses will be performed by the USGS Stable Isotope Laboratory in Denver, Colorado.

\section{Deuterium}

Sample preparation for deuterium analysis of water is carried out offline in batch process by zinc reduction (Kendall and Coplen 1985). Specifically, $2 \mu \mathrm{L}$ of sample is condensed under liquid nitrogen temperatures in butt-sealed pyrex tubes containing approximately $60 \mathrm{mg}$ of Indiana zinc. Following cryogenic purification of the sample, the tube is flame sealed and heated in a muffle furnace at $500^{\circ} \mathrm{C}$ for 30 minutes. Sample $\mathrm{H}_{2}$ gas is admitted to a Thermo-Finnigan 252 mass spectrometer and deuterium measured by dual inlet viscous flow. Samples are compared to reference gas of known isotopic composition and final $\delta^{2} \mathrm{H}$ values scaled against V-SMOW by post correcting against internal lab standards prepared offline in a similar fashion.

Precision is generally less than $+/-1.5$ per mil. At least one set of sample duplicates is prepared in each batch on the zinc line to monitor measurement precision. Each sample is cycled 8 times in the mass spectrometer to produce a statistically robust average measurement for the sample, and the multiple cycles are checked for consistency and outliers are identified. Each sample is plotted versus $\delta^{18} \mathrm{O}$ values from the same sample, and samples that plot far from the global meteoric water line are flagged as potentially unreliable and in need of confirmation.

\section{Oxygen-18}

Sample preparation for $\delta^{18} \mathrm{O}$ analysis of water is performed in batch process by on-line equilibration with $\mathrm{CO}_{2}$, followed by isotopic analysis of the $\mathrm{CO}_{2}$ headspace gas. This is the classical method for $\delta^{18} \mathrm{O}$ first proposed by Epstein and Mayeda (1953), with slight modification to accommodate automated sample preparation and analysis. Water samples $(200 \mu \mathrm{L})$ are dispensed into $2 \mathrm{~mL}$ borosilicate glass vials, purged with high purity $\mathrm{CO}_{2}$ in a glove bag and sealed with threaded septum-style caps prior to removal from the glove bag. Water- $\mathrm{CO}_{2}$ equilibration is facilitated by an isothermal heating block maintained at $40^{\circ} \mathrm{C}$ for 12 hours. Following equilibration, headspace $\mathrm{CO}_{2}$ is extracted, purified, and admitted to a Micromass Optima mass spectrometer for $\delta^{18} \mathrm{O}-\mathrm{CO}_{2}$ measurement by dual inlet viscous flow. Sample $\mathrm{CO}_{2}$ gas is compared to reference gas of known isotopic composition and final $\delta^{18} \mathrm{O}$ values scaled against V-SMOW by post correcting against internal lab standards prepared online in a similar fashion.

Precision is approximately $+/-0.05$ per mil. Approximately one duplicate is run per 10 samples to monitor measurement precision. Each sample is cycled 8 times in the mass spectrometer to produce a statistically robust average measurement for the sample, and the multiple cycles are checked for consistency and outliers are identified. Each sample is plotted versus $\delta^{2} \mathrm{H}$ values from the same sample, and samples that plot far from the global meteoric water line are flagged as potentially unreliable and in need of confirmation. 


\section{Tritium}

Tritium analyses will be performed by the USGS Noble Gas Laboratory in Denver, Colorado using the ${ }^{3}$ He in-growth method (Bayer et al., 1989). Approximately $170 \mathrm{~mL}$ of sample is placed in a tritium extraction flask, degassed for 30 minutes under vacuum while being agitated using a heated ultrasonic bath, then sealed using a cold-welded crimp. The flask is then stored for approximately 100 days, allowing the accumulation of tritiogenically produced ${ }^{3} \mathrm{He}$. The flask is then attached to an ultra-high vacuum extraction line and the accumulated ${ }^{3} \mathrm{He}$ is released and purified prior to being measured using a magnetic sector mass spectrometer (Mass Analyzer Products 215-50). The ${ }^{3} \mathrm{He}$ concentration is determined by calibration to a known air standard that is run in conjunction with the sample set. Original ${ }^{3} \mathrm{H}$ concentration at the time of sampling is calculated from the measured ${ }^{3} \mathrm{He}$ concentration using the known decay constant $\left(0.05621 \mathrm{yr}^{-1}\right)$ and the amount of time the extracted flask was stored.

The detection limit is approximately 0.05 Tritium Units (TU), where $1 \mathrm{TU}=1$ atom of ${ }^{3} \mathrm{H}$ per 1018 atoms of hydrogen. Total pressure is checked upon sample inlet to verify that the flask did not leak during storage. Each sample is cycled 10 times in the mass spectrometer to produce a statistically robust measurement, and the multiple cycles are checked for consistency and outliers are identified.

\section{Dissolved Gases}

Dissolved gas analyses will be performed at the USGS Noble Gas Laboratory in Denver, Colorado. Dissolved gases are extracted from samples on an ultra-high vacuum extraction line. Major component gases (nitrogen, oxygen, carbon dioxide, and methane) are measured on a quadrupole mass spectrometer in dynamic operation mode. Major component gases are then removed by chemical reaction with a heated titanium/zirconium sponge, and remaining noble gases are separated cryogenically. Noble gas concentrations and isotopic compositions $\left(\mathrm{He},{ }^{3} \mathrm{He} /{ }^{4} \mathrm{He}\right.$ ratio, $\mathrm{Ne}, \mathrm{Ar}, \mathrm{Kr}$, and $\left.\mathrm{Xe}\right)$ are measured using separate aliquots on a magnetic sector mass spectrometer (Mass Analyzer Products 215-50) run in static operation mode. Gas concentrations are determined by calibration to a known air standard. All gas concentrations are reported in units of cubic centimeters at standard temperature and pressure per gram of water $\left(\mathrm{cm}^{3} \mathrm{STP} / \mathrm{g}\right)$.

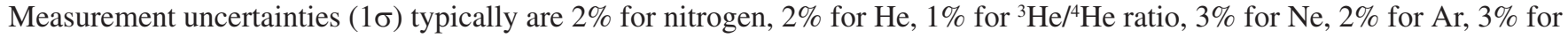
$\mathrm{Kr}$, and $3 \%$ for Xe. Uncertainties for the other major component gases are considerably higher (approximately 10\%), but these gases are analyzed only to screen samples for high levels of these gases, because unusually high levels can increase measurement uncertainty for nitrogen. Each sample tube is carefully checked prior to analysis for any signs of failed seals and any such signs are noted. Each gas aliquot is cycled 8-10 times in the mass spectrometer to produce a statistically robust measurement for the sample, and the multiple cycles are checked for consistency and outliers are identified. Oxygen levels are checked to verify that sample seals did not fail. The total pressure of extracted gases is checked upon initial inlet to evaluate the possibility of bubbles or leaks in the sample tube, or that all gases were not successfully extracted (due to ice blockages, etc.), and irregularities are noted.

\section{References}

Bayer, R., P. Schlosser, G. Bönisch, H. Rupp, F. Zaucker, and G. Zimmek, 1989, Performance and blank components of a mass spectrometric system for routine measurement of helium isotopes and tritium by the 3 He ingrowth method, In Sitzungsberichte der Heidelberger Akademie der Wissenschaften, Mathematisch-naturwissenschaftliche Klasse, vol. 5: Heidelberg, Springer Verlag, p. 241-279.

Donahue, D.J., T.W. Linick, and A.J. Jull, 1990, Isotope-ratio and background corrections for accelerator mass spectrometry radiocarbon measurements, Radiocarbon, v. 32(2), p. 135-142

Epstein, S., and Mayeda, T, 1953, Variation of ${ }^{18} \mathrm{O}$ content of waters from natural sources: Geochimica et Cosmochimica Acta, v. 4, p. 213-224.

Kendall, C., and Coplen, T.B., 1985, Multisample conversion of water to hydrogen by zinc for stable isotope determination: Analytical Chemistry, v. 57, p.1437-1440.

Stute, M., and Schlosser, P., 2000, Atmospheric noble gases, In P.G. Cook and A.L. Herczeg (Editors), Environmental Tracers in Subsurface Hydrology: Boston, Kluwer Academic Publishers, p. 349-377. 
Taggart, J.E. (ed.), 2002, Analytical methods for chemical analysis of geologic and other materials, U.S. Geological Survey, Open-File Report 02-0223.

To, B.T., Nordstrom, D. K., Cunningham, K.M., Ball, J.W., and McCleskey, R.B., 1999, New method for direct determination of dissolved Fe(III) concentrations in acid mine waters: Environmental Science and Technology, v. 33, p. 807-813.

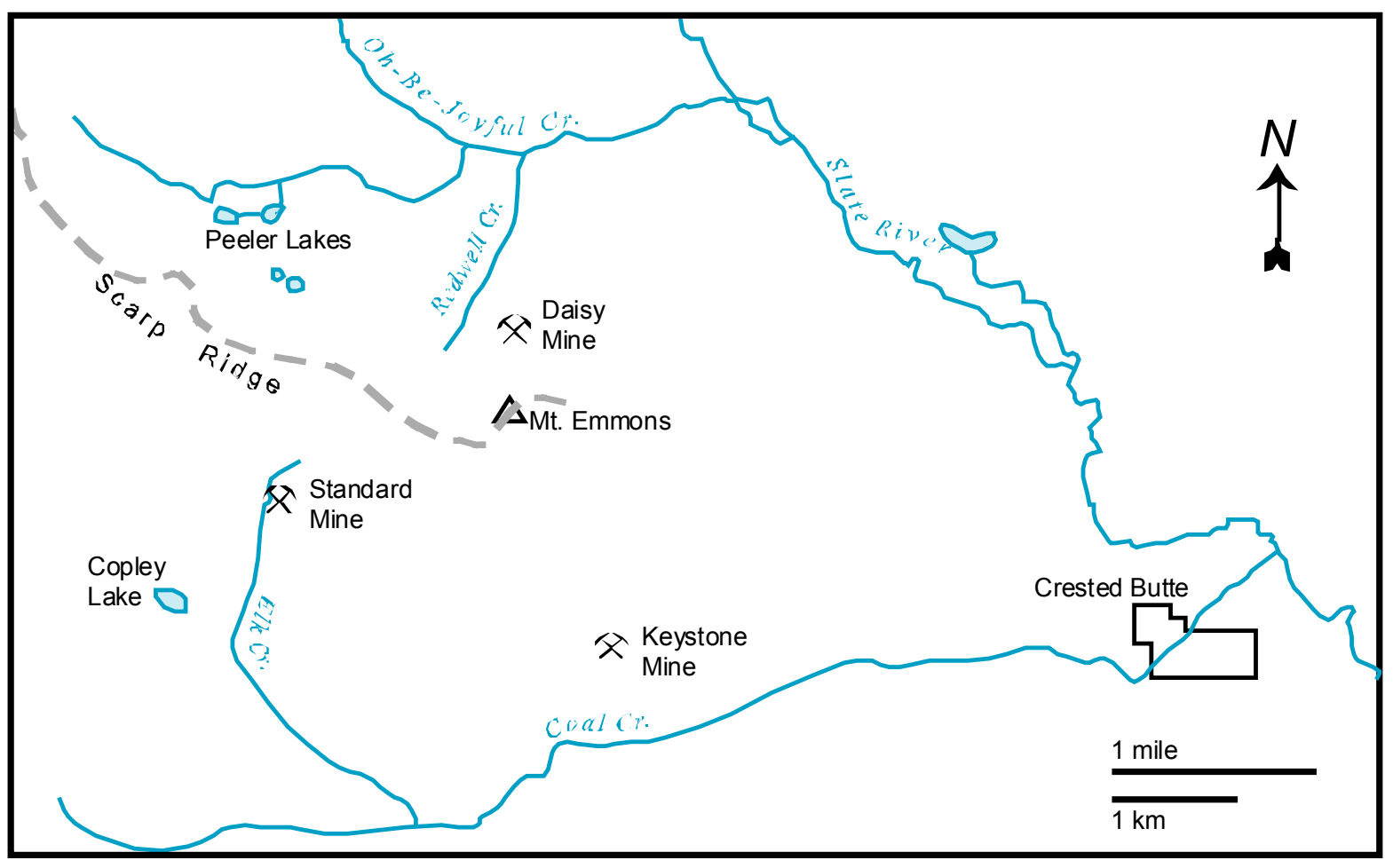

Figure 1. Base map of the Mount Emmons area. 
Attachment A:

Field Sampling Sheet 


\section{GEOHYDROLOGIC INVESTIGATION OF THE STANDARD MINE VICINITY GUNNISON COUNTY, COLORADO}

\section{U. S. GEOLOGICAL SURVEY}

FIELD DATA SHEET: WATER

Crested Butte, CO

Collected by:

Sample ID

UTM coords:

Easting

Northing

NAD

Site Description:
Date

Time

Photos
Depth

Discharge

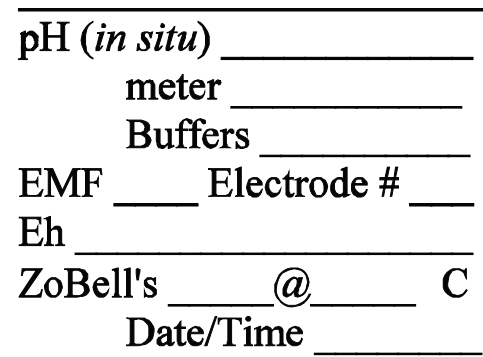

Temperature

$\begin{array}{ll}\text { D.O. } & \mathrm{mg} / \mathrm{L} \\ \text { D.O. } & \%\end{array}$

Conductance Meter
Filtration

Membrane pore size
SAMPLES COLLECTED

FILTERED 125mL HDPE-Anions, alkalinity (FU) 125 HDPE-dis. metals (FA) 60mL HDPE, brown-Fe (2/3) (FEHCl) $1 \mathrm{~L}$ Glass-C isotopes

\section{UNFILTERED}

30mL HDPE-tot. metals (RA) $10 \mathrm{~mL}$ glass- $\mathrm{O} / \mathrm{D}$ isotopes $500 \mathrm{~mL}$ HDPE-Tritium $15 \mathrm{~mL} \mathrm{Cu}$ Tube_dissolved gases 
Appendix 2. Sampling Information and Field Parameters 


\section{Hydrogeochemical Investigation of the Standard Mine Vicinity, Upper Elk Creek Basin, Colorado}

Appendix 2. Sample information and field parameters.

$\left[{ }^{\circ} \mathrm{C}\right.$, degree Celsius; asl, above sea level; $\mathrm{ft}$, feet; gpm, gallons per minute; $\mu \mathrm{S} / \mathrm{cm}$, microsiemens per centimeter; $\mathrm{m}$, meters; $\mathrm{mg} / \mathrm{L}$, milligrams per liter; ${ }^{14} \mathrm{C}$, carbon-13 and carbon-14 isotopes; DG, dissolved gases; D0, dissolved oxygen; EB, equipment blank; Eh, redox potential; FA, filtered, acidified with nitric acid; FEHCL, filtered, acidified with hydrochloric acid; FU, filtered, unacidified; ${ }^{3} \mathrm{H}$, tritium; NA, not applicable; NM, not measured; $-\mathrm{R}$ (appended to sample name), replicate sample; RA, unfiltered, acidified with nitric acid; SAA, same as above; SC, specific conductance; SI, stable isotopes deuterium and oxygen-18; T, discharge temperature; UG, underground; $\mathrm{V}$, volts]

\begin{tabular}{|c|c|c|c|c|c|c|c|c|c|c|c|}
\hline & Site & & Loc & ation' ${ }^{1}$ & & & & Estimated & & I parame & \\
\hline Name & Description & ID & $\begin{array}{c}\text { Easting } \\
(\mathrm{m})\end{array}$ & $\begin{array}{c}\text { Northing } \\
(\mathrm{m})\end{array}$ & $\begin{array}{l}\text { Elevation } \\
\text { (ft asl) }\end{array}$ & $\begin{array}{c}\text { Sample } \\
\text { name }\end{array}$ & $\begin{array}{l}\text { Collection } \\
\text { date }\end{array}$ & $\begin{array}{c}\text { discharge } \\
\text { (gpm) }\end{array}$ & pH & $\begin{array}{l}\text { Eh } \\
\text { (V) }\end{array}$ & $\begin{array}{c}\mathrm{T} \\
\left({ }^{\circ} \mathrm{C}\right)\end{array}$ \\
\hline Elk Creek & Elk Creek near & EC-CELK1 & 321270 & 4302915 & 9,579 & EC-CELK1-01 & $7 / 18 / 2006$ & NM & 7.16 & NM & 7.9 \\
\hline & confluence & & & & & EC-CELK1-02 & $10 / 9 / 2006$ & NM & 6.94 & NM & 3.9 \\
\hline & with Coal & & & & & EC-CELK1-03 & $2 / 25 / 2007$ & NM & 7.102 & NM & 0.5 \\
\hline & Creek & & & & & EC-CELK1-04 & $4 / 14 / 2007$ & NM & 7.392 & NM & 1.0 \\
\hline & & & & & & EC-CELK1-05 & $5 / 5 / 2007$ & NM & 6.40 & NM & 1.0 \\
\hline & & & & & & EC-CELK1-06 & $5 / 15 / 2007$ & NM & 6.12 & NM & 2.5 \\
\hline & & & & & & EC-CELK1-07 & $6 / 3 / 2007$ & NM & 6.29 & NM & 7.4 \\
\hline & & & & & & EC-CELK1-08 & $6 / 17 / 2007$ & NM & 6.78 & NM & 11.8 \\
\hline Tributary 1 & Elk Creek & $\mathrm{EC}-\mathrm{T} 1$ & 320458 & 4305961 & 11,416 & EC-T1-01 & $8 / 15 / 2006$ & $>10$ & 7.70 & 0.490 & 16.0 \\
\hline & Tributary & & & & & $\mathrm{EC}-\mathrm{T} 1-02$ & $8 / 20 / 2006$ & SAA & NM & $\mathrm{NM}$ & 11.0 \\
\hline Tributary 2 & Elk Creek & $\mathrm{EC}-\mathrm{T} 2$ & 320455 & 4305941 & 11,404 & $\mathrm{EC}-\mathrm{T} 2-01$ & $8 / 15 / 2006$ & $>10$ & 7.68 & 0.503 & 13.9 \\
\hline & Tributary & & & & & $\mathrm{EC}-\mathrm{T} 2-02$ & $8 / 20 / 2006$ & SAA & NM & $\mathrm{NM}$ & 9.4 \\
\hline Tributary 3 & Elk Creek & EC-T3 & 319954 & 4305479 & 11,021 & EC-T3-01 & $8 / 17 / 2006$ & $5-10$ & 7.022 & 0.4252 & 12.4 \\
\hline & Tributary & & & & & EC-T3-02 & 8/20/2006 & SAA & NM & NM & 11.2 \\
\hline Spring 1 & $\begin{array}{l}\text { Discharge from } \\
\text { waste rock } \\
\text { outside Level } \\
5 \text { portal }\end{array}$ & EC-S1 & 320610 & 4305936 & 11,510 & $\mathrm{EC}-\mathrm{S} 1-01$ & $8 / 15 / 2006$ & $<1$ & 3.18 & NM & 8.2 \\
\hline Spring 2 & NA & $\mathrm{EC}-\mathrm{S} 2$ & 320669 & 4306012 & 11,580 & $\mathrm{EC}-\mathrm{S} 2-01$ & $8 / 15 / 2006$ & $1-2$ & 6.92 & 0.486 & 6.4 \\
\hline & & & & & & $\mathrm{EC}-\mathrm{S} 2-02$ & $8 / 19 / 2006$ & SAA & NM & $\mathrm{NM}$ & 6.9 \\
\hline & & & & & & $\mathrm{EC}-\mathrm{S} 2-02-\mathrm{R}$ & SAA & SAA & SAA & SAA & SAA \\
\hline & & & & & & $\mathrm{EC}-\mathrm{S} 2-03$ & $10 / 9 / 2006$ & NM & 6.742 & NM & 4.8 \\
\hline & & & & & & $\mathrm{EC}-\mathrm{S} 2-04$ & $6 / 17 / 2007$ & $\mathrm{NM}$ & 6.76 & $\mathrm{NM}$ & 3.0 \\
\hline Spring 3 & NA & EC-S3 & 320543 & 4306331 & 11,663 & EC-S3-01 & $8 / 15 / 2006$ & 1 & 6.66 & 0.485 & 5.4 \\
\hline & & & & & & $\mathrm{EC}-\mathrm{S} 3-02$ & $8 / 18 / 2006$ & SAA & NM & $\mathrm{NM}$ & 5.6 \\
\hline Spring 4 & NA & EC-S4 & 320188 & 4306207 & 11,583 & EC-S4-01 & $8 / 15 / 2006$ & 2 & 7.40 & 0.467 & 3.9 \\
\hline & & & & & & EC-S4-02 & $8 / 19 / 2006$ & SAA & $\mathrm{NM}$ & NM & 4.1 \\
\hline
\end{tabular}


Appendix 2. Sample information and field parameters.-Continued

$\left[{ }^{\circ} \mathrm{C}\right.$, degree Celsius; asl, above sea level; $\mathrm{ft}$, feet; gpm, gallons per minute; $\mu \mathrm{S} / \mathrm{cm}$, microsiemens per centimeter; $\mathrm{m}$, meters; $\mathrm{mg} / \mathrm{L}$, milligrams per liter; ${ }^{14} \mathrm{C}$, carbon-13 and carbon-14 isotopes; DG, dissolved gases; DO, dissolved oxygen; EB, equipment blank; Eh, redox potential; FA, filtered, acidified with nitric acid; FEHCL, filtered, acidified with hydrochloric acid; FU, filtered, unacidified; ${ }^{3} \mathrm{H}$, tritium; NA, not applicable; NM, not measured; $-\mathrm{R}$ (appended to sample name), replicate sample; RA, unfiltered, acidified with nitric acid; SAA, same as above; SC, specific conductance; SI, stable isotopes deuterium and oxygen-18; T, discharge temperature; UG, underground; $V$, volts]

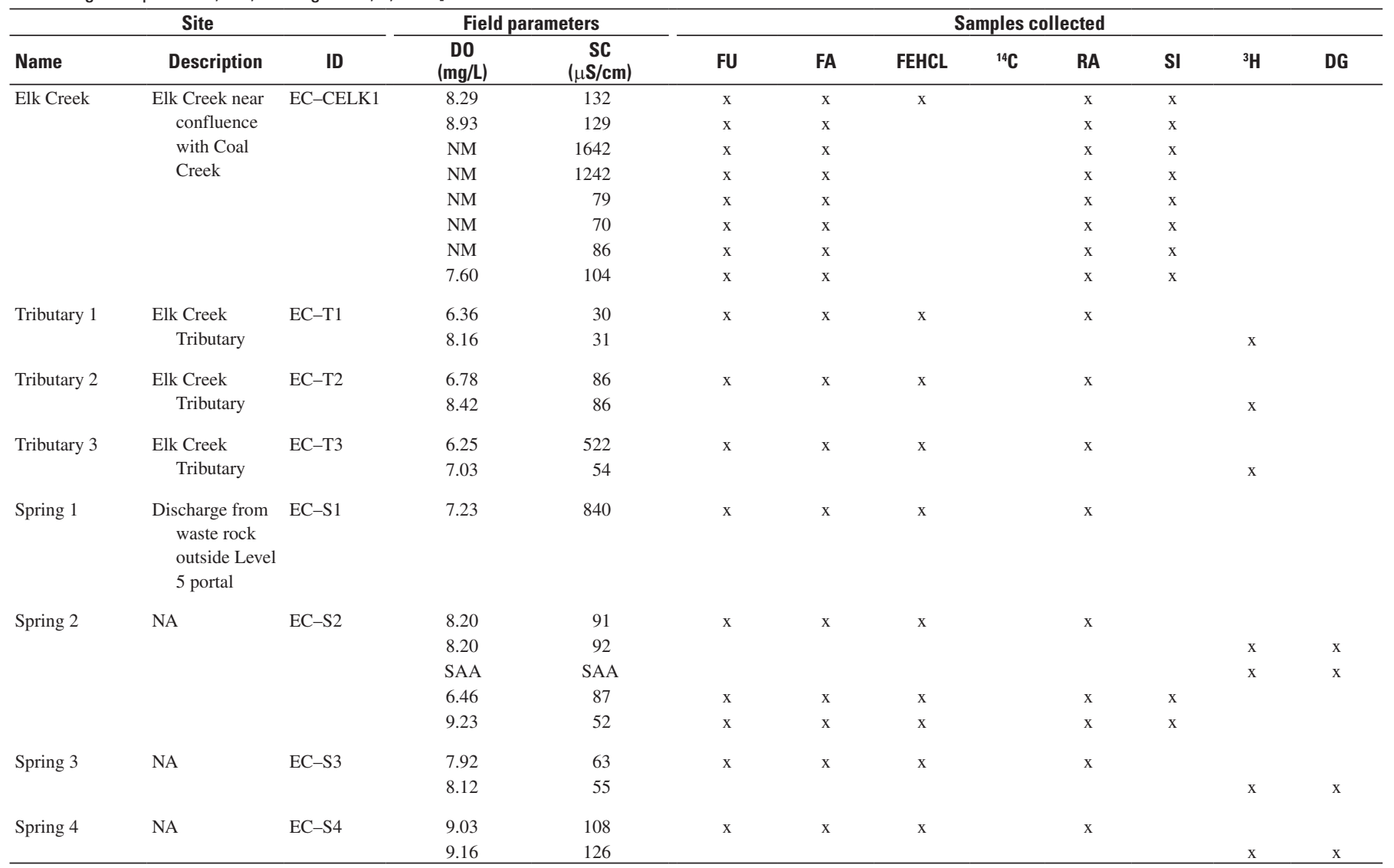




\section{Hydrogeochemical Investigation of the Standard Mine Vicinity, Upper Elk Creek Basin, Colorado}

Appendix 2. Sample information and field parameters.-Continued

$\left[{ }^{\circ} \mathrm{C}\right.$, degree Celsius; asl, above sea level; $\mathrm{ft}$, feet; gpm, gallons per minute; $\mu \mathrm{S} / \mathrm{cm}$, microsiemens per centimeter; $\mathrm{m}$, meters; mg/L, milligrams per liter; ${ }^{14} \mathrm{C}$, carbon-13 and carbon-14 isotopes; DG, dissolved gases; D0, dissolved oxygen; EB, equipment blank; Eh, redox potential; FA, filtered, acidified with nitric acid; FEHCL, filtered, acidified with hydrochloric acid; FU, filtered, unacidified; ${ }^{3} \mathrm{H}$, tritium; NA, not applicable; NM, not measured; $-\mathrm{R}$ (appended to sample name), replicate sample; RA, unfiltered, acidified with nitric acid; SAA, same as above; SC, specific conductance; SI, stable isotopes deuterium and oxygen-18; T, discharge temperature; UG, underground; V, volts]

\begin{tabular}{|c|c|c|c|c|c|c|c|c|c|c|c|}
\hline \multicolumn{3}{|c|}{ Site } & \multicolumn{2}{|c|}{ Location $^{1}$} & \multirow[b]{2}{*}{$\begin{array}{l}\text { Elevation } \\
\text { (ft asl) }\end{array}$} & \multirow{2}{*}{$\begin{array}{c}\text { Sample } \\
\text { name }\end{array}$} & \multirow{2}{*}{$\begin{array}{c}\text { Collection } \\
\text { date }\end{array}$} & \multirow{2}{*}{$\begin{array}{c}\text { Estimated } \\
\text { discharge } \\
\text { (gpm) }\end{array}$} & \multicolumn{3}{|c|}{ Field parameters } \\
\hline Name & Description & ID & $\begin{array}{c}\text { Easting } \\
(\mathrm{m})\end{array}$ & $\begin{array}{c}\text { Northing } \\
(\mathrm{m})\end{array}$ & & & & & $\mathrm{pH}$ & $\begin{array}{l}\text { Eh } \\
\text { (V) }\end{array}$ & $\begin{array}{c}\mathrm{T} \\
\left({ }^{\circ} \mathrm{C}\right)\end{array}$ \\
\hline \multirow[t]{2}{*}{ Spring 5} & NA & EC-S5 & 320445 & 4306065 & 11,490 & EC-S5-01 & $8 / 15 / 2006$ & $<1$ & 6.24 & 0.458 & 13.8 \\
\hline & & & & & & EC-S5-02 & $8 / 20 / 2006$ & SAA & NM & NM & 12.2 \\
\hline \multirow[t]{2}{*}{ Spring 7} & NA & EC-S7 & 319878 & 4305721 & 11,243 & EC-S7-01 & $8 / 15 / 2006$ & 2 & 7.22 & 0.484 & 5.2 \\
\hline & & & & & & EC-S7-02 & $8 / 20 / 2006$ & SAA & NM & NM & 5.5 \\
\hline \multirow[t]{5}{*}{ Spring $8 \mathrm{~A}$} & NA & EC-S8A & 320152 & 4305418 & 11,070 & EC-S8A-01 & $8 / 16 / 2006$ & $1-2$ & 7.13 & 0.452 & 3.4 \\
\hline & & & & & & $\mathrm{EC}-\mathrm{S} 8 \mathrm{~A}-02$ & $8 / 20 / 2006$ & SAA & NM & NM & 3.2 \\
\hline & & & & & & EC-S8A-03 & $10 / 9 / 2006$ & $\mathrm{NM}$ & 6.56 & $\mathrm{NM}$ & 3.0 \\
\hline & & & & & & EC-S8A-04 & $6 / 17 / 2007$ & NM & 7.31 & NM & 2.9 \\
\hline & & & & & & EC-S8A-04-R & SAA & SAA & SAA & SAA & SAA \\
\hline \multirow[t]{3}{*}{ Spring 8B } & NA & EC-S8B & 320159 & 4305449 & 11,071 & EC-S8B-01 & $8 / 16 / 2006$ & 2 & 7.35 & 0.450 & 3.6 \\
\hline & & & & & & $\mathrm{EC}-\mathrm{S} 8 \mathrm{~B}-02$ & $8 / 20 / 2006$ & SAA & NM & NM & 3.0 \\
\hline & & & & & & $\mathrm{EC}-\mathrm{S} 8 \mathrm{~B}-02-\mathrm{R}$ & SAA & SAA & SAA & SAA & SAA \\
\hline \multirow[t]{2}{*}{ Spring 9} & NA & EC-S9 & 320282 & 4305608 & 11,174 & EC-S9-01 & $8 / 16 / 2006$ & $<1$ & 6.38 & 0.474 & 5.5 \\
\hline & & & & & & EC-S9-02 & $8 / 19 / 2006$ & SAA & NM & $\mathrm{NM}$ & 6.2 \\
\hline Spring 10 & $\begin{array}{l}\text { About } 400 \mathrm{ft} \\
\text { directly } \\
\text { downhill from } \\
\text { Spring } 1\end{array}$ & EC-S10 & 320526 & 4305857 & 11,433 & EC-S10-01 & $8 / 16 / 2006$ & $<1$ & 4.71 & 0.571 & 11.9 \\
\hline \multirow[t]{2}{*}{ Spring 11} & Discharge from & EC-S11 & 320345 & 4305912 & 11,356 & EC-S11-01 & $8 / 17 / 2006$ & $<1$ & 6.20 & 0.425 & 13.4 \\
\hline & $\begin{array}{l}\text { waste rock } \\
\text { outside Elk } \\
\text { Lode Mine } \\
\text { portal }\end{array}$ & & & & & EC-S11-01-R & SAA & SAA & SAA & SAA & SAA \\
\hline \multirow[t]{2}{*}{ Spring 12} & NA & EC-S12 & 320157 & 4305229 & 10,990 & EC-S12-01 & $8 / 17 / 2006$ & 10 & 7.25 & 0.475 & 3.5 \\
\hline & & & & & & EC-S12-02 & $8 / 20 / 2006$ & SAA & NM & NM & 3.3 \\
\hline
\end{tabular}


Appendix 2. Sample information and field parameters.-Continued

$\left[{ }^{\circ} \mathrm{C}\right.$, degree Celsius; asl, above sea level; $\mathrm{ft}$, feet; gpm, gallons per minute; $\mu \mathrm{S} / \mathrm{cm}$, microsiemens per centimeter; $\mathrm{m}$, meters; mg/L, milligrams per liter; ${ }^{14} \mathrm{C}$, carbon-13 and carbon-14 isotopes; DG, dissolved gases; DO, dissolved oxygen; EB, equipment blank; Eh, redox potential; FA, filtered, acidified with nitric acid; FEHCL, filtered, acidified with hydrochloric acid; FU, filtered, unacidified; ${ }^{3} \mathrm{H}$, tritium; NA, not applicable; NM, not measured; -R (appended to sample name), replicate sample; RA, unfiltered, acidified with nitric acid; SAA, same as above; $\mathrm{SC}$, specific conductance; $\mathrm{SI}$, stable isotopes deuterium and oxygen-18; $\mathrm{T}$, discharge temperature; UG, underground; $\mathrm{V}$, volts]

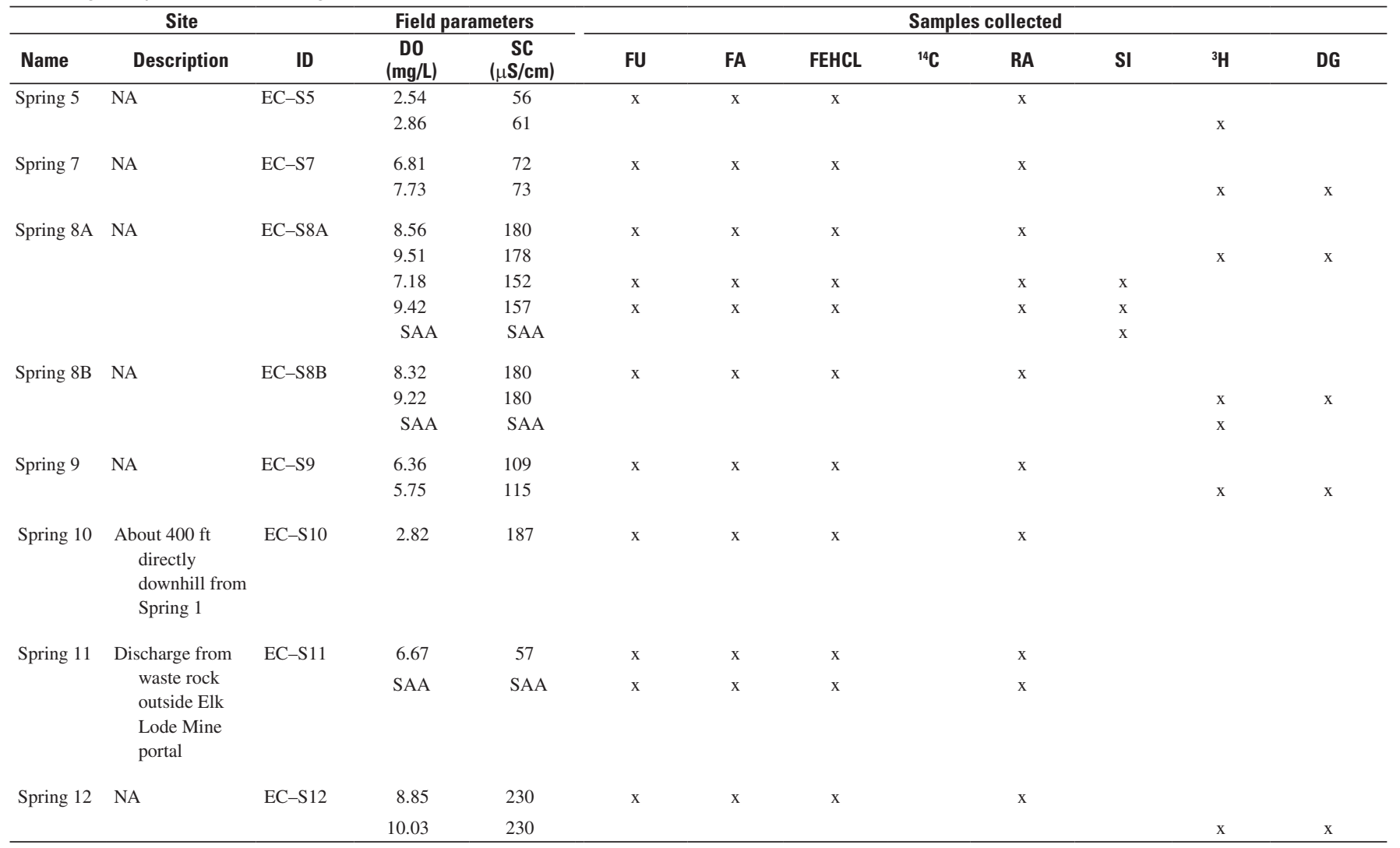




\section{Hydrogeochemical Investigation of the Standard Mine Vicinity, Upper Elk Creek Basin, Colorado}

Appendix 2. Sample information and field parameters.-Continued

$\left[{ }^{\circ} \mathrm{C}\right.$, degree Celsius; asl, above sea level; $\mathrm{ft}$, feet; gpm, gallons per minute; $\mu \mathrm{S} / \mathrm{cm}$, microsiemens per centimeter; $\mathrm{m}$, meters; mg/L, milligrams per liter; ${ }^{14} \mathrm{C}$, carbon-13 and carbon-14 isotopes; DG, dissolved gases; D0, dissolved oxygen; EB, equipment blank; Eh, redox potential; FA, filtered, acidified with nitric acid; FEHCL, filtered, acidified with hydrochloric acid; FU, filtered, unacidified; ${ }^{3} \mathrm{H}$, tritium; NA, not applicable; NM, not measured; $-\mathrm{R}$ (appended to sample name), replicate sample; RA, unfiltered, acidified with nitric acid; SAA, same as above; SC, specific conductance; SI, stable isotopes deuterium and oxygen-18; T, discharge temperature; UG, underground; V, volts]

\begin{tabular}{|c|c|c|c|c|c|c|c|c|c|c|c|}
\hline \multicolumn{3}{|c|}{ Site } & \multicolumn{2}{|c|}{ Location $^{1}$} & \multirow[b]{2}{*}{$\begin{array}{l}\text { Elevation } \\
\text { (ft asl) }\end{array}$} & \multirow[b]{2}{*}{$\begin{array}{l}\text { Sample } \\
\text { name }\end{array}$} & \multirow[b]{2}{*}{$\begin{array}{l}\text { Collection } \\
\text { date }\end{array}$} & \multirow{2}{*}{$\begin{array}{c}\text { Estimated } \\
\text { discharge } \\
(\mathrm{gpm})\end{array}$} & \multicolumn{3}{|c|}{ Field parameters } \\
\hline Name & Description & ID & $\begin{array}{c}\text { Easting } \\
(\mathrm{m})\end{array}$ & $\begin{array}{c}\text { Northing } \\
(\mathrm{m})\end{array}$ & & & & & pH & $\begin{array}{l}\text { Eh } \\
\text { (V) }\end{array}$ & $\begin{array}{c}\mathrm{T} \\
\left({ }^{\circ} \mathrm{C}\right) \\
\end{array}$ \\
\hline $\begin{array}{c}\text { Level } 2 \\
\text { waste } \\
\text { rock }\end{array}$ & $\begin{array}{l}\text { Discharge from } \\
\text { waste rock } \\
\text { outside Level } \\
2 \text { portal }\end{array}$ & EC-MUSTD1 & 320315 & 4305674 & 11,208 & EC-MUSTD1-01 & $7 / 18 / 2006$ & $<1$ & 2.97 & $\mathrm{NM}$ & 10.0 \\
\hline $\begin{array}{l}\text { Redwell } \\
\text { spring } 1\end{array}$ & $\begin{array}{l}\text { Located in Red- } \\
\text { well Basin }\end{array}$ & RW-S1 & 321500 & 4306706 & 11,065 & RW-S1-01 & $8 / 18 / 2006$ & 1 & 6.65 & 0.476 & 2.8 \\
\hline \multirow{2}{*}{$\begin{array}{l}\text { Redwell } \\
\quad \text { spring } 2\end{array}$} & "The Red Well," & RW-S2 & 321671 & 4306947 & 10,782 & RW-S2-01 & $8 / 18 / 2006$ & 10 & 3.68 & 0.547 & 5.4 \\
\hline & $\begin{array}{l}\text { located in } \\
\text { Redwell } \\
\text { Basin }\end{array}$ & & & & & RW-S2-01-R & SAA & SAA & SAA & SAA & SAA \\
\hline Well 1 & $\begin{array}{l}\text { Flowing well } \\
\text { located in } \\
\text { Redwell } \\
\text { Basin }\end{array}$ & RW-W1 & 321711 & 4306789 & 10,912 & RW-W1-01 & $8 / 18 / 2006$ & $10-20$ & NM & NM & 3.6 \\
\hline Pit 4 & Exploration pit & EC-P4 & 320416 & 4305759 & 11,335 & EC-P4-01 & $8 / 16 / 2006$ & NA & 5.60 & 0.491 & 13.4 \\
\hline Pit 5 & Exploration pit & EC-P5 & 320493 & 4305802 & 11,398 & EC-P5-01 & $8 / 17 / 2006$ & NA & 5.78 & 0.461 & 9.2 \\
\hline \multirow{11}{*}{$\begin{array}{l}\text { Level } 1 \\
\text { portal }\end{array}$} & Discharge & EC-MSTD1 & 320124 & 4305517 & 11,008 & EC-MSTD1-01 & 7/18/2006 & $\mathrm{NM}$ & 5.62 & NM & 4.5 \\
\hline & from Level & & & & & EC-MSTD1-02 & $8 / 16 / 2006$ & 11 & 6.20 & 0.422 & 4.5 \\
\hline & Standard & & & & & EC-MSTD1-02-R & SAA & SAA & SAA & SAA & SAA \\
\hline & Mine & & & & & EC-MSTD1-03 & $10 / 9 / 2006$ & $\mathrm{NM}$ & 5.58 & NM & 4.5 \\
\hline & & & & & & EC-MSTD1-03-R & SAA & SAA & SAA & SAA & SAA \\
\hline & & & & & & EC-MSTD1-04 & $2 / 25 / 2007$ & $\mathrm{NM}$ & 6.602 & $\mathrm{NM}$ & 0.5 \\
\hline & & & & & & EC-MSTD1-05 & $4 / 14 / 2007$ & $\mathrm{NM}$ & 6.682 & $\mathrm{NM}$ & 0.5 \\
\hline & & & & & & EC-MSTD1-06 & $5 / 5 / 2007$ & $\mathrm{NM}$ & 4.03 & $\mathrm{NM}$ & 0.5 \\
\hline & & & & & & EC-MSTD1-07 & $5 / 15 / 2007$ & NM & 3.56 & $\mathrm{NM}$ & 3.1 \\
\hline & & & & & & EC-MSTD1-08 & $6 / 3 / 2007$ & $\mathrm{NM}$ & 3.42 & NM & 3.7 \\
\hline & & & & & & EC-MSTD1-09 & $6 / 17 / 2007$ & $\mathrm{NM}$ & 3.84 & $\mathrm{NM}$ & 4.1 \\
\hline $\begin{array}{l}\text { Level } 1 \\
\text { site } 2\end{array}$ & $\begin{array}{l}\text { Standard Mine, } \\
\text { Level } 1, \\
\text { about } 60 \mathrm{ft} \text { in } \\
\text { fromportal at } \\
\text { collapse }\end{array}$ & EC-MSTD2 & UG & UG & UG & EC-MSTD2-01 & $8 / 19 / 2006$ & NM & $\mathrm{NM}$ & $\mathrm{NM}$ & 4.6 \\
\hline
\end{tabular}


Appendix 2. Sample information and field parameters.-Continued

$\left[{ }^{\circ} \mathrm{C}\right.$, degree Celsius; asl, above sea level; $\mathrm{ft}$, feet; gpm, gallons per minute; $\mu \mathrm{S} / \mathrm{cm}$, microsiemens per centimeter; $\mathrm{m}$, meters; $\mathrm{mg} / \mathrm{L}$, milligrams per liter; ${ }^{14} \mathrm{C}$, carbon-13 and carbon-14 isotopes; DG, dissolved gases; DO, dissolved oxygen; EB, equipment blank; Eh, redox potential; FA, filtered, acidified with nitric acid; FEHCL, filtered, acidified with hydrochloric acid; FU, filtered, unacidified; ${ }^{3} \mathrm{H}$, tritium; NA, not applicable; NM, not measured; $-\mathrm{R}$ (appended to sample name), replicate sample; RA, unfiltered, acidified with nitric acid; SAA, same as above; SC, specific conductance; SI, stable isotopes deuterium and oxygen-18; T, discharge temperature; UG, underground; $V$, volts]

\begin{tabular}{|c|c|c|c|c|c|c|c|c|c|c|c|c|}
\hline Name & Description & ID & \multicolumn{2}{|c|}{ Field parameters } & \multicolumn{8}{|c|}{ Samples collected } \\
\hline $\begin{array}{l}\text { Level } 2 \\
\quad \text { waste } \\
\text { rock }\end{array}$ & $\begin{array}{l}\text { Discharge from } \\
\text { waste rock } \\
\text { outside Level } \\
2 \text { portal }\end{array}$ & EC-MUSTD1 & 5.60 & 773 & $\mathrm{x}$ & $\mathrm{x}$ & $\mathrm{x}$ & & $\mathrm{x}$ & $\mathrm{x}$ & & \\
\hline $\begin{array}{l}\text { Redwell } \\
\quad \text { spring } 1\end{array}$ & $\begin{array}{l}\text { Located in Red- } \\
\text { well Basin }\end{array}$ & RW-S1 & 9.43 & 75 & $\mathrm{x}$ & $\mathrm{x}$ & $\mathrm{x}$ & $\mathrm{x}$ & $\mathrm{x}$ & $\mathrm{x}$ & $\mathrm{x}$ & $\mathrm{x}$ \\
\hline Redwell & "The Red Well," & RW-S2 & 0.54 & 249 & $\mathrm{x}$ & $\mathrm{x}$ & $\mathrm{x}$ & $\mathrm{x}$ & $\mathrm{x}$ & $\mathrm{x}$ & $\mathrm{x}$ & $\mathrm{x}$ \\
\hline spring 2 & $\begin{array}{l}\text { located in } \\
\text { Redwell } \\
\text { Basin }\end{array}$ & & SAA & SAA & $\mathrm{x}$ & $\mathrm{x}$ & $\mathrm{x}$ & $\mathrm{x}$ & $\mathrm{x}$ & $\mathrm{x}$ & $\mathrm{x}$ & $\mathrm{x}$ \\
\hline Well 1 & $\begin{array}{c}\text { Flowing well } \\
\quad \text { located in } \\
\text { Redwell } \\
\text { Basin }\end{array}$ & RW-W1 & 0.18 & 618 & & & & & & & $\mathrm{x}$ & $\mathrm{x}$ \\
\hline Pit 5 & Exploration pit & EC-P5 & 6.90 & 78 & $\mathrm{x}$ & $\mathrm{x}$ & $\mathrm{x}$ & & $\mathrm{x}$ & & & \\
\hline \multirow{9}{*}{$\begin{array}{l}\text { Level } 1 \\
\quad \text { portal }\end{array}$} & \multirow{9}{*}{$\begin{array}{l}\text { Discharge from } \\
\text { Level } 1 \text { portal } \\
\text { of Standard } \\
\text { Mine }\end{array}$} & \multirow[t]{9}{*}{ EC-MSTD1 } & 6.55 & 479 & $\mathrm{x}$ & $\mathrm{x}$ & $\mathrm{x}$ & & $\mathrm{x}$ & $\mathrm{x}$ & & \\
\hline & & & 8.23 & 518 & $\mathrm{x}$ & $\mathrm{x}$ & $\mathrm{x}$ & & $\mathrm{x}$ & $\mathrm{x}$ & & \\
\hline & & & SAA & SAA & $\mathrm{x}$ & $\mathrm{x}$ & $\mathrm{x}$ & & $\mathrm{x}$ & $\mathrm{x}$ & & \\
\hline & & & 6.31 & 452 & $\mathrm{x}$ & $\mathrm{x}$ & $\mathrm{x}$ & & $\mathrm{x}$ & $\mathrm{x}$ & & \\
\hline & & & SAA & SAA & $\mathrm{x}$ & $\mathrm{x}$ & $\mathrm{x}$ & & $\mathrm{x}$ & $\mathrm{x}$ & & \\
\hline & & & NM & 6132 & $\mathrm{x}$ & $\mathrm{x}$ & $\mathrm{x}$ & & $\mathrm{x}$ & $\mathrm{x}$ & & \\
\hline & & & NM & 5722 & $\mathrm{x}$ & $\mathrm{x}$ & $\mathrm{x}$ & & $\mathrm{x}$ & $\mathrm{x}$ & & \\
\hline & & & NM & 485 & $\mathrm{x}$ & $\mathrm{x}$ & $\mathrm{x}$ & & $\mathrm{x}$ & $\mathrm{x}$ & & \\
\hline & & & NM & 488 & $\mathrm{x}$ & $\mathrm{x}$ & $\mathrm{x}$ & & $\mathrm{x}$ & $\mathrm{x}$ & & \\
\hline
\end{tabular}




\section{Hydrogeochemical Investigation of the Standard Mine Vicinity, Upper Elk Creek Basin, Colorado}

Appendix 2. Sample information and field parameters.-Continued

$\left[{ }^{\circ} \mathrm{C}\right.$, degree Celsius; asl, above sea level; $\mathrm{ft}$, feet; gpm, gallons per minute; $\mu \mathrm{S} / \mathrm{cm}$, microsiemens per centimeter; $\mathrm{m}$, meters; $\mathrm{mg} / \mathrm{L}$, milligrams per liter; ${ }^{14} \mathrm{C}$, carbon-13 and carbon-14 isotopes; DG, dissolved gases; D0, dissolved oxygen; EB, equipment blank; Eh, redox potential; FA, filtered, acidified with nitric acid; FEHCL, filtered, acidified with hydrochloric acid; FU, filtered, unacidified; ${ }^{3} \mathrm{H}$, tritium; NA, not applicable; NM, not measured; -R (appended to sample name), replicate sample; RA, unfiltered, acidified with nitric acid; SAA, same as above SC, specific conductance; SI, stable isotopes deuterium and oxygen-18; T, discharge temperature; UG, underground; $V$, volts]

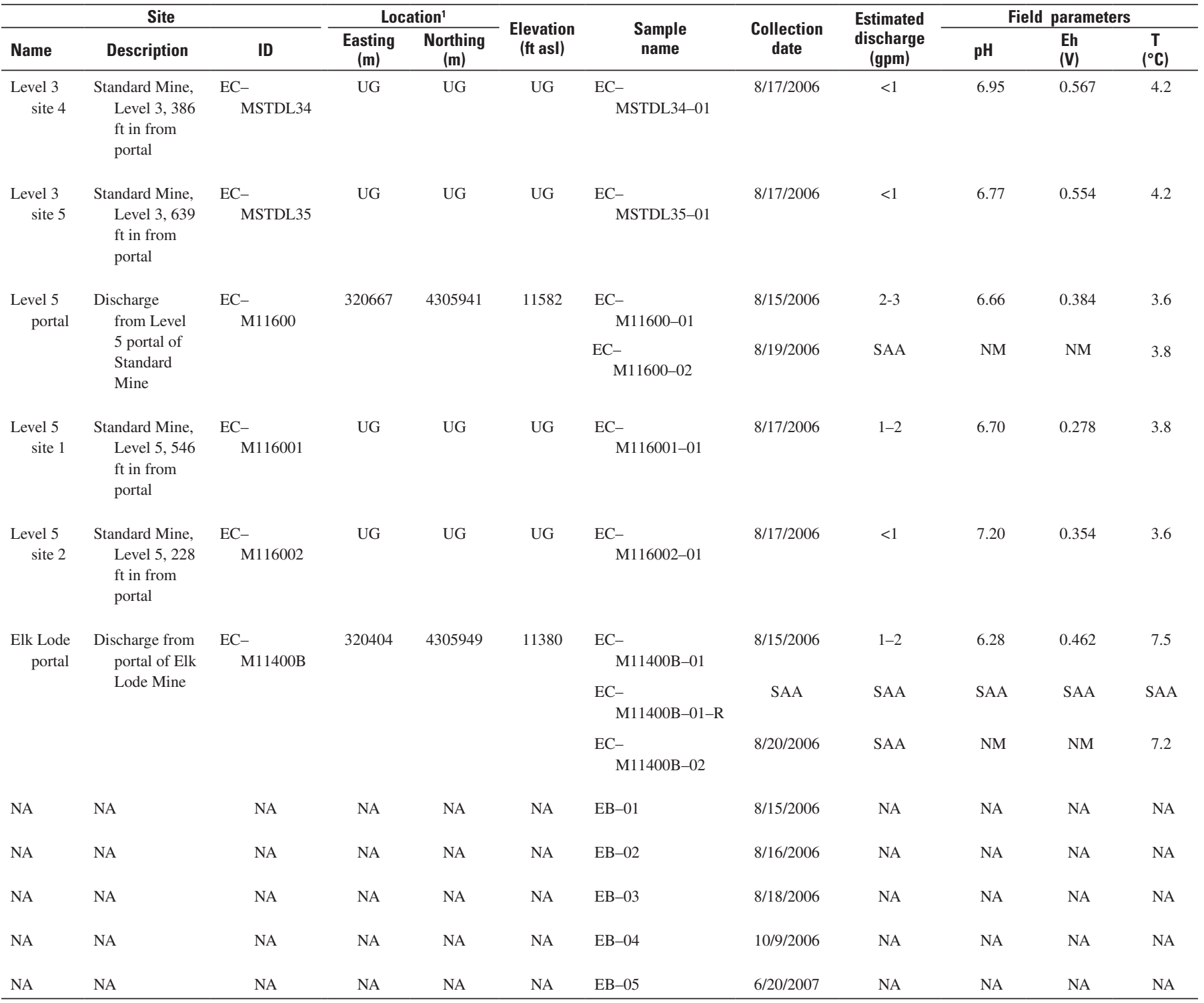


Appendix 2. Sample information and field parameters.-Continued

$\left[{ }^{\circ} \mathrm{C}\right.$, degree Celsius; asl, above sea level; $\mathrm{ft}$, feet; gpm, gallons per minute; $\mu \mathrm{S} / \mathrm{cm}$, microsiemens per centimeter; $\mathrm{m}$, meters; $\mathrm{mg} / \mathrm{L}$, milligrams per liter; ${ }^{14} \mathrm{C}$, carbon-13 and carbon-14 isotopes; DG, dissolved gases; DO, dissolved oxygen; EB, equipment blank; Eh, redox potential; $F A$, filtered, acidified with nitric acid; $\mathrm{FEHCL}$, filtered, acidified with hydrochloric acid; FU, filtered, unacidified; ${ }^{3} \mathrm{H}$, tritium; NA, not applicable; NM, not measured; -R (appended to sample name), replicate sample; RA, unfiltered, acidified with nitric acid; SAA, same as above SC, specific conductance; SI, stable isotopes deuterium and oxygen-18; T, discharge temperature; UG, underground; V, volts]

\begin{tabular}{|c|c|c|c|c|c|c|c|c|c|c|c|c|}
\hline \multicolumn{3}{|c|}{ Site } & \multicolumn{2}{|c|}{ Field parameters } & \multicolumn{8}{|c|}{ Samples collected } \\
\hline Name & Description & ID & $\begin{array}{c}\mathrm{DO} \\
(\mathrm{mg} / \mathrm{L})\end{array}$ & $\begin{array}{c}\mathrm{SC} \\
(\mathrm{mS} / \mathrm{cm})\end{array}$ & FU & FA & FEHCL & ${ }^{14} \mathrm{C}$ & RA & SI & ${ }^{3} \mathrm{H}$ & DG \\
\hline $\begin{array}{l}\text { Level } 3 \\
\quad \text { site } 4\end{array}$ & $\begin{array}{l}\text { Standard Mine, } \\
\text { Level 3, } 386 \\
\mathrm{ft} \text { in from } \\
\text { portal }\end{array}$ & $\begin{array}{l}\text { EC- } \\
\quad \text { MSTDL34 }\end{array}$ & 8.74 & 188 & $\mathrm{x}$ & $\mathrm{x}$ & $\mathrm{x}$ & & $\mathrm{x}$ & $\mathrm{x}$ & $\mathrm{x}$ & \\
\hline $\begin{array}{l}\text { Level } 3 \\
\quad \text { site } 5\end{array}$ & $\begin{array}{l}\text { Standard Mine, } \\
\text { Level 3, } 639 \\
\mathrm{ft} \text { in from } \\
\text { portal }\end{array}$ & $\begin{array}{l}\text { EC- } \\
\quad \text { MSTDL35 }\end{array}$ & 8.78 & 265 & $\mathrm{x}$ & $\mathrm{x}$ & $\mathrm{x}$ & & $\mathrm{x}$ & $\mathrm{x}$ & $\mathrm{x}$ & \\
\hline $\begin{array}{l}\text { Level } 5 \\
\quad \text { portal }\end{array}$ & $\begin{array}{l}\text { Discharge } \\
\text { from Level } \\
5 \text { portal of } \\
\text { Standard } \\
\text { Mine }\end{array}$ & $\begin{array}{l}\text { EC- } \\
\text { M11600 }\end{array}$ & $\begin{array}{l}8.55 \\
8.75\end{array}$ & $\begin{array}{l}215 \\
123\end{array}$ & $\mathrm{x}$ & $\mathrm{x}$ & $\mathrm{x}$ & & $\mathrm{x}$ & & $\mathrm{x}$ & \\
\hline $\begin{array}{l}\text { Level } 5 \\
\quad \text { site } 1\end{array}$ & $\begin{array}{l}\text { Standard Mine, } \\
\text { Level 5, 546 } \\
\mathrm{ft} \text { in from } \\
\text { portal }\end{array}$ & $\begin{array}{l}\text { EC- } \\
\quad \text { M116001 }\end{array}$ & 3.62 & 302 & $\mathrm{x}$ & $\mathrm{x}$ & $\mathrm{x}$ & & $\mathrm{x}$ & $\mathrm{x}$ & $\mathrm{x}$ & $\mathrm{x}$ \\
\hline $\begin{array}{l}\text { Level } 5 \\
\quad \text { site } 2\end{array}$ & $\begin{array}{l}\text { Standard Mine, } \\
\text { Level 5, } 228 \\
\mathrm{ft} \text { in from } \\
\text { portal }\end{array}$ & $\begin{array}{l}\text { EC- } \\
\quad \text { M116002 }\end{array}$ & NM & 241 & $\mathrm{x}$ & $\mathrm{x}$ & $\mathrm{x}$ & & $\mathrm{x}$ & $\mathrm{x}$ & $\mathrm{x}$ & \\
\hline \multirow[t]{3}{*}{$\begin{array}{r}\text { Elk Lode } \\
\text { portal }\end{array}$} & $\begin{array}{l}\text { Discharge from } \\
\text { portal of Elk }\end{array}$ & $\begin{array}{l}\text { EC- } \\
\quad \text { M11400B }\end{array}$ & 5.88 & 88 & $\mathrm{x}$ & $\mathrm{x}$ & $\mathrm{x}$ & & $\mathrm{x}$ & & & \\
\hline & Lode Mine & & SAA & SAA & $\mathrm{x}$ & $\mathrm{x}$ & $\mathrm{x}$ & & $\mathrm{x}$ & & & \\
\hline & & & 6.16 & 92 & & & & & & & $\mathrm{x}$ & $\mathrm{x}$ \\
\hline NA & NA & NA & NA & NA & $\mathrm{x}$ & $\mathrm{x}$ & $\mathrm{x}$ & & $\mathrm{x}$ & & & \\
\hline NA & NA & NA & NA & NA & $\mathrm{x}$ & $\mathrm{x}$ & $\mathrm{x}$ & & $\mathrm{x}$ & & & \\
\hline NA & NA & NA & NA & NA & $\mathrm{x}$ & $\mathrm{x}$ & $\mathrm{x}$ & & $\mathrm{x}$ & & & \\
\hline NA & NA & NA & NA & NA & $\mathrm{x}$ & $\mathrm{x}$ & $\mathrm{x}$ & & $\mathrm{x}$ & & & \\
\hline NA & NA & NA & NA & NA & $\mathrm{x}$ & $\mathrm{x}$ & $\mathrm{x}$ & & $\mathrm{x}$ & & & \\
\hline
\end{tabular}

${ }^{1}$ Coordinates are Universal Transverse Mercator (UTM) coordinate system, North American Datum of 1983, Zone 13S.

${ }^{2} \mathrm{Not}$ measured in situ, but generally within 12 hours of sampling and at a temperature $<16^{\circ} \mathrm{C}$. 

Appendix 3. Concentrations of Major lons
and Selected Metals 


\section{Hydrogeochemical Investigation of the Standard Mine Vicinity, Upper Elk Creek Basin, Colorado}

Appendix 3. Concentrations of major ions and selected metals.

$\left[{ }^{\circ} \mathrm{C}\right.$, degrees Celsius; $\mu \mathrm{S} / \mathrm{cm}$, microsiemens per centimeter; meq/L, milliequivalents per liter; $\mathrm{mg} / \mathrm{L}$, milligrams per liter; C.I., charge imbalance; $\mathrm{DO}$, dissolved oxygen; EB, equipment blank; Eh, redox potential; FA, filtered, acidified; Fe(II), ferrous iron; FU, filtered, unacidified; NC, not computed; NM, not measured; -R (appended to sample name), replicate sample; RA, unfiltered, acidified; SC, specific conductance; T, total; V, volts]

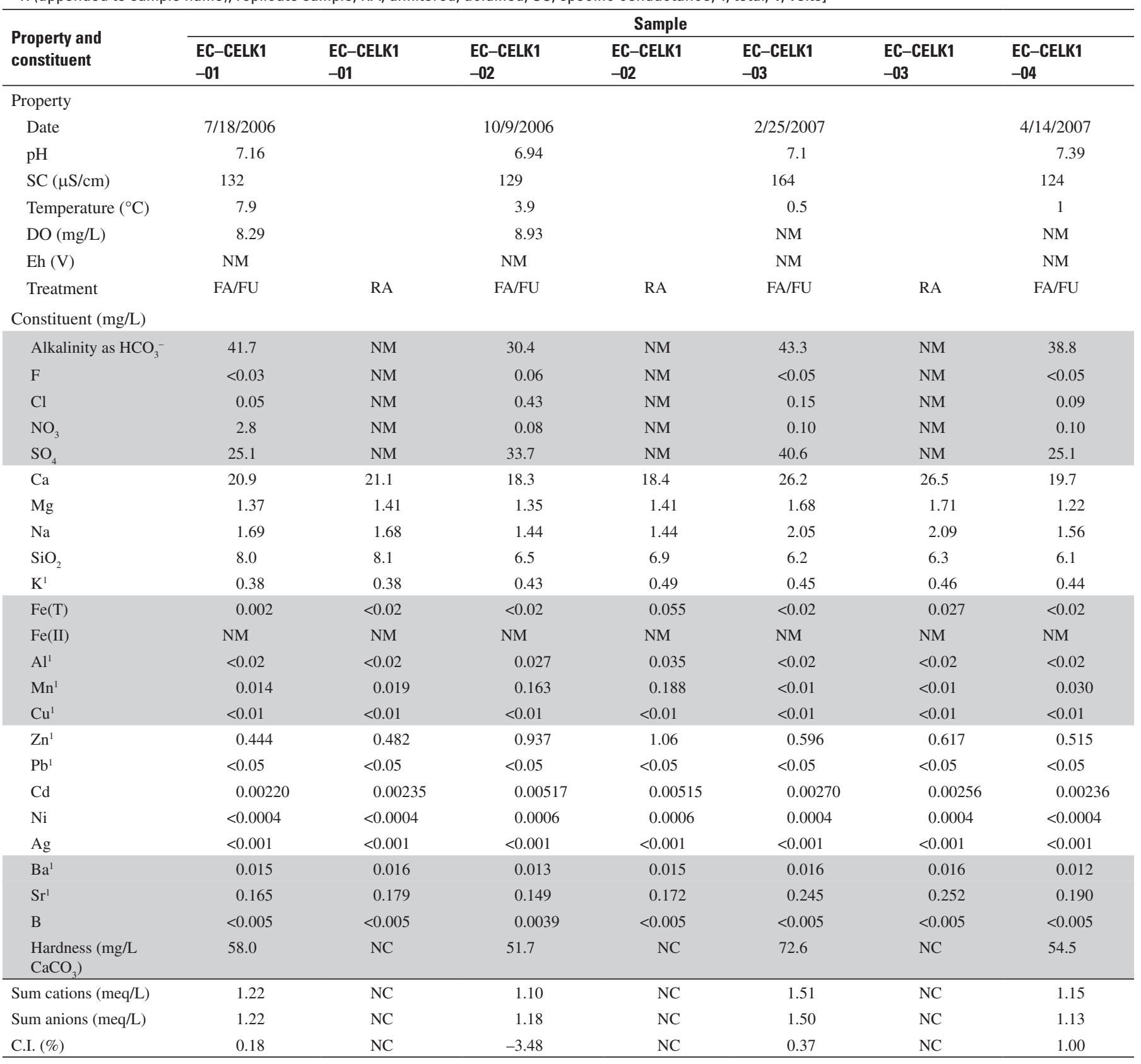


Appendix 3. Concentrations of major ions and selected metals.-Continued

$\left[{ }^{\circ} \mathrm{C}\right.$, degrees Celsius; $\mu \mathrm{S} / \mathrm{cm}$, microsiemens per centimeter; meq/L, milliequivalents per liter; $\mathrm{mg} / \mathrm{L}$, milligrams per liter; C.I., charge imbalance; $\mathrm{DO}$, dissolved oxygen; EB, equipment blank; Eh, redox potential; FA, filtered, acidified; Fe(II), ferrous iron; FU, filtered, unacidified; NC, not computed; NM, not measured; -R (appended to sample name), replicate sample; RA, unfiltered, acidified; SC, specific conductance; T, total; $V$, volts]

\begin{tabular}{|c|c|c|c|c|c|c|c|}
\hline \multirow{2}{*}{$\begin{array}{l}\text { Property and } \\
\text { constituent }\end{array}$} & \multicolumn{7}{|c|}{ Sample } \\
\hline & $\begin{array}{l}\text { EC-CELK1 } \\
-04\end{array}$ & $\begin{array}{l}\text { EC-CELK1 } \\
-05\end{array}$ & $\begin{array}{l}\text { EC-CELK1 } \\
-05\end{array}$ & $\begin{array}{l}\text { EC-CELK1 } \\
-06\end{array}$ & $\begin{array}{l}\text { EC-CELK1 } \\
-06\end{array}$ & $\begin{array}{l}\text { EC-CELK1 } \\
-07\end{array}$ & $\begin{array}{l}\text { EC-CELK1 } \\
-07\end{array}$ \\
\hline \multicolumn{8}{|l|}{ Property } \\
\hline Date & & $5 / 5 / 2007$ & & $5 / 15 / 2007$ & & $6 / 3 / 2007$ & \\
\hline $\mathrm{pH}$ & & 6.4 & & 6.12 & & 6.29 & \\
\hline $\mathrm{SC}(\mu \mathrm{S} / \mathrm{cm})$ & & 79 & & 70 & & 86 & \\
\hline Temperature $\left({ }^{\circ} \mathrm{C}\right)$ & & 1 & & 2.5 & & 7.4 & \\
\hline DO (mg/L) & & NM & & NM & & NM & \\
\hline Eh $(V)$ & & NM & & NM & & NM & \\
\hline Treatment & RA & $\mathrm{FA} / \mathrm{FU}$ & RA & FA/FU & RA & $\mathrm{FA} / \mathrm{FU}$ & RA \\
\hline \multicolumn{8}{|l|}{ Constituent (mg/L) } \\
\hline Alkalinity as $\mathrm{HCO}_{3}^{-}$ & NM & 23.6 & NM & 18.4 & NM & 23.4 & NM \\
\hline $\mathrm{F}$ & NM & $<0.05$ & NM & $<0.05$ & NM & $<0.05$ & NM \\
\hline $\mathrm{Cl}$ & NM & 0.07 & NM & 0.07 & NM & 0.08 & NM \\
\hline $\mathrm{NO}_{3}$ & NM & 0.08 & NM & 0.08 & NM & $<0.05$ & NM \\
\hline $\mathrm{SO}_{4}$ & NM & 16.1 & NM & 15.5 & NM & 19.1 & NM \\
\hline $\mathrm{Ca}$ & 19.2 & 12.1 & 11.6 & 9.66 & 9.59 & 12.8 & 12.7 \\
\hline $\mathrm{Mg}$ & 1.22 & 0.86 & 0.83 & 0.78 & 0.79 & 0.92 & 0.92 \\
\hline $\mathrm{Na}$ & 1.55 & 1.19 & 0.83 & 1.04 & 0.95 & 1.31 & 1.22 \\
\hline $\mathrm{SiO}_{2}$ & 6.1 & 5.4 & 5.4 & 4.9 & 5.1 & 5.5 & 5.5 \\
\hline $\mathrm{K}$ & 0.35 & 0.37 & 0.36 & 0.34 & 0.34 & 0.39 & 0.36 \\
\hline $\mathrm{Fe}(\mathrm{T})$ & 0.036 & 0.046 & 0.217 & 0.054 & 0.428 & 0.041 & 0.142 \\
\hline $\mathrm{Fe}(\mathrm{II})$ & NM & NM & NM & NM & NM & NM & NM \\
\hline $\mathrm{Al}$ & 0.026 & 0.033 & 0.135 & 0.044 & 0.201 & 0.044 & 0.095 \\
\hline $\mathrm{Mn}$ & 0.032 & 0.116 & 0.116 & 0.170 & 0.185 & 0.111 & 0.121 \\
\hline $\mathrm{Cu}$ & $<0.01$ & $<0.01$ & 0.011 & 0.011 & 0.019 & 0.010 & 0.014 \\
\hline $\mathrm{Zn}$ & 0.526 & 0.646 & 0.652 & 0.791 & 0.856 & 0.610 & 0.651 \\
\hline $\mathrm{Pb}$ & $<0.05$ & $<0.05$ & $<0.05$ & $<0.05$ & $<0.05$ & $<0.05$ & $<0.05$ \\
\hline $\mathrm{Cd}$ & 0.00232 & 0.00376 & 0.00366 & 0.00492 & 0.00488 & 0.00393 & 0.00381 \\
\hline $\mathrm{Ni}$ & $<0.0004$ & 0.0005 & 0.0005 & 0.0008 & 0.0006 & 0.0005 & 0.0005 \\
\hline $\mathrm{Ag}$ & $<0.001$ & $<0.001$ & $<0.001$ & $<0.001$ & $<0.001$ & $<0.001$ & $<0.001$ \\
\hline $\mathrm{Ba}$ & 0.012 & 0.0086 & 0.0087 & 0.0078 & 0.0086 & 0.010 & 0.011 \\
\hline $\mathrm{Sr}$ & 0.183 & 0.098 & 0.094 & 0.070 & 0.074 & 0.089 & 0.090 \\
\hline B & $<0.005$ & $<0.005$ & $<0.005$ & $<0.005$ & $<0.005$ & $<0.005$ & $<0.005$ \\
\hline Hardness ( $\mathrm{mg} / \mathrm{L} \mathrm{CaCO}_{3}$ ) & $\mathrm{NC}$ & 34.1 & $\mathrm{NC}$ & 27.7 & $\mathrm{NC}$ & 36.1 & $\mathrm{NC}$ \\
\hline Sum cations (meq/L) & $\mathrm{NC}$ & 0.75 & $\mathrm{NC}$ & 0.63 & $\mathrm{NC}$ & 0.79 & $\mathrm{NC}$ \\
\hline Sum anions (meq/L) & $\mathrm{NC}$ & 0.71 & $\mathrm{NC}$ & 0.61 & $\mathrm{NC}$ & 0.77 & $\mathrm{NC}$ \\
\hline C.I. $(\%)$ & $\mathrm{NC}$ & 2.81 & $\mathrm{NC}$ & 0.88 & $\mathrm{NC}$ & 1.70 & $\mathrm{NC}$ \\
\hline
\end{tabular}




\section{Hydrogeochemical Investigation of the Standard Mine Vicinity, Upper Elk Creek Basin, Colorado}

Appendix 3. Concentrations of major ions and selected metals.-Continued

$\left[{ }^{\circ} \mathrm{C}\right.$, degrees Celsius; $\mu \mathrm{S} / \mathrm{cm}$, microsiemens per centimeter; meq/L, milliequivalents per liter; $\mathrm{mg} / \mathrm{L}$, milligrams per liter; C.I., charge imbalance; $\mathrm{DO}$, dissolved oxygen; EB, equipment blank; Eh, redox potential; FA, filtered, acidified; Fe(II), ferrous iron; FU, filtered, unacidified; NC, not computed; NM, not measured; -R (appended to sample name), replicate sample; RA, unfiltered, acidified; SC, specific conductance; $T$, total; $V$, volts]

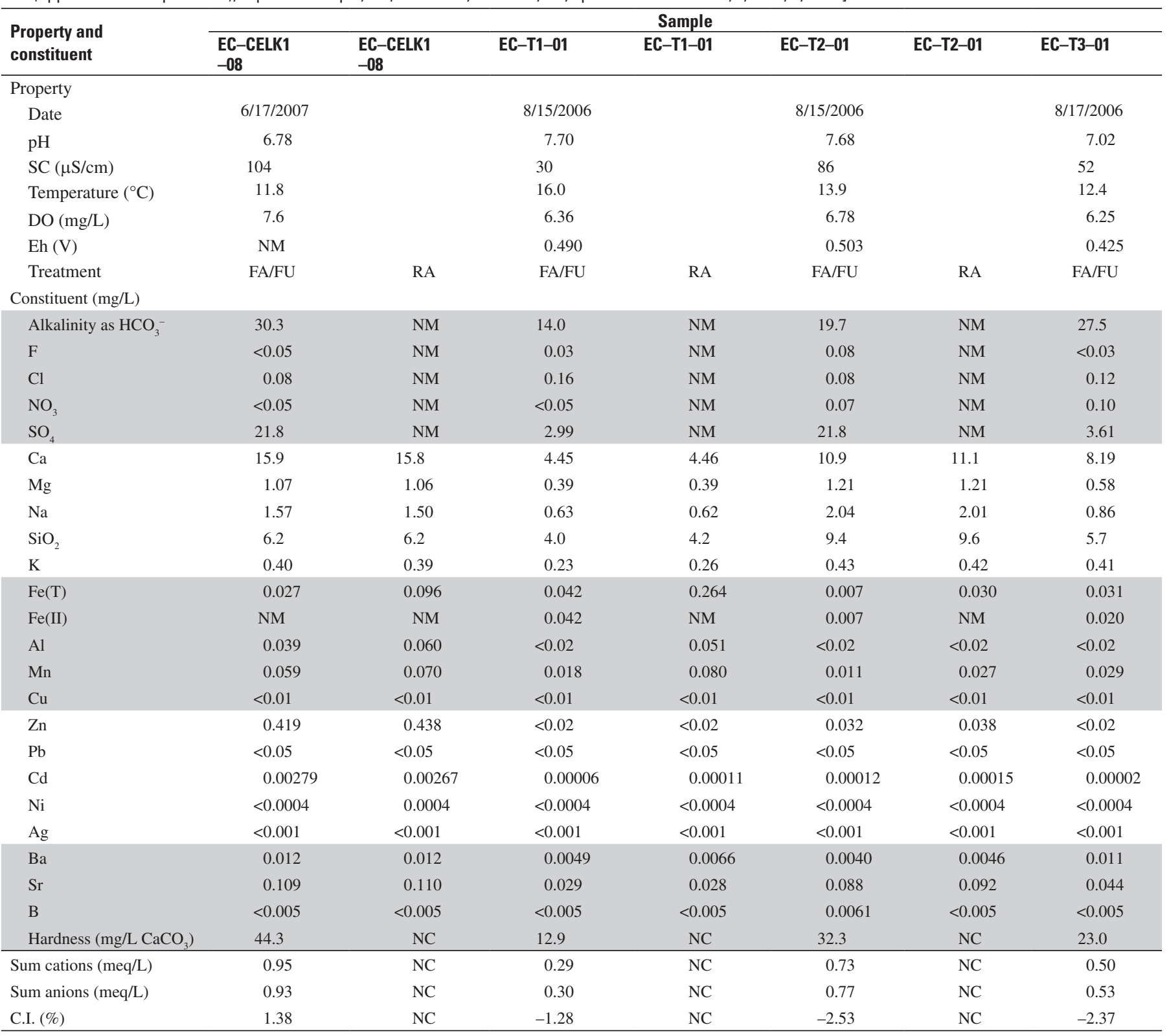


Appendix 3. Concentrations of major ions and selected metals.-Continued

$\left[{ }^{\circ} \mathrm{C}\right.$, degrees Celsius; $\mu \mathrm{S} / \mathrm{cm}$, microsiemens per centimeter; meq/L, milliequivalents per liter; $\mathrm{mg} / \mathrm{L}$, milligrams per liter; C.I., charge imbalance; $\mathrm{DO}$, dissolved oxygen; EB, equipment blank; Eh, redox potential; FA, filtered, acidified; Fe(II), ferrous iron; FU, filtered, unacidified; NC, not computed; NM, not measured; -R (appended to sample name), replicate sample; RA, unfiltered, acidified; SC, specific conductance; $T$, total; $V$, volts]

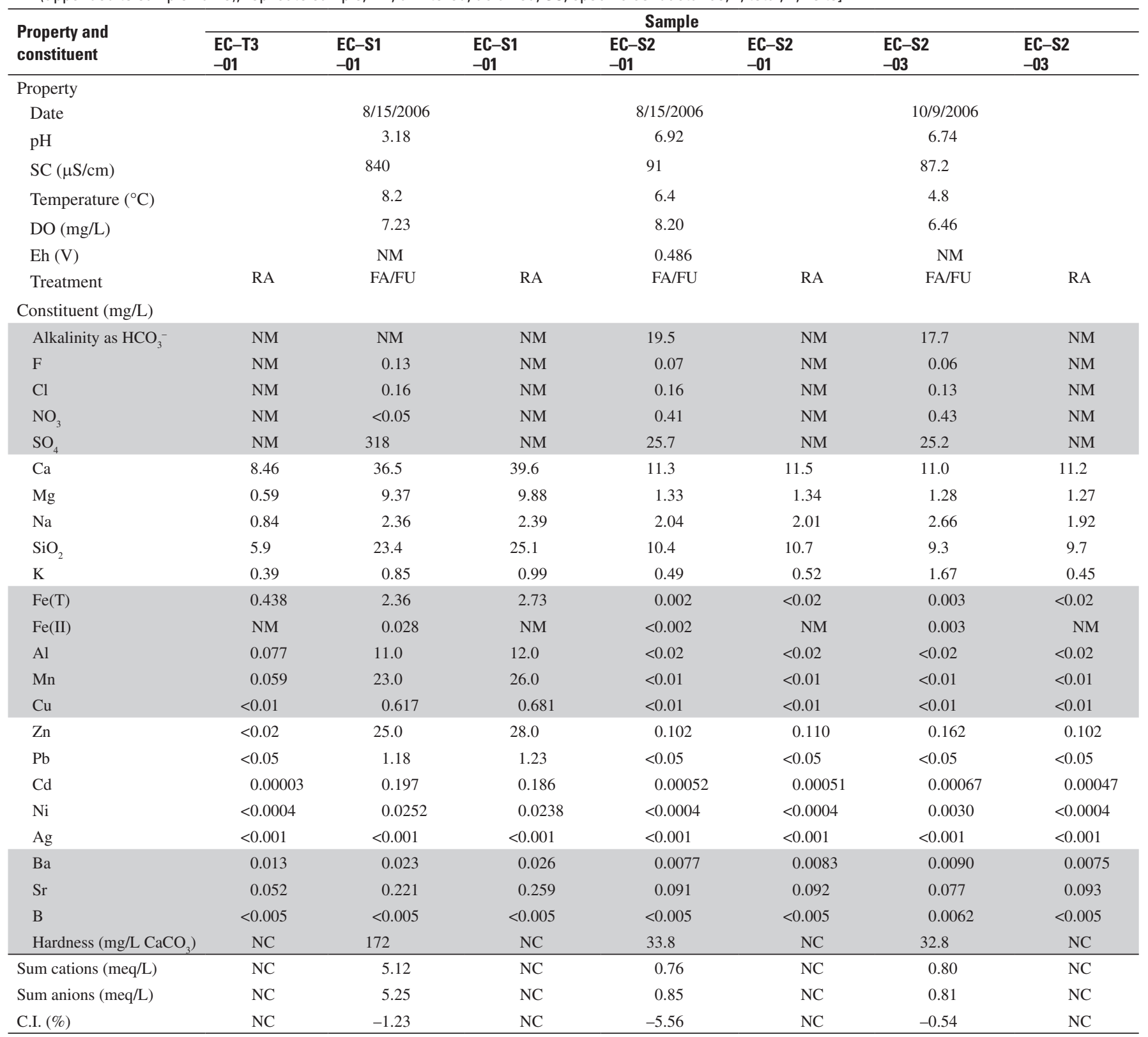


Appendix 3. Concentrations of major ions and selected metals.-Continued

$\left[{ }^{\circ} \mathrm{C}\right.$, degrees Celsius; $\mu \mathrm{S} / \mathrm{cm}$, microsiemens per centimeter; meq/L, milliequivalents per liter; mg/L, milligrams per liter; C.I., charge imbalance; DO, dissolved oxygen; EB, equipment blank; Eh, redox potential; FA, filtered, acidified; Fe(II), ferrous iron; FU, filtered, unacidified; NC, not computed; NM, not measured; -R (appended to sample name), replicate sample; RA, unfiltered, acidified; SC, specific conductance; T, total; V, volts]

\begin{tabular}{|c|c|c|c|c|c|c|c|}
\hline \multirow[b]{2}{*}{$\begin{array}{l}\text { Property and } \\
\text { constituent }\end{array}$} & \multicolumn{7}{|c|}{ Sample } \\
\hline & $\begin{array}{l}\text { EC-S2 } \\
-04\end{array}$ & $\begin{array}{l}\text { EC-S2 } \\
-04\end{array}$ & $\begin{array}{l}\text { EC-S3 } \\
-01\end{array}$ & $\begin{array}{l}\text { EC-S3 } \\
-01 \\
\end{array}$ & $\begin{array}{l}\text { EC-S4 } \\
-01 \\
\end{array}$ & $\begin{array}{l}\text { EC-S4 } \\
-01\end{array}$ & $\begin{array}{l}\text { EC-S5 } \\
-01\end{array}$ \\
\hline \multicolumn{8}{|l|}{ Property } \\
\hline Date & $6 / 17 / 2007$ & & $8 / 15 / 2006$ & & $8 / 15 / 2006$ & & $8 / 15 / 2006$ \\
\hline $\mathrm{pH}$ & 6.76 & & 6.66 & & 7.40 & & 6.24 \\
\hline $\mathrm{SC}(\mu \mathrm{S} / \mathrm{cm})$ & 52 & & 63 & & 108 & & 56 \\
\hline Temperature $\left({ }^{\circ} \mathrm{C}\right)$ & 3 & & 5.4 & & 3.9 & & 13.8 \\
\hline $\mathrm{DO}(\mathrm{mg} / \mathrm{L})$ & 9.23 & & 7.92 & & 9.03 & & 2.54 \\
\hline Eh $(V)$ & NM & & 0.485 & & 0.467 & & 0.458 \\
\hline Treatment & $\mathrm{Fa} / \mathrm{FU}$ & $\mathrm{RA}$ & $\mathrm{FA} / \mathrm{FU}$ & RA & $\mathrm{FA} / \mathrm{FU}$ & RA & $\mathrm{FA} / \mathrm{FU}$ \\
\hline \multicolumn{8}{|l|}{ Constituent (mg/L) } \\
\hline Alkalinity as $\mathrm{HCO}_{3}^{-}$ & 13.4 & NM & 22.3 & NM & 38.0 & NM & 28.0 \\
\hline $\mathrm{F}$ & $<0.05$ & NM & 0.07 & NM & 0.03 & NM & 0.03 \\
\hline $\mathrm{Cl}$ & 0.08 & NM & 0.06 & $\mathrm{NM}$ & 0.07 & NM & 0.21 \\
\hline $\mathrm{NO}_{3}$ & 0.50 & NM & 0.14 & $\mathrm{NM}$ & 0.33 & NM & 0.13 \\
\hline $\mathrm{SO}_{4}$ & 12.8 & NM & 11.9 & NM & 20.0 & NM & 5.90 \\
\hline $\mathrm{Ca}$ & 6.69 & 6.62 & 9.07 & 9.51 & 17.2 & 17.3 & 8.66 \\
\hline $\mathrm{Mg}$ & 0.75 & 0.74 & 0.67 & 0.68 & 0.78 & 0.82 & 0.58 \\
\hline $\mathrm{Na}$ & 1.58 & 1.25 & 1.11 & 1.11 & 1.53 & 1.56 & 0.92 \\
\hline $\mathrm{SiO}_{2}$ & 7.5 & 7.5 & 7.1 & 7.7 & 7.9 & 8.2 & 6.7 \\
\hline $\mathrm{K}$ & 0.37 & 0.33 & 0.30 & 0.32 & 0.27 & 0.24 & 0.60 \\
\hline $\mathrm{Fe}(\mathrm{T})$ & $<0.02$ & $<0.02$ & $<0.002$ & $<0.02$ & $<0.002$ & $<0.02$ & 0.015 \\
\hline $\mathrm{Fe}$ (II) & NM & NM & $<0.002$ & NM & $<0.002$ & NM & 0.004 \\
\hline $\mathrm{Al}$ & $<0.02$ & 0.023 & $<0.02$ & 0.033 & $<0.02$ & $<0.02$ & $<0.02$ \\
\hline $\mathrm{Mn}$ & $<0.01$ & $<0.01$ & $<0.01$ & $<0.01$ & $<0.01$ & $<0.01$ & 0.112 \\
\hline $\mathrm{Cu}$ & $<0.01$ & $<0.01$ & $<0.01$ & $<0.01$ & $<0.01$ & $<0.01$ & $<0.01$ \\
\hline $\mathrm{Zn}$ & 0.063 & 0.063 & $<0.02$ & $<0.02$ & $<0.02$ & $<0.02$ & $<0.02$ \\
\hline $\mathrm{Pb}$ & $<0.05$ & $<0.05$ & $<0.05$ & $<0.05$ & $<0.05$ & $<0.05$ & $<0.05$ \\
\hline $\mathrm{Cd}$ & 0.00032 & 0.00027 & $<0.00002$ & $<0.00002$ & $<0.00002$ & $<0.00002$ & 0.00006 \\
\hline $\mathrm{Ni}$ & $<0.0004$ & $<0.0004$ & $<0.0004$ & $<0.0004$ & $<0.0004$ & $<0.0004$ & $<0.0004$ \\
\hline $\mathrm{Ag}$ & $<0.001$ & $<0.001$ & $<0.001$ & $<0.001$ & $<0.001$ & $<0.001$ & $<0.001$ \\
\hline $\mathrm{Ba}$ & 0.0043 & 0.0043 & 0.0027 & 0.0031 & 0.0036 & 0.0040 & 0.010 \\
\hline $\mathrm{Sr}$ & 0.049 & 0.048 & 0.046 & 0.055 & 0.141 & 0.164 & 0.043 \\
\hline B & $<0.005$ & $<0.005$ & $<0.005$ & $<0.005$ & 0.0065 & $<0.005$ & $<0.005$ \\
\hline Hardness $\left(\mathrm{mg} / \mathrm{L} \mathrm{CaCO}_{3}\right)$ & 19.9 & $\mathrm{NC}$ & 25.5 & $\mathrm{NC}$ & 46.3 & $\mathrm{NC}$ & 24.3 \\
\hline Sum cations (meq/L) & 0.47 & $\mathrm{NC}$ & 0.56 & $\mathrm{NC}$ & 0.98 & $\mathrm{NC}$ & 0.54 \\
\hline Sum anions (meq/L) & 0.48 & $\mathrm{NC}$ & 0.61 & $\mathrm{NC}$ & 1.03 & $\mathrm{NC}$ & 0.59 \\
\hline C.I. $(\%)$ & -1.16 & $\mathrm{NC}$ & -4.77 & $\mathrm{NC}$ & -2.44 & $\mathrm{NC}$ & -4.46 \\
\hline
\end{tabular}


Appendix 3. Concentrations of major ions and selected metals.-Continued

$\left[{ }^{\circ} \mathrm{C}\right.$, degrees Celsius; $\mu \mathrm{S} / \mathrm{cm}$, microsiemens per centimeter; meq/L, milliequivalents per liter; $\mathrm{mg} / \mathrm{L}$, milligrams per liter; C.I., charge imbalance; DO, dissolved oxygen; EB, equipment blank; Eh, redox potential; FA, filtered, acidified; Fe(II), ferrous iron; FU, filtered, unacidified; NC, not computed; NM, not measured; $-\mathrm{R}$, (appended to sample name), replicate sample; RA, unfiltered, acidified; SC, specific conductance; $T$, total; V, volts]

\begin{tabular}{|c|c|c|c|c|c|c|c|}
\hline \multirow[b]{2}{*}{$\begin{array}{l}\text { Property and } \\
\text { constituent }\end{array}$} & \multicolumn{7}{|c|}{ Sample } \\
\hline & $\begin{array}{l}\text { EC-S5 } \\
-01\end{array}$ & $\begin{array}{l}\text { EC-S7 } \\
-01\end{array}$ & $\begin{array}{l}\text { EC-S7 } \\
-01\end{array}$ & $\begin{array}{l}\text { EC-S8A } \\
-01\end{array}$ & $\begin{array}{l}\text { EC-S8A } \\
-01\end{array}$ & $\begin{array}{l}\text { EC-S8A } \\
-03\end{array}$ & $\begin{array}{l}\text { EC-S8A } \\
-03\end{array}$ \\
\hline \multicolumn{8}{|l|}{ Property } \\
\hline Date & & $8 / 15 / 2006$ & & $8 / 16 / 2006$ & & $10 / 9 / 2006$ & \\
\hline $\mathrm{pH}$ & & 7.22 & & 7.13 & & 6.56 & \\
\hline $\mathrm{SC}(\mu \mathrm{S} / \mathrm{cm})$ & & 72 & & 180 & & 152 & \\
\hline Temperature $\left({ }^{\circ} \mathrm{C}\right)$ & & 5.2 & & 3.4 & & 3.5 & \\
\hline DO (mg/L) & & 6.81 & & 8.56 & & 7.68 & \\
\hline Eh (V) & & 0.484 & & 0.452 & & NM & \\
\hline Treatment & RA & $\mathrm{FA} / \mathrm{FU}$ & RA & $\mathrm{FA} / \mathrm{FU}$ & RA & $\mathrm{FA} / \mathrm{FU}$ & RA \\
\hline \multicolumn{8}{|l|}{ Constituent (mg/L) } \\
\hline Alkalinity as $\mathrm{HCO}_{3}^{-}$ & NM & 34.8 & NM & 49.8 & NM & 45.9 & NM \\
\hline $\mathrm{F}$ & NM & 0.03 & NM & 0.08 & NM & 0.09 & NM \\
\hline $\mathrm{Cl}$ & NM & 0.03 & NM & 0.11 & NM & 0.47 & NM \\
\hline $\mathrm{NO}_{3}$ & NM & $<0.05$ & NM & 0.29 & NM & 0.32 & NM \\
\hline $\mathrm{SO}_{4}$ & NM & 7.67 & NM & 46.7 & NM & 36.1 & NM \\
\hline $\mathrm{Ca}$ & 9.14 & 11.1 & 11.5 & 28.9 & 30.0 & 23.7 & 24.6 \\
\hline $\mathrm{Mg}$ & 0.64 & 0.67 & 0.67 & 1.41 & 1.51 & 1.18 & 1.20 \\
\hline $\mathrm{Na}$ & 0.94 & 1.26 & 1.22 & 1.90 & 1.93 & 1.71 & 1.67 \\
\hline $\mathrm{SiO}_{2}$ & 7.7 & 7.6 & 7.9 & 9.3 & 11.1 & 8.8 & 9.2 \\
\hline $\mathrm{K}$ & 0.67 & 0.15 & 0.15 & 0.42 & 0.53 & 0.34 & 0.39 \\
\hline $\mathrm{Fe}(\mathrm{T})$ & 0.248 & 0.003 & $<0.02$ & $<0.002$ & 0.477 & 0.012 & $<0.02$ \\
\hline $\mathrm{Fe}(\mathrm{II})$ & NM & $<0.002$ & NM & $<0.002$ & NM & $<0.002$ & NM \\
\hline $\mathrm{Al}$ & 0.270 & $<0.02$ & $<0.02$ & $<0.02$ & 0.507 & $<0.02$ & 0.025 \\
\hline $\mathrm{Mn}$ & 0.157 & $<0.01$ & $<0.01$ & $<0.01$ & 0.042 & $<0.01$ & $<0.01$ \\
\hline $\mathrm{Cu}$ & $<0.01$ & $<0.01$ & $<0.01$ & $<0.01$ & $<0.01$ & $<0.01$ & $<0.01$ \\
\hline $\mathrm{Zn}$ & 0.021 & $<0.02$ & $<0.02$ & $<0.02$ & $<0.02$ & $<0.02$ & $<0.02$ \\
\hline $\mathrm{Pb}$ & $<0.05$ & $<0.05$ & $<0.05$ & $<0.05$ & $<0.05$ & $<0.05$ & $<0.05$ \\
\hline $\mathrm{Cd}$ & 0.00010 & $<0.00002$ & $<0.00002$ & $<0.00002$ & 0.00002 & $<0.00002$ & $<0.00002$ \\
\hline $\mathrm{Ni}$ & 0.0004 & $<0.0004$ & $<0.0004$ & $<0.0004$ & $<0.0004$ & $<0.0004$ & $<0.0004$ \\
\hline $\mathrm{Ag}$ & $<0.001$ & $<0.001$ & $<0.001$ & $<0.001$ & $<0.001$ & $<0.001$ & $<0.001$ \\
\hline $\mathrm{Ba}$ & 0.014 & 0.0051 & 0.0054 & 0.0055 & 0.010 & 0.0046 & 0.0053 \\
\hline $\mathrm{Sr}$ & 0.051 & 0.054 & 0.061 & 0.143 & 0.165 & 0.116 & 0.120 \\
\hline B & $<0.005$ & $<0.005$ & $<0.005$ & $<0.005$ & $<0.005$ & $<0.005$ & $<0.005$ \\
\hline Hardness $\left(\mathrm{mg} / \mathrm{L} \mathrm{CaCO}_{3}\right)$ & $\mathrm{NC}$ & 30.5 & $\mathrm{NC}$ & 78.1 & $\mathrm{NC}$ & 64.2 & $\mathrm{NC}$ \\
\hline Sum cations (meq/L) & $\mathrm{NC}$ & 0.66 & $\mathrm{NC}$ & 1.58 & $\mathrm{NC}$ & 1.32 & $\mathrm{NC}$ \\
\hline Sum anions $(\mathrm{meq} / \mathrm{L})$ & $\mathrm{NC}$ & 0.73 & $\mathrm{NC}$ & 1.73 & $\mathrm{NC}$ & 1.48 & $\mathrm{NC}$ \\
\hline C.I. $(\%)$ & $\mathrm{NC}$ & -4.61 & $\mathrm{NC}$ & -4.39 & $\mathrm{NC}$ & -5.76 & $\mathrm{NC}$ \\
\hline
\end{tabular}


Appendix 3. Concentrations of major ions and selected metals.-Continued

$\left[{ }^{\circ} \mathrm{C}\right.$, degrees Celsius; $\mu \mathrm{S} / \mathrm{cm}$, microsiemens per centimeter; meq/L, milliequivalents per liter; mg/L, milligrams per liter; C.I., charge imbalance; DO, dissolved oxygen; EB, equipment blank; Eh, redox potential; FA, filtered, acidified; Fe(II), ferrous iron; FU, filtered, unacidified; NC, not computed; NM, not measured; -R (appended to sample name), replicate sample; RA, unfiltered, acidified; SC, specific conductance; T, total; V, volts]

\begin{tabular}{|c|c|c|c|c|c|c|c|}
\hline \multirow[b]{2}{*}{$\begin{array}{l}\text { Property and } \\
\text { constituent }\end{array}$} & \multicolumn{7}{|c|}{ Sample } \\
\hline & $\begin{array}{l}\text { EC-S8A } \\
-04\end{array}$ & $\begin{array}{l}\text { EC-S8A } \\
-04\end{array}$ & $\begin{array}{l}\text { EC-S8B } \\
-01\end{array}$ & $\begin{array}{l}\text { EC-S8B } \\
-01\end{array}$ & $\begin{array}{l}\text { EC-S9 } \\
-01\end{array}$ & $\begin{array}{l}\text { EC-S9 } \\
-01\end{array}$ & $\begin{array}{l}\text { EC-S10 } \\
-01\end{array}$ \\
\hline \multicolumn{8}{|l|}{ Property } \\
\hline Date & $6 / 17 / 2007$ & & $8 / 16 / 2006$ & & $8 / 16 / 2006$ & & $8 / 16 / 2006$ \\
\hline $\mathrm{pH}$ & 7.31 & & 7.35 & & 6.38 & & 4.71 \\
\hline $\mathrm{SC}(\mu \mathrm{S} / \mathrm{cm})$ & 157 & & 180 & & 109 & & 187 \\
\hline Temperature $\left({ }^{\circ} \mathrm{C}\right)$ & 2.9 & & 3.6 & & 5.5 & & 11.9 \\
\hline $\mathrm{DO}(\mathrm{mg} / \mathrm{L})$ & 9.42 & & 8.32 & & 6.36 & & 2.82 \\
\hline Eh $(\mathrm{V})$ & NM & & 0.450 & & 0.474 & & 0.571 \\
\hline Treatment & $\mathrm{FA} / \mathrm{FU}$ & RA & $\mathrm{FA} / \mathrm{FU}$ & RA & $\mathrm{FA} / \mathrm{FU}$ & RA & $\mathrm{FA} / \mathrm{FU}$ \\
\hline \multicolumn{8}{|l|}{ Constituent (mg/L) } \\
\hline Alkalinity as $\mathrm{HCO}_{3}^{-}$ & 41.2 & NM & 48.6 & NM & 19.2 & NM & $<1.0$ \\
\hline $\mathrm{F}$ & 0.05 & NM & 0.08 & NM & 0.06 & NM & 0.18 \\
\hline $\mathrm{Cl}$ & 0.09 & $\mathrm{NM}$ & 0.15 & NM & 0.11 & NM & 0.21 \\
\hline $\mathrm{NO}_{3}$ & 0.12 & $\mathrm{NM}$ & 0.22 & $\mathrm{NM}$ & $<0.05$ & NM & 0.12 \\
\hline $\mathrm{SO}_{4}$ & 37.4 & NM & 45.4 & NM & 34.2 & NM & 73.0 \\
\hline $\mathrm{Ca}$ & 25.9 & 26.1 & 28.8 & 29.6 & 16.1 & 15.5 & 17.3 \\
\hline $\mathrm{Mg}$ & 1.23 & 1.27 & 1.38 & 1.45 & 1.18 & 1.20 & 3.58 \\
\hline $\mathrm{Na}$ & 1.97 & 1.99 & 1.87 & 1.85 & 1.23 & 1.17 & 2.21 \\
\hline $\mathrm{SiO}_{2}$ & 7.7 & 7.9 & 9.4 & 10.2 & 7.6 & 7.9 & 15.8 \\
\hline K & 0.39 & 0.37 & 0.67 & 0.90 & 0.39 & 0.47 & 1.03 \\
\hline $\mathrm{Fe}(\mathrm{T})$ & $<0.02$ & 0.132 & 0.002 & 0.185 & 0.014 & 0.141 & 0.017 \\
\hline $\mathrm{Fe}(\mathrm{II})$ & NM & NM & 0.002 & $\mathrm{NM}$ & 0.010 & NM & 0.011 \\
\hline $\mathrm{Al}$ & 0.072 & 0.095 & $<0.02$ & 0.213 & $<0.02$ & 0.073 & 1.20 \\
\hline $\mathrm{Mn}$ & $<0.01$ & 0.013 & $<0.01$ & 0.026 & $<0.01$ & 0.019 & 0.816 \\
\hline $\mathrm{Cu}$ & $<0.01$ & $<0.01$ & $<0.01$ & $<0.01$ & $<0.01$ & $<0.01$ & 0.038 \\
\hline $\mathrm{Zn}$ & $<0.02$ & $<0.02$ & $<0.02$ & $<0.02$ & 0.195 & 0.216 & 3.33 \\
\hline $\mathrm{Pb}$ & $<0.05$ & $<0.05$ & $<0.05$ & $<0.05$ & $<0.05$ & $<0.05$ & 0.232 \\
\hline $\mathrm{Cd}$ & $<0.00002$ & $<0.00002$ & $<0.00002$ & 0.00002 & 0.00038 & 0.00043 & 0.0262 \\
\hline $\mathrm{Ni}$ & $<0.0004$ & $<0.0004$ & $<0.0004$ & $<0.0004$ & 0.0005 & 0.0005 & 0.0043 \\
\hline $\mathrm{Ag}$ & $<0.001$ & $<0.001$ & $<0.001$ & $<0.001$ & $<0.001$ & $<0.001$ & $<0.001$ \\
\hline $\mathrm{Ba}$ & 0.0048 & 0.0054 & 0.0052 & 0.0075 & 0.0038 & 0.0048 & 0.037 \\
\hline $\mathrm{Sr}$ & 0.122 & 0.125 & 0.143 & 0.163 & 0.094 & 0.095 & 0.118 \\
\hline B & 0.0089 & $<0.005$ & 0.0055 & $<0.005$ & $<0.005$ & $<0.005$ & 0.0066 \\
\hline Hardness $\left(\mathrm{mg} / \mathrm{L} \mathrm{CaCO}{ }_{3}\right)$ & 69.9 & $\mathrm{NC}$ & 77.8 & $\mathrm{NC}$ & 45.2 & $\mathrm{NC}$ & 59.6 \\
\hline Sum cations (meq/L) & 1.44 & $\mathrm{NC}$ & 1.58 & $\mathrm{NC}$ & 0.94 & $\mathrm{NC}$ & 1.43 \\
\hline Sum anions $(\mathrm{meq} / \mathrm{L})$ & 1.41 & $\mathrm{NC}$ & 1.68 & $\mathrm{NC}$ & 1.00 & $\mathrm{NC}$ & 1.40 \\
\hline C.I. $(\%)$ & 1.18 & $\mathrm{NC}$ & -3.10 & $\mathrm{NC}$ & -3.10 & $\mathrm{NC}$ & 1.20 \\
\hline
\end{tabular}


Appendix 3. Concentrations of major ions and selected metals.-Continued

$\left[{ }^{\circ} \mathrm{C}\right.$, degrees Celsius; $\mu \mathrm{S} / \mathrm{cm}$, microsiemens per centimeter; meq/L, milliequivalents per liter; $\mathrm{mg} / \mathrm{L}$, milligrams per liter; C.I., charge imbalance; DO, dissolved oxygen; EB, equipment blank; Eh, redox potential; FA, filtered, acidified; Fe(II), ferrous iron; FU, filtered, unacidified; NC, not computed; NM, not measured; -R (appended to sample name), replicate sample; RA, unfiltered, acidified; SC, specific conductance; T, total; $V$, volts]

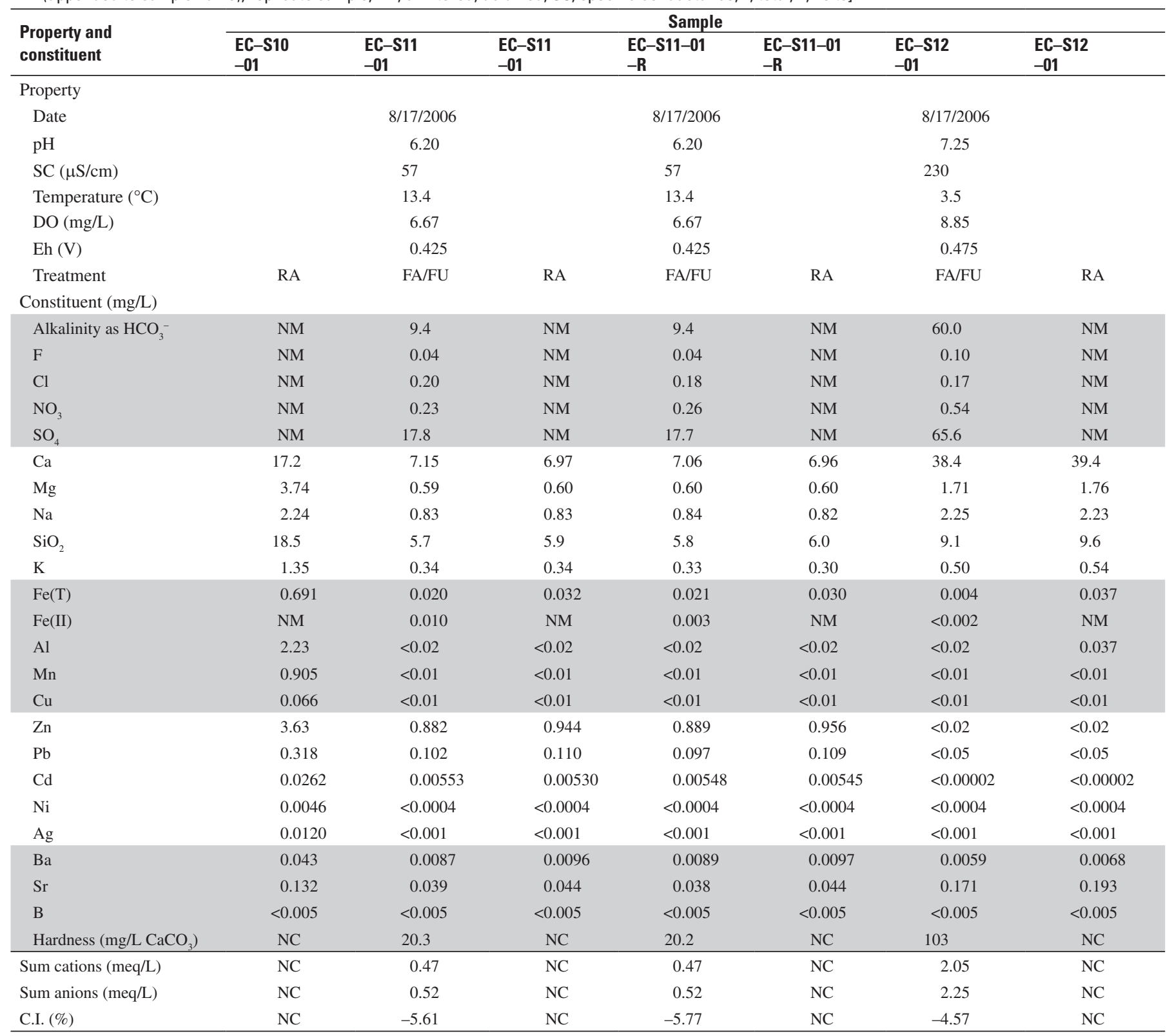


Appendix 3. Concentrations of major ions and selected metals.-Continued

$\left[{ }^{\circ} \mathrm{C}\right.$, degrees Celsius; $\mu \mathrm{S} / \mathrm{cm}$, microsiemens per centimeter; meq/L, milliequivalents per liter; mg/L, milligrams per liter; C.I., charge imbalance; DO, dissolved oxygen; EB, equipment blank; Eh, redox potential; FA, filtered, acidified; Fe(II), ferrous iron; FU, filtered, unacidified; NC, not computed; NM, not measured; -R (appended to sample name), replicate sample; RA, unfiltered, acidified; SC, specific conductance; T, total; V, volts]

\begin{tabular}{|c|c|c|c|c|c|c|c|}
\hline \multirow[b]{2}{*}{$\begin{array}{l}\text { Property and } \\
\text { constituent }\end{array}$} & \multicolumn{7}{|c|}{ Sample } \\
\hline & $\begin{array}{l}\text { EC-MUSTD1 } \\
-01\end{array}$ & $\begin{array}{l}\text { EC-MUSTD1 } \\
-01\end{array}$ & $\begin{array}{l}\text { RW-S1 } \\
-01\end{array}$ & $\begin{array}{l}\text { RW-S1 } \\
-01\end{array}$ & $\begin{array}{l}\text { RW-S2 } \\
-01\end{array}$ & $\begin{array}{l}\text { RW-S2 } \\
-01\end{array}$ & $\begin{array}{l}\text { RW-S2-01 } \\
-R\end{array}$ \\
\hline \multicolumn{8}{|l|}{ Property } \\
\hline Date & $7 / 18 / 2006$ & & $8 / 18 / 2006$ & & $8 / 18 / 2006$ & & $8 / 18 / 2006$ \\
\hline $\mathrm{pH}$ & 2.97 & & 6.65 & & 3.68 & & 3.68 \\
\hline $\mathrm{SC}(\mu \mathrm{S} / \mathrm{cm})$ & 773 & & 75 & & 249 & & 249 \\
\hline Temperature $\left({ }^{\circ} \mathrm{C}\right)$ & 10.0 & & 2.8 & & 5.40 & & 5.40 \\
\hline DO (mg/L) & 5.60 & & 9.43 & & 0.54 & & 0.54 \\
\hline Eh (V) & NM & & 0.476 & & 0.547 & & 0.547 \\
\hline Treatment & $\mathrm{FA} / \mathrm{FU}$ & RA & $\mathrm{FA} / \mathrm{FU}$ & RA & $\mathrm{FA} / \mathrm{FU}$ & RA & $\mathrm{FA} / \mathrm{FU}$ \\
\hline \multicolumn{8}{|l|}{ Constituent (mg/L) } \\
\hline Alkalinity as $\mathrm{HCO}_{3}^{-}$ & NM & NM & 11.2 & NM & NM & NM & NM \\
\hline $\mathrm{F}$ & 0.05 & NM & 0.06 & NM & 0.86 & NM & 0.88 \\
\hline $\mathrm{Cl}$ & 0.08 & NM & 0.07 & NM & 0.30 & NM & 0.18 \\
\hline $\mathrm{NO}_{3}$ & 0.43 & NM & 0.86 & NM & $<0.05$ & NM & $<0.05$ \\
\hline $\mathrm{SO}_{4}$ & 183 & NM & 25.4 & NM & 81.5 & NM & 79.5 \\
\hline $\mathrm{Ca}$ & 18.7 & 19.9 & 10.2 & 10.7 & 4.09 & 4.20 & 4.25 \\
\hline $\mathrm{Mg}$ & 3.85 & 4.05 & 0.96 & 0.96 & 1.68 & 1.72 & 1.74 \\
\hline $\mathrm{Na}$ & 1.66 & 1.68 & 0.94 & 0.92 & 0.65 & 0.59 & 0.69 \\
\hline $\mathrm{SiO}_{2}$ & 16.8 & 17.8 & 5.9 & 6.1 & 15.3 & 15.7 & 15.9 \\
\hline $\mathrm{K}$ & 0.59 & 0.73 & 0.35 & 0.35 & 1.17 & 1.27 & 1.20 \\
\hline $\mathrm{Fe}(\mathrm{T})$ & 2.30 & 2.58 & 0.002 & $<0.02$ & 17.1 & 22.0 & 18.4 \\
\hline $\mathrm{Fe}(\mathrm{II})$ & 0.122 & NM & $<0.002$ & NM & 17.0 & NM & 17.9 \\
\hline $\mathrm{Al}$ & 4.04 & 4.45 & $<0.02$ & 0.048 & 2.85 & 3.07 & 2.97 \\
\hline $\mathrm{Mn}$ & 5.42 & 6.18 & $<0.01$ & 0.014 & 1.48 & 1.63 & 1.54 \\
\hline $\mathrm{Cu}$ & 1.08 & 1.19 & $<0.01$ & $<0.01$ & $<0.01$ & $<0.01$ & $<0.01$ \\
\hline $\mathrm{Zn}$ & 24.0 & 27.0 & 0.148 & 0.160 & 5.84 & 6.19 & 6.10 \\
\hline $\mathrm{Pb}$ & 0.622 & 0.644 & $<0.05$ & $<0.05$ & 1.88 & 1.92 & 1.94 \\
\hline $\mathrm{Cd}$ & 0.190 & 0.181 & 0.00070 & 0.00068 & 0.0540 & 0.0542 & 0.0553 \\
\hline $\mathrm{Ni}$ & 0.0154 & 0.0150 & $<0.0004$ & $<0.0004$ & 0.0035 & 0.0036 & 0.0036 \\
\hline $\mathrm{Ag}$ & 0.0012 & 0.0011 & $<0.001$ & $<0.001$ & $<0.001$ & $<0.001$ & $<0.001$ \\
\hline $\mathrm{Ba}$ & 0.016 & 0.018 & 0.0073 & 0.0080 & 0.016 & 0.018 & 0.017 \\
\hline $\mathrm{Sr}$ & 0.148 & 0.171 & 0.057 & 0.067 & 0.016 & 0.018 & 0.017 \\
\hline B & $<0.005$ & $<0.005$ & $<0.005$ & $<0.005$ & $<0.005$ & $<0.005$ & $<0.005$ \\
\hline Hardness $\left(\mathrm{mg} / \mathrm{L} \mathrm{CaCO}{ }_{3}\right)$ & 72.8 & $\mathrm{NC}$ & 29.5 & $\mathrm{NC}$ & 50.3 & $\mathrm{NC}$ & 52.6 \\
\hline Sum cations (meq/L) & 3.51 & $\mathrm{NC}$ & 0.63 & $\mathrm{NC}$ & 1.62 & $\mathrm{NC}$ & 1.69 \\
\hline Sum anions (meq/L) & 3.21 & $\mathrm{NC}$ & 0.71 & $\mathrm{NC}$ & 1.55 & $\mathrm{NC}$ & 1.50 \\
\hline C.I. (\%) & 4.47 & $\mathrm{NC}$ & -6.52 & $\mathrm{NC}$ & 1.92 & $\mathrm{NC}$ & 5.97 \\
\hline
\end{tabular}


Appendix 3. Concentrations of major ions and selected metals.-Continued

$\left[{ }^{\circ} \mathrm{C}\right.$, degrees Celsius; $\mu \mathrm{S} / \mathrm{cm}$, microsiemens per centimeter; meq/L, milliequivalents per liter; $\mathrm{mg} / \mathrm{L}$, milligrams per liter; C.I., charge imbalance; DO, dissolved oxygen; EB, equipment blank; Eh, redox potential; FA, filtered, acidified; Fe(II), ferrous iron; FU, filtered, unacidified; NC, not computed; NM, not measured; -R (appended to sample name), replicate sample; RA, unfiltered, acidified; SC, specific conductance; T, total; $V$, volts]

\begin{tabular}{|c|c|c|c|c|c|c|c|}
\hline \multirow[b]{2}{*}{$\begin{array}{l}\text { Property and } \\
\text { constituent }\end{array}$} & \multicolumn{7}{|c|}{ Sample } \\
\hline & $\begin{array}{l}\text { RW-S2-01 } \\
-\mathrm{R}\end{array}$ & $\begin{array}{l}\text { EC-P4 } \\
-01\end{array}$ & $\begin{array}{l}\text { EC-P4 } \\
-01\end{array}$ & $\begin{array}{l}\text { EC-P5 } \\
-01\end{array}$ & $\begin{array}{l}\text { EC-P5 } \\
-01\end{array}$ & $\begin{array}{l}\text { EC-MSTD1 } \\
-01\end{array}$ & $\begin{array}{l}\text { EC-MSTD1 } \\
-01\end{array}$ \\
\hline \multicolumn{8}{|l|}{ Property } \\
\hline Date & & $8 / 16 / 2006$ & & $8 / 17 / 2006$ & & $7 / 18 / 2006$ & \\
\hline $\mathrm{pH}$ & & 5.60 & & 5.78 & & 5.62 & \\
\hline $\mathrm{SC}(\mu \mathrm{S} / \mathrm{cm})$ & & 47 & & 78 & & 479 & \\
\hline Temperature $\left({ }^{\circ} \mathrm{C}\right)$ & & 13.4 & & 9.2 & & 4.5 & \\
\hline $\mathrm{DO}(\mathrm{mg} / \mathrm{L})$ & & 6.70 & & 6.90 & & 6.55 & \\
\hline $\mathrm{Eh}(\mathrm{V})$ & & 0.491 & & 0.461 & & $\mathrm{NM}$ & \\
\hline Treatment & RA & $\mathrm{FA} / \mathrm{FU}$ & RA & $\mathrm{FA} / \mathrm{FU}$ & RA & $\mathrm{FA} / \mathrm{FU}$ & RA \\
\hline \multicolumn{8}{|l|}{ Constituent (mg/L) } \\
\hline Alkalinity as $\mathrm{HCO}_{3}^{-}$ & NM & 2.0 & NM & 4.6 & NM & 6.7 & NM \\
\hline $\mathrm{F}$ & NM & 0.04 & NM & 0.09 & NM & 0.30 & NM \\
\hline $\mathrm{Cl}$ & NM & 0.09 & NM & 0.12 & NM & 0.14 & NM \\
\hline $\mathrm{NO}_{3}$ & NM & $<0.05$ & NM & $<0.05$ & NM & 1.8 & NM \\
\hline $\mathrm{SO}_{4}$ & NM & 16.2 & NM & 27.5 & NM & 212 & NM \\
\hline $\mathrm{Ca}$ & 4.34 & 4.38 & 4.41 & 7.91 & 7.98 & 55.8 & 60.9 \\
\hline $\mathrm{Mg}$ & 1.77 & 0.84 & 0.85 & 1.56 & 1.57 & 6.34 & 6.80 \\
\hline $\mathrm{Na}$ & 0.61 & 0.58 & 0.58 & 1.27 & 1.27 & 2.59 & 2.69 \\
\hline $\mathrm{SiO}_{2}$ & 16.3 & 2.7 & 3.0 & 7.9 & 8.2 & 10.9 & 12.0 \\
\hline $\mathrm{K}$ & 1.34 & 0.62 & 0.73 & 0.48 & 0.48 & 0.87 & 1.01 \\
\hline $\mathrm{Fe}(\mathrm{T})$ & 22.0 & 0.188 & 2.09 & 0.055 & 0.123 & 0.570 & 1.70 \\
\hline $\mathrm{Fe}(\mathrm{II})$ & NM & 0.181 & NM & 0.034 & NM & 0.303 & NM \\
\hline $\mathrm{Al}$ & 3.14 & $<0.02$ & 0.065 & 0.048 & 0.068 & 0.390 & 0.977 \\
\hline $\mathrm{Mn}$ & 1.68 & 0.086 & 0.104 & 0.328 & 0.348 & 9.00 & 10.0 \\
\hline $\mathrm{Cu}$ & $<0.01$ & $<0.01$ & 0.073 & $<0.01$ & $<0.01$ & 0.419 & 0.508 \\
\hline $\mathrm{Zn}$ & 6.43 & 0.174 & 0.211 & 0.777 & 0.857 & 24.0 & 27.0 \\
\hline $\mathrm{Pb}$ & 1.99 & 0.410 & 1.05 & $<0.05$ & $<0.05$ & 0.859 & 1.16 \\
\hline $\mathrm{Cd}$ & 0.0526 & 0.00071 & 0.00090 & 0.00482 & 0.00514 & 0.154 & 0.154 \\
\hline $\mathrm{Ni}$ & 0.0034 & 0.0007 & 0.0009 & 0.0010 & 0.0011 & 0.0155 & 0.0146 \\
\hline $\mathrm{Ag}$ & $<0.001$ & $<0.001$ & 0.0048 & $<0.001$ & $<0.001$ & $<0.001$ & $<0.001$ \\
\hline $\mathrm{Ba}$ & 0.018 & 0.043 & 0.047 & 0.041 & 0.046 & 0.013 & 0.015 \\
\hline $\mathrm{Sr}$ & 0.019 & 0.033 & 0.033 & 0.058 & 0.069 & 0.448 & 0.530 \\
\hline B & $<0.005$ & $<0.005$ & $<0.005$ & $<0.005$ & $<0.005$ & 0.012 & 0.011 \\
\hline Hardness $\left(\mathrm{mg} / \mathrm{L} \mathrm{CaCO}{ }_{3}\right)$ & $\mathrm{NC}$ & 14.9 & $\mathrm{NC}$ & 26.9 & $\mathrm{NC}$ & 183 & $\mathrm{NC}$ \\
\hline Sum cations (meq/L) & $\mathrm{NC}$ & 0.34 & $\mathrm{NC}$ & 0.62 & $\mathrm{NC}$ & 3.99 & $\mathrm{NC}$ \\
\hline Sum anions $(\mathrm{meq} / \mathrm{L})$ & $\mathrm{NC}$ & 0.37 & $\mathrm{NC}$ & 0.63 & $\mathrm{NC}$ & 3.96 & $\mathrm{NC}$ \\
\hline C.I. $(\%)$ & $\mathrm{NC}$ & -3.22 & $\mathrm{NC}$ & -1.55 & $\mathrm{NC}$ & 0.32 & $\mathrm{NC}$ \\
\hline
\end{tabular}


Appendix 3. Concentrations of major ions and selected metals.-Continued

$\left[{ }^{\circ} \mathrm{C}\right.$, degrees Celsius; $\mu \mathrm{S} / \mathrm{cm}$, microsiemens per centimeter; meq/L, milliequivalents per liter; mg/L, milligrams per liter; C.I., charge imbalance; DO, dissolved oxygen; EB, equipment blank; Eh, redox potential; FA, filtered, acidified; Fe(II), ferrous iron; FU, filtered, unacidified; NC, not computed; NM, not measured; -R (appended to sample name), replicate sample; RA, unfiltered, acidified; SC, specific conductance; T, total; V, volts]

\begin{tabular}{|c|c|c|c|c|c|c|c|}
\hline \multirow{2}{*}{$\begin{array}{l}\text { Property and } \\
\text { constituent }\end{array}$} & \multicolumn{7}{|c|}{ Sample } \\
\hline & $\begin{array}{l}\text { EC-MSTD1 } \\
-02\end{array}$ & $\begin{array}{l}\text { EC-MSTD1 } \\
-02\end{array}$ & $\begin{array}{l}\text { EC-MSTD1 } \\
-02 R\end{array}$ & $\begin{array}{l}\text { EC-MSTD1 } \\
-02 R\end{array}$ & $\begin{array}{l}\text { EC-MSTD1 } \\
-03\end{array}$ & $\begin{array}{l}\text { EC-MSTD1 } \\
-03\end{array}$ & $\begin{array}{l}\text { EC-MSTD1 } \\
-03 R\end{array}$ \\
\hline \multicolumn{8}{|l|}{ Property } \\
\hline Date & $8 / 16 / 2006$ & & $8 / 16 / 2006$ & & $10 / 9 / 2006$ & & $10 / 9 / 2006$ \\
\hline $\mathrm{pH}$ & 6.20 & & 6.20 & & 5.58 & & 5.58 \\
\hline $\mathrm{SC}(\mu \mathrm{S} / \mathrm{cm})$ & 518 & & 518 & & 452 & & 452 \\
\hline Temperature $\left({ }^{\circ} \mathrm{C}\right)$ & 4.5 & & 4.5 & & 4.5 & & 4.5 \\
\hline DO (mg/L) & 8.23 & & 8.23 & & 6.31 & & 6.31 \\
\hline Eh $(V)$ & 0.422 & & 0.422 & & NM & & NM \\
\hline Treatment & FA/FU & RA & $\mathrm{FA} / \mathrm{FU}$ & RA & FA/FU & RA & FA/FU \\
\hline \multicolumn{8}{|l|}{ Constituent (mg/L) } \\
\hline Alkalinity as $\mathrm{HCO}_{3}^{-}$ & 12.0 & NM & 11.7 & NM & 3.5 & NM & 3.4 \\
\hline $\mathrm{F}$ & 0.35 & NM & 0.35 & NM & 0.34 & NM & 0.37 \\
\hline $\mathrm{Cl}$ & 0.15 & NM & 0.15 & NM & 0.12 & NM & 0.17 \\
\hline $\mathrm{NO}_{3}$ & 0.26 & NM & 0.28 & $\mathrm{NM}$ & 0.62 & NM & 0.66 \\
\hline $\mathrm{SO}_{4}$ & 232 & NM & 233 & NM & 235 & NM & 232 \\
\hline $\mathrm{Ca}$ & 60.4 & 63.0 & 60.6 & 65.5 & 58.5 & 60.2 & 55.9 \\
\hline $\mathrm{Mg}$ & 6.91 & 7.10 & 6.94 & 7.36 & 6.89 & 6.54 & 6.49 \\
\hline $\mathrm{Na}$ & 2.74 & 2.77 & 2.76 & 2.80 & 2.63 & 2.51 & 2.54 \\
\hline $\mathrm{SiO}_{2}$ & 10.6 & 11.4 & 10.6 & 11.6 & 12.0 & 12.2 & 11.5 \\
\hline $\mathrm{K}$ & 0.91 & 1.00 & 0.91 & 1.04 & 0.88 & 1.00 & 0.85 \\
\hline $\mathrm{Fe}(\mathrm{T})$ & 0.510 & 1.68 & 0.518 & 1.73 & 1.79 & 3.89 & 1.70 \\
\hline $\mathrm{Fe}(\mathrm{II})$ & 0.510 & NM & 0.499 & $\mathrm{NM}$ & 1.58 & $\mathrm{NM}$ & 1.51 \\
\hline $\mathrm{Al}$ & 0.221 & 0.849 & 0.236 & 0.846 & 0.489 & 1.30 & 0.485 \\
\hline $\mathrm{Mn}$ & 10.0 & 11.0 & 10.0 & 12.0 & 9.79 & 10.0 & 9.48 \\
\hline $\mathrm{Cu}$ & 0.226 & 0.304 & 0.227 & 0.309 & 0.375 & 0.443 & 0.368 \\
\hline $\mathrm{Zn}$ & 24.0 & 27.0 & 24.0 & 27.0 & 25.0 & 27.0 & 24.0 \\
\hline $\mathrm{Pb}$ & 0.661 & 1.02 & 0.672 & 1.03 & 1.09 & 1.54 & 1.04 \\
\hline $\mathrm{Cd}$ & 0.151 & 0.148 & 0.156 & 0.147 & 0.155 & 0.150 & 0.156 \\
\hline $\mathrm{Ni}$ & 0.0162 & 0.0154 & 0.0167 & 0.0159 & 0.0184 & 0.0173 & 0.0184 \\
\hline $\mathrm{Ag}$ & $<0.001$ & $<0.001$ & $<0.001$ & $<0.001$ & 0.0012 & 0.0013 & 0.0012 \\
\hline $\mathrm{Ba}$ & 0.014 & 0.015 & 0.014 & 0.015 & 0.014 & 0.015 & 0.014 \\
\hline $\mathrm{Sr}$ & 0.487 & 0.552 & 0.489 & 0.572 & 0.468 & 0.532 & 0.448 \\
\hline B & 0.013 & 0.011 & 0.011 & 0.011 & 0.012 & 0.0082 & 0.0098 \\
\hline Hardness $\left(\mathrm{mg} / \mathrm{L} \mathrm{CaCO}_{3}\right)$ & 199 & $\mathrm{NC}$ & 200 & $\mathrm{NC}$ & 196 & $\mathrm{NC}$ & 187 \\
\hline Sum cations (meq/L) & 4.21 & $\mathrm{NC}$ & 4.22 & $\mathrm{NC}$ & 4.21 & $\mathrm{NC}$ & 4.02 \\
\hline Sum anions (meq/L) & 4.37 & $\mathrm{NC}$ & 4.39 & $\mathrm{NC}$ & 4.29 & $\mathrm{NC}$ & 4.26 \\
\hline C.I. $(\%)$ & -1.87 & $\mathrm{NC}$ & -1.88 & $\mathrm{NC}$ & -1.00 & $\mathrm{NC}$ & -2.87 \\
\hline
\end{tabular}


Appendix 3. Concentrations of major ions and selected metals.-Continued

$\left[{ }^{\circ} \mathrm{C}\right.$, degrees Celsius; $\mu \mathrm{S} / \mathrm{cm}$, microsiemens per centimeter; meq/L, milliequivalents per liter; $\mathrm{mg} / \mathrm{L}$, milligrams per liter; C.I., charge imbalance; $\mathrm{DO}$, dissolved oxygen; EB, equipment blank; Eh, redox potential; FA, filtered, acidified; Fe(II), ferrous iron; FU, filtered, unacidified; NC, not computed; NM, not measured; -R (appended to sample name), replicate sample; RA, unfiltered, acidified; SC, specific conductance; T, total; $V$, volts]

\begin{tabular}{|c|c|c|c|c|c|c|c|}
\hline \multirow[b]{2}{*}{$\begin{array}{l}\text { Property and } \\
\text { constituent }\end{array}$} & \multicolumn{7}{|c|}{ Sample } \\
\hline & $\begin{array}{l}\text { EC-MSTD1 } \\
-03 R\end{array}$ & $\begin{array}{l}\text { EC-MSTD1 } \\
-04\end{array}$ & $\begin{array}{l}\text { EC-MSTD1 } \\
-04\end{array}$ & $\begin{array}{l}\text { EC-MSTD1 } \\
-05\end{array}$ & $\begin{array}{l}\text { EC-MSTD1 } \\
-05\end{array}$ & $\begin{array}{l}\text { EC-MSTD1 } \\
-06\end{array}$ & $\begin{array}{l}\text { EC-MSTD1 } \\
-06\end{array}$ \\
\hline \multicolumn{8}{|l|}{ Property } \\
\hline $\mathrm{pH}$ & & 6.60 & & 6.68 & & 4.03 & \\
\hline $\mathrm{SC}(\mu \mathrm{S} / \mathrm{cm})$ & & 613 & & 572 & & 485 & \\
\hline Temperature $\left({ }^{\circ} \mathrm{C}\right)$ & & 0.5 & & 0.5 & & 0.5 & \\
\hline Treatment & RA & $\mathrm{FA} / \mathrm{FU}$ & RA & $\mathrm{FA} / \mathrm{FU}$ & RA & FA/FU & RA \\
\hline \multicolumn{8}{|l|}{ Constituent (mg/L) } \\
\hline Alkalinity as $\mathrm{HCO}_{3}^{-}$ & NM & 25.2 & NM & 22.7 & NM & NM & NM \\
\hline $\mathrm{F}$ & NM & 0.49 & NM & 0.44 & NM & 0.13 & NM \\
\hline $\mathrm{Cl}$ & NM & 0.22 & NM & 0.19 & NM & 0.19 & NM \\
\hline $\mathrm{NO}_{3}$ & NM & $<0.05$ & NM & $<0.05$ & NM & 0.50 & NM \\
\hline $\mathrm{Na}$ & 2.55 & 3.56 & 3.80 & 3.41 & 3.59 & 2.31 & 2.60 \\
\hline $\mathrm{SiO}_{2}$ & 12.4 & 8.4 & 8.8 & 9.0 & 9.5 & 10.0 & 9.4 \\
\hline $\mathrm{K}$ & 1.07 & 1.10 & 1.14 & 1.04 & 1.08 & 0.86 & 1.91 \\
\hline $\mathrm{Fe}(\mathrm{T})$ & 3.65 & 0.277 & 1.14 & 0.280 & 1.55 & 1.90 & 4.79 \\
\hline $\mathrm{Fe}(\mathrm{II})$ & NM & 0.227 & NM & 0.227 & NM & 1.54 & NM \\
\hline $\mathrm{Al}$ & 1.32 & $<0.02$ & 0.283 & $<0.02$ & 0.622 & 1.63 & 1.63 \\
\hline $\mathrm{Mn}$ & 11.0 & 11.0 & 11.0 & 10.0 & 11.0 & 7.96 & 7.35 \\
\hline $\mathrm{Cu}$ & 0.435 & 0.080 & 0.131 & 0.113 & 0.203 & 0.590 & 0.560 \\
\hline $\mathrm{Zn}$ & 27.0 & 25.0 & 26.0 & 25.0 & 26.0 & 23.0 & 22.0 \\
\hline $\mathrm{Pb}$ & 1.58 & 0.067 & 0.321 & 0.205 & 0.678 & 1.78 & 1.67 \\
\hline $\mathrm{Cd}$ & 0.149 & 0.132 & 0.132 & 0.138 & 0.134 & 0.141 & 0.133 \\
\hline Sum anions (meq/L) & $\mathrm{NC}$ & 5.37 & $\mathrm{NC}$ & 5.12 & $\mathrm{NC}$ & 3.99 & $\mathrm{NC}$ \\
\hline C.I. $(\%)$ & $\mathrm{NC}$ & -0.02 & $\mathrm{NC}$ & 0.34 & $\mathrm{NC}$ & 0.79 & $\mathrm{NC}$ \\
\hline
\end{tabular}


Appendix 3. Concentrations of major ions and selected metals.-Continued

$\left[{ }^{\circ} \mathrm{C}\right.$, degrees Celsius; $\mu \mathrm{S} / \mathrm{cm}$, microsiemens per centimeter; meq/L, milliequivalents per liter; $\mathrm{mg} / \mathrm{L}$, milligrams per liter; C.I., charge imbalance; $\mathrm{DO}$, dissolved oxygen; EB, equipment blank; Eh, redox potential; FA, filtered, acidified; Fe(II), ferrous iron; FU, filtered, unacidified; NC, not computed; NM, not measured; -R (appended to sample name), replicate sample; RA, unfiltered, acidified; SC, specific conductance; T, total; V, volts]

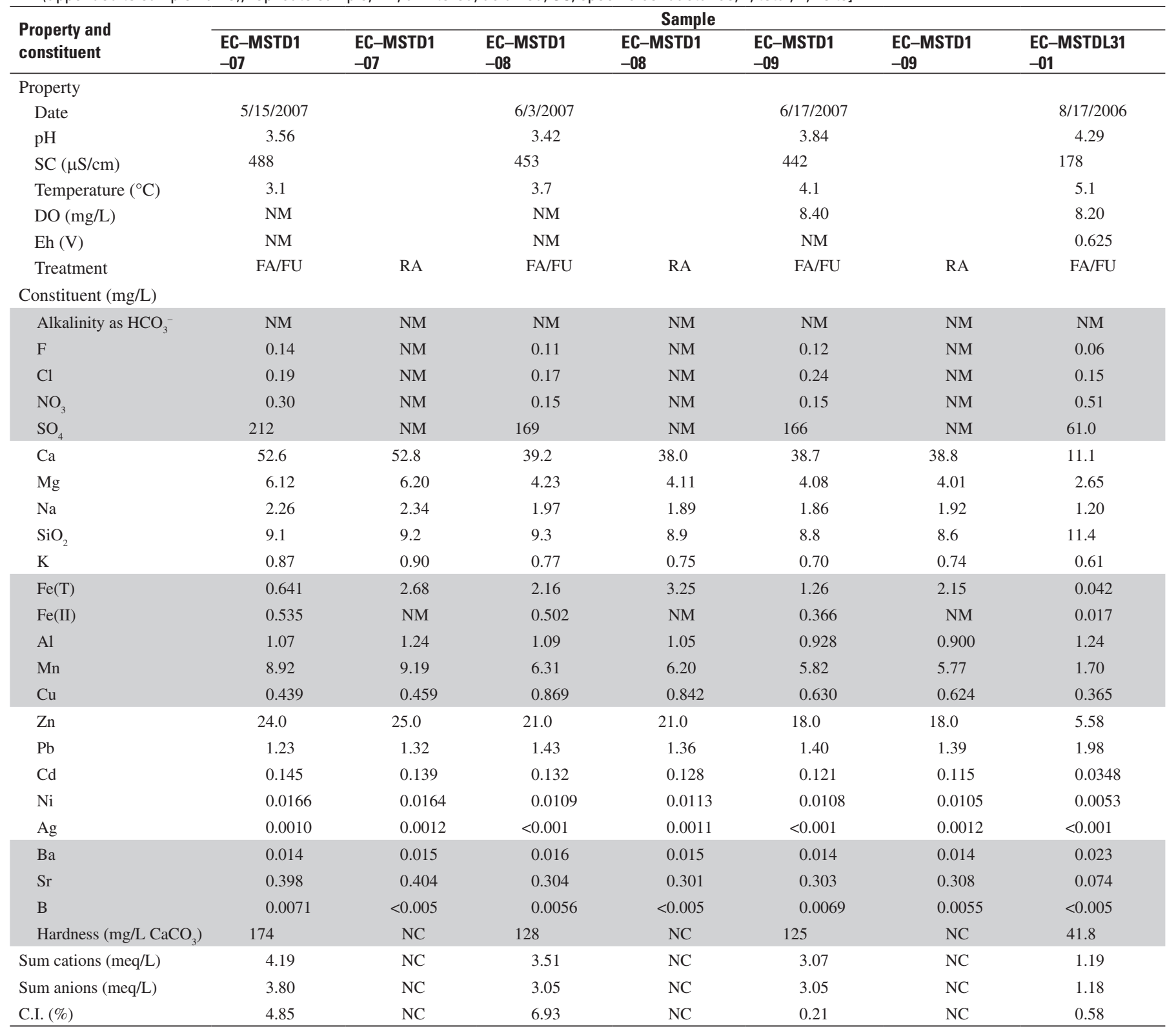


Appendix 3. Concentrations of major ions and selected metals.-Continued

$\left[{ }^{\circ} \mathrm{C}\right.$, degrees Celsius; $\mu \mathrm{S} / \mathrm{cm}$, microsiemens per centimeter; meq/L, milliequivalents per liter; $\mathrm{mg} / \mathrm{L}$, milligrams per liter; C.I., charge imbalance; DO, dissolved oxygen; EB, equipment blank; Eh, redox potential; FA, filtered, acidified; Fe(II), ferrous iron; FU, filtered, unacidified; NC, not computed; NM, not measured; $-\mathrm{R}$ (appended to sample name), replicate sample; RA, unfiltered, acidified; SC, specific conductance; T, total; V, volts]

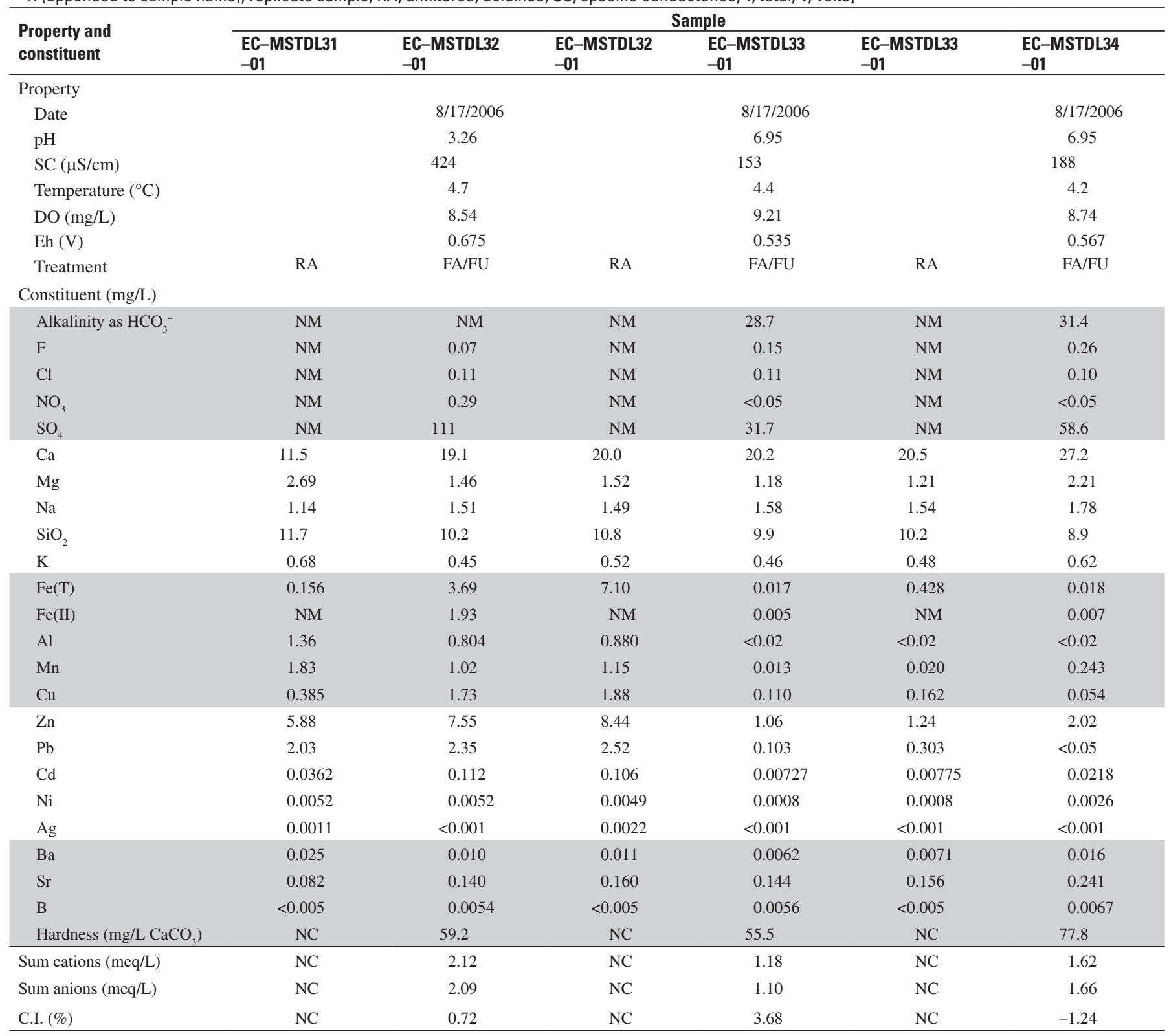


Appendix 3. Concentrations of major ions and selected metals.-Continued

$\left[{ }^{\circ} \mathrm{C}\right.$, degrees Celsius; $\mu \mathrm{S} / \mathrm{cm}$, microsiemens per centimeter; meq/L, milliequivalents per liter; $\mathrm{mg} / \mathrm{L}$, milligrams per liter; $\mathrm{C} . \mathrm{I}$, charge imbalance; $\mathrm{DO}$, dissolved oxygen; EB, equipment blank; Eh, redox potential; FA, filtered, acidified; Fe(II), ferrous iron; FU, filtered, unacidified; NC, not computed; NM, not measured; -R (appended to sample name), replicate sample; RA, unfiltered, acidified; SC, specific conductance; T, total; V, volts]

\begin{tabular}{|c|c|c|c|c|c|c|}
\hline $\begin{array}{l}\text { Property and } \\
\text { constituent }\end{array}$ & \multicolumn{6}{|c|}{ Sample } \\
\hline \multicolumn{7}{|l|}{ Property } \\
\hline $\mathrm{pH}$ & & 6.77 & & 6.66 & & 6.70 \\
\hline $\mathrm{SC}(\mu \mathrm{S} / \mathrm{cm})$ & & 265 & & 215 & & 302 \\
\hline Temperature $\left({ }^{\circ} \mathrm{C}\right)$ & & 4.2 & & 3.6 & & 3.8 \\
\hline $\mathrm{DO}(\mathrm{mg} / \mathrm{L})$ & & 8.78 & & 8.55 & & 3.62 \\
\hline Treatment & RA & $\mathrm{FA} / \mathrm{FU}$ & RA & FA/FU & RA & $\mathrm{FA} / \mathrm{FU}$ \\
\hline \multicolumn{7}{|l|}{ Constituent (mg/L) } \\
\hline Alkalinity as $\mathrm{HCO}_{3}^{-}$ & NM & 33.7 & NM & 10.8 & NM & 46.4 \\
\hline $\mathrm{F}$ & NM & 0.29 & NM & 0.37 & NM & 0.53 \\
\hline $\mathrm{Cl}$ & NM & 0.24 & NM & 0.25 & NM & 0.21 \\
\hline $\mathrm{NO}_{3}$ & NM & $<0.05$ & NM & $<0.05$ & NM & $<0.05$ \\
\hline $\mathrm{Na}$ & 1.75 & 2.06 & 2.12 & 2.75 & 2.74 & 2.99 \\
\hline $\mathrm{SiO}_{2}$ & 10.3 & 10.1 & 10.6 & 13.4 & 14.7 & 8.4 \\
\hline $\mathrm{K}$ & 0.77 & 0.80 & 0.95 & 0.72 & 0.90 & 0.66 \\
\hline $\mathrm{Fe}(\mathrm{T})$ & 1.21 & 0.022 & 0.038 & 0.557 & 1.68 & 5.44 \\
\hline $\mathrm{Fe}(\mathrm{II})$ & NM & 0.006 & NM & 0.529 & NM & 5.28 \\
\hline $\mathrm{Al}$ & 0.622 & $<0.02$ & $<0.02$ & $<0.02$ & 0.254 & $<0.02$ \\
\hline Mn & 0.280 & 0.207 & 0.237 & 2.31 & 2.57 & 4.40 \\
\hline $\mathrm{Cu}$ & 0.201 & 0.435 & 0.491 & $<0.01$ & $<0.01$ & $<0.01$ \\
\hline $\mathrm{Zn}$ & 2.29 & 2.80 & 3.14 & 2.95 & 3.31 & 2.26 \\
\hline $\mathrm{Pb}$ & 0.393 & 0.152 & 0.159 & $<0.05$ & 0.227 & $<0.05$ \\
\hline $\mathrm{Cd}$ & 0.0231 & 0.0221 & 0.0209 & 0.0245 & 0.0241 & 0.00008 \\
\hline Sum anions $(\mathrm{meq} / \mathrm{L})$ & $\mathrm{NC}$ & 2.31 & $\mathrm{NC}$ & 1.77 & $\mathrm{NC}$ & 2.65 \\
\hline C.I. $(\%)$ & $\mathrm{NC}$ & -1.84 & $\mathrm{NC}$ & 0.11 & $\mathrm{NC}$ & -0.46 \\
\hline
\end{tabular}


Appendix 3. Concentrations of major ions and selected metals.-Continued

$\left[{ }^{\circ} \mathrm{C}\right.$, degrees Celsius; $\mu \mathrm{S} / \mathrm{cm}$, microsiemens per centimeter; meq/L, milliequivalents per liter; $\mathrm{mg} / \mathrm{L}$, milligrams per liter; C.I., charge imbalance; DO, dissolved oxygen; EB, equipment blank; Eh, redox potential; FA, filtered, acidified; Fe(II), ferrous iron; FU, filtered, unacidified; NC, not computed; NM, not measured; $-\mathrm{R}$ (appended to sample name), replicate sample; RA, unfiltered, acidified; SC, specific conductance; T, total; V, volts]

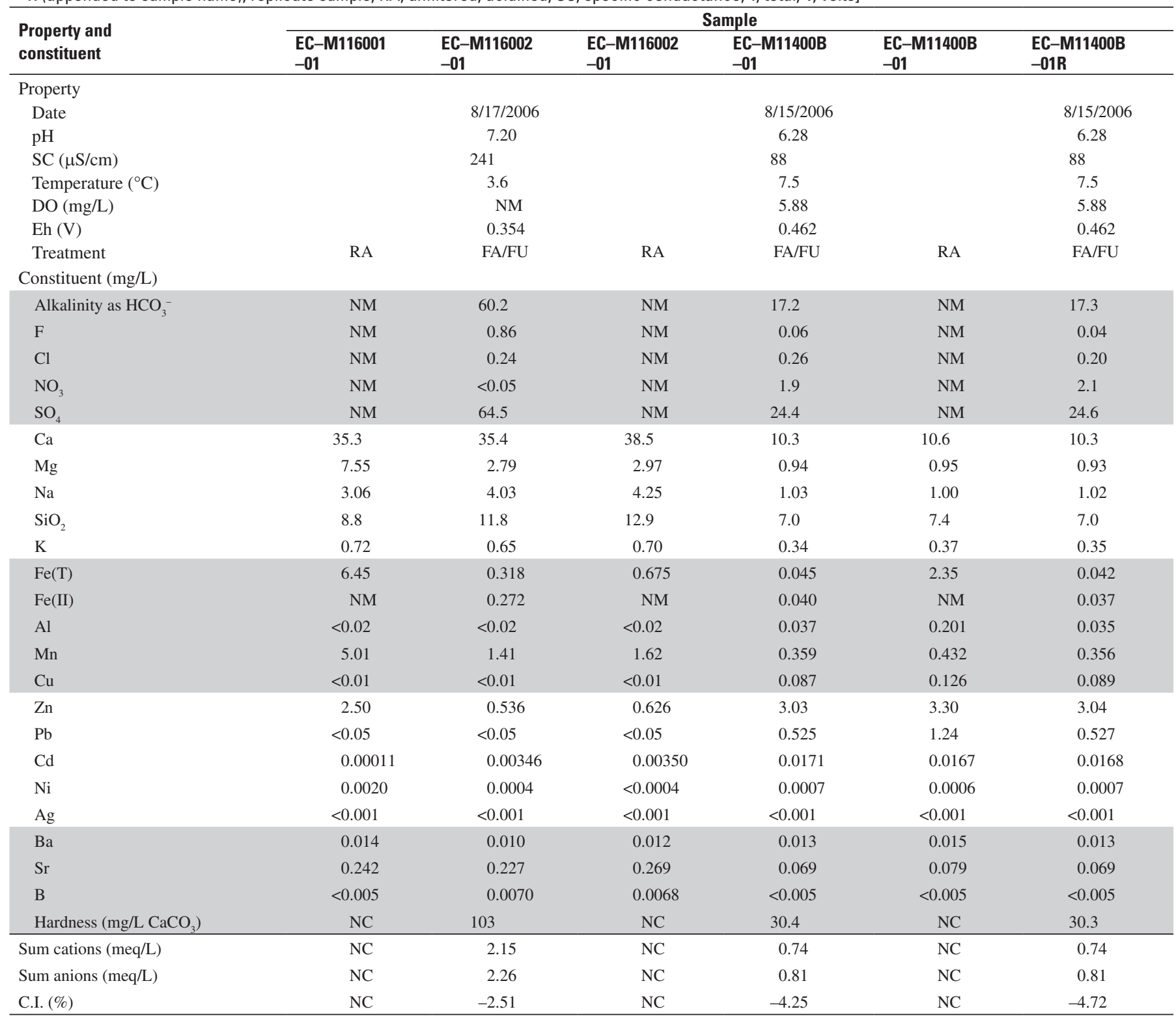


Appendix 3. Concentrations of major ions and selected metals.-Continued

$\left[{ }^{\circ} \mathrm{C}\right.$, degrees Celsius; $\mu \mathrm{S} / \mathrm{cm}$, microsiemens per centimeter; meq/L, milliequivalents per liter; $\mathrm{mg} / \mathrm{L}$, milligrams per liter; $\mathrm{C} . \mathrm{I}$, charge imbalance; $\mathrm{DO}$, dissolved oxygen; EB, equipment blank; Eh, redox potential; FA, filtered, acidified; Fe(II), ferrous iron; FU, filtered, unacidified; NC, not computed; NM, not measured; -R (appended to sample name), replicate sample; RA, unfiltered, acidified; SC, specific conductance; T, total; V, volts]

\begin{tabular}{|c|c|c|c|c|c|c|c|}
\hline \multirow[b]{2}{*}{$\begin{array}{l}\text { Property and } \\
\text { constituent }\end{array}$} & \multicolumn{7}{|c|}{ Sample } \\
\hline & $\begin{array}{l}\text { EC-M11400B } \\
-01 R\end{array}$ & EB-01 & EB-01 & EB-02 & EB-02 & EB-03 & EB-03 \\
\hline \multicolumn{8}{|l|}{ Property } \\
\hline Date & & $8 / 15 / 2006$ & & $8 / 16 / 2006$ & & $8 / 18 / 2006$ & \\
\hline $\mathrm{pH}$ & & $\mathrm{NM}$ & & NM & & NM & \\
\hline $\mathrm{SC}(\mu \mathrm{S} / \mathrm{cm})$ & & NM & & NM & & NM & \\
\hline Temperature $\left({ }^{\circ} \mathrm{C}\right)$ & & NM & & NM & & NM & \\
\hline DO (mg/L) & & NM & & NM & & NM & \\
\hline $\mathrm{Eh}(\mathrm{V})$ & & NM & & NM & & NM & \\
\hline Treatment & RA & $\mathrm{FA} / \mathrm{FU}$ & RA & FA/FU & RA & $\mathrm{FA} / \mathrm{FU}$ & RA \\
\hline \multicolumn{8}{|l|}{ Constituent (mg/L) } \\
\hline Alkalinity as $\mathrm{HCO}_{3}^{-}$ & NM & 2.2 & NM & 2.0 & NM & 2.0 & NM \\
\hline $\mathrm{F}$ & NM & $<0.03$ & NM & $<0.03$ & NM & $<0.03$ & NM \\
\hline $\mathrm{Cl}$ & NM & $<0.03$ & NM & $<0.03$ & NM & $<0.03$ & NM \\
\hline $\mathrm{NO}_{3}$ & NM & $<0.05$ & NM & $<0.05$ & NM & $<0.05$ & NM \\
\hline $\mathrm{SO}_{4}$ & NM & $<0.1$ & NM & $<0.1$ & NM & $<0.1$ & NM \\
\hline $\mathrm{Ca}$ & 10.5 & $<0.1$ & $<0.1$ & $<0.1$ & $<0.1$ & $<0.1$ & $<0.1$ \\
\hline $\mathrm{Mg}$ & 0.91 & $<0.1$ & $<0.1$ & $<0.1$ & $<0.1$ & $<0.1$ & $<0.1$ \\
\hline $\mathrm{Na}$ & 0.98 & $<0.1$ & $<0.1$ & $<0.1$ & $<0.1$ & $<0.1$ & $<0.1$ \\
\hline $\mathrm{SiO}_{2}$ & 7.0 & $<0.1$ & 0.21 & $<0.1$ & 0.18 & $<0.1$ & 0.21 \\
\hline $\mathrm{K}$ & 0.35 & $<0.1$ & $<0.1$ & $<0.1$ & $<0.1$ & $<0.1$ & $<0.1$ \\
\hline $\mathrm{Fe}(\mathrm{T})$ & 1.12 & $<0.002$ & $<0.02$ & $<0.002$ & $<0.02$ & $<0.002$ & $<0.02$ \\
\hline $\mathrm{Fe}(\mathrm{II})$ & NM & $<0.002$ & NM & $<0.002$ & NM & $<0.002$ & NM \\
\hline $\mathrm{Al}$ & 0.113 & $<0.02$ & $<0.02$ & $<0.02$ & $<0.02$ & $<0.02$ & $<0.02$ \\
\hline $\mathrm{Mn}$ & 0.395 & $<0.01$ & $<0.01$ & $<0.01$ & $<0.01$ & $<0.01$ & $<0.01$ \\
\hline $\mathrm{Cu}$ & 0.106 & $<0.01$ & $<0.01$ & $<0.01$ & $<0.01$ & $<0.01$ & $<0.01$ \\
\hline $\mathrm{Zn}$ & 3.21 & $<0.02$ & $<0.02$ & $<0.02$ & $<0.02$ & $<0.02$ & $<0.02$ \\
\hline $\mathrm{Pb}$ & 0.909 & $<0.05$ & $<0.05$ & $<0.05$ & $<0.05$ & $<0.05$ & $<0.05$ \\
\hline $\mathrm{Cd}$ & 0.0167 & $<0.00002$ & $<0.00002$ & $<0.00002$ & $<0.00002$ & $<0.00002$ & $<0.00002$ \\
\hline $\mathrm{Ni}$ & 0.0007 & $<0.0004$ & $<0.0004$ & $<0.0004$ & $<0.0004$ & $<0.0004$ & $<0.0004$ \\
\hline $\mathrm{Ag}$ & $<0.001$ & $<0.001$ & $<0.001$ & $<0.001$ & $<0.001$ & $<0.001$ & $<0.001$ \\
\hline $\mathrm{Ba}$ & 0.014 & $<0.001$ & $<0.001$ & $<0.001$ & $<0.001$ & $<0.001$ & $<0.001$ \\
\hline $\mathrm{Sr}$ & 0.079 & $<0.001$ & $<0.001$ & $<0.001$ & $<0.001$ & $<0.001$ & $<0.001$ \\
\hline B & $<0.005$ & $<0.005$ & $<0.005$ & $<0.005$ & $<0.005$ & $<0.005$ & $<0.005$ \\
\hline Hardness $\left(\mathrm{mg} / \mathrm{L} \mathrm{CaCO}{ }_{3}\right)$ & $\mathrm{NC}$ & $\mathrm{NC}$ & $\mathrm{NC}$ & $\mathrm{NC}$ & $\mathrm{NC}$ & $\mathrm{NC}$ & $\mathrm{NC}$ \\
\hline Sum cations (meq/L) & $\mathrm{NC}$ & $\mathrm{NC}$ & $\mathrm{NC}$ & $\mathrm{NC}$ & $\mathrm{NC}$ & $\mathrm{NC}$ & $\mathrm{NC}$ \\
\hline Sum anions (meq/L) & $\mathrm{NC}$ & $\mathrm{NC}$ & $\mathrm{NC}$ & $\mathrm{NC}$ & $\mathrm{NC}$ & $\mathrm{NC}$ & $\mathrm{NC}$ \\
\hline C.I. $(\%)$ & $\mathrm{NC}$ & $\mathrm{NC}$ & $\mathrm{NC}$ & $\mathrm{NC}$ & $\mathrm{NC}$ & $\mathrm{NC}$ & $\mathrm{NC}$ \\
\hline
\end{tabular}


Appendix 3. Concentrations of major ions and selected metals.-Continued

$\left[{ }^{\circ} \mathrm{C}\right.$, degrees Celsius; $\mu \mathrm{S} / \mathrm{cm}$, microsiemens per centimeter; meq/L, milliequivalents per liter; $\mathrm{mg} / \mathrm{L}$, milligrams per liter; C.I., charge imbalance; $\mathrm{DO}$, dissolved oxygen; EB, equipment blank; Eh, redox potential; FA, filtered, acidified; Fe(II), ferrous iron; FU, filtered, unacidified; NC, not computed; NM, not measured; $-\mathrm{R}$ (appended to sample name), replic ate sample; RA, unfiltered, acidified; SC, specific conductance; T, total; V, volts]

\begin{tabular}{|c|c|c|c|c|}
\hline \multirow{2}{*}{$\begin{array}{l}\text { Property and } \\
\text { constituent }\end{array}$} & \multicolumn{4}{|c|}{ Sample } \\
\hline & EB-04 & EB-04 & EB-05 & EB-05 \\
\hline \multicolumn{5}{|l|}{ Property } \\
\hline $\mathrm{pH}$ & NM & & NM & \\
\hline $\mathrm{SC}(\mu \mathrm{S} / \mathrm{cm})$ & NM & & NM & \\
\hline Eh $(V)$ & NM & & NM & \\
\hline Treatment & $\mathrm{FA} / \mathrm{FU}$ & RA & $\mathrm{FA} / \mathrm{FU}$ & RA \\
\hline \multicolumn{5}{|l|}{ Constituent (mg/L) } \\
\hline Alkalinity as $\mathrm{HCO}_{3}^{-}$ & 2.0 & NM & 2.2 & NM \\
\hline $\mathrm{F}$ & $<0.03$ & NM & $<0.05$ & NM \\
\hline $\mathrm{Mg}$ & $<0.1$ & $<0.1$ & $<0.1$ & $<0.1$ \\
\hline $\mathrm{Na}$ & $<0.1$ & $<0.1$ & 0.13 & $<0.1$ \\
\hline $\mathrm{SiO}_{2}$ & $<0.1$ & $<0.1$ & $<0.1$ & $<0.1$ \\
\hline $\mathrm{K}$ & $<0.1$ & $<0.1$ & $<0.1$ & $<0.1$ \\
\hline $\mathrm{Fe}(\mathrm{T})$ & 0.002 & $<0.02$ & $<0.002$ & $<0.02$ \\
\hline $\mathrm{Fe}(\mathrm{II})$ & $<0.002$ & NM & $<0.002$ & NM \\
\hline $\mathrm{Al}$ & $<0.02$ & $<0.02$ & $<0.02$ & $<0.02$ \\
\hline $\mathrm{Mn}$ & $<0.01$ & $<0.01$ & $<0.01$ & $<0.01$ \\
\hline $\mathrm{Cu}$ & $<0.01$ & $<0.01$ & $<0.01$ & $<0.01$ \\
\hline $\mathrm{Zn}$ & $<0.02$ & $<0.02$ & $<0.02$ & $<0.02$ \\
\hline Hardness $\left(\mathrm{mg} / \mathrm{L} \mathrm{CaCO}{ }_{3}\right)$ & $\mathrm{NC}$ & $\mathrm{NC}$ & $\mathrm{NC}$ & $\mathrm{NC}$ \\
\hline Sum cations (meq/L) & $\mathrm{NC}$ & $\mathrm{NC}$ & $\mathrm{NC}$ & $\mathrm{NC}$ \\
\hline Sum anions (meq/L) & $\mathrm{NC}$ & $\mathrm{NC}$ & $\mathrm{NC}$ & $\mathrm{NC}$ \\
\hline C.I. $(\%)$ & $\mathrm{NC}$ & $\mathrm{NC}$ & $\mathrm{NC}$ & $\mathrm{NC}$ \\
\hline
\end{tabular}

${ }^{1} \mathrm{ICP}-\mathrm{AES}$ results shown. See appendix 4 for ICP-MS results. 


\section{Appendix 4. Results of ICP-MS Analyses}


Appendix 4. Results of ICP-MS analyses.

[ $\mu \mathrm{g} / \mathrm{L}$, micrograms per liter; EB,equipment blank; FA, filtered, acidified; -R (appended to sample name), replicate sample; RA, unfiltered, acidified]

\begin{tabular}{|c|c|c|c|c|c|c|c|}
\hline \multirow{3}{*}{$\begin{array}{l}\text { Constituent } \\
\text { (mg/L) }\end{array}$} & \multicolumn{7}{|c|}{ Sample and treatment } \\
\hline & EC-CELK1-01 & EC-CELK1-01 & EC-CELK1-02 & EC-CELK1-02 & EC-CELK1-03 & EC-CELK1-03 & EC-CELK1-04 \\
\hline & FA & RA & FA & RA & FA & RA & FA \\
\hline $\mathrm{Ag}$ & $<1$ & $<1$ & $<1$ & $<1$ & $<1$ & $<1$ & $<1$ \\
\hline $\mathrm{Al}$ & 5.0 & 8.6 & 15.7 & 42.0 & 3.4 & 7.5 & 13.1 \\
\hline As & 2 & 2 & 1 & 1 & 1 & 1 & 1 \\
\hline $\mathrm{Ba}$ & 14.5 & 15.2 & 13.7 & 13.4 & 16.9 & 16.1 & 12.6 \\
\hline $\mathrm{Be}$ & $<0.05$ & $<0.05$ & $<0.05$ & $<0.05$ & $<0.05$ & $<0.05$ & $<0.05$ \\
\hline $\mathrm{Bi}$ & $<0.2$ & $<0.2$ & $<0.2$ & $<0.2$ & $<0.2$ & $<0.2$ & $<0.2$ \\
\hline $\mathrm{Cd}$ & 2.20 & 2.35 & 5.17 & 5.15 & 2.70 & 2.56 & 2.36 \\
\hline $\mathrm{Ce}$ & 0.03 & 0.06 & 0.25 & 0.54 & 0.04 & 0.06 & 0.10 \\
\hline Co & $<0.02$ & $<0.02$ & 0.24 & 0.23 & $<0.02$ & $<0.02$ & 0.03 \\
\hline $\mathrm{Cr}$ & $<1$ & $<1$ & $<1$ & $<1$ & $<1$ & $<1$ & $<1$ \\
\hline Cs & $<0.02$ & $<0.02$ & $<0.02$ & $<0.02$ & $<0.02$ & $<0.02$ & $<0.02$ \\
\hline $\mathrm{Cu}$ & 2.0 & 2.1 & 4.7 & 6.3 & 1.8 & 2.1 & 2.7 \\
\hline Dy & 0.006 & 0.008 & 0.02 & 0.04 & 0.007 & 0.01 & 0.02 \\
\hline Er & $<0.005$ & 0.005 & 0.009 & 0.02 & $<0.005$ & $<0.005$ & 0.008 \\
\hline $\mathrm{Eu}$ & $<0.005$ & $<0.005$ & 0.01 & 0.02 & $<0.005$ & 0.005 & 0.006 \\
\hline $\mathrm{Ga}$ & $<0.05$ & $<0.05$ & $<0.05$ & $<0.05$ & $<0.05$ & $<0.05$ & $<0.05$ \\
\hline Gd & 0.01 & 0.01 & 0.02 & 0.063 & 0.008 & 0.008 & 0.02 \\
\hline $\mathrm{Ge}$ & $<0.05$ & $<0.05$ & $<0.05$ & $<0.05$ & $<0.05$ & $<0.05$ & $<0.05$ \\
\hline Ho & $<0.005$ & $<0.005$ & $<0.005$ & 0.007 & $<0.005$ & $<0.005$ & $<0.005$ \\
\hline $\mathrm{K}$ & 340 & 340 & 450 & 420 & 430 & 500 & 390 \\
\hline $\mathrm{La}$ & 0.06 & 0.09 & 0.20 & 0.36 & 0.08 & 0.09 & 0.14 \\
\hline $\mathrm{Li}$ & 1.8 & 2.2 & 2.0 & 2.0 & 2.4 & 1.5 & 1.2 \\
\hline $\mathrm{Lu}$ & $<0.1$ & $<0.1$ & $<0.1$ & $<0.1$ & $<0.1$ & $<0.1$ & $<0.1$ \\
\hline $\mathrm{Mn}$ & 12.9 & 14.1 & 168 & 160 & 7.2 & 8.2 & 30.9 \\
\hline Mo & $<2$ & $<2$ & $<2$ & $<2$ & $<2$ & $<2$ & $<2$ \\
\hline $\mathrm{Nb}$ & $<0.2$ & $<0.2$ & $<0.2$ & $<0.2$ & $<0.2$ & $<0.2$ & $<0.2$ \\
\hline $\mathrm{Nd}$ & 0.04 & 0.08 & 0.16 & 0.30 & 0.05 & 0.06 & 0.12 \\
\hline $\mathrm{Ni}$ & $<0.4$ & $<0.4$ & 0.6 & 0.6 & 0.4 & 0.4 & $<0.4$ \\
\hline $\mathrm{P}$ & $<10$ & $<10$ & $<10$ & $<10$ & $<10$ & $<10$ & $<10$ \\
\hline $\mathrm{Pb}$ & 0.4 & 0.95 & 1.8 & 7.4 & 0.3 & 0.66 & 0.5 \\
\hline $\operatorname{Pr}$ & 0.01 & 0.02 & 0.04 & 0.07 & 0.01 & 0.02 & 0.03 \\
\hline $\mathrm{Rb}$ & 0.33 & 0.34 & 0.41 & 0.42 & 0.33 & 0.32 & 0.30 \\
\hline $\mathrm{Sb}$ & 0.42 & $<0.3$ & $<0.3$ & $<0.3$ & $<0.3$ & $<0.3$ & $<0.3$ \\
\hline $\mathrm{Sc}$ & 0.6 & 0.6 & $<0.6$ & $<0.6$ & $<0.6$ & $<0.6$ & $<0.6$ \\
\hline $\mathrm{Se}$ & $<1$ & $<1$ & $<1$ & $<1$ & $<1$ & $<1$ & $<1$ \\
\hline $\mathrm{Sm}$ & $<0.01$ & 0.02 & 0.02 & 0.05 & $<0.01$ & $<0.01$ & 0.02 \\
\hline $\mathrm{Sr}$ & 152 & 154 & 147 & 152 & 248 & 233 & 197 \\
\hline $\mathrm{Ta}$ & 0.06 & 0.02 & $<0.02$ & $<0.02$ & $<0.02$ & $<0.02$ & $<0.02$ \\
\hline $\mathrm{Tb}$ & $<0.005$ & $<0.005$ & $<0.005$ & 0.007 & $<0.005$ & $<0.005$ & $<0.005$ \\
\hline Th & $<0.2$ & $<0.2$ & $<0.2$ & $<0.2$ & $<0.2$ & $<0.2$ & $<0.2$ \\
\hline $\mathrm{Ti}$ & $<0.5$ & $<0.5$ & $<0.5$ & $<0.5$ & 0.6 & 0.9 & 0.5 \\
\hline $\mathrm{Tl}$ & $<0.1$ & $<0.1$ & $<0.1$ & $<0.1$ & $<0.1$ & $<0.1$ & $<0.1$ \\
\hline $\mathrm{Tm}$ & $<0.005$ & $<0.005$ & $<0.005$ & $<0.005$ & $<0.005$ & $<0.005$ & $<0.005$ \\
\hline $\mathrm{U}$ & $<0.1$ & $<0.1$ & $<0.1$ & $<0.1$ & $<0.1$ & $<0.1$ & $<0.1$ \\
\hline V & $<0.5$ & $<0.5$ & $<0.5$ & $<0.5$ & $<0.5$ & $<0.5$ & $<0.5$ \\
\hline W & $<0.5$ & $<0.5$ & $<0.5$ & $<0.5$ & $<0.5$ & $<0.5$ & $<0.5$ \\
\hline $\mathrm{Y}$ & 0.04 & 0.06 & 0.11 & 0.20 & 0.06 & 0.05 & 0.12 \\
\hline $\mathrm{Yb}$ & $<0.005$ & $<0.005$ & 0.009 & 0.01 & $<0.005$ & $<0.005$ & 0.008 \\
\hline $\mathrm{Zn}$ & 428 & 432 & 986 & 991 & 626 & 582 & 553 \\
\hline $\mathrm{Zr}$ & $<0.2$ & $<0.2$ & $<0.2$ & $<0.2$ & $<0.2$ & $<0.2$ & $<0.2$ \\
\hline
\end{tabular}


Appendix 4. Results of ICP-MS analyses.-Continued

[ $\mu \mathrm{g} / \mathrm{L}$, micrograms per liter; EB,equipment blank; FA, filtered, acidified; $-\mathrm{R}$ (appended to sample name), replicate sample; RA, unfiltered, acidified]

\begin{tabular}{|c|c|c|c|c|c|c|c|}
\hline \multirow{2}{*}{$\begin{array}{l}\text { Constituent } \\
\text { (mg/L) }\end{array}$} & \multicolumn{7}{|c|}{ Sample and treatment } \\
\hline & EC-CELK1-04 & EC-CELK1-05 & EC-CELK1-05 & EC-CELK1-06 & EC-CELK1-06 & EC-CELK1-07 & EC-CELK1-07 \\
\hline $\mathrm{Ag}$ & $<1$ & $<1$ & $<1$ & $<1$ & $<1$ & $<1$ & $<1$ \\
\hline As & 1 & $<1$ & 1 & $<1$ & 1 & 1 & 2 \\
\hline $\mathrm{Ba}$ & 12.1 & 9.16 & 9.04 & 8.33 & 8.11 & 10.8 & 10.4 \\
\hline $\mathrm{Be}$ & $<0.05$ & $<0.05$ & $<0.05$ & $<0.05$ & 0.08 & $<0.05$ & 0.06 \\
\hline $\mathrm{Ce}$ & 0.16 & 0.63 & 1.07 & 0.86 & 1.65 & 0.54 & 0.88 \\
\hline Co & 0.04 & 0.24 & 0.23 & 0.42 & 0.45 & 0.21 & 0.24 \\
\hline $\mathrm{Cr}$ & $<1$ & $<1$ & $<1$ & $<1$ & $<1$ & $<1$ & $<1$ \\
\hline Cs & $<0.02$ & $<0.02$ & 0.03 & $<0.02$ & 0.03 & $<0.02$ & 0.02 \\
\hline $\mathrm{Cu}$ & 3.6 & 9.3 & 12.5 & 12.4 & 20.1 & 11.1 & 14.5 \\
\hline Dy & 0.02 & 0.060 & 0.095 & 0.070 & 0.13 & 0.054 & 0.082 \\
\hline Но & $<0.005$ & 0.01 & 0.02 & 0.01 & 0.02 & 0.01 & 0.01 \\
\hline K & 430 & 360 & 400 & 320 & 370 & 350 & 390 \\
\hline $\mathrm{La}$ & 0.19 & 0.54 & 0.77 & 0.62 & 1.06 & 0.41 & 0.65 \\
\hline $\mathrm{Li}$ & 0.7 & 0.7 & 0.3 & 0.8 & 0.8 & 1.1 & 0.8 \\
\hline $\mathrm{Lu}$ & $<0.1$ & $<0.1$ & $<0.1$ & $<0.1$ & $<0.1$ & $<0.1$ & $<0.1$ \\
\hline $\mathrm{Mn}$ & 31.2 & 118 & 118 & 175 & 183 & 114 & 117 \\
\hline Mo & $<2$ & $<2$ & $<2$ & $<2$ & $<2$ & $<2$ & $<2$ \\
\hline $\mathrm{Nb}$ & $<0.2$ & $<0.2$ & $<0.2$ & $<0.2$ & $<0.2$ & $<0.2$ & $<0.2$ \\
\hline $\mathrm{Nd}$ & 0.14 & 0.45 & 0.63 & 0.52 & 0.96 & 0.34 & 0.59 \\
\hline $\mathrm{Ni}$ & $<0.4$ & 0.5 & 0.5 & 0.8 & 0.6 & 0.5 & 0.5 \\
\hline $\mathrm{P}$ & $<10$ & $<10$ & $<10$ & $<10$ & $<10$ & $<10$ & $<10$ \\
\hline $\mathrm{Pb}$ & 1.1 & 2.8 & 10.6 & 2.6 & 17.3 & 6.6 & 16.1 \\
\hline Th & $<0.2$ & $<0.2$ & $<0.2$ & $<0.2$ & $<0.2$ & $<0.2$ & $<0.2$ \\
\hline $\mathrm{Ti}$ & 0.6 & 0.6 & 1.1 & 0.5 & 1.0 & $<0.5$ & 0.9 \\
\hline $\mathrm{Tl}$ & $<0.1$ & $<0.1$ & $<0.1$ & $<0.1$ & $<0.1$ & $<0.1$ & $<0.1$ \\
\hline $\mathrm{Tm}$ & $<0.005$ & $<0.005$ & 0.005 & $<0.005$ & 0.007 & $<0.005$ & 0.005 \\
\hline $\mathrm{U}$ & $<0.1$ & $<0.1$ & $<0.1$ & $<0.1$ & $<0.1$ & $<0.1$ & $<0.1$ \\
\hline V & $<0.5$ & $<0.5$ & $<0.5$ & $<0.5$ & $<0.5$ & $<0.5$ & $<0.5$ \\
\hline W & $<0.5$ & $<0.5$ & $<0.5$ & $<0.5$ & $<0.5$ & $<0.5$ & $<0.5$ \\
\hline Y & 0.14 & 0.37 & 0.55 & 0.40 & 0.67 & 0.27 & 0.40 \\
\hline $\mathrm{Yb}$ & 0.007 & 0.02 & 0.04 & 0.02 & 0.04 & 0.01 & 0.03 \\
\hline $\mathrm{Zn}$ & 513 & 664 & 654 & 826 & 823 & 643 & 633 \\
\hline $\mathrm{Zr}$ & $<0.2$ & $<0.2$ & $<0.2$ & $<0.2$ & $<0.2$ & $<0.2$ & $<0.2$ \\
\hline
\end{tabular}


Appendix 4. Results of ICP-MS analyses.-Continued

[ $\mu \mathrm{g} / \mathrm{L}$, micrograms per liter; EB,equipment blank; FA, filtered, acidified; -R (appended to sample name), replicate sample; RA, unfiltered, acidified]

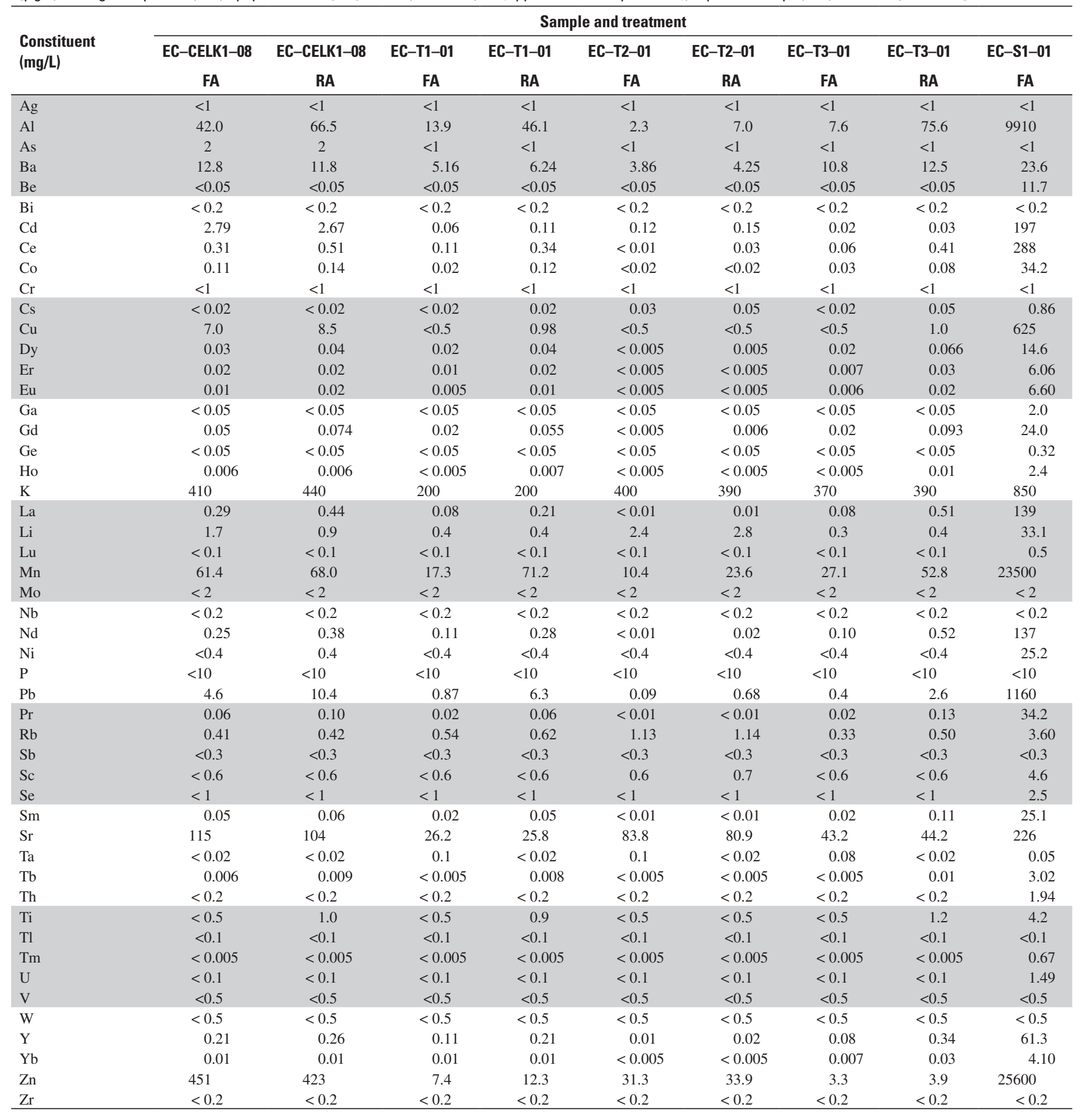


Appendix 4. Results of ICP-MS analyses.-Continued

[ $\mu \mathrm{g} / \mathrm{L}$, micrograms per liter; EB,equipment blank; FA, filtered, acidified; $-\mathrm{R}$ (appended to sample name), replicate sample; RA, unfiltered, acidified]

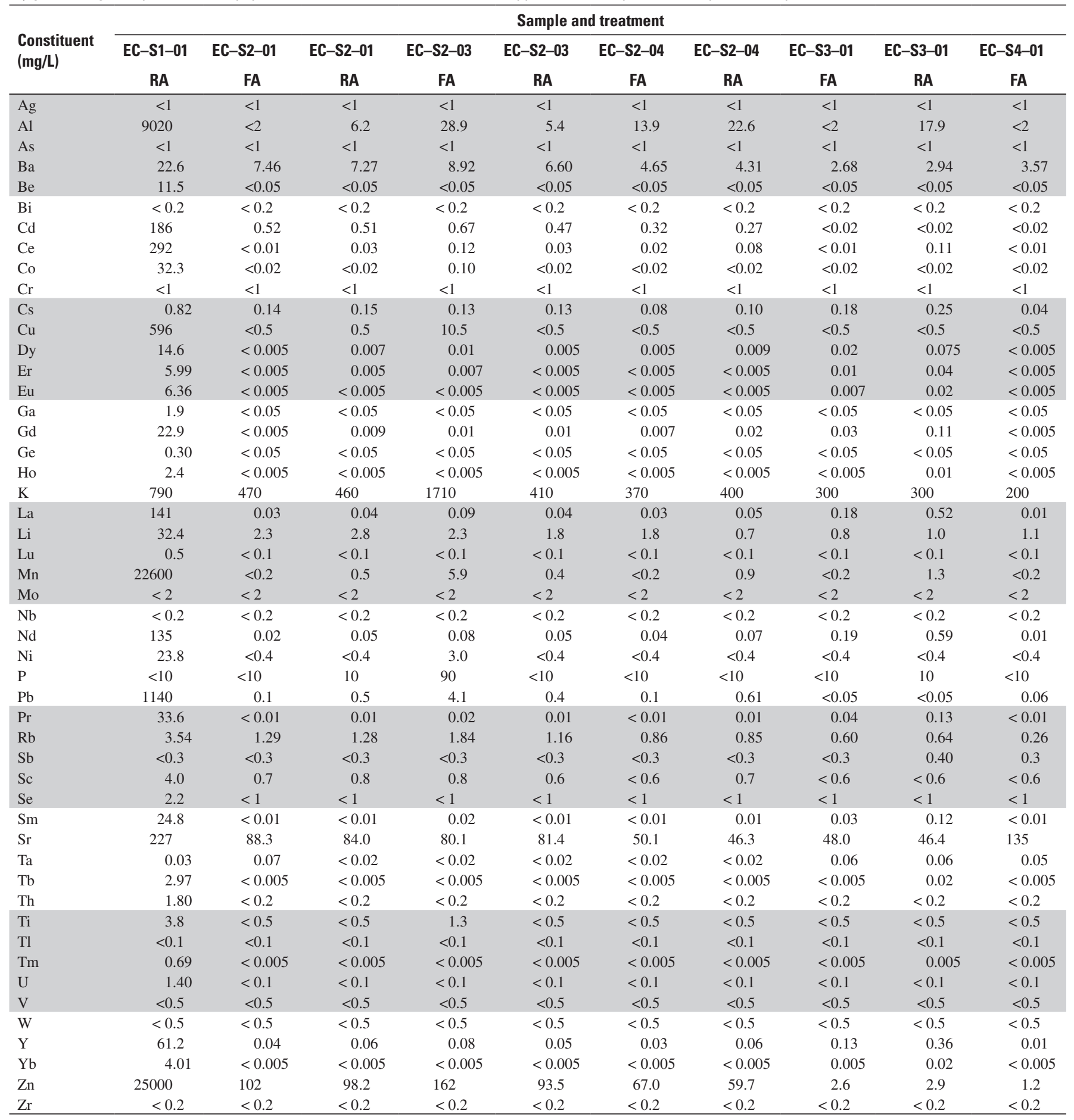


Appendix 4. Results of ICP-MS analyses.-Continued

[ $\mu \mathrm{g} / \mathrm{L}$, micrograms per liter; EB,equipment blank; FA, filtered, acidified; -R (appended to sample name), replicate sample; RA, unfiltered, acidified]

\begin{tabular}{|c|c|c|c|c|c|c|c|c|}
\hline \multirow{3}{*}{$\begin{array}{l}\text { Constituent } \\
\text { (mg/L) }\end{array}$} & \multicolumn{8}{|c|}{ Sample and treatment } \\
\hline & EC-S4-01 & EC-S5-01 & EC-S5-01 & EC-S7-01 & EC-S7-01 & EC-S8A-01 & EC-S8A-01 & EC-S8A-03 \\
\hline & RA & FA & RA & FA & RA & FA & RA & FA \\
\hline $\mathrm{Ag}$ & $<1$ & $<1$ & $<1$ & $<1$ & $<1$ & $<1$ & $<1$ & $<1$ \\
\hline $\mathrm{Al}$ & 3.9 & 7.8 & 227 & $<2$ & 6.5 & 2.2 & 366 & $<2$ \\
\hline As & $<1$ & $<1$ & $<1$ & $<1$ & $<1$ & $<1$ & 2 & $<1$ \\
\hline $\mathrm{Ba}$ & 3.57 & 9.63 & 12.8 & 4.83 & 5.09 & 5.32 & 8.52 & 4.49 \\
\hline $\mathrm{Be}$ & $<0.05$ & $<0.05$ & $<0.05$ & $<0.05$ & $<0.05$ & $<0.05$ & $<0.05$ & $<0.05$ \\
\hline $\mathrm{Bi}$ & $<0.2$ & $<0.2$ & $<0.2$ & $<0.2$ & $<0.2$ & $<0.2$ & $<0.2$ & $<0.2$ \\
\hline $\mathrm{Cd}$ & $<0.02$ & 0.06 & 0.10 & $<0.02$ & $<0.02$ & $<0.02$ & 0.02 & $<0.02$ \\
\hline $\mathrm{Ce}$ & $<0.01$ & 0.06 & 0.77 & $<0.01$ & 0.02 & 0.01 & 2.41 & $<0.01$ \\
\hline $\mathrm{Co}$ & $<0.02$ & 0.13 & 0.26 & $<0.02$ & $<0.02$ & $<0.02$ & 0.14 & $<0.02$ \\
\hline $\mathrm{Cr}$ & $<1$ & $<1$ & $<1$ & $<1$ & $<1$ & $<1$ & $<1$ & $<1$ \\
\hline Cs & 0.05 & 0.02 & 0.18 & $<0.02$ & 0.02 & 0.12 & 1.02 & 0.10 \\
\hline $\mathrm{Cu}$ & $<0.5$ & $<0.5$ & 1.2 & $<0.5$ & $<0.5$ & $<0.5$ & 1.2 & $<0.5$ \\
\hline Dy & $<0.005$ & 0.02 & 0.078 & $<0.005$ & $<0.005$ & 0.005 & 0.26 & 0.007 \\
\hline $\mathrm{Er}$ & $<0.005$ & 0.007 & 0.04 & $<0.005$ & $<0.005$ & $<0.005$ & 0.12 & $<0.005$ \\
\hline $\mathrm{Eu}$ & $<0.005$ & 0.005 & 0.02 & $<0.005$ & $<0.005$ & $<0.005$ & 0.11 & $<0.005$ \\
\hline $\mathrm{Ga}$ & $<0.05$ & $<0.05$ & 0.07 & $<0.05$ & $<0.05$ & $<0.05$ & 0.1 & $<0.05$ \\
\hline Gd & 0.005 & 0.02 & 0.13 & $<0.005$ & 0.006 & 0.006 & 0.46 & 0.01 \\
\hline $\mathrm{Ge}$ & $<0.05$ & $<0.05$ & $<0.05$ & $<0.05$ & $<0.05$ & $<0.05$ & $<0.05$ & $<0.05$ \\
\hline Ho & $<0.005$ & $<0.005$ & 0.02 & $<0.005$ & $<0.005$ & $<0.005$ & 0.051 & $<0.005$ \\
\hline K & 200 & 570 & 660 & 100 & 100 & 400 & 420 & 360 \\
\hline $\mathrm{La}$ & 0.01 & 0.08 & 0.59 & $<0.01$ & 0.02 & 0.03 & 1.57 & 0.03 \\
\hline $\mathrm{Li}$ & 1.2 & 0.3 & 0.8 & 0.8 & 1.1 & 3.2 & 4.7 & 3.1 \\
\hline $\mathrm{Lu}$ & $<0.1$ & $<0.1$ & $<0.1$ & $<0.1$ & $<0.1$ & $<0.1$ & $<0.1$ & $<0.1$ \\
\hline $\mathrm{Mn}$ & $<0.2$ & 106 & 138 & 0.3 & 0.8 & 0.7 & 36.4 & $<0.2$ \\
\hline Мo & $<2$ & $<2$ & $<2$ & $<2$ & $<2$ & $<2$ & $<2$ & $<2$ \\
\hline $\mathrm{Nb}$ & $<0.2$ & $<0.2$ & $<0.2$ & $<0.2$ & $<0.2$ & $<0.2$ & $<0.2$ & $<0.2$ \\
\hline $\mathrm{Nd}$ & 0.02 & 0.09 & 0.62 & $<0.01$ & 0.02 & 0.03 & 1.90 & 0.03 \\
\hline $\mathrm{Ni}$ & $<0.4$ & $<0.4$ & 0.4 & $<0.4$ & $<0.4$ & $<0.4$ & $<0.4$ & $<0.4$ \\
\hline $\mathrm{P}$ & 10 & $<10$ & 20 & $<10$ & $<10$ & $<10$ & 20 & $<10$ \\
\hline $\mathrm{Pb}$ & $<0.05$ & 4.3 & 22.4 & $<0.05$ & 0.1 & 0.4 & 2.8 & $<0.05$ \\
\hline $\operatorname{Pr}$ & $<0.01$ & 0.02 & 0.14 & $<0.01$ & $<0.01$ & $<0.01$ & 0.41 & $<0.01$ \\
\hline $\mathrm{Rb}$ & 0.28 & 0.62 & 1.29 & 0.13 & 0.16 & 0.68 & 1.56 & 0.67 \\
\hline $\mathrm{Sb}$ & $<0.3$ & $<0.3$ & $<0.3$ & 0.34 & $<0.3$ & $<0.3$ & $<0.3$ & $<0.3$ \\
\hline $\mathrm{Sc}$ & 0.6 & $<0.6$ & 0.6 & $<0.6$ & 0.6 & 0.8 & 1.0 & 0.8 \\
\hline $\mathrm{Se}$ & $<1$ & $<1$ & $<1$ & $<1$ & $<1$ & $<1$ & $<1$ & $<1$ \\
\hline $\mathrm{Sm}$ & $<0.01$ & 0.02 & 0.11 & $<0.01$ & $<0.01$ & $<0.01$ & 0.38 & $<0.01$ \\
\hline $\mathrm{Sr}$ & 135 & 42.0 & 42.9 & 54.7 & 54.4 & 136 & 134 & 111 \\
\hline $\mathrm{Ta}$ & $<0.02$ & 0.07 & $<0.02$ & 0.2 & 0.03 & 0.02 & $<0.02$ & $<0.02$ \\
\hline $\mathrm{Tb}$ & $<0.005$ & $<0.005$ & 0.02 & $<0.005$ & $<0.005$ & $<0.005$ & 0.053 & $<0.005$ \\
\hline Th & $<0.2$ & $<0.2$ & $<0.2$ & $<0.2$ & $<0.2$ & $<0.2$ & $<0.2$ & $<0.2$ \\
\hline $\mathrm{Ti}$ & $<0.5$ & $<0.5$ & 4.5 & $<0.5$ & $<0.5$ & 0.6 & 4.9 & $<0.5$ \\
\hline $\mathrm{Tl}$ & $<0.1$ & $<0.1$ & $<0.1$ & $<0.1$ & $<0.1$ & $<0.1$ & $<0.1$ & $<0.1$ \\
\hline $\mathrm{Tm}$ & $<0.005$ & $<0.005$ & 0.005 & $<0.005$ & $<0.005$ & $<0.005$ & 0.01 & $<0.005$ \\
\hline $\mathrm{U}$ & $<0.1$ & $<0.1$ & $<0.1$ & $<0.1$ & $<0.1$ & $<0.1$ & 0.12 & $<0.1$ \\
\hline V & $<0.5$ & $<0.5$ & $<0.5$ & $<0.5$ & $<0.5$ & $<0.5$ & $<0.5$ & $<0.5$ \\
\hline W & $<0.5$ & $<0.5$ & $<0.5$ & $<0.5$ & $<0.5$ & $<0.5$ & $<0.5$ & $<0.5$ \\
\hline $\mathrm{Y}$ & 0.02 & 0.10 & 0.40 & $<0.01$ & 0.02 & 0.04 & 1.64 & 0.05 \\
\hline $\mathrm{Yb}$ & $<0.005$ & 0.01 & 0.03 & $<0.005$ & $<0.005$ & $<0.005$ & 0.06 & $<0.005$ \\
\hline $\mathrm{Zn}$ & $<0.5$ & 14.7 & 17.8 & 0.5 & 0.9 & 2.4 & 4.4 & $<0.5$ \\
\hline $\mathrm{Zr}$ & $<0.2$ & $<0.2$ & $<0.2$ & $<0.2$ & $<0.2$ & $<0.2$ & $<0.2$ & $<0.2$ \\
\hline
\end{tabular}


Appendix 4. Results of ICP-MS analyses.-Continued

[ $\mu \mathrm{g} / \mathrm{L}$, micrograms per liter; EB,equipment blank; FA, filtered, acidified; $-\mathrm{R}$ (appended to sample name), replicate sample; RA, unfiltered, acidified]

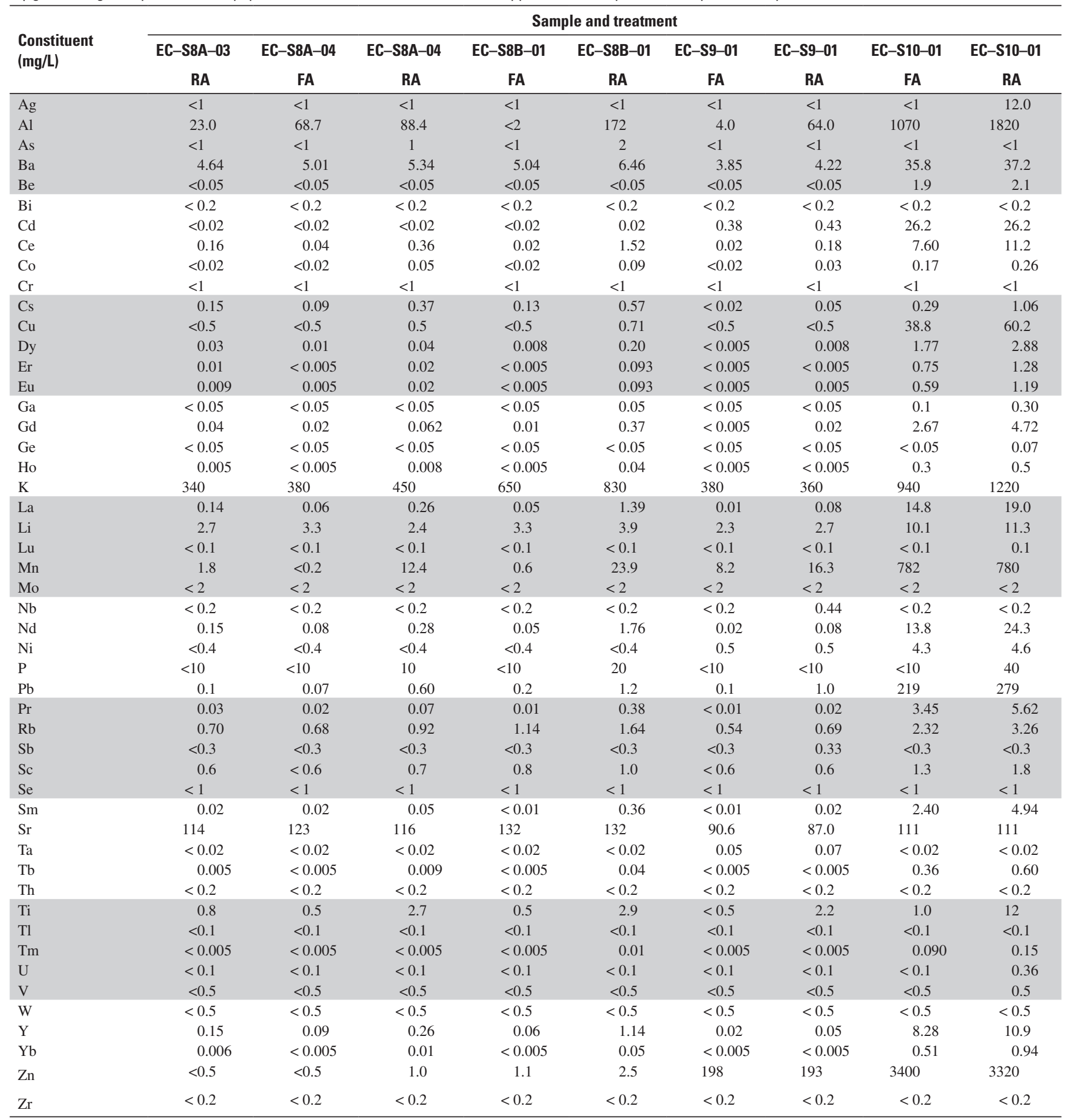


Appendix 4. Results of ICP-MS analyses.-Continued

[ $\mu \mathrm{g} / \mathrm{L}$, micrograms per liter; EB,equipment blank; FA, filtered, acidified; -R (appended to sample name), replicate sample; RA, unfiltered, acidified]

\begin{tabular}{|c|c|c|c|c|c|c|c|}
\hline \multirow{3}{*}{$\begin{array}{l}\text { Constituent } \\
\text { (mg/L) }\end{array}$} & \multicolumn{7}{|c|}{ Sample and treatment } \\
\hline & EC-S11-01 & EC-S11-01 & EC-S11-01-R & EC-S11-01-R & EC-S12-01 & EC-S12-01 & EC-MUSTD1-01 \\
\hline & FA & RA & FA & RA & FA & RA & FA \\
\hline $\mathrm{Ag}$ & $<1$ & $<1$ & $<1$ & $<1$ & $<1$ & $<1$ & 1.2 \\
\hline $\mathrm{Al}$ & 3.9 & 9.3 & 4.0 & 8.8 & $<2$ & 32.3 & 3670 \\
\hline As & $<1$ & $<1$ & $<1$ & $<1$ & 4.4 & 4.5 & $<1$ \\
\hline $\mathrm{Ba}$ & 8.73 & 8.35 & 8.81 & 8.90 & 5.75 & 5.80 & 16.5 \\
\hline $\mathrm{Be}$ & $<0.05$ & $<0.05$ & $<0.05$ & $<0.05$ & $<0.05$ & $<0.05$ & 3.1 \\
\hline $\mathrm{Bi}$ & $<0.2$ & $<0.2$ & $<0.2$ & $<0.2$ & $<0.2$ & $<0.2$ & $<0.2$ \\
\hline $\mathrm{Cd}$ & 5.53 & 5.30 & 5.48 & 5.45 & $<0.02$ & $<0.02$ & 190 \\
\hline $\mathrm{Ce}$ & 0.03 & 0.04 & 0.02 & 0.03 & 0.34 & 0.15 & 53.0 \\
\hline $\mathrm{Co}$ & 0.05 & 0.05 & 0.04 & 0.05 & $<0.02$ & $<0.02$ & 19.9 \\
\hline $\mathrm{Cr}$ & $<1$ & $<1$ & $<1$ & $<1$ & $<1$ & $<1$ & $<1$ \\
\hline Cs & $<0.02$ & 0.02 & $<0.02$ & 0.02 & 0.11 & 0.15 & 0.41 \\
\hline $\mathrm{Cu}$ & 6.2 & 9.0 & 5.8 & 8.7 & $<0.5$ & 0.59 & 1080 \\
\hline Dy & 0.01 & 0.01 & 0.01 & 0.01 & 0.006 & 0.02 & 3.04 \\
\hline Er & 0.007 & 0.009 & 0.007 & 0.008 & $<0.005$ & $<0.005$ & 1.29 \\
\hline $\mathrm{Eu}$ & $<0.005$ & 0.007 & 0.005 & 0.006 & $<0.005$ & 0.007 & 1.16 \\
\hline $\mathrm{Ga}$ & $<0.05$ & $<0.05$ & $<0.05$ & $<0.05$ & $<0.05$ & $<0.05$ & 0.44 \\
\hline $\mathrm{Gd}$ & 0.01 & 0.02 & 0.02 & 0.02 & 0.02 & 0.02 & 4.49 \\
\hline $\mathrm{Ge}$ & $<0.05$ & $<0.05$ & $<0.05$ & $<0.05$ & $<0.05$ & $<0.05$ & 0.06 \\
\hline Ho & $<0.005$ & $<0.005$ & $<0.005$ & $<0.005$ & $<0.005$ & $<0.005$ & 0.52 \\
\hline K & 320 & 310 & 310 & 320 & 490 & 430 & 580 \\
\hline $\mathrm{La}$ & 0.07 & 0.08 & 0.07 & 0.08 & 0.20 & 0.14 & 27.2 \\
\hline $\mathrm{Li}$ & 0.3 & 1.2 & 0.4 & 0.5 & 3.5 & 3.4 & 19.0 \\
\hline $\mathrm{Lu}$ & $<0.1$ & $<0.1$ & $<0.1$ & $<0.1$ & $<0.1$ & $<0.1$ & 0.1 \\
\hline $\mathrm{Mn}$ & 6.6 & 6.6 & 6.5 & 6.9 & 0.6 & 1.6 & 5380 \\
\hline Mo & $<2$ & $<2$ & $<2$ & $<2$ & $<2$ & $<2$ & $<2$ \\
\hline $\mathrm{Nb}$ & $<0.2$ & $<0.2$ & $<0.2$ & $<0.2$ & $<0.2$ & $<0.2$ & $<0.2$ \\
\hline $\mathrm{Nd}$ & 0.09 & 0.09 & 0.08 & 0.10 & 0.14 & 0.13 & 24.6 \\
\hline $\mathrm{Ni}$ & $<0.4$ & $<0.4$ & $<0.4$ & $<0.4$ & $<0.4$ & $<0.4$ & 15.4 \\
\hline $\mathrm{P}$ & $<10$ & $<10$ & $<10$ & $<10$ & $<10$ & 10 & $<10$ \\
\hline $\mathrm{Pb}$ & 95.7 & 102 & 96.7 & 102 & 1.4 & 0.52 & 604 \\
\hline $\operatorname{Pr}$ & 0.02 & 0.02 & 0.02 & 0.02 & 0.04 & 0.03 & 6.41 \\
\hline $\mathrm{Rb}$ & 0.50 & 0.52 & 0.49 & 0.52 & 0.75 & 0.83 & 1.91 \\
\hline $\mathrm{Sb}$ & $<0.3$ & $<0.3$ & $<0.3$ & $<0.3$ & $<0.3$ & $<0.3$ & 0.45 \\
\hline $\mathrm{Sc}$ & $<0.6$ & $<0.6$ & $<0.6$ & $<0.6$ & 0.8 & 0.8 & 1.7 \\
\hline $\mathrm{Se}$ & $<1$ & $<1$ & $<1$ & $<1$ & $<1$ & $<1$ & 1.5 \\
\hline $\mathrm{Sm}$ & 0.01 & 0.02 & 0.02 & 0.02 & 0.01 & 0.03 & 4.50 \\
\hline $\mathrm{Sr}$ & 37.5 & 36.7 & 37.7 & 36.7 & 157 & 156 & 146 \\
\hline $\mathrm{Ta}$ & 0.06 & $<0.02$ & 0.06 & $<0.02$ & $<0.02$ & 0.03 & 0.06 \\
\hline $\mathrm{Tb}$ & $<0.005$ & $<0.005$ & $<0.005$ & $<0.005$ & $<0.005$ & $<0.005$ & 0.61 \\
\hline Th & $<0.2$ & $<0.2$ & $<0.2$ & $<0.2$ & $<0.2$ & $<0.2$ & 0.30 \\
\hline $\mathrm{Ti}$ & $<0.5$ & $<0.5$ & $<0.5$ & $<0.5$ & 0.7 & 1.4 & 2.2 \\
\hline $\mathrm{Tl}$ & $<0.1$ & $<0.1$ & $<0.1$ & $<0.1$ & $<0.1$ & $<0.1$ & $<0.1$ \\
\hline $\mathrm{Tm}$ & $<0.005$ & $<0.005$ & $<0.005$ & $<0.005$ & $<0.005$ & $<0.005$ & 0.14 \\
\hline $\mathrm{U}$ & $<0.1$ & $<0.1$ & $<0.1$ & $<0.1$ & $<0.1$ & $<0.1$ & 0.31 \\
\hline V & $<0.5$ & $<0.5$ & $<0.5$ & $<0.5$ & $<0.5$ & $<0.5$ & $<0.5$ \\
\hline W & $<0.5$ & $<0.5$ & $<0.5$ & $<0.5$ & $<0.5$ & $<0.5$ & $<0.5$ \\
\hline $\mathrm{Y}$ & 0.08 & 0.09 & 0.08 & 0.09 & 0.04 & 0.08 & 12.9 \\
\hline $\mathrm{Yb}$ & 0.006 & 0.008 & $<0.005$ & 0.005 & $<0.005$ & $<0.005$ & 0.84 \\
\hline $\mathrm{Zn}$ & 883 & 873 & 876 & 893 & 2.0 & 1.4 & 24400 \\
\hline $\mathrm{Zr}$ & $<0.2$ & $<0.2$ & $<0.2$ & $<0.2$ & $<0.2$ & $<0.2$ & $<0.2$ \\
\hline
\end{tabular}


Appendix 4. Results of ICP-MS analyses.-Continued

[ $\mu \mathrm{g} / \mathrm{L}$, micrograms per liter; EB,equipment blank; FA, filtered, acidified; -R (appended to sample name), replicate sample; RA, unfiltered, acidified]

\begin{tabular}{|c|c|c|c|c|c|c|c|c|c|}
\hline \multirow{3}{*}{$\begin{array}{l}\text { Constituent } \\
\text { (mg/L) }\end{array}$} & \multicolumn{9}{|c|}{ Sample and treatment } \\
\hline & EC-MUSTD1-01 & RW-S1-01 & RW-S1-01 & RW-S2-01 & RW-S2-01 & RW-S2-01-R & RW-S2-01-R & EC-P4-01 & EC-P4-01 \\
\hline & RA & FA & RA & FA & RA & FA & RA & FA & RA \\
\hline $\mathrm{Al}$ & 3330 & 7.9 & 36.0 & 2550 & 2340 & 2590 & 2280 & 9.6 & 59.0 \\
\hline As & $<1$ & $<1$ & $<1$ & 6.8 & 7.8 & 7.0 & 7.6 & $<1$ & 2 \\
\hline $\mathrm{Ba}$ & 15.6 & 7.33 & 7.16 & 15.9 & 15.5 & 16.0 & 15.1 & 39.7 & 41.8 \\
\hline $\mathrm{Cd}$ & 181 & 0.70 & 0.68 & 54.0 & 54.2 & 55.3 & 52.6 & 0.71 & 0.90 \\
\hline $\mathrm{Ce}$ & 51.0 & 0.02 & 0.16 & 5.02 & 4.95 & 5.12 & 4.93 & 0.06 & 0.39 \\
\hline Co & 19.1 & $<0.02$ & $<0.02$ & 5.96 & 5.86 & 6.01 & 5.65 & 0.20 & 0.27 \\
\hline $\mathrm{Cr}$ & $<1$ & $<1$ & $<1$ & $<1$ & $<1$ & $<1$ & $<1$ & $<1$ & $<1$ \\
\hline Cs & 0.40 & 0.10 & 0.20 & 0.76 & 0.75 & 0.79 & 0.73 & $<0.02$ & 0.06 \\
\hline $\mathrm{Cu}$ & 1030 & $<0.5$ & 0.86 & 4.8 & 4.9 & 4.8 & 5.0 & $<0.5$ & 71.2 \\
\hline Dy & 3.09 & 0.03 & 0.071 & 0.52 & 0.53 & 0.53 & 0.50 & 0.006 & 0.02 \\
\hline $\mathrm{Ge}$ & 0.06 & $<0.05$ & $<0.05$ & $<0.05$ & $<0.05$ & $<0.05$ & $<0.05$ & $<0.05$ & $<0.05$ \\
\hline Но & 0.50 & 0.005 & 0.01 & 0.11 & 0.1 & 0.12 & 0.11 & $<0.005$ & 0.005 \\
\hline $\mathrm{K}$ & 540 & 310 & 300 & 1160 & 1120 & 1180 & 1100 & 610 & 670 \\
\hline $\mathrm{La}$ & 26.3 & 0.22 & 0.48 & 2.60 & 2.57 & 2.62 & 2.50 & 0.03 & 0.21 \\
\hline $\mathrm{Li}$ & 17.2 & 1.0 & 1.4 & 4.9 & 4.8 & 4.6 & 5.2 & 0.9 & 0.9 \\
\hline $\mathrm{Lu}$ & 0.1 & $<0.1$ & $<0.1$ & $<0.1$ & $<0.1$ & $<0.1$ & $<0.1$ & $<0.1$ & $<0.1$ \\
\hline $\mathrm{Mn}$ & 5190 & 5.1 & 12.3 & 1360 & 1340 & 1410 & 1310 & 81.0 & 93.1 \\
\hline Mo & $<2$ & $<2$ & $<2$ & $<2$ & $<2$ & $<2$ & $<2$ & $<2$ & $<2$ \\
\hline $\mathrm{Nb}$ & $<0.2$ & $<0.2$ & $<0.2$ & 0.3 & $<0.2$ & $<0.2$ & $<0.2$ & $<0.2$ & $<0.2$ \\
\hline $\mathrm{Nd}$ & 23.7 & 0.17 & 0.46 & 2.30 & 2.18 & 2.26 & 2.15 & 0.03 & 0.17 \\
\hline $\mathrm{Ni}$ & 15.0 & $<0.4$ & $<0.4$ & 3.5 & 3.6 & 3.6 & 3.4 & 0.7 & 0.9 \\
\hline $\mathrm{P}$ & $<10$ & $<10$ & $<10$ & 40 & 60 & 40 & 60 & $<10$ & 20 \\
\hline $\mathrm{Tb}$ & 0.58 & 0.005 & 0.01 & 0.084 & 0.083 & 0.091 & 0.081 & $<0.005$ & $<0.005$ \\
\hline Th & 0.24 & $<0.2$ & $<0.2$ & 0.42 & 0.48 & 0.43 & 0.48 & $<0.2$ & $<0.2$ \\
\hline $\mathrm{Ti}$ & 1.9 & $<0.5$ & 0.8 & 1.3 & 1.2 & 1.1 & 1.1 & $<0.5$ & 1.0 \\
\hline $\mathrm{Tl}$ & $<0.1$ & $<0.1$ & $<0.1$ & 0.3 & 0.2 & 0.3 & 0.2 & $<0.1$ & $<0.1$ \\
\hline $\mathrm{Tm}$ & 0.14 & $<0.005$ & $<0.005$ & 0.060 & 0.056 & 0.057 & 0.053 & $<0.005$ & $<0.005$ \\
\hline $\mathrm{U}$ & 0.28 & $<0.1$ & $<0.1$ & 1.16 & 1.07 & 1.17 & 1.05 & $<0.1$ & $<0.1$ \\
\hline V & $<0.5$ & $<0.5$ & $<0.5$ & 1.5 & 1.6 & 1.5 & 1.6 & $<0.5$ & $<0.5$ \\
\hline W & $<0.5$ & $<0.5$ & $<0.5$ & $<0.5$ & $<0.5$ & $<0.5$ & $<0.5$ & $<0.5$ & $<0.5$ \\
\hline $\mathrm{Y}$ & 12.7 & 0.21 & 0.46 & 3.75 & 3.73 & 3.80 & 3.68 & 0.02 & 0.10 \\
\hline $\mathrm{Yb}$ & 0.87 & 0.006 & 0.02 & 0.46 & 0.46 & 0.44 & 0.42 & $<0.005$ & 0.008 \\
\hline $\mathrm{Zn}$ & 23900 & 148 & 145 & 5760 & 5560 & 5880 & 5440 & 166 & 194 \\
\hline $\mathrm{Zr}$ & $<0.2$ & $<0.2$ & $<0.2$ & $<0.2$ & $<0.2$ & $<0.2$ & $<0.2$ & $<0.2$ & $<0.2$ \\
\hline
\end{tabular}


Appendix 4. Results of ICP-MS analyses.-Continued

[ $\mu \mathrm{g} / \mathrm{L}$, micrograms per liter; EB,equipment blank; FA, filtered, acidified; -R (appended to sample name), replicate sample; RA, unfiltered, acidified]

\begin{tabular}{|c|c|c|c|c|c|c|c|}
\hline \multirow{3}{*}{$\begin{array}{l}\text { Constituent } \\
\text { (mg/L) }\end{array}$} & \multicolumn{7}{|c|}{ Sample and treatment } \\
\hline & EC-P5-01 & EC-P5-01 & EC-MSTD1-01 & EC-MSTD1-01 & EC-MSTD1-02 & EC-MSTD1-02 & EC-MSTD1-02R \\
\hline & FA & $\mathbf{R A}$ & FA & $\mathbf{R A}$ & FA & $\mathbf{R A}$ & FA \\
\hline $\mathrm{Ag}$ & $<1$ & $<1$ & $<1$ & $<1$ & $<1$ & $<1$ & $<1$ \\
\hline $\mathrm{Al}$ & 47.6 & 61.1 & 324 & 716 & 194 & 637 & 199 \\
\hline As & $<1$ & $<1$ & $<1$ & 1 & $<1$ & 1 & $<1$ \\
\hline $\mathrm{Ba}$ & 38.8 & 40.3 & 13.7 & 13.1 & 13.7 & 13.3 & 14.5 \\
\hline $\mathrm{Be}$ & 0.3 & 0.3 & 1.0 & 1.3 & 0.7 & 1.0 & 0.8 \\
\hline $\mathrm{Bi}$ & $<0.2$ & $<0.2$ & $<0.2$ & $<0.2$ & $<0.2$ & $<0.2$ & $<0.2$ \\
\hline $\mathrm{Cd}$ & 4.82 & 5.14 & 154 & 154 & 151 & 148 & 156 \\
\hline $\mathrm{Ce}$ & 0.26 & 0.39 & 15.1 & 15.3 & 12.4 & 13.3 & 12.6 \\
\hline $\mathrm{Co}$ & 0.14 & 0.16 & 15.8 & 15.4 & 15.3 & 15.0 & 15.9 \\
\hline $\mathrm{Cr}$ & $<1$ & $<1$ & $<1$ & $<1$ & $<1$ & $<1$ & $<1$ \\
\hline Cs & 0.03 & 0.04 & 0.48 & 0.45 & 0.48 & 0.46 & 0.51 \\
\hline $\mathrm{Cu}$ & $<0.5$ & 2.4 & 399 & 414 & 225 & 258 & 236 \\
\hline Dy & 0.02 & 0.03 & 1.16 & 1.24 & 0.89 & 1.07 & 0.93 \\
\hline $\mathrm{Er}$ & 0.01 & 0.01 & 0.48 & 0.53 & 0.36 & 0.44 & 0.37 \\
\hline $\mathrm{Eu}$ & 0.01 & 0.02 & 0.39 & 0.41 & 0.31 & 0.35 & 0.30 \\
\hline $\mathrm{Ga}$ & $<0.05$ & $<0.05$ & 0.26 & 0.23 & 0.26 & 0.25 & 0.25 \\
\hline $\mathrm{Gd}$ & 0.04 & 0.053 & 1.73 & 1.87 & 1.31 & 1.59 & 1.41 \\
\hline $\mathrm{Ge}$ & $<0.05$ & $<0.05$ & $<0.05$ & $<0.05$ & $<0.05$ & $<0.05$ & $<0.05$ \\
\hline Ho & $<0.005$ & 0.006 & 0.20 & 0.22 & 0.15 & 0.18 & 0.16 \\
\hline K & 440 & 440 & 880 & 820 & 910 & 860 & 940 \\
\hline $\mathrm{La}$ & 0.30 & 0.42 & 11.4 & 11.6 & 10.4 & 10.8 & 10.6 \\
\hline $\mathrm{Li}$ & 2.4 & 2.8 & 14.2 & 14.1 & 15.9 & 15.1 & 16.8 \\
\hline $\mathrm{Lu}$ & $<0.1$ & $<0.1$ & $<0.1$ & $<0.1$ & $<0.1$ & $<0.1$ & $<0.1$ \\
\hline $\mathrm{Mn}$ & 305 & 312 & 9130 & 8590 & 10100 & 9740 & 10600 \\
\hline Mo & $<2$ & $<2$ & $<2$ & $<2$ & $<2$ & $<2$ & $<2$ \\
\hline $\mathrm{Nb}$ & $<0.2$ & $<0.2$ & $<0.2$ & $<0.2$ & $<0.2$ & $<0.2$ & $<0.2$ \\
\hline $\mathrm{Nd}$ & 0.20 & 0.28 & 9.17 & 9.29 & 7.35 & 8.48 & 8.03 \\
\hline $\mathrm{Ni}$ & 1.0 & 1.1 & 15.5 & 14.6 & 16.2 & 15.4 & 16.7 \\
\hline $\mathrm{P}$ & $<10$ & $<10$ & $<10$ & $<10$ & $<10$ & $<10$ & $<10$ \\
\hline $\mathrm{Pb}$ & 17.1 & 18.6 & 829 & 1010 & 654 & 917 & 675 \\
\hline $\operatorname{Pr}$ & 0.05 & 0.08 & 2.39 & 2.46 & 1.97 & 2.24 & 2.05 \\
\hline $\mathrm{Rb}$ & 0.62 & 0.64 & 2.69 & 2.56 & 2.72 & 2.64 & 2.88 \\
\hline $\mathrm{Sb}$ & $<0.3$ & $<0.3$ & $<0.3$ & $<0.3$ & $<0.3$ & $<0.3$ & $<0.3$ \\
\hline $\mathrm{Sc}$ & $<0.6$ & 0.6 & 1.0 & 1.0 & 1.0 & 1.0 & 0.9 \\
\hline $\mathrm{Se}$ & $<1$ & $<1$ & 1 & $<1$ & $<1$ & $<1$ & $<1$ \\
\hline $\mathrm{Sm}$ & 0.02 & 0.05 & 1.56 & 1.68 & 1.16 & 1.40 & 1.19 \\
\hline $\mathrm{Sr}$ & 59.5 & 58.7 & 474 & 461 & 508 & 503 & 538 \\
\hline $\mathrm{Ta}$ & 0.1 & $<0.02$ & 0.02 & $<0.02$ & 0.02 & $<0.02$ & $<0.02$ \\
\hline $\mathrm{Tb}$ & 0.005 & 0.007 & 0.23 & 0.24 & 0.18 & 0.20 & 0.18 \\
\hline $\mathrm{Th}$ & $<0.2$ & $<0.2$ & $<0.2$ & 0.27 & $<0.2$ & 0.25 & $<0.2$ \\
\hline $\mathrm{Ti}$ & $<0.5$ & 0.5 & 2.5 & 2.5 & 2.6 & 2.4 & 2.8 \\
\hline $\mathrm{Tl}$ & $<0.1$ & $<0.1$ & 0.1 & $<0.1$ & 0.1 & $<0.1$ & 0.1 \\
\hline $\mathrm{Tm}$ & $<0.005$ & $<0.005$ & 0.056 & 0.056 & 0.04 & 0.05 & 0.04 \\
\hline $\mathrm{U}$ & $<0.1$ & $<0.1$ & 0.1 & 0.14 & $<0.1$ & $<0.1$ & $<0.1$ \\
\hline V & $<0.5$ & $<0.5$ & $<0.5$ & $<0.5$ & $<0.5$ & $<0.5$ & $<0.5$ \\
\hline W & $<0.5$ & $<0.5$ & $<0.5$ & $<0.5$ & $<0.5$ & $<0.5$ & $<0.5$ \\
\hline $\mathrm{Y}$ & 0.14 & 0.18 & 6.29 & 6.67 & 4.93 & 5.68 & 5.09 \\
\hline $\mathrm{Yb}$ & $<0.005$ & 0.009 & 0.29 & 0.32 & 0.21 & 0.28 & 0.20 \\
\hline $\mathrm{Zn}$ & 752 & 776 & 24100 & 23500 & 24100 & 23500 & 25200 \\
\hline $\mathrm{Zr}$ & $<0.2$ & $<0.2$ & $<0.2$ & $<0.2$ & $<0.2$ & $<0.2$ & $<0.2$ \\
\hline
\end{tabular}


Appendix 4. Results of ICP-MS analyses.-Continued

[ $\mu \mathrm{g} / \mathrm{L}$, micrograms per liter; EB,equipment blank; FA, filtered, acidified; -R (appended to sample name), replicate sample; RA, unfiltered, acidified]

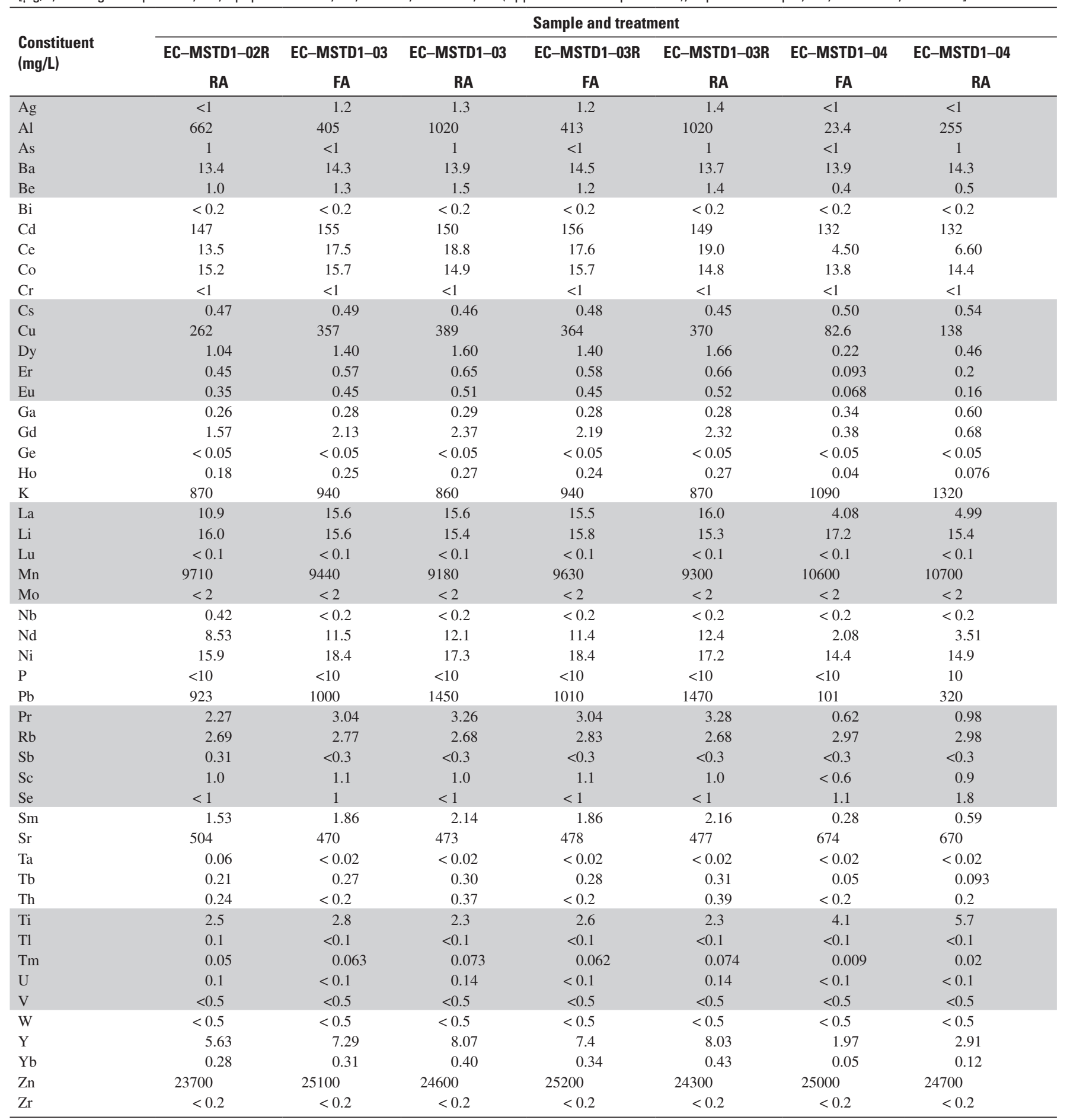


Appendix 4. Results of ICP-MS analyses.-Continued

[ $\mu \mathrm{g} / \mathrm{L}$, micrograms per liter; EB,equipment blank; FA, filtered, acidified; -R (appended to sample name), replicate sample; RA, unfiltered, acidified]

\begin{tabular}{|c|c|c|c|c|c|c|c|c|}
\hline \multirow{3}{*}{$\begin{array}{l}\text { Constituent } \\
\text { (mg/L) }\end{array}$} & \multicolumn{8}{|c|}{ Sample and treatment } \\
\hline & EC-MSTD1-05 & EC-MSTD1-05 & EC-MSTD1-06 & EC-MSTD1-06 & EC-MSTD1-07 & EC-MSTD1-07 & EC-MSTD1-08 & EC-MSTD1-08 \\
\hline & FA & RA & FA & $\mathbf{R A}$ & FA & $\mathbf{R A}$ & FA & RA \\
\hline $\mathrm{Ag}$ & $<1$ & $<1$ & 1.5 & $<1$ & 1.0 & 1.2 & $<1$ & 1.1 \\
\hline $\mathrm{Al}$ & 26.0 & 580 & 1550 & 1910 & 1010 & 1170 & 987 & 990 \\
\hline As & $<1$ & 2 & $<1$ & 3.7 & $<1$ & 2 & $<1$ & 1 \\
\hline $\mathrm{Ba}$ & 14.0 & 13.8 & 15.7 & 24.5 & 15.2 & 14.8 & 15.5 & 14.5 \\
\hline $\mathrm{Be}$ & 0.4 & 0.7 & 1.8 & 1.6 & 1.4 & 1.2 & 1.6 & 1.5 \\
\hline $\mathrm{Bi}$ & $<0.2$ & $<0.2$ & $<0.2$ & $<0.2$ & $<0.2$ & $<0.2$ & $<0.2$ & $<0.2$ \\
\hline $\mathrm{Cd}$ & 138 & 134 & 141 & 133 & 145 & 139 & 132 & 128 \\
\hline $\mathrm{Ce}$ & 7.27 & 11.0 & 23.4 & 22.8 & 18.7 & 18.4 & 16.9 & 16.1 \\
\hline $\mathrm{Co}$ & 14.2 & 14.4 & 14.5 & 14.1 & 15.8 & 15.8 & 15.5 & 15.8 \\
\hline $\mathrm{Cr}$ & $<1$ & $<1$ & $<1$ & $<1$ & $<1$ & $<1$ & $<1$ & $<1$ \\
\hline Cs & 0.54 & 0.54 & 0.41 & 0.44 & 0.42 & 0.40 & 0.36 & 0.36 \\
\hline $\mathrm{Cu}$ & 122 & 209 & 576 & 577 & 428 & 443 & 801 & 813 \\
\hline Dy & 0.38 & 0.87 & 2.12 & 2.10 & 1.57 & 1.53 & 1.32 & 1.24 \\
\hline $\mathrm{Er}$ & 0.17 & 0.37 & 0.87 & 0.83 & 0.68 & 0.67 & 0.54 & 0.51 \\
\hline $\mathrm{Eu}$ & 0.12 & 0.30 & 0.71 & 0.68 & 0.51 & 0.51 & 0.46 & 0.44 \\
\hline $\mathrm{Ga}$ & 0.34 & 0.68 & 0.40 & 0.32 & 0.39 & 0.59 & 0.37 & 0.49 \\
\hline $\mathrm{Gd}$ & 0.65 & 1.27 & 3.16 & 3.01 & 2.28 & 2.18 & 1.94 & 1.75 \\
\hline $\mathrm{Ge}$ & $<0.05$ & $<0.05$ & $<0.05$ & 0.05 & $<0.05$ & $<0.05$ & $<0.05$ & $<0.05$ \\
\hline Ho & 0.070 & 0.15 & 0.35 & 0.34 & 0.27 & 0.25 & 0.22 & 0.20 \\
\hline $\mathrm{K}$ & 1110 & 1310 & 880 & 2080 & 860 & 1000 & 690 & 800 \\
\hline $\mathrm{La}$ & 6.99 & 8.50 & 20.6 & 19.9 & 15.5 & 15.0 & 11.7 & 11.2 \\
\hline $\mathrm{Li}$ & 17.7 & 16.0 & 13.6 & 13.5 & 12.8 & 10.8 & 9.6 & 7.8 \\
\hline $\mathrm{Lu}$ & $<0.1$ & $<0.1$ & $<0.1$ & $<0.1$ & $<0.1$ & $<0.1$ & $<0.1$ & $<0.1$ \\
\hline $\mathrm{Mn}$ & 10300 & 10200 & 7740 & 7470 & 8680 & 8570 & 5840 & 5780 \\
\hline Mo & $<2$ & $<2$ & $<2$ & $<2$ & $<2$ & $<2$ & $<2$ & $<2$ \\
\hline $\mathrm{Nb}$ & $<0.2$ & $<0.2$ & $<0.2$ & $<0.2$ & $<0.2$ & $<0.2$ & $<0.2$ & $<0.2$ \\
\hline $\mathrm{Nd}$ & 3.65 & 6.69 & 15.8 & 15.3 & 11.6 & 11.1 & 9.82 & 9.14 \\
\hline $\mathrm{Ni}$ & 16.5 & 16.6 & 18.2 & 18.9 & 16.6 & 16.4 & 10.9 & 11.3 \\
\hline $\mathrm{P}$ & $<10$ & $<10$ & $<10$ & 90 & $<10$ & $<10$ & $<10$ & $<10$ \\
\hline $\mathrm{Pb}$ & 226 & 664 & 1700 & 1700 & 1180 & 1220 & 1300 & 1250 \\
\hline $\operatorname{Pr}$ & 1.11 & 1.80 & 4.31 & 4.10 & 3.23 & 3.09 & 2.66 & 2.47 \\
\hline $\mathrm{Rb}$ & 3.02 & 3.09 & 2.44 & 2.98 & 2.49 & 2.46 & 2.04 & 2.02 \\
\hline $\mathrm{Sb}$ & $<0.3$ & $<0.3$ & $<0.3$ & $<0.3$ & $<0.3$ & $<0.3$ & $<0.3$ & $<0.3$ \\
\hline $\mathrm{Sc}$ & $<0.6$ & 1.0 & 0.8 & 0.8 & 0.6 & 0.9 & $<0.6$ & 0.9 \\
\hline $\mathrm{Se}$ & 1.5 & 2.0 & 1.4 & 1.4 & 1.4 & 2.1 & 1.3 & 2.0 \\
\hline $\mathrm{Sm}$ & 0.50 & 1.23 & 2.79 & 2.75 & 1.99 & 1.90 & 1.71 & 1.66 \\
\hline $\mathrm{Sr}$ & 677 & 655 & 433 & 410 & 422 & 399 & 296 & 277 \\
\hline $\mathrm{Ta}$ & $<0.02$ & $<0.02$ & $<0.02$ & 0.04 & $<0.02$ & $<0.02$ & $<0.02$ & $<0.02$ \\
\hline $\mathrm{Tb}$ & 0.081 & 0.18 & 0.43 & 0.42 & 0.32 & 0.30 & 0.26 & 0.25 \\
\hline Th & $<0.2$ & 0.29 & 0.23 & 0.79 & $<0.2$ & 0.58 & 0.46 & 0.46 \\
\hline $\mathrm{Ti}$ & 4.1 & 6.3 & 3.1 & 4.3 & 3.1 & 4.2 & 2.4 & 3.2 \\
\hline $\mathrm{Tl}$ & $<0.1$ & $<0.1$ & $<0.1$ & $<0.1$ & $<0.1$ & $<0.1$ & 0.1 & 0.1 \\
\hline $\mathrm{Tm}$ & 0.02 & 0.04 & 0.096 & 0.086 & 0.073 & 0.069 & 0.065 & 0.060 \\
\hline $\mathrm{U}$ & $<0.1$ & 0.13 & 0.21 & 0.21 & 0.15 & 0.17 & 0.25 & 0.24 \\
\hline V & $<0.5$ & $<0.5$ & $<0.5$ & $<0.5$ & $<0.5$ & $<0.5$ & $<0.5$ & $<0.5$ \\
\hline W & $<0.5$ & $<0.5$ & $<0.5$ & $<0.5$ & $<0.5$ & $<0.5$ & $<0.5$ & $<0.5$ \\
\hline Y & 3.07 & 4.72 & 11.3 & 10.9 & 8.72 & 8.26 & 6.95 & 6.38 \\
\hline $\mathrm{Yb}$ & 0.08 & 0.21 & 0.56 & 0.51 & 0.39 & 0.40 & 0.39 & 0.32 \\
\hline $\mathrm{Zn}$ & 26300 & 25200 & 24000 & 22800 & 24500 & 23500 & 20400 & 19300 \\
\hline $\mathrm{Zr}$ & $<0.2$ & $<0.2$ & $<0.2$ & 0.4 & $<0.2$ & $<0.2$ & $<0.2$ & $<0.2$ \\
\hline
\end{tabular}


Appendix 4. Results of ICP-MS analyses.-Continued

[ $\mu \mathrm{g} / \mathrm{L}$, micrograms per liter; EB,equipment blank; FA, filtered, acidified; -R (appended to sample name), replicate sample; RA, unfiltered, acidified]

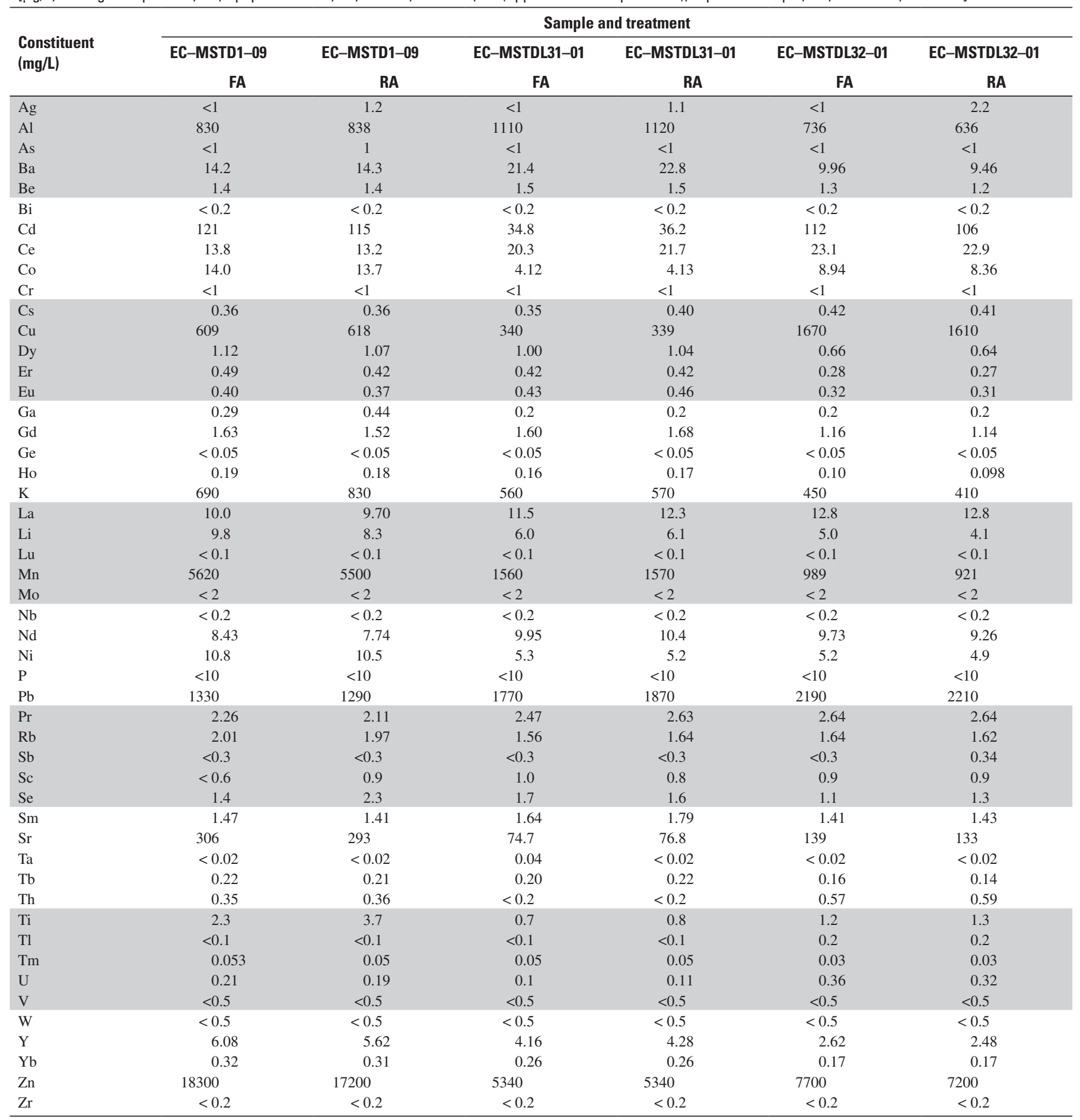


Appendix 4. Results of ICP-MS analyses.-Continued

[ $\mu \mathrm{g} / \mathrm{L}$, micrograms per liter; EB,equipment blank; FA, filtered, acidified; -R (appended to sample name), replicate sample; RA, unfiltered, acidified]

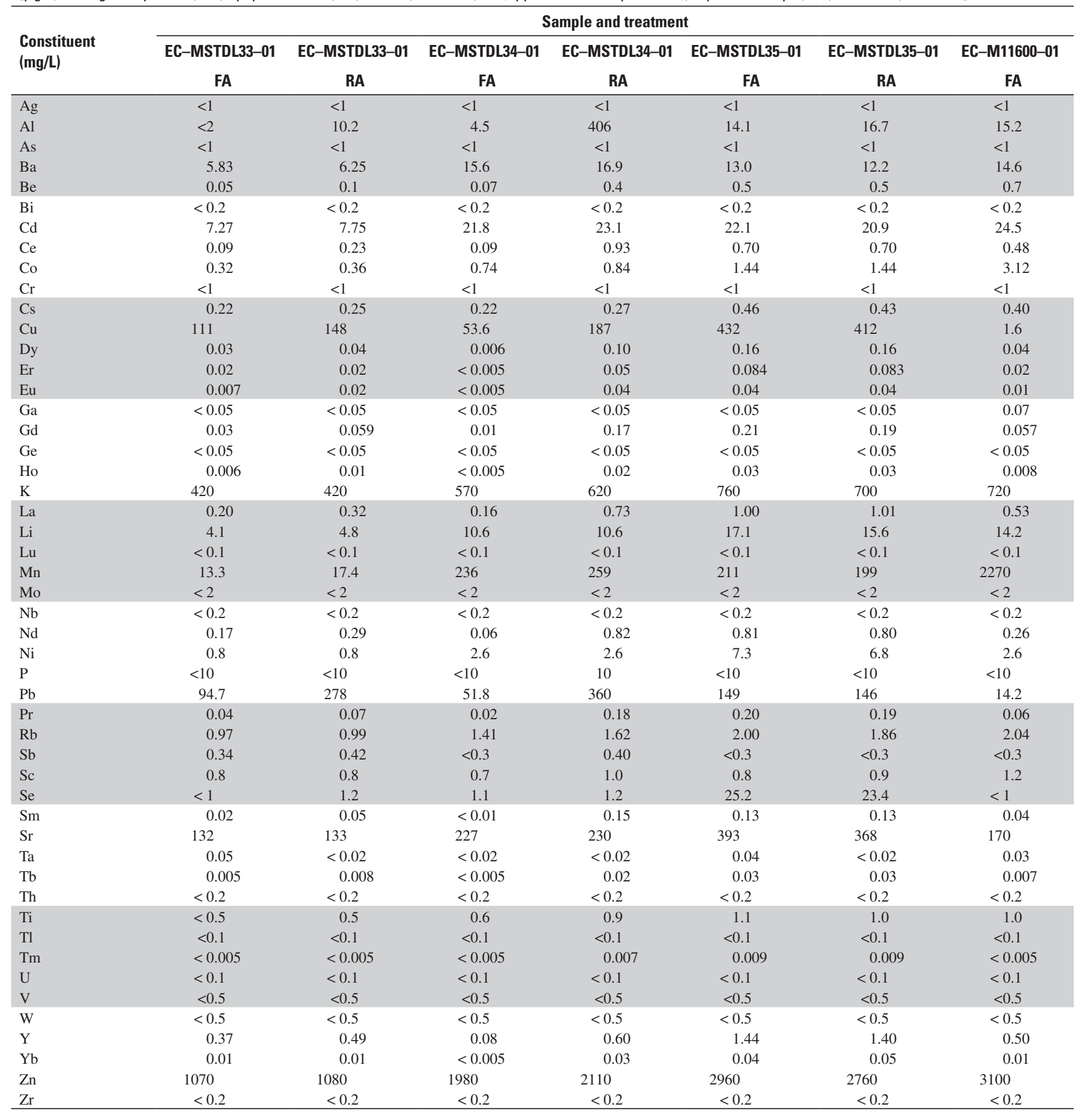


Appendix 4. Results of ICP-MS analyses.-Continued

[ $\mu \mathrm{g} / \mathrm{L}$, micrograms per liter; EB,equipment blank; FA, filtered, acidified; -R (appended to sample name), replicate sample; RA, unfiltered, acidified]

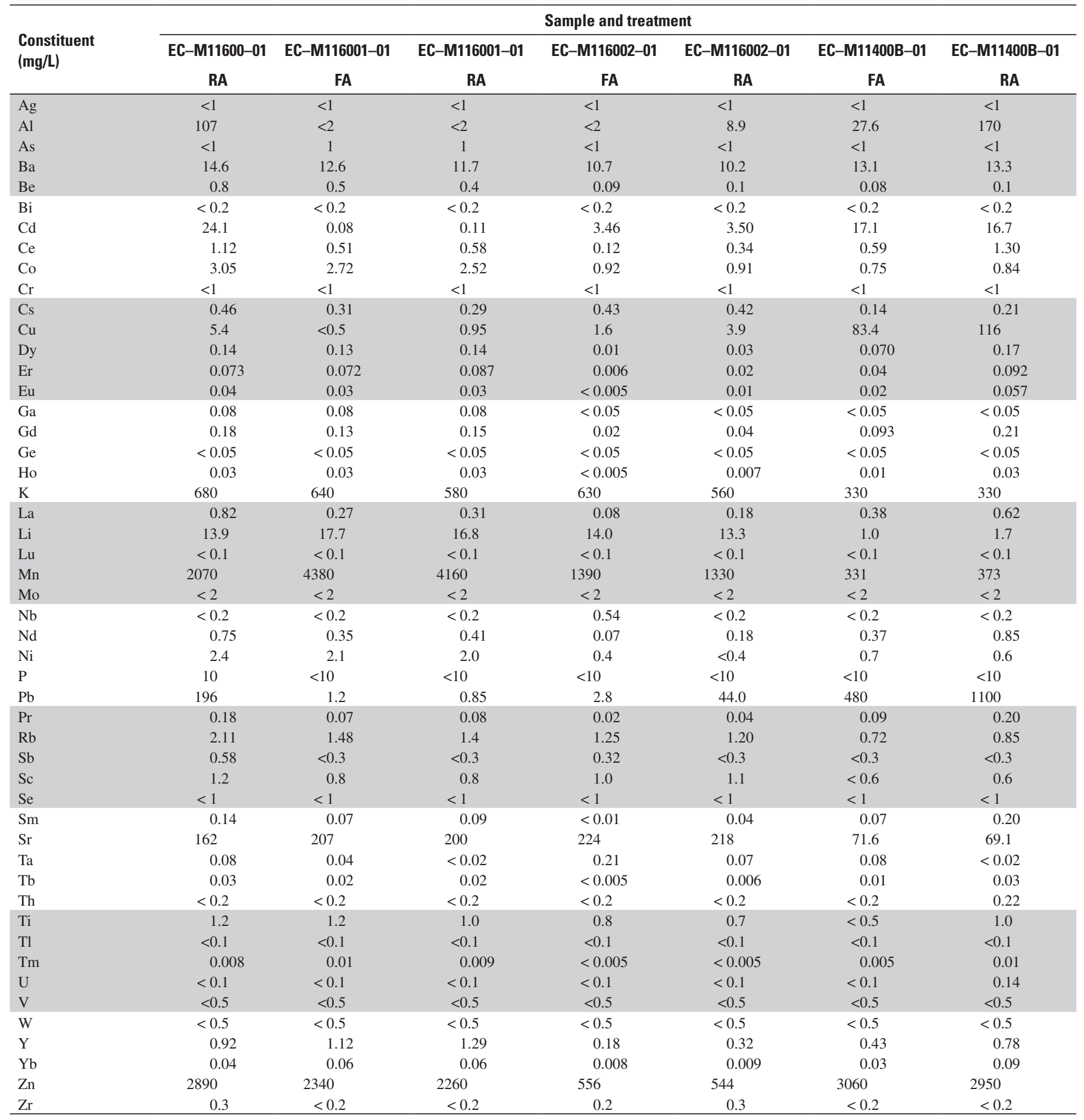


Appendix 4. Results of ICP-MS analyses.-Continued

[ $\mu \mathrm{g} / \mathrm{L}$, micrograms per liter; EB,equipment blank; FA, filtered, acidified; -R (appended to sample name), replicate sample; RA, unfiltered, acidified]

\begin{tabular}{|c|c|c|c|c|c|c|c|c|}
\hline \multirow{3}{*}{$\begin{array}{l}\text { Constituent } \\
\text { (mg/L) }\end{array}$} & \multicolumn{8}{|c|}{ Sample and treatment } \\
\hline & EC-M11400B-01R & EC-M11400B-01R & EB-01 & EB-01 & EB-02 & EB-02 & EB-03 & EB-03 \\
\hline & FA & $\mathbf{R A}$ & FA & $\mathbf{R A}$ & FA & $\mathbf{R A}$ & FA & RA \\
\hline $\mathrm{Ag}$ & $<1$ & $<1$ & $<1$ & $<1$ & $<1$ & $<1$ & $<1$ & $<1$ \\
\hline $\mathrm{Al}$ & 28.4 & 90.1 & $<2$ & $<2$ & 2.4 & $<2$ & $<2$ & $<2$ \\
\hline As & $<1$ & $<1$ & $<1$ & $<1$ & $<1$ & $<1$ & $<1$ & $<1$ \\
\hline $\mathrm{Ba}$ & 12.8 & 13.0 & $<0.2$ & $<0.2$ & $<0.2$ & $<0.2$ & $<0.2$ & $<0.2$ \\
\hline $\mathrm{Be}$ & 0.1 & 0.09 & $<0.05$ & $<0.05$ & $<0.05$ & $<0.05$ & $<0.05$ & $<0.05$ \\
\hline $\mathrm{Bi}$ & $<0.2$ & $<0.2$ & $<0.2$ & $<0.2$ & $<0.2$ & $<0.2$ & $<0.2$ & $<0.2$ \\
\hline $\mathrm{Cd}$ & 16.8 & 16.7 & $<0.02$ & $<0.02$ & $<0.02$ & $<0.02$ & $<0.02$ & $<0.02$ \\
\hline $\mathrm{Ce}$ & 0.60 & 1.00 & $<0.01$ & $<0.01$ & $<0.01$ & $<0.01$ & $<0.01$ & 0.01 \\
\hline $\mathrm{Co}$ & 0.73 & 0.79 & $<0.02$ & $<0.02$ & $<0.02$ & $<0.02$ & $<0.02$ & $<0.02$ \\
\hline $\mathrm{Cr}$ & $<1$ & $<1$ & $<1$ & $<1$ & $<1$ & $<1$ & $<1$ & $<1$ \\
\hline Cs & 0.14 & 0.17 & $<0.02$ & $<0.02$ & $<0.02$ & $<0.02$ & $<0.02$ & $<0.02$ \\
\hline $\mathrm{Cu}$ & 85.2 & 102 & $<0.5$ & $<0.5$ & $<0.5$ & 0.71 & $<0.5$ & 0.5 \\
\hline Dy & 0.075 & 0.11 & $<0.005$ & $<0.005$ & $<0.005$ & $<0.005$ & $<0.005$ & $<0.005$ \\
\hline $\mathrm{Er}$ & 0.04 & 0.063 & $<0.005$ & $<0.005$ & $<0.005$ & $<0.005$ & $<0.005$ & $<0.005$ \\
\hline $\mathrm{Eu}$ & 0.02 & 0.04 & $<0.005$ & $<0.005$ & $<0.005$ & $<0.005$ & $<0.005$ & $<0.005$ \\
\hline $\mathrm{Ga}$ & $<0.05$ & $<0.05$ & $<0.05$ & $<0.05$ & $<0.05$ & $<0.05$ & $<0.05$ & $<0.05$ \\
\hline Gd & 0.091 & 0.15 & $<0.005$ & $<0.005$ & $<0.005$ & $<0.005$ & $<0.005$ & $<0.005$ \\
\hline $\mathrm{Ge}$ & $<0.05$ & $<0.05$ & $<0.05$ & $<0.05$ & $<0.05$ & $<0.05$ & $<0.05$ & $<0.05$ \\
\hline Ho & 0.02 & 0.02 & $<0.005$ & $<0.005$ & $<0.005$ & $<0.005$ & $<0.005$ & $<0.005$ \\
\hline $\mathrm{K}$ & 320 & 330 & $<30$ & $<30$ & $<30$ & $<30$ & $<30$ & $<30$ \\
\hline $\mathrm{La}$ & 0.37 & 0.49 & $<0.01$ & $<0.01$ & $<0.01$ & $<0.01$ & $<0.01$ & $<0.01$ \\
\hline $\mathrm{Li}$ & 0.9 & 1.3 & 0.9 & $<0.1$ & 0.4 & 0.6 & 0.2 & 0.2 \\
\hline $\mathrm{Lu}$ & $<0.1$ & $<0.1$ & $<0.1$ & $<0.1$ & $<0.1$ & $<0.1$ & $<0.1$ & $<0.1$ \\
\hline $\mathrm{Mn}$ & 327 & 363 & $<0.2$ & $<0.2$ & 0.5 & $<0.2$ & $<0.2$ & $<0.2$ \\
\hline Mo & $<2$ & $<2$ & $<2$ & $<2$ & $<2$ & $<2$ & $<2$ & $<2$ \\
\hline $\mathrm{Nb}$ & $<0.2$ & $<0.2$ & $<0.2$ & 0.31 & $<0.2$ & $<0.2$ & $<0.2$ & $<0.2$ \\
\hline $\mathrm{Nd}$ & 0.38 & 0.59 & $<0.01$ & $<0.01$ & $<0.01$ & $<0.01$ & $<0.01$ & $<0.01$ \\
\hline $\mathrm{Ni}$ & 0.7 & 0.7 & $<0.4$ & $<0.4$ & $<0.4$ & $<0.4$ & $<0.4$ & $<0.4$ \\
\hline $\mathrm{P}$ & $<10$ & $<10$ & $<10$ & $<10$ & $<10$ & $<10$ & $<10$ & $<10$ \\
\hline $\mathrm{Pb}$ & 486 & 830 & $<0.05$ & $<0.05$ & 0.4 & $<0.05$ & $<0.05$ & 43.0 \\
\hline $\operatorname{Pr}$ & 0.09 & 0.14 & $<0.01$ & $<0.01$ & $<0.01$ & $<0.01$ & $<0.01$ & $<0.01$ \\
\hline $\mathrm{Rb}$ & 0.72 & 0.77 & $<0.01$ & $<0.01$ & $<0.01$ & $<0.01$ & $<0.01$ & $<0.01$ \\
\hline $\mathrm{Sb}$ & $<0.3$ & $<0.3$ & 0.44 & $<0.3$ & $<0.3$ & $<0.3$ & $<0.3$ & $<0.3$ \\
\hline $\mathrm{Sc}$ & $<0.6$ & $<0.6$ & $<0.6$ & $<0.6$ & $<0.6$ & $<0.6$ & $<0.6$ & $<0.6$ \\
\hline $\mathrm{Se}$ & $<1$ & $<1$ & $<1$ & $<1$ & $<1$ & $<1$ & $<1$ & $<1$ \\
\hline $\mathrm{Sm}$ & 0.06 & 0.14 & $<0.01$ & $<0.01$ & $<0.01$ & $<0.01$ & $<0.01$ & $<0.01$ \\
\hline $\mathrm{Sr}$ & 71.4 & 69.0 & $<0.5$ & $<0.5$ & $<0.5$ & $<0.5$ & $<0.5$ & $<0.5$ \\
\hline $\mathrm{Ta}$ & 0.07 & $<0.02$ & 0.2 & 0.05 & 0.2 & 0.02 & 0.1 & $<0.02$ \\
\hline $\mathrm{Tb}$ & 0.01 & 0.02 & $<0.005$ & $<0.005$ & $<0.005$ & $<0.005$ & $<0.005$ & $<0.005$ \\
\hline Th & $<0.2$ & $<0.2$ & $<0.2$ & $<0.2$ & $<0.2$ & $<0.2$ & $<0.2$ & $<0.2$ \\
\hline $\mathrm{Ti}$ & $<0.5$ & 0.5 & $<0.5$ & $<0.5$ & $<0.5$ & $<0.5$ & $<0.5$ & $<0.5$ \\
\hline $\mathrm{Tl}$ & $<0.1$ & $<0.1$ & $<0.1$ & $<0.1$ & $<0.1$ & $<0.1$ & $<0.1$ & $<0.1$ \\
\hline $\mathrm{Tm}$ & $<0.005$ & 0.008 & $<0.005$ & $<0.005$ & $<0.005$ & $<0.005$ & $<0.005$ & $<0.005$ \\
\hline $\mathrm{U}$ & $<0.1$ & $<0.1$ & $<0.1$ & $<0.1$ & $<0.1$ & $<0.1$ & $<0.1$ & $<0.1$ \\
\hline V & $<0.5$ & $<0.5$ & $<0.5$ & $<0.5$ & $<0.5$ & $<0.5$ & $<0.5$ & $<0.5$ \\
\hline W & $<0.5$ & $<0.5$ & 0.5 & $<0.5$ & $<0.5$ & $<0.5$ & $<0.5$ & $<0.5$ \\
\hline Y & 0.44 & 0.56 & $<0.01$ & $<0.01$ & $<0.01$ & $<0.01$ & $<0.01$ & $<0.01$ \\
\hline $\mathrm{Yb}$ & 0.03 & 0.05 & $<0.005$ & $<0.005$ & $<0.005$ & $<0.005$ & $<0.005$ & $<0.005$ \\
\hline $\mathrm{Zn}$ & 3060 & 3020 & 0.6 & $<0.5$ & 1.4 & 1.0 & 1.0 & 0.7 \\
\hline $\mathrm{Zr}$ & $<0.2$ & $<0.2$ & $<0.2$ & $<0.2$ & $<0.2$ & $<0.2$ & $<0.2$ & $<0.2$ \\
\hline
\end{tabular}


Appendix 4. Results of ICP-MS analyses.-Continued

[ $\mu \mathrm{g} / \mathrm{L}$, micrograms per liter; EB,equipment blank; FA, filtered, acidified; $-\mathrm{R}$ (appended to sample name), replicate sample; $R A$, unfiltered, acidified]

\begin{tabular}{|c|c|c|c|c|}
\hline \multirow{3}{*}{$\begin{array}{l}\text { Constituent } \\
\text { (mg/L) }\end{array}$} & \multicolumn{4}{|c|}{ Sample and treatment } \\
\hline & EB-04 & EB-04 & EB-05 & EB-05 \\
\hline & FA & RA & FA & RA \\
\hline $\mathrm{Ag}$ & $<1$ & $<1$ & $<1$ & $<1$ \\
\hline $\mathrm{Al}$ & $<2$ & $<2$ & $<2$ & $<2$ \\
\hline As & $<1$ & $<1$ & $<1$ & $<1$ \\
\hline $\mathrm{Ba}$ & $<0.2$ & $<0.2$ & $<0.2$ & $<0.2$ \\
\hline $\mathrm{Be}$ & $<0.05$ & $<0.05$ & $<0.05$ & $<0.05$ \\
\hline $\mathrm{Bi}$ & $<0.2$ & $<0.2$ & $<0.2$ & $<0.2$ \\
\hline $\mathrm{Cd}$ & $<0.02$ & $<0.02$ & $<0.02$ & $<0.02$ \\
\hline $\mathrm{Ce}$ & $<0.01$ & $<0.01$ & $<0.01$ & $<0.01$ \\
\hline Co & $<0.02$ & $<0.02$ & $<0.02$ & $<0.02$ \\
\hline $\mathrm{Cr}$ & $<1$ & $<1$ & $<1$ & $<1$ \\
\hline Cs & $<0.02$ & $<0.02$ & $<0.02$ & $<0.02$ \\
\hline $\mathrm{Cu}$ & $<0.5$ & 0.51 & $<0.5$ & $<0.5$ \\
\hline Dy & $<0.005$ & $<0.005$ & $<0.005$ & $<0.005$ \\
\hline $\mathrm{Er}$ & $<0.005$ & $<0.005$ & $<0.005$ & $<0.005$ \\
\hline $\mathrm{Eu}$ & $<0.005$ & $<0.005$ & $<0.005$ & $<0.005$ \\
\hline $\mathrm{Ga}$ & $<0.05$ & $<0.05$ & $<0.05$ & $<0.05$ \\
\hline $\mathrm{Gd}$ & $<0.005$ & $<0.005$ & $<0.005$ & $<0.005$ \\
\hline $\mathrm{Ge}$ & $<0.05$ & $<0.05$ & $<0.05$ & $<0.05$ \\
\hline Но & $<0.005$ & $<0.005$ & $<0.005$ & $<0.005$ \\
\hline K & $<30$ & $<30$ & $<30$ & $<30$ \\
\hline $\mathrm{La}$ & $<0.01$ & $<0.01$ & $<0.01$ & $<0.01$ \\
\hline $\mathrm{Li}$ & $<0.1$ & $<0.1$ & 0.2 & $<0.1$ \\
\hline $\mathrm{Lu}$ & $<0.1$ & $<0.1$ & $<0.1$ & $<0.1$ \\
\hline Mn & $<0.2$ & $<0.2$ & $<0.2$ & $<0.2$ \\
\hline Mo & $<2$ & $<2$ & $<2$ & $<2$ \\
\hline $\mathrm{Nb}$ & $<0.2$ & $<0.2$ & $<0.2$ & $<0.2$ \\
\hline $\mathrm{Nd}$ & $<0.01$ & $<0.01$ & $<0.01$ & $<0.01$ \\
\hline $\mathrm{Ni}$ & $<0.4$ & $<0.4$ & $<0.4$ & $<0.4$ \\
\hline $\mathrm{P}$ & $<10$ & $<10$ & $<10$ & $<10$ \\
\hline $\mathrm{Pb}$ & $<0.05$ & 0.05 & 0.08 & 0.08 \\
\hline $\operatorname{Pr}$ & $<0.01$ & $<0.01$ & $<0.01$ & $<0.01$ \\
\hline $\mathrm{Rb}$ & $<0.01$ & $<0.01$ & $<0.01$ & $<0.01$ \\
\hline $\mathrm{Sb}$ & $<0.3$ & $<0.3$ & $<0.3$ & $<0.3$ \\
\hline $\mathrm{Sc}$ & $<0.6$ & $<0.6$ & $<0.6$ & $<0.6$ \\
\hline $\mathrm{Se}$ & $<1$ & $<1$ & $<1$ & $<1$ \\
\hline Sm & $<0.01$ & $<0.01$ & $<0.01$ & $<0.01$ \\
\hline $\mathrm{Sr}$ & $<0.5$ & $<0.5$ & $<0.5$ & $<0.5$ \\
\hline $\mathrm{Ta}$ & $<0.02$ & $<0.02$ & $<0.02$ & $<0.02$ \\
\hline $\mathrm{Tb}$ & $<0.005$ & $<0.005$ & $<0.005$ & $<0.005$ \\
\hline Th & $<0.2$ & $<0.2$ & $<0.2$ & $<0.2$ \\
\hline $\mathrm{Ti}$ & $<0.5$ & $<0.5$ & $<0.5$ & $<0.5$ \\
\hline $\mathrm{Tl}$ & $<0.1$ & $<0.1$ & $<0.1$ & $<0.1$ \\
\hline $\mathrm{Tm}$ & $<0.005$ & $<0.005$ & $<0.005$ & $<0.005$ \\
\hline $\mathrm{U}$ & $<0.1$ & $<0.1$ & $<0.1$ & $<0.1$ \\
\hline V & $<0.5$ & $<0.5$ & $<0.5$ & $<0.5$ \\
\hline W & $<0.5$ & $<0.5$ & $<0.5$ & $<0.5$ \\
\hline Y & $<0.01$ & $<0.01$ & $<0.01$ & $<0.01$ \\
\hline $\mathrm{Yb}$ & $<0.005$ & $<0.005$ & $<0.005$ & $<0.005$ \\
\hline $\mathrm{Zn}$ & $<0.5$ & 0.6 & 0.5 & 1.4 \\
\hline $\mathrm{Zr}$ & $<0.2$ & $<0.2$ & $<0.2$ & $<0.2$ \\
\hline
\end{tabular}


